\title{
Platelet procoagulant activity and thrombus formation
}

Citation for published version (APA):

Keuren, J. F. W. (2004). Platelet procoagulant activity and thrombus formation. [Doctoral Thesis, Maastricht University]. Datawyse / Universitaire Pers Maastricht. https://doi.org/10.26481/dis.20041210jk

Document status and date:

Published: 01/01/2004

DOI:

10.26481/dis.20041210jk

Document Version:

Publisher's PDF, also known as Version of record

\section{Please check the document version of this publication:}

- A submitted manuscript is the version of the article upon submission and before peer-review. There can be important differences between the submitted version and the official published version of record.

People interested in the research are advised to contact the author for the final version of the publication, or visit the DOI to the publisher's website.

- The final author version and the galley proof are versions of the publication after peer review.

- The final published version features the final layout of the paper including the volume, issue and page numbers.

Link to publication

\footnotetext{
General rights rights.

- You may freely distribute the URL identifying the publication in the public portal. please follow below link for the End User Agreement:

www.umlib.nl/taverne-license

Take down policy

If you believe that this document breaches copyright please contact us at:

repository@maastrichtuniversity.nl

providing details and we will investigate your claim.
}

Copyright and moral rights for the publications made accessible in the public portal are retained by the authors and/or other copyright owners and it is a condition of accessing publications that users recognise and abide by the legal requirements associated with these

- Users may download and print one copy of any publication from the public portal for the purpose of private study or research.

- You may not further distribute the material or use it for any profit-making activity or commercial gain

If the publication is distributed under the terms of Article $25 \mathrm{fa}$ of the Dutch Copyright Act, indicated by the "Taverne" license above, 


\section{Platelet procoagulant activity and thrombus formation}


Platelet procoagulant activity and thrombus formation/

Jeffrey li:W. Keuren

Thesis University Maastricht - with summary in Dutch

ISBN $905278438: 8$

Lay-out: Roel Gerardts

Printed by: Datawyse, Universitaire Pers Maastricht, The Netherlands

(C) J.F.W. Keuren, Posterholt 2004 


\title{
Platelet procoagulant activity and thrombus formation
}

\author{
PROEFSCHRIFT
}

ter verkrijging van de graad van doctor

aan de Universiteit Maastricht,

op gezag van de Rector Magnificus,

Prof. Mr. G.P.M.F. Mols,

volgens het besluit van het College van Decanen,

in het openbaar te verdedigen

op vrijdag 10 december 2004 om 12.00 uur

door

Jozef Franciscus Wilhelmus Keuren

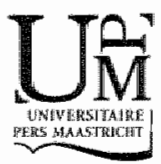


Promotor:

Prof. Dr. I. Rosing

\section{Copromotor:}

Dr. T. Lindhout

Beoordelingscommissie:

Prof. Dr. J.F.C. Glatz (woorzitter)

Prof. Dr. J.W.N. Akkerman (Universiteit Utrecht)

Prof. Dr. H. Deckmyn (Katholieke Universiteit Leuven, België)

Dr. M.G.A. oude Egbrink

Prof. Dr. R.F.A. Zwaal

Financial support by the Netherlands Heart Foundation and the Dr. Ir. van de Laar Stichting for the publication of this thesis is gratefully acknowledged.

Additionally, gratitude is expressed to Medtronic Bakken Research Center, Kordia and Percardia for their financial support. 
Chapter I

Climprer II

Clappter III

Chapter IV

Chapter V

Chapter VI

Chapter VII

Chapter VIII

Wedertandse Samenvathing

Nawoord

Cowalently-bound heparin makes collagen thromboresistant. Arterioscler Thromb Vasc Bial 2004, 24.613.7 generation at heparinized surfaces exposed to flowing blood Thromb Haemost. 2002;87:742-7

Thrombogenicity of polysaccharice-cated surfaces. Biomaterials. $2003,24: 1917 \ldots 24$

General Discussion

Curriculum witae 

Chapter I

GENERAL INTRODUCTION 


\section{Preface}

Arterial thrombosis is an acute complication that develops on chronic atherosclerotic lesilons and caluses heart attacks and stroke, at present the main causes of mortality in developed countries. The key conponents of thrombi that oeclude arteries are plateles and fibrin.

Upon vascular injury platelets adhere to the damaged vascular wall and generate a procoagulant surface to promote thrombin production and consequently fibrin formation. Progress in understanding the mechanisms that calise platelet procoagulant activity might improve the ability to prevent occlusive thrombosis in discased vessels. This chapter reviews current understandings and debates with respect to properties and generation of platelet procodgulant activity.

\section{Thrombus formation}

The core trigger of thrombus formation after wascular darrage is the loss of the endothelial cell barrier between blood and extracellular matrix proteins. In response to this event a primary platelet plug is tormed via platelet adhesion and aggregation processes. Under conditions of high shear: stress, as found in arteries, the initial tethering of platelets to the subendothelium is dependent on the binding of glycoprotein (GP) lbo to subendothelial bound won Willebrand factor (VWF).' This interaction is characterized by a rapid dissociation rate, resulting in platelet translocation. The deceleration in platelet velocity allows adhesive contacts through platelet receptors with slower intrinsic binding kinetics. ${ }^{2-4}$ Integrins are the major class of platelet receptors, mediating stable adhesion. "Integrins are heteroclimeric proteins consisting of $\alpha$ and $\beta$ subunits and are usually present in a resting conformation, with low affinity for the natural ligand. ${ }^{\circ}$ A state of high affinity occurs after activation. A well defined example of this phenomenon is platelet adhesion to subendothelial collagen. After initial tethering of platelets via the GP Ib $\alpha-V W F$ axis, collagen can interact directly and indirectly with activated piatelet integrin $\alpha_{2} \beta_{1}$ and $\alpha_{41} \beta_{3}$ (via VWF), respectively. Collagen first activates these integrins wia $G P$ VI, which is at nember of the immunoglobulin (lg) receptor superfamily due to its Ig homology unit ${ }^{7}$ GP VI signalling triggers platelets to extrude their storage granule content to the platelei"s environment. ${ }^{8}$ "The secondary agonist ADP. released from a-granules, further supports integrin activation via the $G$-protein coupled $P 2 Y_{1}$ and $P 2 Y_{1}$ receptors." A further mechanism important for the amplification of the GP VI response is the synthesis and release of thromboxane $A_{2}$ (TXA, via the cyclooxygenasemediated arachidonic metabolic pathway. ${ }^{10}$ TXA 2 exerts its actions via heterotrimeric $G$ protein-coupled thromboxaneprostanoid receptors (TP receptors): "In addition, activation of the integrin $\alpha_{18 b} p_{3 i}$ can be mediated by GP lbo-VWF signaling or localized thrombin. ${ }^{12}$

Once adhered, adhesive proteins (VWF, fibrinogen, fibronectin), present in plasma or released from storage granules by activated platelets, bind to activated ox: $\beta_{x}$. Like primary adhesion under arterial shear stress conditions, VWF is necessary for initial tethering of platelets. Stable platelet-platelet bridging is then mediated via activated integrin $\alpha_{116} \beta_{3}$ and the adhesive proteins.

The previously described processes of platelet adhesion and aggregation are not sufficient for stable thrombus formation. To obtain a stable thrombus the end product of blood coagulation ${ }_{s}$ fibrin, is required. Upon vascular injury, blood coagulation is initiated by exposure of tissue factor (TF) at the surfaces of smooth muscle cells and fibroblast in the vessel wall or inflammatory cells at the site of injury. Circulating factor VIIa or VII binds to TF and factor VII is consequently activated. The resulting membrane-bound TF/ FVIla enzymatic complex converts factors $[X$ and $X$ into their active forms. At this point procoagulant cell membranes, predominantly those of platelets, catalyse the key reactions of the coagulation cascade, namely, the formation of the tenase and prothrombinase complexes, which respectively convert the zymogens FX and prothrombin (FII) into their active forms Xa and thrombin (IIa), respectively (figure 1). ${ }^{1.3}$ Thrombin subsequently converts soluble fibrinogen into fibrin.

In vivo, procoagulant cell surfaces can be provided by platelets present in the growing thrombus. Yet, circulating platelets do not provide this catalytic surface and therefore the key question addressed in this introduction is: what induces platelet procoagulant activity and how?

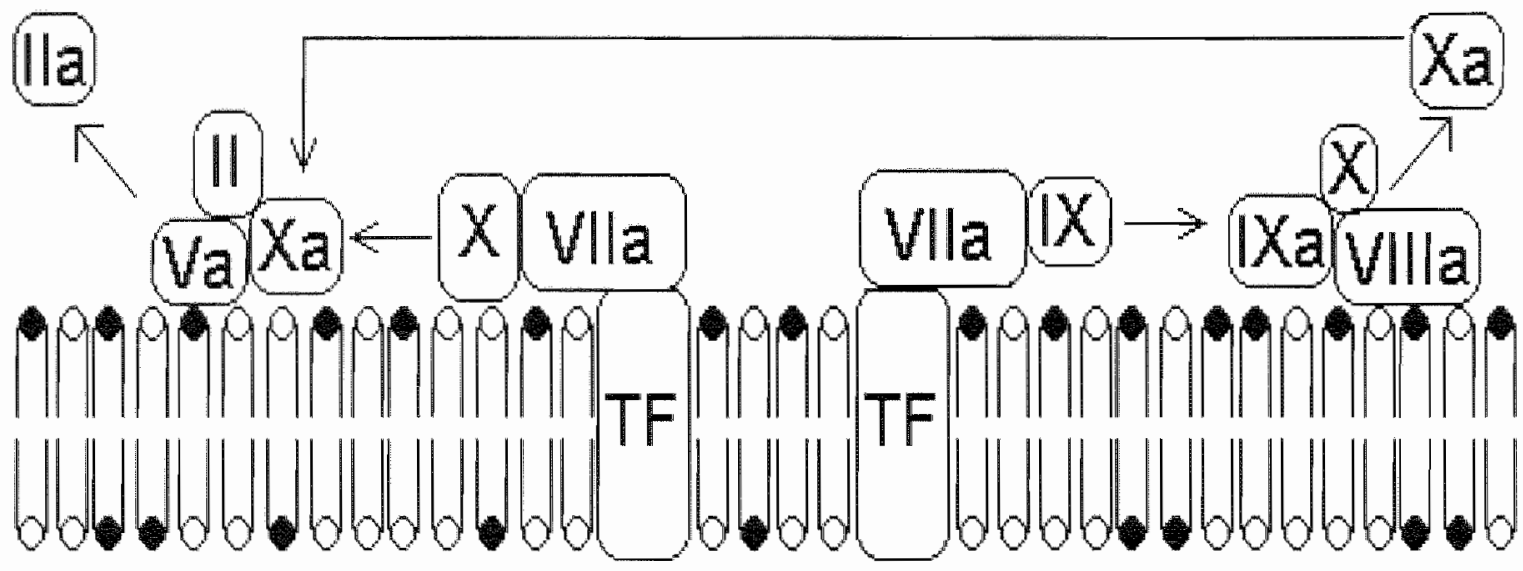

Figure 1: Tissue factor inducer thrombin generation. The membrathe-bound TFMlla enzymatic complex actiwates factor $X$ and $X$. Factors Xa and $X a$ assemble into the tenase and prothrombinase complex, respectively. The catalytic phospholipid surface catalyses $X a$ and lla formation. Black heads represent phosphatidylserine. 


\section{Membrane phospholipid asymmetry}

Cell nembranes of platelets, and other eukaryotic cells, are composed of a bilayer of phospholipids containing proteins. The plasma nembrane of resting platelets is in a state of phospholipid asymmetry. That is, the outer leaflet of the plasma membrane is composed predominanty of the choline-phospholipids sphingomyelin (Spm) and phosphatidylcholne (PtdCho), whereas the inner leaflet mostly contans amino-phospholipids phosphatidylethanolamine (PdEth) and phosphatidylserine (PrdSer). At least two transporter proteins are involved in maintaining lipid asymmetry, namely, 1) the ATP dependert aminophospholipid translocase, which transports PudSer and PtdEth from outer to inner leaflet against the concentration gradient, and 2) the ATP dependent floppase, which transports all phospholipids outward with half times about 10 times longer than translocase. At plysiological intracellular calciun concentrations $( \pm 50 \mathrm{nM})$, the translocase and hoppase are active and they maintain lipid asymmetry. Once platelets are activated, intracellular calcium lewels rise and inhibit translocase and floppase activity. Additionally, the rise in cytoplasmatic calcium activates a non-selective phospholipid transporter protein, called scramblase, which allows lipids to move randomly between inner and outer leaflet. It has been proposed that the calcium signal must be sustained at high level during several minutes to significantly stimulate scramblase activity. ${ }^{14}$ In this situation, the anionic phospholipids PtdSer and PtdEth are exposed at the outer leaflet of the plasma membrane and this provides the catalytic surface for the assembly of tenase and protlumbinase complexes hgur 2). Moreover, this process has been shown to be acompanted by sheddng of procougulant micropartioles fon the platelet plasma nembrane (rubed in ${ }^{3}$ ).

There is incrasing evidence that besides nogatively charged phospholipids, otheir components of the platelat membrane like surface glycoproteins, are important for procoagulant activity. This is supported by sudy of Ramstrồn et al, denonstrating that Padser is necessury, but not sufficint for coagulation amplification. "The clotting times were prolonged for blood stimulated with the nonphysiologic calcium ionophore A23187, exposing the same amounts of PtdSer at the outer leaflet of the platelet plasma menbranes when compared with blood treated with physiologic platelet activators like collagen and thrombin. This suggests that in response to phystologic stimuli platelets might exhibit additional fearures than PtdSer important for the assembly of tenase and prothrombinase complexes. Accordingly, recent studies indicate that platelets express specirio binding sites for coagulation proteins (reviewed in ${ }^{17}$ ).

\section{Platelet procoagulant activity induced by collagen}

More then twenty years ago, Bevers at published the effects of thrombin and collagen on the nembrane phospholipid distribution of platelets. 18 They demonstrated that thrombin and collagen only moderately affect the platelet procoagulant response. On the other hand, a dual

(III)

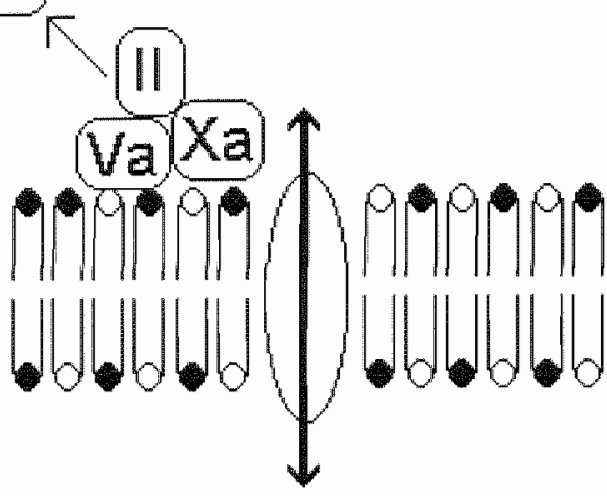

Scramblase

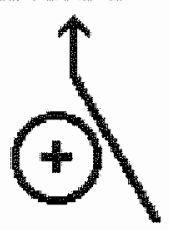

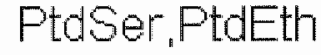

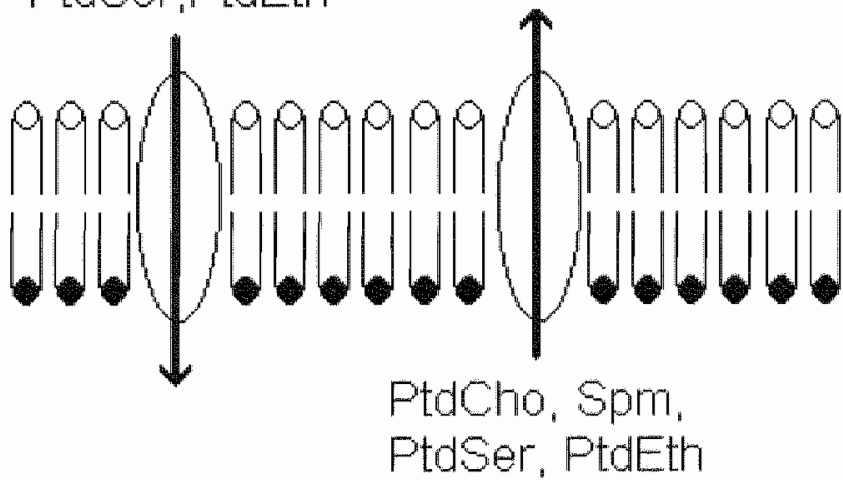

Translocase

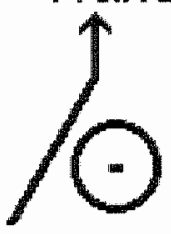

Floppase

Figure 2: Regulation of membrane phospholipid asymmetry. The ATP dependent aminophospholipid tiranslocase is responsityle for inward mowement of PtdSer amd Pld Eth, whereas the ATP dependent foppase transporls all phospholipids outward. A rise in intracellutar caicium concentration activates the non-specific scramblase which induces phospholipid randomisation. This randomisation causes exposure of Ptciser (Black heads) at the outer plasmamembrane which in turn promotes blood coagullation. 
Stimulation with the wow agonists appeared to be the most potent accelerator of prothrombinase activity

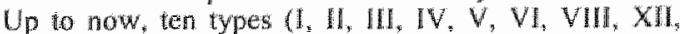
XII. XIV) of collagen have been identified in the vessel wall, with fibrillar lype 1 and III ass the most abundant ones. As already mentiond, two platelet collagen receptorg are important for direct adhesion to collagen, the integrin $\alpha_{2} \beta_{3}$ and the inmung lobutin superfamily member GP W. AT preserts, GP Wis believed to be the main receptor in the collagen-dependent process of generating platelet procougulant activity. GP VI is non-covalently associated wh fe receptor (f $\mathrm{CR}$ ) y cham, which serves as the signal vansducing subunit of the receptor complex. Collagen activates platelets through op $v$ I by clustering the receptor and subsectuent tyrosine phosphorylation of FCR $y$ cha in that contains an immunoreceptor tyrosine based activation moti (ITAM). Through participation of the non-receptor tyrosine kinase $S Y K$, phospholipase $\mathrm{C} / 2$ is actwated, which causes an increase in cytosolic calcium. With respect to the role of integrin $\alpha_{2} \beta_{1}$ in the platelet procoaguant response, Kuijpers et al $\mathrm{l}^{2 /}$ showed a reduction in both collagen induced calciun mobilization and procoagalant activity in $\beta$. daficient mouse platelets. Release of secondary agonists ADP and thromboxane A2, further support collagen induced platelet activation processes via G-protein coupled receptors.

\section{Platelet procoagulant activity induced by thrombin}

Three thrombin receptors have been identified on human platelets, namely, the $\mathrm{GP} I b-\mathrm{X}-\mathrm{V}$ complex and the protease activated receptors PAR-1 and PAR-4 (reviewed in ${ }^{23}$ ) Activation of PAR-receptors occurs when thrombin cleaves the N-terminus of the receptor, exposing a new N-terminus that serwes as ligand for the receptor." Since the ligand cannot diffuse away, this way of activation is highly effective. It was demonstrated that PAR-4 requires ten to hundred times higher concentrations of thrombin with respect to PAR-1, probably because the extracellular doman of PAR 4 lacks the sequences that interact with exosite 1 of thrombin. ${ }^{35_{n} 26}$ "The current idea is that PAR 1 is the main signaling recepton at low doses of thrombin, but PAR-4 signals might be more sustained due to slower kinetics of activation and desensitization. 27,28 Activated PAR-receptors activate $\mathrm{G}$ proteins. Signalling via $G_{1}$ unduces shape change and launching of $\mathrm{Chq}$ loads to the activation of phospholipase $C$. which induces an increase in the cytosolic calcium concentration. Again. release of secondary agonists ADP and thomboxane $A 2$ entance platele activation processes ${ }^{23 .}$ Like other $G$ protellu-coupled receptors, activated PAR-receptors are rapldy uncoupled from signalling and intemalized by phosphorylation dependent nechamisms. The PAR-receptors are then delivered to lysosomes and rapidly degraded.

Recent findings suggest that GP $\mathrm{Gb}$ is important for platelet actiwation by low dose of thrombin. lit was reported that thrombin binding to GP lbo facilitates cleavage of PAR-1 "but not PAR-4." Furthermore, thrombin binding to $\mathrm{GP}^{3}$ loo is thought to induce direct signaling events via receptor crosslinking.

There are sevaral contlicting reports about the role of thrombin and its receptors in the development of procoagulant platelists. In line with Bevers et al., Andersen et al. showed that thrombin is only a very weak inducer of platelet procoagulant nctivity. Anderson at al. idtentified PAR-1 as the main receptor responsible for thrombin induced procoaguant actirty and they exclude a role for PARA. Compatible wh this notion, others showed a significant reduction in clotting time upon PAR-1 activation. 14 . In contrast. Dorman et al demonstrate that upon activation wh thrombin $60.80 \%$ of the platelet are procoagulan and they state that thrombin binding to GP lbo is esseritial for thrombin induced procoagulant activity. This notion is further supported by Dicker et al, who exclude a major role for $P A R-1$ in thrombin induced procoagulant activation.

\section{Role of adhesive proteins and their respective receptors in platelet procoagulant activity}

Current understandings indicate that adhesive receptors, like GP Ibo and integrin $\alpha_{4,} \beta_{3}$, play an imporiant role in the procoagulant activity of platelets. As auready mentioned before, $G P$ lba may stimulate exposure of negatively charged phospholipids in the exoleallet of the platelet plasma menbrane wa its high affinity thrombin binding site. ${ }^{35-37}$ In addition, some data favor a role of the GP IbotVWF interaction in thrombin induced platelet procoagulant activity in coagulating plasma and platelets adhering to fibrin surfaces ${ }^{36}$ Yet, other investigator showed in a system with gell filtered platelets that $G \mathrm{P}$ Ibo-VWF interaction is not important for the development of procoagulant activity. "This could mean that fibrin, but mot VWF, is the important co-factor for thrombin induced platelet procoagulant activity. On the other hand, the apparent disctepancies might be explained by differences in shear rates in the various experimental setups.

Provided that platelets are activated, GP Ibo is able to interact with factor $X 1$. Since thrombin also binds to this complex, factor XI-GP lbo interaction fircilitates the cleavage of factor XI by thrombin. "The cleavage of factor $X l l$ by thrombin serwes in a leedback-loop: Thrombin $\rightarrow F X I$ $(\mathrm{a}) \rightarrow \mathrm{FHX}(\mathrm{a}) \rightarrow \mathrm{FX}(\mathrm{a}) \rightarrow$ (pro)thrombin $\rightarrow$ indicates activation of the zymogen by the enzyme). This might clarify why platelets of Bemard Soulier patients, which lack GP lbo, show a diminished thrombin generation.

Another receptor thought to be important in the development of procoagulant platelets is the integrin $\alpha_{\text {end }} B$. It is still a matter of debate whethar this receptor is involved in thrombin or collagen induced expostre of negatively charged phospholipids at he cuter leatlet of the platelet plasna nembrane. According to Ramström et al ${ }^{150,41}$ there is no effect of integrin $\alpha_{n} \beta$, antagonists, like abciximab, on thombin or collagen induced PtdSer exposure, while Fuman al $a^{16.41}$ show neduced PidSer exposure and factor WNa binding. Nonetheless, whether it occurs via PudSerdependent or -independen mechanisms, several lines of imvestigation indicate that antagonists of integrin $\alpha_{1,3}, 3$, inhibit wollagen and/or thrombin induced prothrombinase activity. ${ }^{35,36,42}$ In line with this, thrombin generation in blood of Glanzmann patients or blood of healthy individuals treated with integrin $\alpha_{116} \beta_{3}$ antagonists is delayed and thrombin generation during the propagation phase is depressed. 37,43

Inhbiting effects of antegrin $\alpha_{n \text { in }} \beta$ antagonists on thitomin generation disappeared with increasing concentrations of TF. For instance, when coagulation of whole blood was triggered with a relatively high $T F$ concentration of $200 \mathrm{pM}$, there was no significant effect of abciximab on thrombin generation. However, when heparin was present in blood triggered with $200 \mathrm{pM}$ tissue factor, additive effects of abciximab on the prolongation of 
the cloting time were reatily detectable. ${ }^{34}$ This implies that the influence of integrin $\alpha_{11} \beta$, becomes limited as soon as thrombin production becomes relatively high.

Several explanations for the inhibiting effect of integrin $\alpha_{1 n} b_{3}$ blockers on platelet procoagulant activition have been offered. It has been suggested that prothrombin binds to inactive integrin $\alpha_{11} \beta_{3}$ and is all set for activation when factor $\mathrm{Xa}$ is generated in the vicinity of the platelet surface ${ }^{45}$ Evidently, prothrombin activation within the prothrombinase complex is more efficient than on integrin $\alpha_{145} \beta_{3}$, but it is possible that the initial spark of thrombin is prowided by activation of prothrombin bound to integrin $\alpha_{14} \beta_{3}$. Alternatively, the shedding of procoagulant microparticles from the platelet plasma menbrane was reported to be reduced in the presence of integrin $\alpha_{n b} B_{3}$ inhibitors. ${ }^{.16-18}$

\section{Scope}

The studies described in the first part of this thesis are conducted to get a better understanding of the proteins and signaling pathways responsible for the procoagullant activation of platelets. A better knowledge of proteins and receptors concerning procoagulant activity might improve the understanding of excessive thrombus growth in diseased vessels. As already oullined in the previous paragraphs there are numerous conflicting data concerning platelet receptors and proteins involved in this process. We were motivated by a number of intriguing hypotheses to elucidate mechanisns involved in the generation of procoagulant platelet mernbranes.

In literature there are deviating results concerning the role of GP Ibo in the platelet procoagullant response induced by thrombin. While some investigators ${ }^{43}$ propose that the contribution of GP Iba is dependent on VWF binding, others ${ }^{35}$ report that binding of thrombin, but not VWF, to GP Ibo is essential for PtdSer exposure. Previous data from our group revealed that washed platelets adherent to fibrin layers generate a procoagulant surface membrane in the presence of thrombin, provided that their adhesion is mediated via GP Ibo-VWF contact. In Chapter 2 we hypothesized that in coagulating plasma shear stress potentiates the thrombin induced scrambling of phospholipids, by way of shear-dependent platelet interaction with VWF and fibrin. To study this, a system was developed in which a rotating cylinder exposed platelets in coagulating plasma to regular shear rates. It was demonstrated that platelet interaction with fibrin through shear dependent epitopes on GP $\|$ bo and by way of integrin $\alpha_{11 b} B_{3}$ plays an important role in thrombin induced platelet procoagulant activity at sufficiently high-shear rates.

The importance of VWF-fibrin contacts in platelet adhesion and procoagulant activity suggests that this interaction plays a key role in thrombus growth. We were interested in finding the fibrin binding site on VWF, because of potential therapeutic benefit: a specific blocker of the $\checkmark W F$-fibrin interaction might prevent excessive thrombus growth. In Chapter 3 , the detailed localization of the fibrin binding-site on VWF is described. Our results intoply that the C-domain of VWF is a critical determinant of platelet adhesion to fibrin under conditions of high shear stress.

Thrombin is a positive mediator of procoagulant activity of platelets, especially of platelets residing in a thrombus and thus in contact with adhesive substrates like collagen. VWF or fibrin(ogen). Current literature is not consistent with respect to which platelet thrombin receptor evokes scramblase activity. ${ }^{253}$ Therefore, Chapter 4 deals with the effects of thrombin binding to GP $\mathrm{Ib} \alpha$ and the protease activated receptors (PAR) $\mathbb{I}$ and 4 on calcium and procoagulant responses in platelets. Aceoding to the sustained calcium signals elicited by PAR 4 . we hypothesized that this receptor is cricial for thrombin induced procoagulan activity. Yet, we established that neither the thrombin binding site on GP lbo nor the activation of PAR-4 are required for thrombin induced platelet procoagulant activity. It appeared that PAR-1 is fully responsible for procoagulant activity elicited by thrombin.

Fundamental research in relation to thrombus formation, as performed in chapters 2,3 and 4 of this thesis, might contribute to improve treatment of patients with disensed atherosclerotic vessels. Finding a dutg that prevents pathological thrombus formation without afrecting nomal haemostasis is the ultimate goal of thrombosis research at this moment. Currently, treatment of atherosclerotic vessels occluded or nearly occluded with thrombi involves bypass surgery with autologous or even synthetic vessels, or balloon angioplasty followed by stent implantation. The clinical manifestations of the biocompatibility of cardiovascular devices, like stents and vascular grafts, are numerous: sudden and complete obstruction of stents acute and subacute thrombotic occlusion in mediun sized grafts $(4-6 \mathrm{~mm})^{50.51}$ and bleeding problems due to antiplatelet or anticoagulant therapy. Therefore, studies in the second part of this thesis involve biocompatibility of artificial surfaces in contact with blood.

To prevent restenosis, a first criterion is a low thrombogenicity of the artificial surface. Thrombin is a prerequisite for the formation of a stable thrombus and, therefore, a possible strategy to improve the blood compatibility of artificial surfaces might be inactivation of locally generated thrombin by surface inmobilized heparin. However, to date heparin coatings have not been shown to significantly reduce the number of postoperative complications. ${ }^{52}$ The studies described in Chapters 5-7 were undertaken to 1) get a better understanding of the precise antithrombotic functions of immobilized heparin and, 2) to improve biocompatibility of heparin coatings.

It was established that the thromboresistant property of heparinized surfaces relies on neutralization of locally formed thrombin by surface bound heparin-antithrombin complexes, and not so much modulating protein adsorption and platelet adhesion (Chapter 5). $A$ possible disadvantage of highly sulphated polysaccharides, like heparin, concens binding of growth factors, which mighn positively nediate restenosis. Hence, antithrombogenic propertics of immobilized heparin are compared wilh mildy sulphated polysaccharides, namely, chondroillin suphate and alginate (Chapter 6). These polysaccharides appeared to be proteinand thromboresistant and ruight be used in combination with heparin on blood contacting surfaces. In Chapter 7 , experiments with heparinized collagen are described. The low antigenicity of collagen makess it at outstanding candidate for coatings of medical devices in contact with blood, although the thrombogenic nature limits its application. If is demonstrated that heparin, already when used as a crosslinker of collagen, effectively prewents thrombus formation in collagen coated stents.

\section{References}

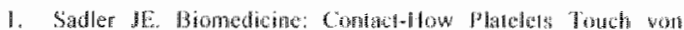
Willewathe factor. Science. $2002,297: 112 x-1$ 1 20

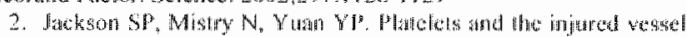

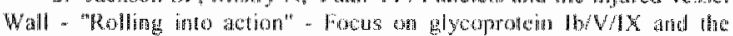

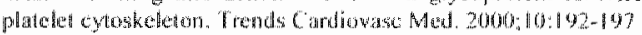

3. Matsa H. Sugholo M, Mizumo 
49. Butt JA. Coronary sten occlusion: thronbus horribilis. If Am Coll Cartiol 1996;28:368-370

50. Nebson SR, deSouza MM, Allison DJ. Endowascular stents atud stent-grafts: Io heparin coating desifable? Cardiovasc lnterwent Roulol $2000,23-252-255$

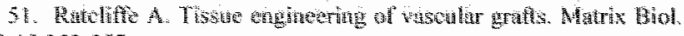
$2000+19+353 \cdot 35 ?$

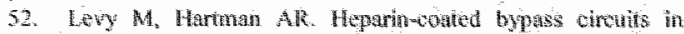

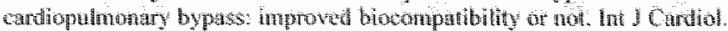
1996,5354468108 


\section{Integrin $\alpha_{\text {IIb }} \beta_{3}$ and shear-dependent action of glycoprotein Ib $\alpha$ stimulate platelet-dependent thrombin formation in stirred plasma.}

$J$ Lab Clin Med. 2003;141:350-8 


\title{
Integrin $\alpha_{11 \mathrm{~b}} \beta_{3}$ and shear-dependent action of glycoprotein lba stimulate platelet-dependent thrombin formation in stirred plasma
}

\author{
JEFFREY F. W. KEUREN, HANS ULRICHTS, MARION A. H. FEIJGE, KARLY HAMULYAK, HANS \\ DECKMYN, THEO LINDHOUT, and JOHAN W. M. HEEMSKERK
}

MAASTRICHT, THE NETHERLANDS, and LEUVEN, BELGIUM

\begin{abstract}
Under condifions of arterial-wall shear rates, platelets bind to von Willebrand faction (vWi) by way of the glycoprotein Ib (GP Ib) complex and integrin $\alpha_{1 \mathrm{bb}} \beta_{3^{\prime \prime}}$. Bafh adhesive receptors may also play roles in the development of procoagulant activity of platelets. Here, we investigated the effect of shear stress, as provided by a rolating cylinder, on GP Ib-and integrin $\alpha_{11 b} \beta_{3}$-dependent thrombin generation in coagulating platelet-rich plasma (PRP). We measured thrombin continuously with the use of fluoromeiry from the cleavage rafe of a fluorescent low-affinity substrate. The infegrin $\alpha_{1 t a} \beta_{3}$ antagonist abciximab progressively reduced the peak of thrombin formation up to $43 \%$ when rate of stirring and shear stress were increased (estimated shear rates of $105-420 \mathrm{~s}^{-1}$ ). Abciximab did not lower the peak of thrombin formation in stirred PRP from patients with Glanzmann's thrombasthenla lacking $\alpha_{\text {Hib }} \beta_{3}$ but, surprisingly, shortened the time until onset. In PRP from control subjects, antibadies specifically directed against vWF-binding epitopes on GP Iboreduced thrombin formation, with $25 \%$ th $30 \%$ at the high but not at the low stirring rate. In combination with the anti-GP Ib antibody, abciximab relained its strong inhibltory effect only at the high stirring rate. We conclude that thrombin formation and coagulation in stirred PRP depend, to a large extent, on platelet adhesion to integrin $\alpha_{11 \mathrm{~b}} \beta_{3}$ and, in a shear-dependent way, on GP Ib. (J Lab Clin Med 2003;141:350-8)
\end{abstract}

\footnotetext{
Abbreviations: FITC = fuorescein isothiocyanate; GP ID-HX-V = glycoprotein b-IX-V; HEPES = M-2-hydraxyethypiperazine-N2-ethanesultonic acid: PARI = protease-activoted receotor 1 : PFP = platelet-free plasma: PRP = platelet-rich plasma: WWF = von Willebrand factor: ZGGRAMC = berzyloxycarbonyl Gly-Giy-Arg 7-amido-4-methyl-coumarin
}

$\mathbf{T}$ he platelet glycoprotein Ib-IX-V (GP Ib-IX-V) complex plays an important, although not yet completcly understood, role in platelet adhesion and activation. Under conditions of high shear stress.

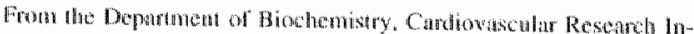

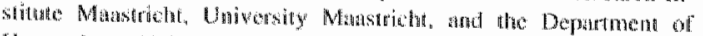
Hematolyy, Lniversily Hospilal Mans richt: and the Laboratory for Thrombers Reseated, K. U. l.ennen. Compess Kortrijk

Subnithed for publication October 25, 2002: accepted November 26 2012.

Reprint requeste Jeffrey F, W. Keuren, MD, University of MansIfichn, Depantach of Biochemisary, pO Box 616 . Mastricht 6200 MD. Netherlatudis.
vWf undergoes a conformational change that allows flowing platelets to bind reversibly to a surface by way of their GP Ib complex. ${ }^{2}$ "This binding is immediately followed by stable platelet adhesion to a haemostatic surface as provided by collagen or fibrim fibers. ${ }^{3,4} \mathrm{Sta-}$ bilization on fibrin is highly dependent on activated glycoprotein Ilb/IIa (integrin $\alpha_{1 \mathrm{rb}} \beta_{3}$ ), which acts as a high-affinity receptor for both wWI and fibrin. ${ }^{\text {s. }}$

Activated platelets play an indispensable role in the coagulation process, mainly but not exclusively through the surface exposure of the procoagulant phosphatidylserine. Exposed phosphatidylserine dramatically stimulates the proteolytic conversion of factor $X$ and prothrombin into the serine proteases factor $X a$ and thrombin, respectively. Although it is clear that platelets strongly stimulate the process of thrombin forma- 
tron in coagulating plasma in an adhesion-dependent way ${ }^{3}$ precisely which adhesive receptors and activation pathways are involved is still incompletely under stood. Antagonists of integrin $\alpha_{4} \beta_{3}{ }^{12-15}$ such as the chimeric antibody abciximab, ${ }^{\text {sin }}$ effectively decrease thrombin generation in PRP. Inhibition of GP Ib-V-IX binding, whether or not in combination with anti-integrins, has a similar lowering effect on thrombin fomation ${ }^{12,172,8}$ Although Beguin at al ${ }^{18}$ propose that the contribution of GP Ib is also dependent on wW, others report that GP Ib binding to thrombin butt not to wWf is essential for platelet phosphatidylserine exposure. Because thrombin binding to GP ID facilitates PAR I activation, ${ }^{20}$ GP lb may thereby enhance the stimulating effect of PAR 1 on procoagulant activity of plate lets. ${ }^{21}$ The exact function of $\mathrm{GP}$ Ib intaraction in the development of platelet procoagulant activity there tore remains to be clarified.

Knowing the shear-dependent action of wWf, we hypothesized that the presence of shear stress plays a role in stimulating the GP Ib- and integrin dependent procoagtalant platelet response (phosphatidylserine exposure)-for instance, by way of shear-dependent platelet interaction with VWF and fibrin. To provide regular shear stress to platelets, we generated a fibrin clot with aggregated platelets in coagulating PRP at the surface of a cylinder, which was notated at defined stir rates. We then monitored thrombin generation continuously with the use of a fluorescent thrombin substrate. Antibody fragments specifically blocking shear-induced and $v W f$-dependent athesion events were used to determine the involvement of this shear-dependent pathway in the procoagulant effect of platelets.

\section{METHODS}

Materiols. Fluongenic thrombin substrate Z.GGR-AMC came from Bachem (Bubendert. Swizerland). Abciximab (c7E3 Fab) was purchased from Centocor (Leiden Neherlands). Homan $\alpha$-ihrombin was purifed as alescribed previously. $\left.{ }^{22} \mathrm{~F}_{(\mathrm{ab}}\right)_{2}$ fragments of monoclonal antibodies $6 \mathrm{~B} 4$.

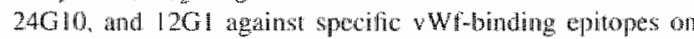
GPJbo were generated and charactenzed as described earli$\mathrm{er}^{2},{ }^{23}$ the $\mathrm{PAC}-1$ antibody against activated integrin $\alpha_{\mathrm{n}} \beta_{3}$ came from Becton-Dickinson (San Jose, Caht). The PARI receptor agonist Ser-Phe-Let-Leu-Ag-Asn (SFLLRN) was from $1 \mathrm{HB}$ (Leiden. Netherlands). Other materials came from sutres mentioned alse where. ${ }^{25}$

Blood donation and preparation of plasma. Blood was rreshy obrained from healthy volunters who denied having taken antiplatele medication for at least 2 weeks. Blood was also obtanced from thee patients with type I Glanzonano disease, wh platelets completely deficient in integrum $\mathrm{n}_{\mathrm{m}} \beta_{3},{ }^{36}$ Arter collecting blood into $1 / 9$ wolume of 0.13 mol/L. arisodium cilras. we centrifuged it at $190 \mathrm{~g}$ for 15 minutes to obtain PRP. PFP was immediately prepared from the PRP by means of contrifugation at 10,000 g for 10

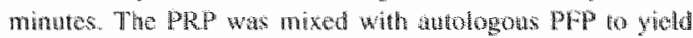
the desired pistelet count. The nomialized PRP was ast

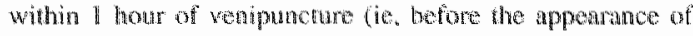
plateleterved microvesicles wh high procongulatat activi. y). All subjects gave full informed consent before donating blomat.

Flow cytometry. Pap containing $2 \times 10^{\text {R }}$ platelets/and was preincubatcol with antibodies for 10 minutes. Platelets were then activated whit 15 HmoM. SFLLRN and afier 10 minutes, evaluated on aftrity modulation of integrin $\alpha_{1} \beta_{3}$ with the use of FITC-Hbeled PAC-1 antiboty agains the actirated integrin. ${ }^{27}$ Measurements were petformed with an Epics XL flow cyometer from Coulic Electrones (Luton. UK).

Thrombin generotion modsurement, Wa mensured thrombin generation in cloring PRP, usually contuining $2 \times$ $10^{8}$ platelets/m in $10 \mathrm{~mm}$ huorecence chrefles contining a cylindrical stiring bur (diancter $9 \mathrm{~mm}$, height $8 \mathrm{~mm}$ ) using an SLM-Aminco 8100 spectrofltorometer (SLM Instrimenti. Rochester, NY). Four civetes were placed in the thermosidtequipped cuvetre house of the furometer in such a way that thorescence was measured in a window of $10104.5 \mathrm{~mm}$ above the bothoms of the cuvettes. Stiring wh alone contin nously at a rate of 100 to $400 \mathrm{mpm}$. The cuvenes containd $1.87 \mathrm{~mL} \mathrm{PRP} \mathrm{(platelet} \mathrm{count} \mathrm{as} \mathrm{indicated)} \mathrm{stnd} 0.93 \mathrm{~mL}$ HEPES buffer $136 \mathrm{mmol} / \mathrm{L}$. NaCl, $2.7 \mathrm{mmol} / \mathrm{LCl}, 2$ mmol/L $\mathrm{MgCl}_{2}, 10 \mathrm{mmol} / \mathrm{L}$ Hepes; $\mathrm{pH}$ 7.45). After suppli: mentation with 0.25 mmol/L Z-GGR-AMC, congulation was triggered with $16.7 \mathrm{mmol} / . . \mathrm{CaCl}$ (fina concentrations). the PRP mixlure was prencubated with the indicited antibodics for 10 minutes before the addition of $\mathrm{CaCl}_{2}$. Where indicasted. 10 nmol/L human $\alpha$ ththombin was added immediately before $\mathrm{CuCl}_{2}$. Flumescence catused by cleaved amidomethyl coumat tin was continuously recorded on excitation at $390 \mathrm{~nm}$ and an emission wavelength of $460 \mathrm{~nm}(5 \mathrm{~mm}$ band passes). Measurements were perfomed at $37^{\circ} \mathrm{C}$.

To provide a defined shear stress, we set the stirring eyl-

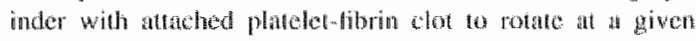
angular spoed $(\Omega)$. The shear rate $(\gamma)$ at the surfice of the cylinder was then calculated as $\gamma=0.5 \Omega \mathrm{W} / \mathrm{e}$, where $W$ is the width of the cuwete (10 mm) and 8 sis the distance between the clwetle wall and the cylinder 60.5 mm with centered bar). Al string gates of 100,200 , and $400 \mathrm{mph}$, the conespondings shear rates wore 105,210 and $420 \mathrm{x}^{\cdots \frac{3}{3}}$, resper. tively. Note that $400 \mathrm{mpm}$ was the highest stirting ratte that condd be achicved in this cuvette system without anthens resutuing from strong fluctuations in the rotation of the cylinder.

Lag times of onset of the burst of thrombin formetion were

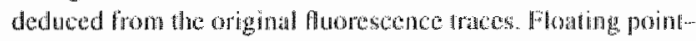
aweraged first-derivalive trates were then constructed to oth. tain curves of thrombin generation. as described by Henker et a1. ${ }^{2 *}$ Thrombin generation was firs expressed as atritary uniss of flurescence intensity per mimutes (AU/min). The convession factor from fluorescence units 10 thrombin concentrations was determined in partallel experiments, in which thrombin was measured with 52238 substrate in samples. 


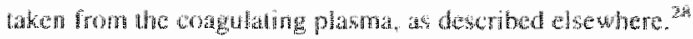

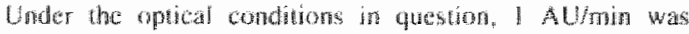

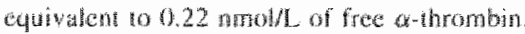

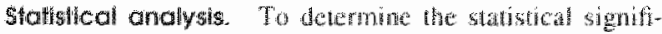

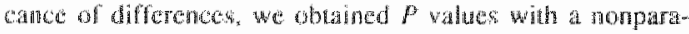

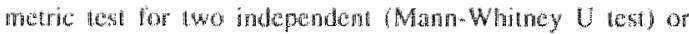
two dependent variables. (Whoswon signct-rank test), using

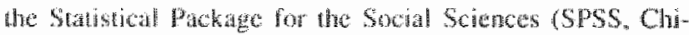
cago. $111 \%$.

\section{RESULTS}

Effect of stirting on thrombin generation in clotting PRP. Thrombin generation was monitored in citrated PRP triggred with $\mathrm{CaCl}_{2}$ at a controlled shear rate. We therefore adapted a method with which thrombin generation can be measured continuously from the cleavage of a low-affnity fuorogenic thrombin substrate, Z “GR-AMC " As described in such a plasmat system the major burst of thrombin fomation occurs after a threshold amount of thrombin ( $<0.5$ nmolll $)$ has been produced. The threshoud amouns of thrombin are sufficient to activate platelets and form forin but cannot be detected by the low-atfinity substrate. A major advantage of such substrate, nowever, is its low thrnover; it only mininally competes with the natural thrombin substrates in plasma and therefore does not interfere with the burst of thrombin generation. ${ }^{23}$.31, 3

Using cuventes stired with a lange rotating magnetic cylinder to provide regular shear stress, we comtiruously measured fuorescence accumulation of the cleaved Z-GGR-AMC by means of a window in the cuvetre house above the bar. Inder standard conditions with freshly isolated PRP from healthy subjects $2 \times$ $10^{s}$ platelets/mL), a fibrin clot trapping most of the platelets formed at the outer surface of the stirring bat aher about 10 minutes of triggering with $\mathrm{CaCl}_{2}$. De. lectable anounts of Auoresconce appewed atfer 12 to 15 minutes, when the burs of thombin fomation started (Fig 1, A). In the presence of heparin, no huorescent signew was observed, dremonstmating that it was complenely thombin-dependent. We constructed first-

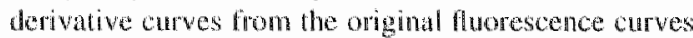
to beter visuatize the aceumutrion and inactivation of Ilroubin in time. Peak levels of thrombin were lypically observed after bout 10 minutes of thorescence (Fig 1. B). When the string rate was increased from 0 to 200 and then 400 ppm, the onset of thombin shortened who 3 minutes, whereas the thrombin peta in creased foutold, from 25 to $100 \mathrm{nmol} / \mathrm{h}$. Similarly, the area under the cuve, eather designated the andogenous thrombin podentid and reprosenting the cumulate activily of thrombin during the coagutat process as a whole, ${ }^{3}, 3.3$ increased about tourfold wh a higher stir-
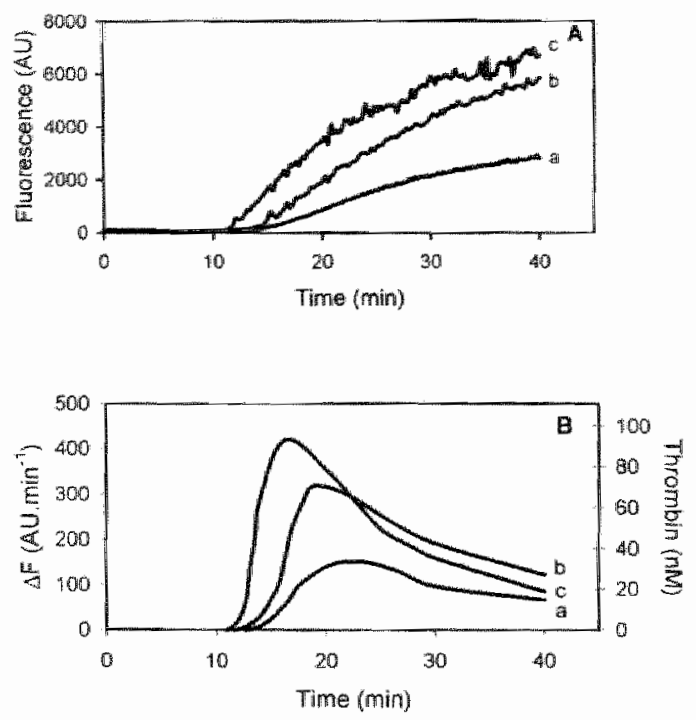

Fig 1. Effec of sir rate on thrombio generation in conguhang PRP. Citruted PRP (final platedet coun $2 \times 10^{8} / \mathrm{mL}$ ) wats triggered with

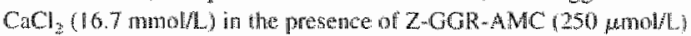
at warious stir mates. Thrombin anciviny was measured from the aces. mulation of thorescent amidonethyl coumarin (A). First-derivative curves were constructed to yiald time courses of thrombin generation (B). The stir rate during the experiment was $0(a), 200(b)$, or $400 \mathrm{rpm}$ (c), equiratent wo shear rates of 105,210 , and $420 \mathrm{~s}^{-1}$, respectively. Tances ane from an experinem trepresentaline of thre performed.

ring rate. The coagulant activity of triggered PRP thus appeared to increase with the rate of stirring.

To determine the dependence of platelets in the thrombin generation process, we took measurements at various platelet concentrations at a stirring rate of 200 rpm. With the use of PFP (ic, in the absence of platelets), no substrate cleavage was observed for at least 60 min (Fig $2, A$ ). Increasing the platelet count in plasma from $0.25102 \times 10^{8} / \mathrm{mLL}$ resulted in a shortering of the lang period of thrombin formation by $40 \%$; the thrombin peak values increased fourfold (Fig 2, B). This finding illustrates the critical role of platelets in the propagation of thrombin generation in our experimental seup.

Contribution of integrin $\alpha_{418} \beta_{3}$ to thrombin generation in stimed PRP. We nexi determined whether, in this rapidstiming system, thrombin formation was dependent on integrin $\alpha_{\mathrm{In}} \beta_{3}$ activation, as has been described in the absence of stirring or under slow-stirring conditions. ${ }^{12.16,17,34}$ It has been shown that antibody-derived $\alpha_{116}, \beta_{3}$ inhibitors are most effective in suppressing platelet procoagulant activity. Widely used is the chimeric antibody abciximab (c7E3 Fab; Reopro), which has a consistent anticoagulant effect in other platelet. 

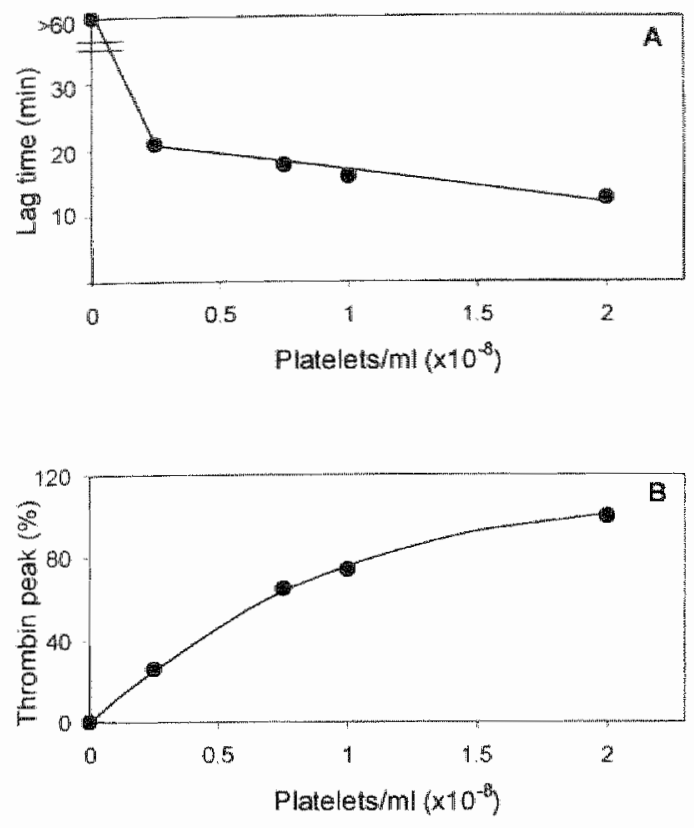

Nig 2. Fotect of platelel concentation on thrombin generation in stirred, congulating PRP. Citrated PRP, difuted wint autologons PFP io various platelet concentrations, was triggered with CaCI2 416.7 mmol/L) in the presence of Z-GGR-AMC (250 phoh/L) during continuous stirring at 200 ppun. Delay times of detectuble thrombin generation (A) and thrombin peak walues (B) are plotted as functions of platelet conn. Thrombizy peath values are expressed ats percentiges relative 10 standard conditions (platelet count $2 \times 1 \mathrm{f}^{\mathrm{h}} \mathrm{m} \mathrm{mL}$.). Data are from an experiment representative of threc pertorned.

plasma systems and established antithrombotic action in clinical practice. ${ }^{16.34-35}$ When used in the thrombingeneration assay under nonstirring conditions, abeiximab has a more prominent effect on the thrombin peak level than on endogenous thrombin potential. This indicates that platelet activation affects to a larger extent the rate of thrombin formation than the total amount of active thrombin formed cluring the cloting process.

When added to stirred PRP before the $\mathrm{CaCl}_{2}$ trigger, abeiximab at concentrations of $5 \mu \mathrm{g} / \mathrm{mL}$ and greater caused a consistent lengthening of the lag time of thrombin formation ( $\mathrm{Fig} 3, A$ ) and al clear decrease in the thrombits peak value (Fig 3, B). At $10 \mu \mathrm{g} / \mathrm{mL}$. abciximab prolonged the lime of onset to sudden thrombin production from $13.2 \pm 2$ to $27.3 \pm 11.6$ minutes (mean \pm SD: $n=5, P<.001$ ) but decreased the thrombin peak to $57.3 \% \pm 21 \%(P<.001)$ with respect to control conditions. Higher levels of abciximab did not further increase these effects (Fig $3, A$ and B).

To confim that integrin $\alpha_{11}, \beta_{3}$ was involved in the
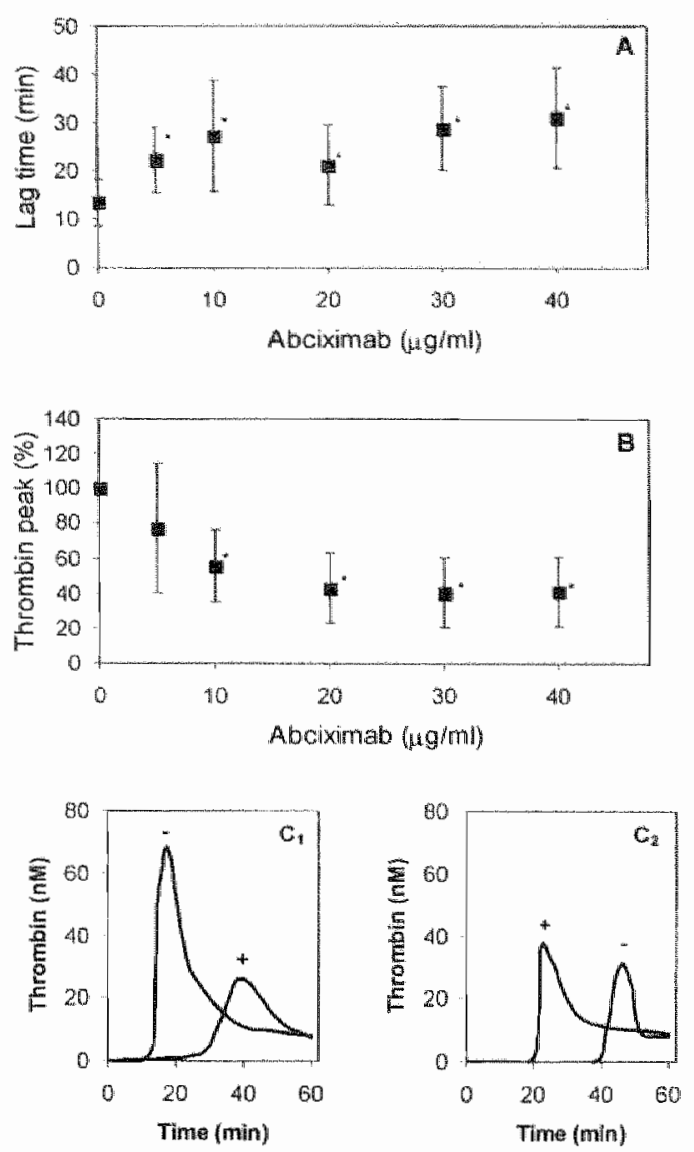

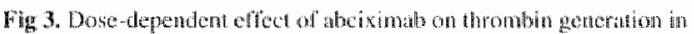
stined PRP. Thombin generahon was mexsured from nherescenec accumtiation in PRP stired at $200 \mathrm{rpm}$, as describud in the legent co

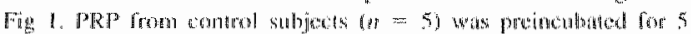

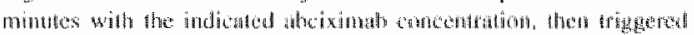

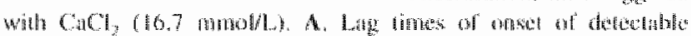

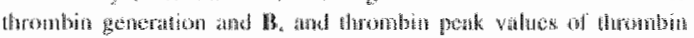

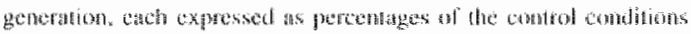

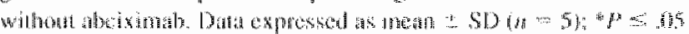

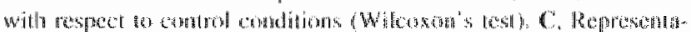

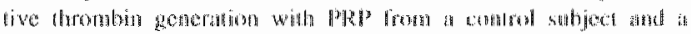

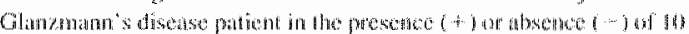

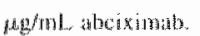

inthibitory effect of abciximab under these stirring conditions, we conducted further experiments with plasma from three patients with type I Glanzmann disease, whose platelets completely lack this integrin. Thrombin generation was markedly allered in the stired PRP from the patients. For two patients, lag times of thrombin formation after triggering of the coagulation were 39.4 and 40.9 minutes, mucty longer than the latg time of $13.2 \pm 2$ minutes in PRP from control subjects. Throm- 


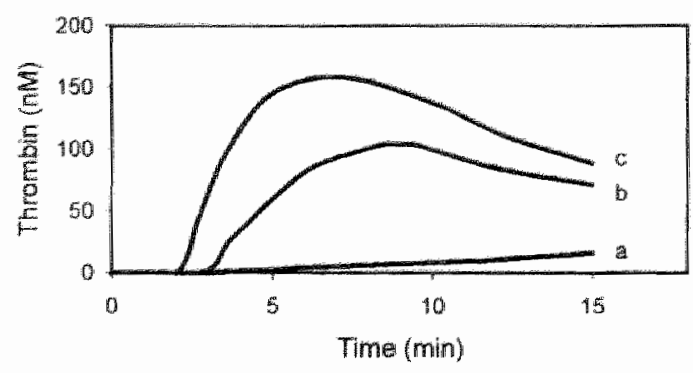

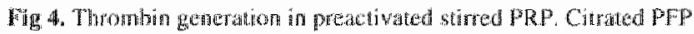

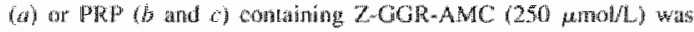

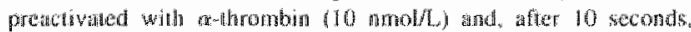

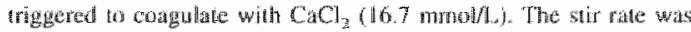

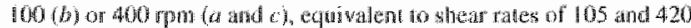

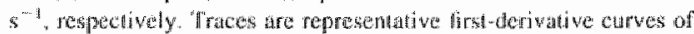
utrombingenerations (fout experiments pertomazd)

bin park values in patient plasma were approximately hatf the normal level (Fig $3, C$ ). In PRP from the third Glanzmann patient, no detectabl thrombir was formed during the 60 -minute measurement period. Addition of abciximab $(10 \mu \mathrm{g} / \mathrm{mL})$ to stirred PRP from the first two Glanzmant patients did not affect the thrombin peak value but, surprisingly, shortened lag time from 39.4 and 40.9 minutes to 18.2 and 20.0 mirutes. In the thind patien, lag time remained greater than 60 minutes in the presence of abciximab. These data indicate that in the stirred-PRP system, integrin $\alpha_{10} \beta_{y}$-mediated interactions, most likely with in situ-generated fibrin, prominently contribute to the thrombin-forming process.

Enhanced thrombin generation in preactivated, sfirred PRP. In the experiments described so far, clots in PRP were produced at the rotating cylindrical bar after about 10 minutes of recalcification. We reasoned that regutar shea-dependent focts ahong the GP Ib-vWF axis are only obtained when the platelets immediately adhere to the rotang cylinder. We achieved this by accelerating the processes of platelet activation and clot formation, adding human $\alpha$-thrombirt. The citrated PRP was preincubated with a single dose of thrombin (10 nmohL) for 10 seconds before the start of stiming and addition of CaCl. Within 20 seconds, this resulted in the apperarace of a clot, rapidly contracting at the surtace of the rotating cylinder and trapping aggregating platelets in the plasma. Two or 3 minutes after recalcification. depending on the stir rate, fuorescent amidomethyl coumurin stated to accumulate, pointing to the start of the burst of thrombin fomation (Fig 4). Control experiments incorporating PFP showed that the aded thrombin here also ctused clot formation but not a fluorescent signal (Fig 4) indicating that it was rapidy inactivated, most likely by plasma antithrombin. In the thrombin preactivated PRP, the time of onset of thrombin generation was slighty shortened when the stir rate was increased from 100 to $400 \mathrm{rpm}$, and the thrombin peak value incressed by about $25 \%$ (Fig 4 ). In most incubations, the platele-fobrin clot remained fixed at the stirring cylinder during the entire measurement period. In a few cases, the clot was released from the cylinder, resulting in antificial fuorescence signals (not showny. We concluded that because of the continuous rotation al the cylinder surface, the adhering platelets are subjected to more ar less regular shear stress during the period of thrombin-generation measurement.

Effect of specific onti-GPlba antibodies on thrombin generation in PRP with preformed fbrin clots under stinting conditions. To examine the involvement of shear stress-dependent GP Ib interactions in the procese of thrombin gemeration, we used $\mathrm{F}(\mathrm{ab})_{2}$ fragments from three monoclonal antibodies raised against specific epitopes of the GP lb complex. Earlier studies have indicated that the antibodies $6 \mathrm{~B} 4$ and $24 \mathrm{G} 10$ each bind to a different epitope on the GP Ibo chain, but both inbibit the shear- and ristocetin/botrocetin-induced binding of GP Ib to $\mathrm{Wf}^{24}$ Antibody $12 \mathrm{Gl}$ does not prevent of only weakly preverts ristocetin/botrocetininduced binding but strongly interferes with the shearinduced binding of GP Ib to vWf. Only $24 \mathrm{G} 10 \mathrm{ap}$ peared to have a minor effect on GP Ib interaction with thrombin. 23.24

Bffects of the three antibody fragments (each 10 $\mu \mathrm{g} / \mathrm{mL}$ ) were determined in thrombin-preactivated PRP that was stimed at 100 (low stir rate) or $400 \mathrm{rpm}$ (high stir rate). We conducted these tests in the presence or absence of abciximab $(10 \mu \mathrm{g} / \mathrm{mL})$ to detemine possible cumalative effects of $\mathrm{GP} \mathrm{Tb}$ and integrin $\alpha_{\mathrm{m}} \beta_{3}$ inhibition. As shown in Table 1, none of the three anti-GP lbo antibody fragments influenced the thrombin generation when the preactivated PRP was stired at 100 rpm. In contrast, at the high str rate of 400 pm, the $6 \mathrm{~B} 4,12 \mathrm{Cl}$, and $24 \mathrm{G} \| \mathrm{O}$ antibody fragments all reduced the thrombin peak level by $25 \%$ to $30 \%$. The effects of 6B4 $(P=.01$. Wilcoxon's test $)$ and $12 \mathrm{Gl}(P=.049)$ at a high stir rate were statistically significant.

Agan, abciximab caused a partialy inhibitory effect on thrombin generation in the thrombin-preactiveted PRP (Table 1). Al the low stir rate, abciximab (10 $\mu \mathrm{g} / \mathrm{mL}$ ) reduced the thrombin peak value by $23 \%$, but at 400 rom it catused a significartly greater reduction of $43 \%(P=.03$. Mam-Whitney U test). Only at $400 \mathrm{rpm}$ did abciximab reduce thrombin generation in the presence of the 6B-4 fragment; the difference between treatment with $6 \mathrm{~B} 4$ and whth $6 \mathrm{~B} 4 /$ abciximal was statistcally significant $(P=.01)$.

However, we noted no significant difference between 
Table I. Inhibitory effecis of antibodies against sheat-dependent eptopes on GP Iba and integrin $\alpha_{\text {ib }} \beta_{3}$ on thrombin generation in stired PRP

\begin{tabular}{|c|c|c|c|}
\hline \multirow[b]{2}{*}{ Anitibody } & \multicolumn{3}{|c|}{ Thrombin peats cos of controllit } \\
\hline & Low stir rato & High stir nctie & $\begin{array}{l}\text { P(Momn- } \\
\text { (Whilney) }\end{array}$ \\
\hline $6 \mathrm{~B}^{4}$ & $1082+24.6(5)$ & $74.8 \pm 20.7(10 \%$ & 0.023 \\
\hline 24010 & $139.4(1)$ & $76.5 \pm 7.5(3)$ & -in- \\
\hline 1201 & $88.7 \pm 24.6(4)$ & $64.6 \pm 15.614$ & 0.149 \\
\hline ADcixtrab & $77.4 \pm 152(5)$ & $50.7 \pm 13.577$ & 0.030 \\
\hline $684+a t$ - aximab & $930-37.96$ & $45.5 \pm 15.116 \mathrm{j}$ & 0.030 \\
\hline
\end{tabular}

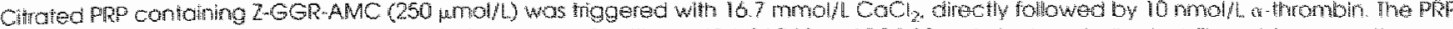

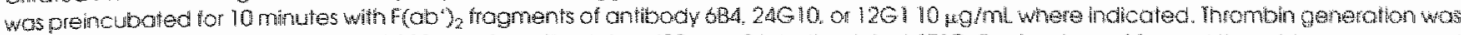

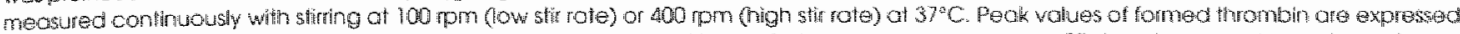

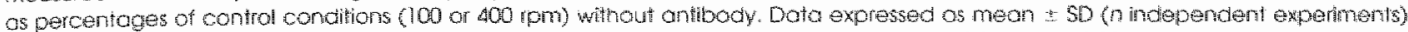

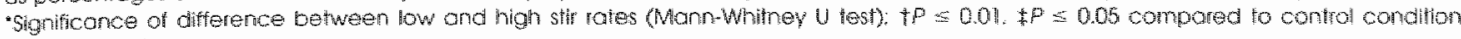
(witcoxon testy.

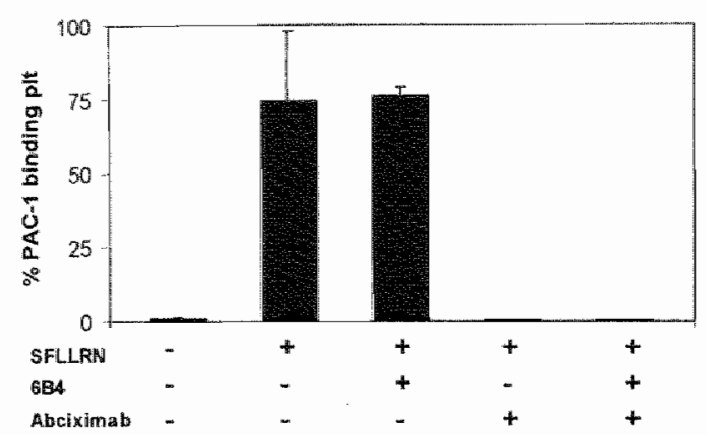

Fig 5. Effeci of the anti-GFlba antibody $6 \mathrm{~B} 4$ and ataciximab on PAC-I binding to resting and aetivated plateles. Plateles in PRP were incubated for 10 minutes with or withou 6 B 4 . F(ab) fragment (10) $\mu \mathrm{g} / \mathrm{mL})$, abeiximab (10 $\mu \mathrm{g} / \mathrm{mL})$, or both. PAC 1 binding was determincel after 10 minutes of activation of the platelets with SFLLRN $(15 \mu \mathrm{mol} / \mathrm{L})$ with the use of flow cytometry. Controls were

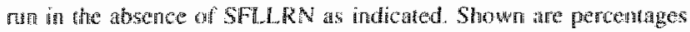
of platelots saining poritively for FTC-PAC-H, Dat expresed as sheans $+\mathrm{SD}, n=3 \mathrm{j}$.

treatment with abciximab alone and with abciximab/ $6 \mathrm{~B} 4(P=.25)$. Further statistical analysis showed that the difference in thrombin levels between low and high stir rates was significant in the incubations containing 6B4 fragment $(P=.028)$ or abciximab $(P=.030$; Table I) Note that the vWf activator ristocetin could not be used in these experiments because it interferes with the coagulation activity in plasma. ${ }^{18}$

Flow cytometry was used to check whether the 6BA4 $\left.\mathrm{F}(\mathrm{ab})_{2}\right)_{2}$ fragment interferes with the binding of abciximab to platelets. Integrin $\alpha_{1 m} \beta_{3}$ activation of the platelets was therefore monitored with FTTC-labeled antibody PACl. As shown in Figure 5, at the concentration used in the thrombin-generation experiments, 6B4 (10 $\mu \mathrm{g} / \mathrm{mL}$ ) did not cause activation of the integrin and did not interfere with PAC-1 binding on platelets activated with thrombin receptor-activating peptide SFLLRN. Nor did $6 \mathrm{~B} 4$ abolish the binding of abciximab (10 $\mu \mathrm{g} / \mathrm{mL})$ to the activated integrin, which would result in restoration of $\mathrm{PAC}-1$ binding.

These results provide evidence that a shear-dependent binding site for $\mathrm{WWf}$ on GP Ibo, as accessed by the antibody fragments, plays a substantial role in plateletdependent thrombin generation when the clot-bound platelets are subjected to a sufficiently lhigh shear rate. Furthermore, because the abciximab effect was not further potentiated by shear-dependent anti-GP Ib antibodies, it appeass that the shear/GP Ib-dependent effect to a large extent involves integrin $\alpha_{11 h} \beta_{3}$.

\section{DISCUSSION}

In this article, we describe a method with which thrombin generation in coagulating PR.P is continuously measured under defined stiming conditions. A large, rotating magnetic cylinder, forming the site of attachment of platelet-fibrin thrombi, is used to subject the clot-bound platelets to regular shear stress. Thrombin generation is quantified from the accumulation of the fluorescent cleavage product of the low-alfinity substrate Z-GGR-AMC, which interferes only at little with the thrombin-generation process per se. ${ }^{\text {zon }}$ In this measurement system, the process of thrombin genera. tion appears to depend fully on the presence of plate. lets, and it is accelerated and increased at higher stir rates. During stirring at $400 \mathrm{rpm}$, which was the highesi rate achievable, the formed thrombin reaches peaks ats high as 100 nmol/L, at finding in agreement with the earlier notion that the presence of the fluorescent thrombin substrate allows full development of the thrombin-generation process.

It is difficult to precisely determine the actual shear 
stresses sensed by the plateles in the stimed cuvette. It is estinated that plateles adhering at the outer surface of the stirred cylinder are exposed to a shear rate of 105 and $420 \mathrm{~s}^{-1}$ when stirring is performed at 100 and 400 rpm, respectively (see Methods). Other authors have shown that at low/intermediate physiologic shear rates of 150-600 s "the binding by way of CP lib becomes increasingly important for platelet adhesion to w Wf and the subsequent induction of integrin $\alpha_{413} \beta_{3}$ activation. ${ }^{37}$ The shear rates generated under these condilions thus seem sulficient to promote shear-dependent w W $-G P$ Ib interaction and later integrin activation.

Our data confirm earlier work with tunstired or sowly stirred PRP showing that the integrin antagonist abciximats is a potent inhibitor of the thrombin-generation process. ${ }^{16}$ " The results newly indicate that the inhibitory effect of abciximab on thrombin generation, at least on the thrombin peak level, increases with stir rate and thus with shear (Table 1 ). Abcixirnab was inhbibitory from concentrations greater than $5 \mu \mathrm{g} / \mathrm{mL}$ and had a nearly maximal effect at $10 \mu \mathrm{g} / \mathrm{mL}$ (Fig 3 ). These concentratons are similati to those used by other authors (eg, those studying the elfects of abciximab on platelet-dependent coagulation with preadded fibrin clons under minimal shear stress). ${ }^{12.3 .4}$ In the same concentration range, abciximab is clinically eftective in the prevention of thrombotic complications after percutaneous corconary angioplasty - that is, an bolus injection of $0.25 \mathrm{mg} / \mathrm{kg}$, equivalent to a peak value in plasma of approximately $3.5 \mu \mathrm{g} / \mathrm{mL}$ followed by at 12 -hour infusion at $0.6 \mathrm{mg} / \mathrm{h}$ (approximately $8.5 \mu \mathrm{g} / \mathrm{mL} / \mathrm{h}$ ) Note that similar coagulation decreasing effects of integrinblocking agents other than abciximab (eg, other antibodies, eptifbatide, and MK-383) have been obtained by other authors, although only in the absence of stirring or at a low stir nate. 13.46 .17

Experiments wilh PRP from patients with Glanzmann disease confirm a role of integrin $\alpha_{10} \beta_{3}$ in thrombin formantion. Thrombin lommation in patient PRP was delayed and reduced, and abciximat no longer inthibthed this process. However, suprisingly, abciximab shortened the lag time of thrombin generation in PRP of iwo of three patients with Glanzmann disease. Becatuse abciximab did not influene the thrombin-generation process in (patient) plasma in the absence of platelets, the effect must bo platelet-dependent. As a possible cxplantion, we staggest that abciximab, at least in the absence of integrim $\alpha_{18}, \beta_{3}$ can interaet with other (perhaps low-affinity) binding sites on platelets, which then thet in a platelet-stimuhatory fashion.

As reviewed elsewhere, the medhanism by which integrin $\alpha_{11} \beta_{3}$ blocking inftuences the procoagulant activity of platelets in plasma is unclear. It has been suggested that binding of prothrombin to inactivated integrin $\alpha_{10} \beta_{3}$ triggers the generation of traces o thrombin, which in turn induce (by way of cleaver thrombin receptors) platelet procoagulant activity. Blocking of integrin $\alpha_{m} \beta_{3}$ with abciximab may delay initial thrombin generation and thus prolong the las period of thrombin generation. Alternatively, integrir $\alpha_{14} \beta_{3}$ antagonism may infuence coagulation by inlib. iting the formation of procoagulant platelet derived mi crowesicles. ${ }^{34.39}$

To oblain immediate shear--dependent effects, we activated the citrated PRP with human $\alpha$-thrombin shortly before adding $\mathrm{CaCl}_{2}$. This resulted in rapid formation of a rotating platelet-fibrin clot before the calciumdependent burst of thrombin generation. It should be noted that the added thrombin is rapidly inactivated in plasma (hall-life of approximately 7 seconds), and therefore only the later massive burst of thrombin formation is detectable with the low-affinity huorescent thrombin substrate. With three different antibody: $\mathrm{F}\left(\mathrm{ab} \mathrm{b}^{\prime}\right)$, ragments, $6 \mathrm{~B} 4,24 \mathrm{G} 10$, or $12 \mathrm{G} 1(10 \mu \mathrm{g} / \mathrm{mL})$, each specifically directed against platelet GP Ibo and each inhibiting shear-dependent binding of GP $\mathrm{lb}$ to WWf, we observed reduced thrombin formation only at a high (400 rpm) but not at a low $(100 \mathrm{rpm})$ stir rate. This implies that the antibodies are only capable of influencing the thrombin-generation process at the higher shear rate of $420 \mathrm{~s}^{-1}$. Additional evidence that GP Ib- $\mathrm{WW}$ interactions are involved in platelet adhesion under these circumstances comes from flow studies in which whole blood from baboons was perfused over a collagen/vWt surface. It appeared that the $6 \mathrm{~B} 4$ fragment $(10 \mu \mathrm{g} / \mathrm{mL})$ decreases platelet deposition by about $50 \%$ at a wall-shear rate of $650 \mathrm{~s}^{-1}$. ${ }^{24}$ The physiologic significance of the antibody effect is apparent from the observation that a bolus infusion of $6 \mathrm{~B} 4$ antibody of $640 \mu \mathrm{g} / \mathrm{kg}$ (equivalent to a plasma level of about $10 \mu \mathrm{g} / \mathrm{mL}$ ) reduced the platelet deposition arterial thrombosis in this primate model by $65 \% \%^{2.4}$

A typical observation was that the reduction of thrombin formation by the $6 \mathbb{B} 4$ anti-GP lb fragment was enhanced by abciximab, but only at whigh stir rate (Table 1). Given that $6 \mathrm{~B} 4$ does not affect the inhibitory effect of abciximab, we can conclude that $6 \mathrm{~B} 4$ under high-stir-rate conditions interferes with the same for similar) plateletactivation processes as abciximab. Thus the shear-dependent effect on platelet thrombin formation seems to be at least in part upstream of integrin $\alpha_{11} \beta_{3}$-mediated effects. This GP lb effect, like that of integrin $\alpha_{12}, \beta_{3}$, most likely involves increased expression of phosphatidylserine on the platelet surface; this is a predominant parameter determining thrombin formation in platelet-containing plas. ma. ${ }^{12,18,19,40}$ The shear-dependent effect we observed may therefore explain the apparently deviating results 
of Dömann et $a{ }^{19}$ who reported that wW binding to GP Ib is not essential for the procoagulant response of thrombin-stimulated platelets, because the work was conducted in the absence of high-shear conditions.

We conclude that platelet interaction with fibrin through shear-dependent epitopes on GP Ib and by way of integrin $\alpha_{116} \beta_{3}$ plays an important role in the plateletdependent coagulation process as assayed under suficiently high shear conditions. The work thereby suggests that the interaction of platelet GP Ib with immobilized wWf, such as that which occurs under moderate and high wall-shear rates, has a more diverse effect on hemostasis than previously thought. It not only serves to tether platelets at sites of wW deposition but supports the subsequent platelet-dependent stimulation of the coagulation process.

\section{REFERENCES}

1. Berndi MC, Sten Y, Dopheide SM, Gardiner EE, Andrews RK The wascular biology of the glycoprotein IbuIX W complex. Thromb Haenost 2001,86:178-88.

2. Rugger ZM. Platelet-vessel wall interactions in fowing blood. In: Colman RW. Firsh J. Marder VJ, of all, eds, Haenoslasis and thrombosis. Plilatelphias: Lippincolt, 2001:683-98.

3. Hantgan RR. Hindriks G. Taylor RG. Six ma H, de Groot PO. Glycoprocin lb, von Willebrand factor, and glycomrotein I lbilla ate all involwed in platelet adhesion to tabrin in fowing whole blood. Blood 1990:76:345 53.

4. Endenbutg $5 \mathrm{C}$, Hatugan RR, Lindebonm-Blokzijl L, Lankhot $H_{\text {. }}$ Jerome $W G$, Lewis IC, et al. On the role of von Willebrand factor in promoting platelet adhesion to fibrin in fowing blood. Blood 1095;86:4158-65.

5. Hantgan RR, Taylor RG, Lewis JC. Platelets interact with tibrilt only after activation. Blood 1985,65:1209-311.

6. Sandars MW, Nicuwenhuys CMA, Feigge MAH, Rook M, Bégun S. Heemskerk JWM. The procoagullanu effect of thrombin on fivritogen)-bound platelets. Haenost 1998;28:289-300).

7. Zathan Y. Meyer SC. Negresen E, Reddy KB, Fox JE Signaling

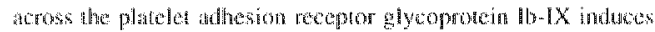
allogs activation both ia platellets and a transfected Clanese hamster oury bell system. Bial Chen 2000:275:16779-87

8. Hermikers IWM. Bovers FM. Lindoun "T. Platelet activation and blow coagatation. Thromb Hamosi $2002 ; 88: 186-6)$.

9. Kumar R. Béguin S, Hanker HC. The effect of fibrin chots and

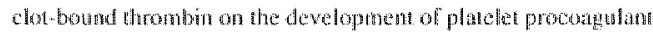
acherity. Thromb Hamost $1095 ; 74,962-8$.

10. Butenas S. Cawthern KM. Wait Veer C. DiLorenzo ME Lod

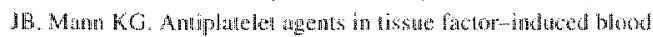
congulation. Blood 2001:97:2314.22.

11. Hemkerk IWM, Siljander PRM, Buers EM, Forndsle RW Lindhou $\mathrm{T}$. Rexepters and signalling mechanism in the proco-

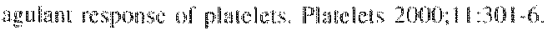

12. Dicker IB, Pedicord DL, Sejferd DA Jamieson CA, Greo N

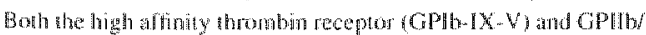
Hila are implicaticd in expression of thrombin-induced platelet procotedant actiwly. Thromb Haemoso 2000 1:86:1065-9.

13. Kentarts IMLW. Béguin S, de Zwan C. Henker HC. Treatenen with a GPIlth/lla antigenise inhibis thrombin geveration in platedet-ricla plasma from patients. Thromb Hacmoss 1998:80: 370.1

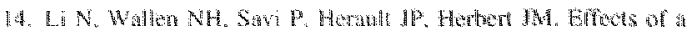

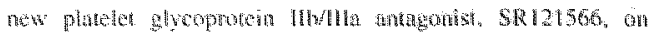

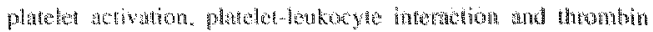

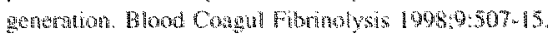

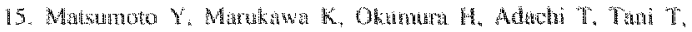

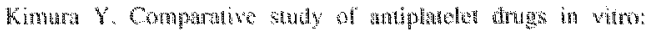

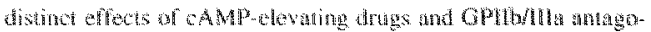
aists on thrombin-induced platele nesponses: Thromb Ros 1999 ; $95: 19.29$

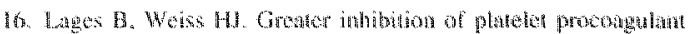

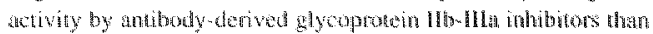

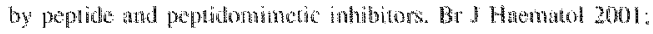
$11,65.71$.

17. Thomas S. Metcale P. Gnotal AH, Griy E. Monodonal suti-

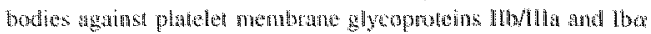

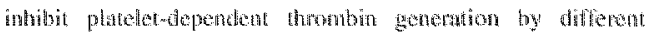

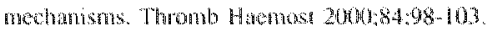

18. Béguin S. Kunar R. Keulars 1, Seligsohn U. Coller BS, Henther HC. Fibrin-uependem platelet procongulant factivity requires

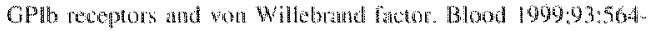
70 .

19. Dormann D. Clemetson KJ, Kehrel BE. The GPlb thmubia

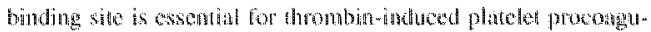
lant activity. Blood 2000956:2460)-78

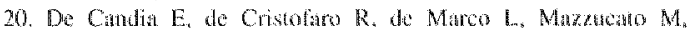
Picozzi M. Lancholf R. Thombin interaction with platele GPIb:

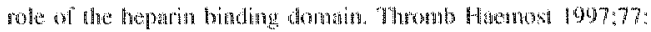
$735-40$.

21. Andersen $H$, Greenberg DL, Fujikawa $K$, Xa W. Chung DH,

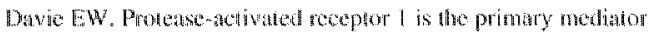

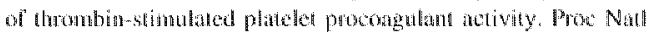
Acud Sci U S A 1990:96:11189-93.

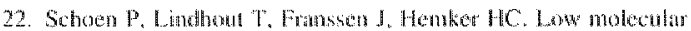

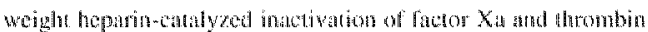

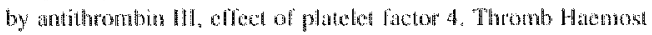
$1991: 66: 435 \cdots 41$

23. Cauwenberghs $\mathrm{N}$, Vanhorelbeke $\mathrm{K}$, Valuerin $\mathrm{S}$. Westra DF, Rono G. Huxinga EG, of at. Eptope mappita of inhibiory antibodes against plantes glycoprotin lbo reweats interachion

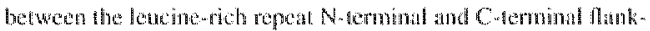
ing domains of glycoproten lbor. B100d 2001.98:652-60.

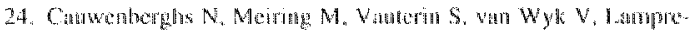

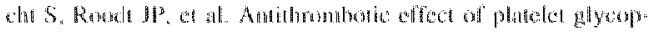

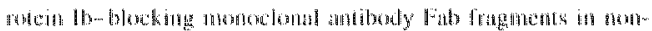

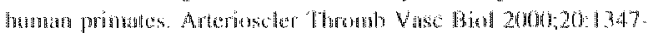
53

25. Hewaskerk JWM, Vain WMU, Toijge MAH. Retuelingsperger

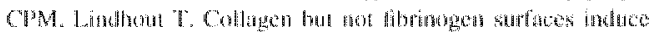

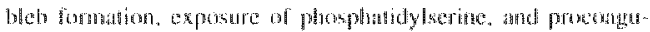

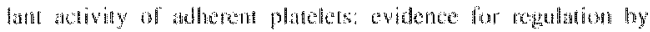

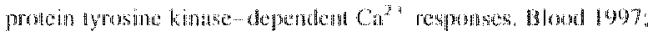
$902615-25$

26. Restado I, Meijer E, Hemskerk JWM, Sage SO. Fibrinomen

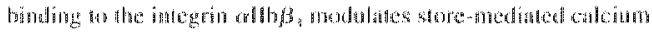
entry in homan planclets. Bloced 2001:57:2648-50

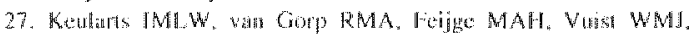

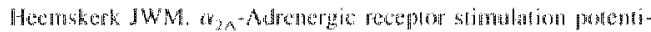

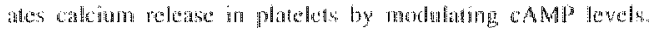
I Bul Cham 2000):275:176,3-72

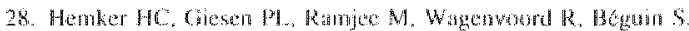

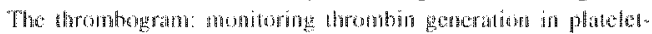

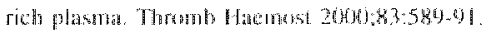

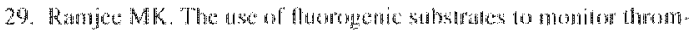




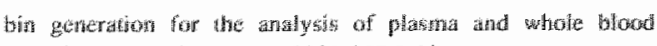

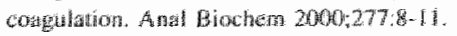

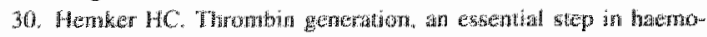

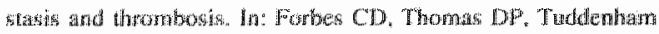

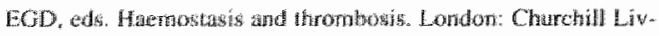
ingsone, $1993 \div 477-90$.

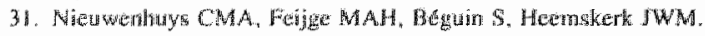

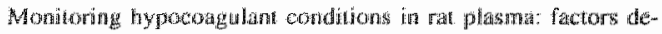

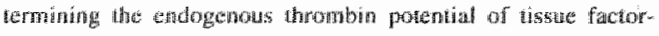

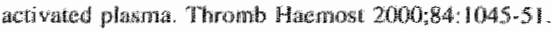

32. Déguin S. Kumar R. Thrombin, fibrin and platelets; a resonence loop an which won Willebrind factor is an necessary link. Thromb Hatnosi $1997,78: 590$ m.

33. Hemker HC. The endogenous thrombin motential a new labora-

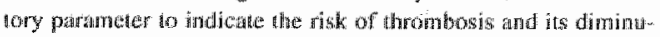

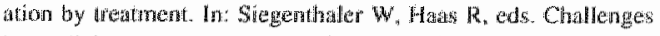

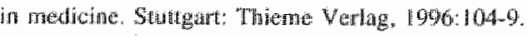

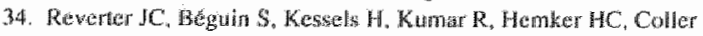

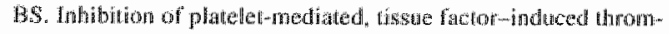

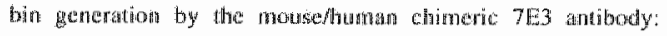
potential inylications for the effoct of e7es fab treatment on

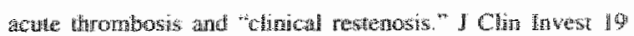
$98: 863-74$

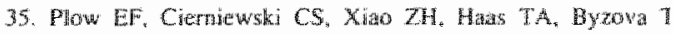

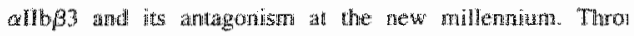
HaEms: 2001:86,34.40

36. Coller BS. Anderson K. Weisman HF. New antiplatelet agen platefet GPLb/Ha andagonise. Thromb Haemost $1995,74: 302$

37. Yap CL. Hupham SC, Cranmer SL. Niesbiur WS, Romey MI Ginliano $S$, and synergistic adhesive interactions and signall, medhanisms operating between platelet glycoproten $1 \mathrm{~b} / \mathrm{X}$ a

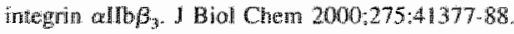

38. The EPIC investigators. Use of a monoclonal antibody directi agginsit the platelet glycoprotein IIb/nla receptor in hightrit cononaty angioplasty. Nengl J Mad 1994,330:956-61.

39. Haga IH, SHack SM, Jennings LK. Chatacterization of phat wicropanticle formation and procoagulant activity in the presen of $\alpha$ ilb $\beta_{3}$, andagonists under shear soress XVIHU Congress of 1 Intercational Sockety of Thrombosts and Haemostatsis, Pari France. 2001.

40. Bevers EM Comferitus P, Zwaal RFA. Changes in menbrar phospholipid distribution during platelen acisation. Bicchin Biophys Acta: 1983,73657-666. 


\section{Von Willebrand factor $\mathrm{C} 1 \mathrm{C} 2$ domain is involved in platelet adhesion to polymerized fibrin at high shear rate.}

Blood. 2004;103:1741-6 


\title{
Von Willebrand factor $\mathrm{C} 1 \mathrm{C} 2$ domain is involved in platelet adhesion to polymerized fibrin at high shear rate
}

Jetrey F. W. Keturen, Dominque Baruch, Pauldte Legendre, Cechle W. Denis, Peter J. Lenting, Jean-Pierre Gima, and Theo Lindhout

\begin{abstract}
Fibrin is alctively involwad in platelet reacthons essentlat for thrombus growihis in which von Whllebrand lactor (WWF) might be an important mediator. The am of this study was to locallte VWF domains that bind to tibrin and to determine thetr retevaince in platelet adhesion. WWF binds specifleatly to fibrin with an apparent. $K_{\mathrm{d}}$ of $2.2 \mu \mathrm{g} / \mathrm{mL}$. Competition in the presence of 2 complementary fragments, Splll (tresidues 1-1365) and Spll (resildues 1366 2050), indicated that the high atfinity bind.
\end{abstract}

ing sitte for Hibrin $1 \mathrm{~s}$ located in the $\mathrm{C}$ terminal part, thus distinct from the $A$ domains. Comparison of 2 deleted rVWF (ADAB-rWWF, $\triangle C 1 C 2-r V W F$ ) suggested that the $\mathrm{C} 1 \mathrm{C} 2$ domains contained a fibin binding sife. Thils site is distinct from AGD, as shown by binding of Di746GNWWF to fibrim. Perfusion studies at high shear rate demonstrated that $\mathrm{C} \| \mathrm{C}_{2} \mathrm{do}$ mains were required for optimal platelet adhesion to fibrin. With the use of a WWF-deficient mouse model, it was found

\begin{abstract}
that piasma WWF is critical for plat tethering and adhesion to tibrin. Tr resutts sugigest a duall role of $\mathrm{TH}$ bound WWF in thrombus formation: fibrin-bound WWF is critical in the rec ment of platelets by way of glycopro (GP) Ib, and, second, titt contributes stationary platelet adhesion by way binding to activatted $\alpha^{\alpha} \beta_{3} \beta_{3^{*}}$ (Blood. 2 $103: 1741-1746)$
\end{abstract}

2004 by The American Society of Hematol

\section{Introduction}

The process of hemosiasis and pathologic thombus formation at an injured vessel wall is intiald when platelets are captured from Howng blood by why of a rapid bond lormation between then: gllyapraten (CP) ib receptor and von Willebrand factor (VWF) irmmobitired on collagen. Pandets subsequently roll over the

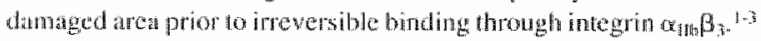

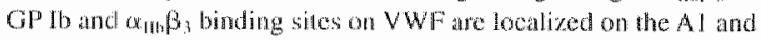
Cl demain, respechely. Imonobilized VWF present on the platelet membrines then seres for further platclet recruatment and intombus growhin."

In patalled with the platelet athesion process, coagulation is intitated through release of tissue factor from the damaged vessel wall . Propagation of blood conguation occurs by locallzed ensymatic complexes assonbled of the plasma membrane of adheron platelets that cxpose negatively charged phospholipids (reviowed in Hecmskert ef all'). The thombin thus formed further notiwates platelets and stabilizes the growing thrombus by the

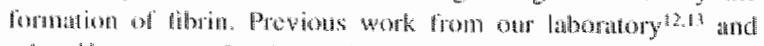
obers suggests that in aldition o ith nonspectic frapping of

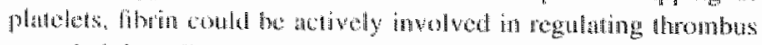

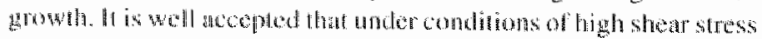

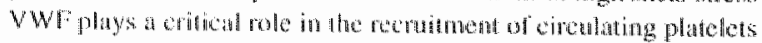

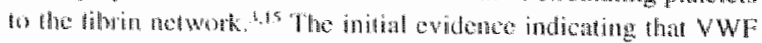

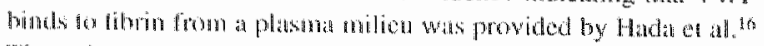

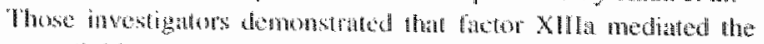

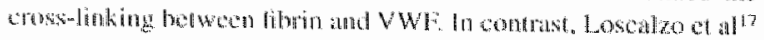

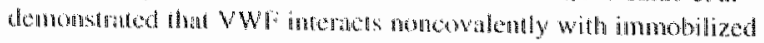

fibrin monomers. Other investigators extended this holling demonstrating that $\mathrm{VWF}$ interaction with fibren depends on presence of high-molecular-keight $V W F$ mulimers 18 Wore cently, it has been shown that W WF binds to forin only in a purit protein system and not from plasma. It was postulated that ot plasma proteins compete with VWF for binding to tibrin. Aco ing to these investigatons, interactions between VWF ath $h b$ could only be detected when platelets were present. Altoget these conflicting observations initiated the present study in wh we atdressed the following questions: Does VWF conain specitic librin-binding site and does plasma VWF contribute tethering plateles to fibrin under physiologically relevant con tions? Our results imply that the C-domain of WWF is a criti determinant of platelet adheston to fibrin under conditions of ha shear shless.

\section{Materilals and methods}

\section{Proteins}

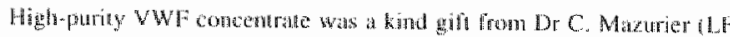

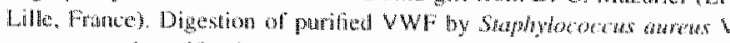
protease and puricication of 2 dimeric complementary fragneats.

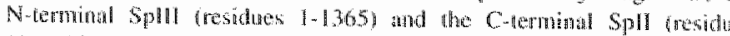

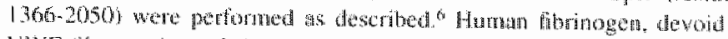

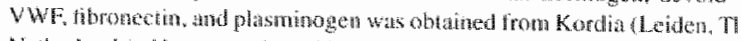

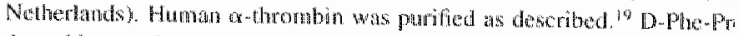
Arg thlormedbylkerone (PPACK) came Trom Cubrowem (San Dieg

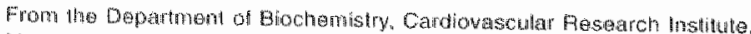
Mas atrich Untugersiby, Marstritht, The Natherlands; Institut Mational de la

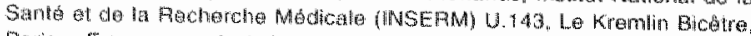
Paris, farance; and laboratory for Thanombosis and Hemostasis, Department of tomethology. Universily Madical Genter Utrecht, Utrecht. The Netheriands.

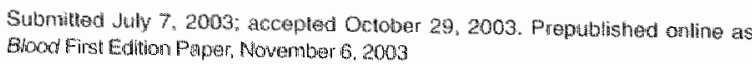

Stuported by INSEFM and the Dutch Fesearch Organization ZonMth- MW (grant 910-408-027) (D.B. T.L.)

Peprints: Theo Linohout, Dopatment of Bochemistry, Maastricht Uniwersity, PO BC

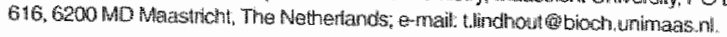

The publication costs of this article were defrayed in part by page charg payment. Therefore, and solely to indicate this fiact, this articte is hereb marked "aclvertsement" in accordance with 18 U.S.C. secton" 1734. 


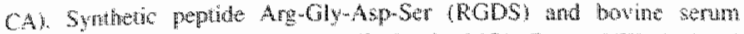

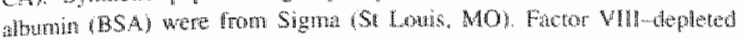

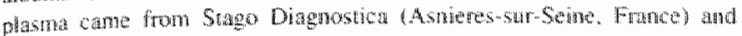
contaned less than 1 \% WWF Ag. Reombinart VWF IWWF and its

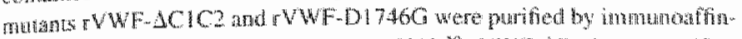

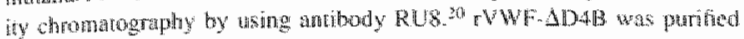

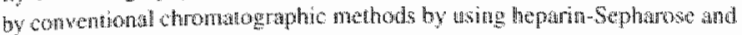
rabno Sephurose. The disnegrin kistrin. an RGD containng eysteint-

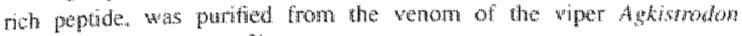
Hodortona as deseribed."

\section{Animals}

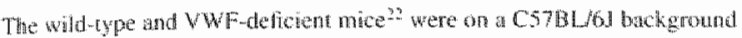
and were used between 10 and 16 weeks of age. Howsing and experinents

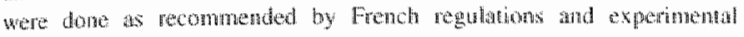
gutdelnes of the European thion.

\section{Antilbadies}

A polychnall antibody against VWF was from Dako (Capinteria. CA). Polyclonal antibodies to human Spll or 5 plll fragnents were nased ia rabbils by immuntation wing the purifued fragments. The immunoglobulin

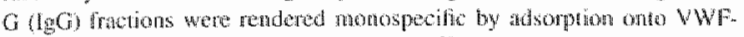

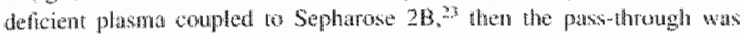
inmunoadsonbed onto purifed WW coupled to Sephurose 2B. ${ }^{34}$ Specific anbodies were eluted with $0.1 \mathrm{M}$ gilycina, $0.5 \mathrm{M} \mathrm{NaCl}, \mathrm{pH} 2.4$

\section{SDS-agarose gel electrophoresis}

Matimeric composition of 25 l. WWF added to librits and that of the

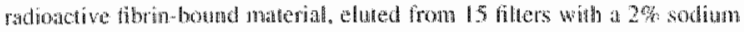
fodecyl sutate (SDS) wolution, was analyzed by $0.1 \%$ SDS-1\% agarose (Amersham, Uppsala, Sweden) gell electrophoresis tonder monreducing condinions as described earlier. ${ }^{25}$

\section{5i-WWF binding to fibrin}

VWF was labeled with Na 1 (Amerham) and lodo-gen ${ }^{\text {an }}$ Specific

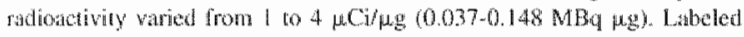
pronein was stored at ${ }^{2} \mathrm{C}$ and nsed with 1 beek. Fibrin was formed in

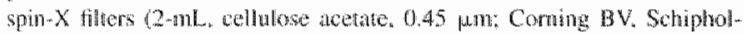

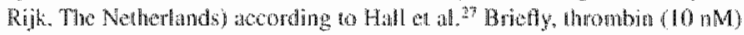

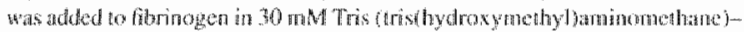

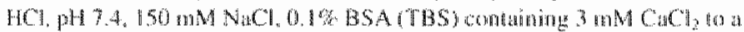

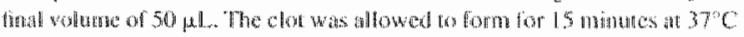

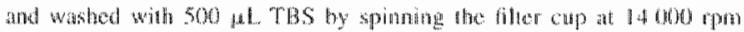

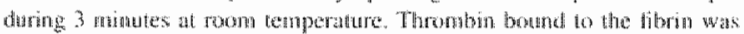

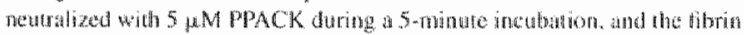

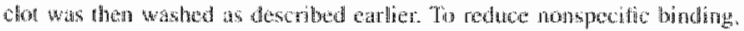

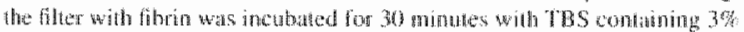
BSA. VWF binding was dectmined by incubitang the fibrin clot wa the

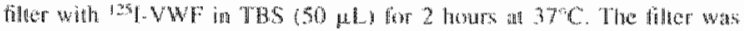

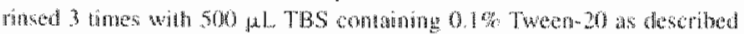

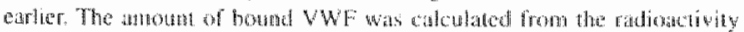

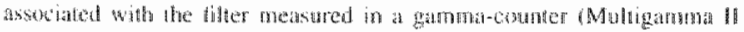
atuner. LKB Instruments $S A$. Fromma, Swodent. Specilic binding was

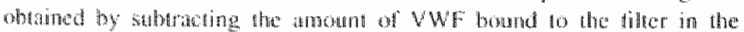

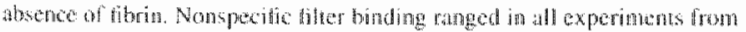

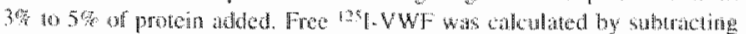

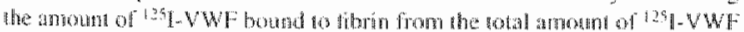
adhed. Mean values \pm SEM were calchlated for 6 independent expermonts.

\section{Preparation of plasma-free human blood cells}

Preparation of wakho blood cells was athapted from Savage at al. Briefly.

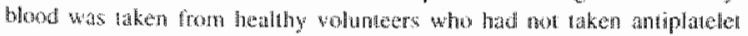
madition for the preceding 2 weens. Fine volumes of blood were tathen

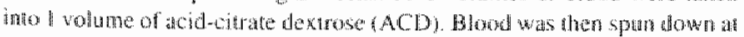
2100 o for 15 minutes at $23 \mathrm{C}$. The supernatann plasnat was discarded and

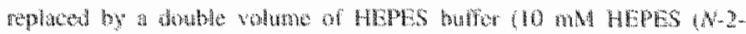

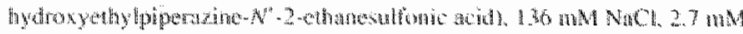

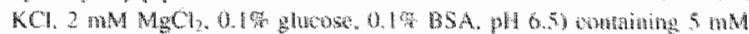

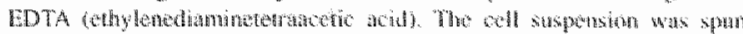

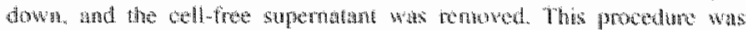

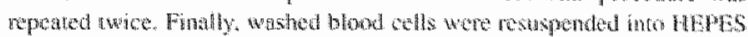

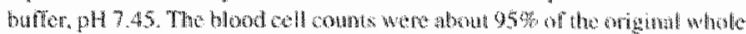
blawd viluber.

\section{Preparation of mouse thin-coated and human fibrin-coatted coversilps}

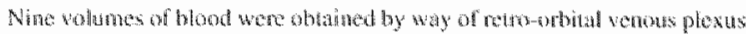

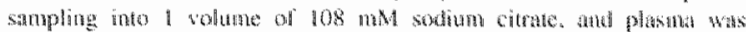

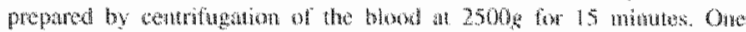

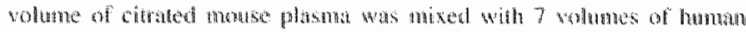

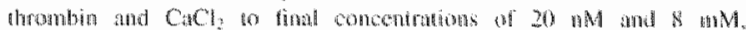

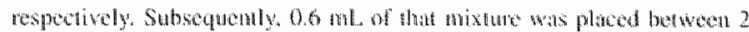

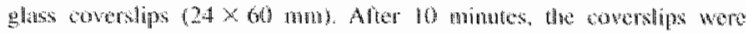

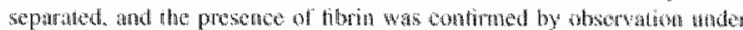

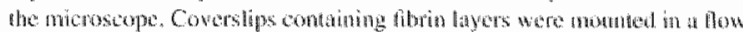

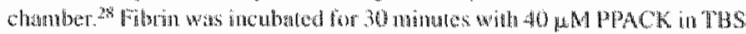

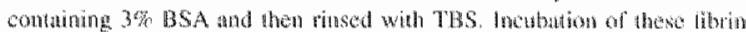

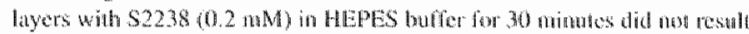

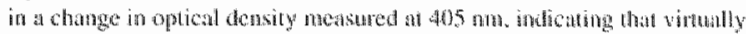
all throblym atetivity was metaralized.

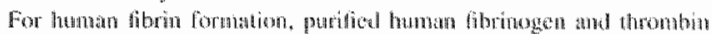
were mixed to timall concentrations of 0.5 wight. ind $10 \mathrm{mM}$. mespecthely.

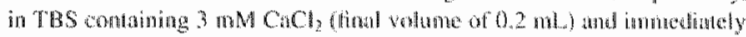

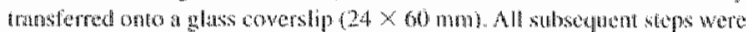
as descrbed for the preparation of mouse ibrincosted oovershes. All

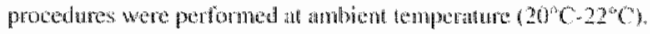

\section{Flow experiments with mouse blood}

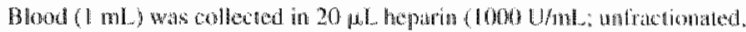

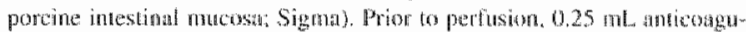

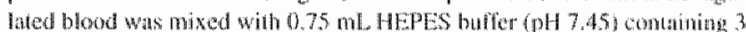

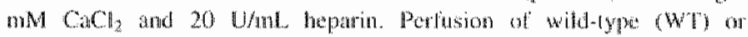

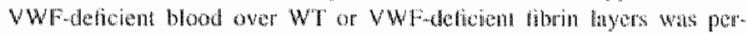

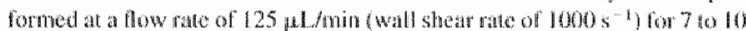
minutes ad row themperature $(20 \mathrm{C}-22 \mathrm{C})$ and visualized by using witho

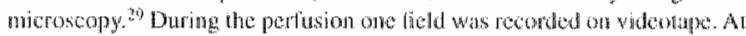

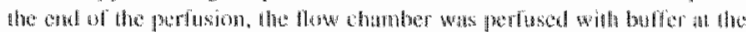

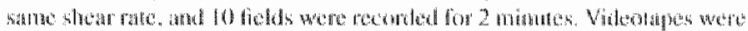

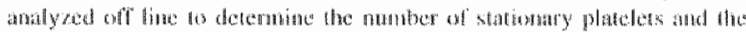

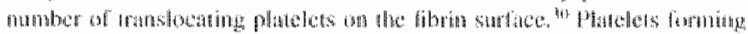

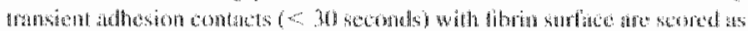

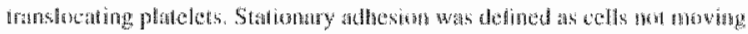

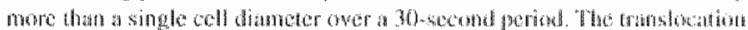

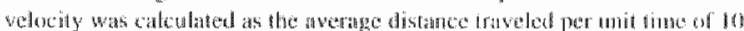

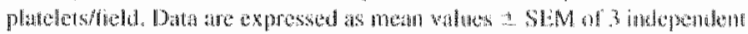
experiments

\section{Perfusion experiments with plasma-frea human blood cells}

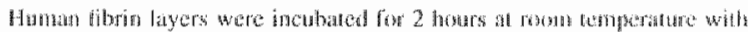

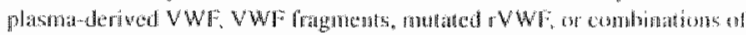

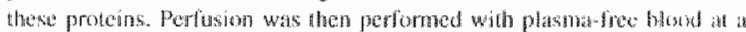

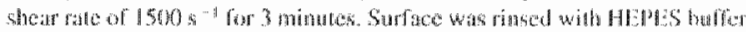

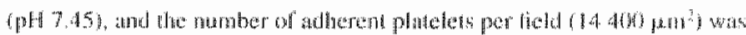

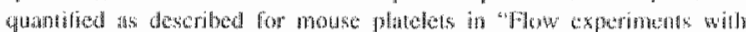

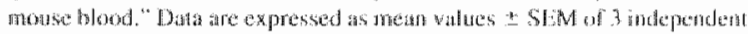
experiments

\section{Stathstical analysis}

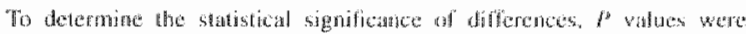

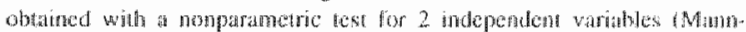

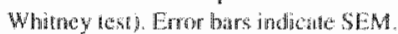




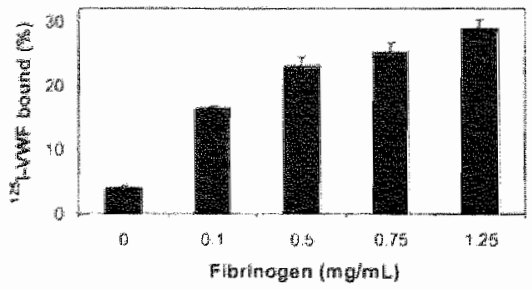

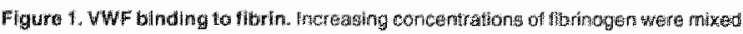

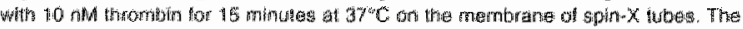

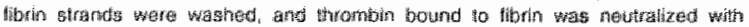

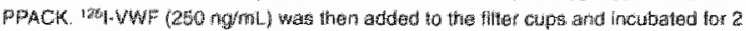

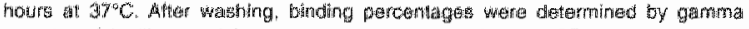

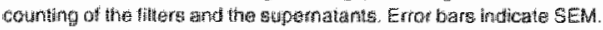

\section{Results}

\section{Characterization of 125 -VWF binding to fibrin}

In an inithal experiment. at fixed amount of purifed hemart

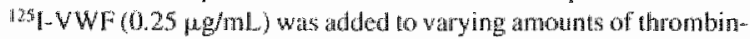
cloted fibrinoger. Figure I shows that relative to total WWF, the perentage of bound 125 -VW increased nomlinutly with increasing fibrinogen concentrations It was observed that when fibrinogen eoncentrations higher than $1.5 \mathrm{mg} / \mathrm{mL}$ were used, some retention of buffer occured on the fither membrine. leading to ineffective washing of the fibrin. Therefore, all subseguent experiments were performed with clots prepared from incubations of $0.75 \mathrm{mg} / \mathrm{mL}$ dibrinogen with thrombin.

Figure 2 reveats no diflerence in the maltimeric composition of purified luman VWF (tane $A$ ) and that of VWF eluted from the fibrin clot (1ane B). Thus, both high-moleculat-weight and lowmolecular-weight multimers are capable of binding to fibrin under the present experimenten conditions, using a VWF concentration that is about 40-fold below the VWF plasma concentration.

Figure 3 allows the amount of fibrin-bound I\%l-VWF ats a function of the concentation of frae ${ }^{125}$ I.VWF. It is apparent that the binding data fits the Langrnuer model with an apparent dissociation constant of $2.2 \mu \mathrm{g} / \mathrm{mL}$. The maximal binding capacily of librin $(37.5 \mathrm{pg})$ on the filde was 76 mg VWF. Thus, urader saturating conditions about $2 \mathrm{ng}$ VW binds per 1 pug thrombinfomed filxrin.

To axmine the specticity of the 12 - VWF binding to haria, a compenition experiment was performed with rondabeled VWr.

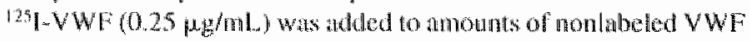
that varied from 0 10 $0.2 \mathrm{mg} / \mathrm{mL}$. and incubated with form present on the flee nembone. It is clearly shown in Figure 4 that

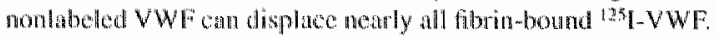

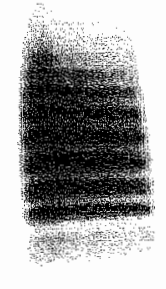

A

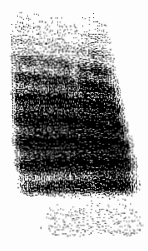

B

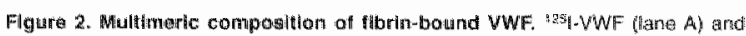

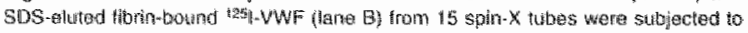

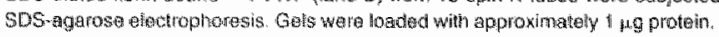

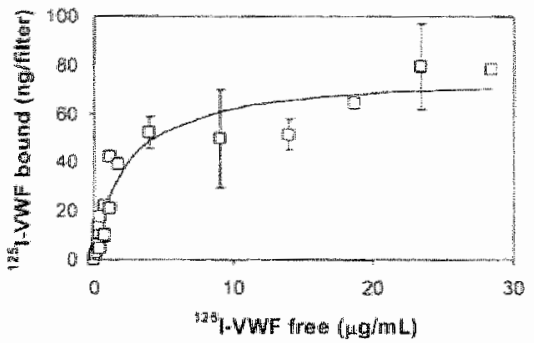

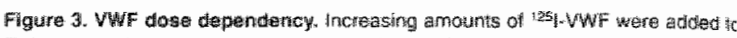

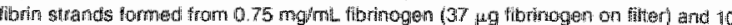

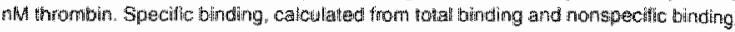

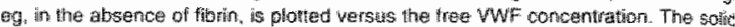
lime is the resutt of a nonlinear tegression analysis that tits the data polins of a

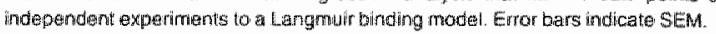

To investigate whener plasma proteins compete with WWF for binding to fibrin, we performed serial ditutions of VWFudehcian plasma in HEPES bufer and determined the specific binding of $12 \mathrm{~J}_{\mathrm{J}}$ VWF $(0.25 \mu \mathrm{g} / \mathrm{mL})$. Compared with a specific binding of ${ }^{125} \|-V W T$ of $26 \%$ in the absence of VWT-deficient plasma, it was found that binding percentages waried around this walte when the plasma protein concervtration increased from $1 \%$ to $100 \%$. It is conchuded that other plasma proteins do not interfere with the binding of VWF to fibrin.

\section{Identification of the fibrin binding sites on VWF}

Figure 5 shows that the binding of $125 \mathrm{I}-\mathrm{VWF}(0.25 \mu \mathrm{g} / \mathrm{mL})$ to fibrin $(0.75 \mathrm{mg} / \mathrm{mL})$ is completely abrogated in the presence of a polyclonal antibody against VWF $2.5 \mu \mathrm{g} / \mathrm{mL}$, whereas polyclonal antibodies against the Spll fragment inhibited the binding of $V W F$ dose dependently. down to $5 \%$ of the amount obtained in the absence of antibody. In contrast, in the presence of anti-Splil 5 $\mu \mathrm{g} / \mathrm{mL}$ ), binding reached $50 \%$ of that in the absence of antibody. Next, purifed VWF fragments splI and Splll were examined for their ability to compete with 135 LVWF for binding to fibrin. Low concentuations of Spll effectively inhibited binding of VWF to fibrin (Figure 6). In contrast, Splll did not appear to inthibit 125-VWF binding to fibrin in an effecent way. Collectively. these results imply that Spll contains $V W F ' s$ major binding sile for fibrin.

Competition experiments performed with ${ }^{25} \mathrm{LrVWF}$ in the presence of motated rVWF lacking the domars $D 4$ and $B$ $(\triangle D 4 B-V W F)$ or $C 1$ and $C 2$ ( $\triangle C I C 2-r V W F$ ) reveated that both rVWF and the AD4B-rVWF were capable of competing with 125 I- VWF for interaction with fibrin (Figure 7). Howewer, the $\triangle C U C 2$ WWF hardly affected the binding of $125-r W F$, indicating

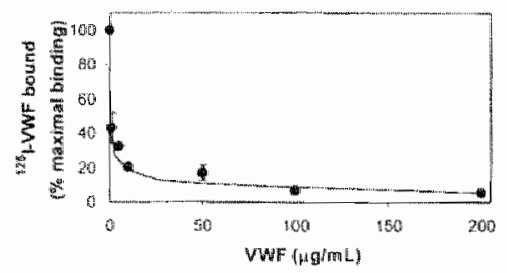

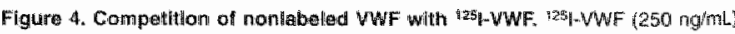
and increasirng concentrations of unlabeled WWF wore incubated in thiters without and with filorin $\left(37\right.$ fag) for 2 rours al $37^{\circ} \mathrm{C}$. Norspecific binding in the absence of fibrin was

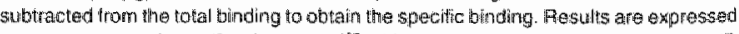

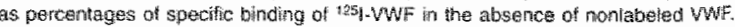
Error bars indicato SEN. 


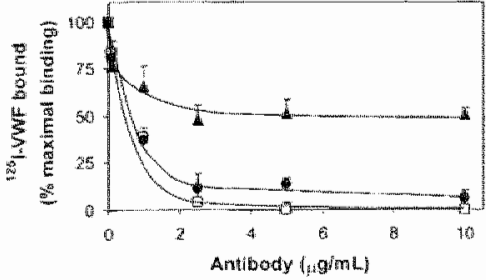

Figure 5 inhabitor of $12 x_{1-1}$-VWF binding to fibrin by polyclomal antibodies aganst WWF and its proteolytic Iragments spll and Spllt. Polychlonal antibodias to

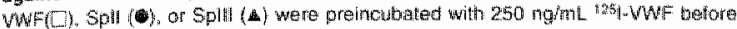
addition to falleirs without and with fibrry $(37.9)$ for 2 hours at $37^{\circ} \mathrm{C}$. For each point monspectic tinding ( $3 \%$ of total binding) was suldtracted from the total bindrat to obtain the specific binding. Pesults are expressed as percentages of spocitic binding

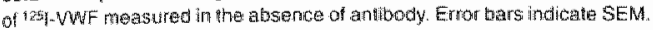

that this mutant lacks the fibrin binding site. In addion, Figure 7 also shows that D1746G-rVWF" could compere with rVWF for bindimg to fibrin, showing that the primary binding site in whe $C$ domains does not require an intact RGD sequence. Moreover. meither the RGDS peptide nor the disintegrin kistrin competed with WWF for binding to hibrin (data not shown).

\section{Platelet adhesion on fibrin layers incubated with human VWF, WWF fragments, or mutated rWWF under high shear rate conditions}

Incubation of fibrin layers with VWF was also evaluated for its rovance in platelet adhesion at high shear tate. Three minutes anter the start of a high shear rate $\left(15008^{-1}\right)$ perfusion of washed blood cells over a fibrin surface, preincubated with purified plasmi-derived VWF (5 fog $1 \mathrm{LL}), 379 \pm 62$ stationary platelets/ theld were measured. This is 2.6 -fold higher that the control thin Iayers that were not preincubated with VWF (Figure 8A). These results confirm the role of $V W F$ in platelet adhesion to fibrin under high shear rate conditions.

The platelet athesion data from the perfusion experiments with 5 pll $(0.2 \mathrm{mg} / \mathrm{mL})$ and SpllI $(0.2 \mathrm{mg} / \mathrm{mL})$ in the presence of VWF (5 $\mu \mathrm{g} / \mathrm{mL}$ ) are in accordance with their competing potencies as established in the direct binding experinnents. That is, Splll did not affect $(P=53)$ the WWF-mediated plater abhesion 10 fibrim. mereas Spll significanty $(p<002)$ reduced the number of adherent piatelets to the value found in the absence of V WF (Figure A. Furthemone, the resuls of phatelet athesion experiments with

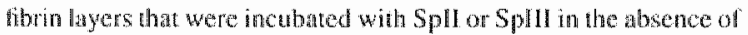
WWE are compatible with thase obuained with the competition expeniments. That is, fibrin layers incubated with Spll showed owen a lower number of adherent plateles when compared with the control. whereas fibrim incubuted with splll showed a pintly

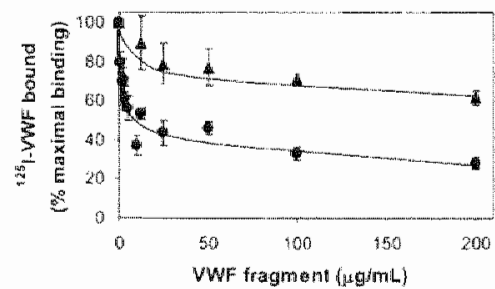

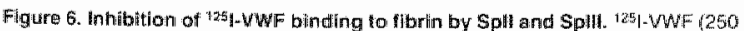

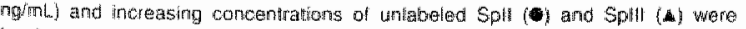
inculdated on fillers without and with fibrin $(37,1,9)$ for 2 hours at $37^{\circ} \mathrm{C}$. For wach point

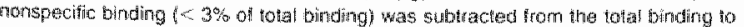
obtain the spewific binding. Restllss are cxpresser as percentages of specific binding

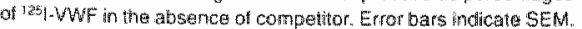

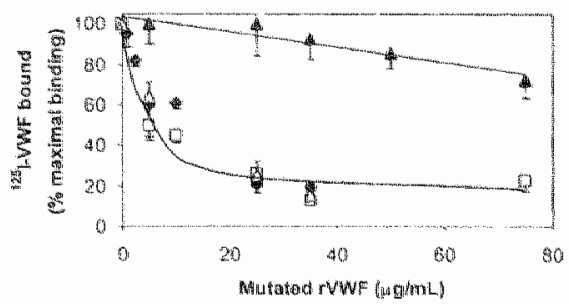

Fibure 7 .

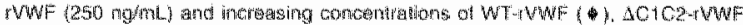

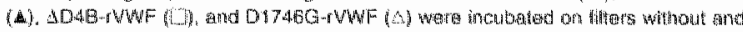

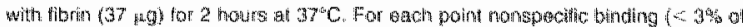

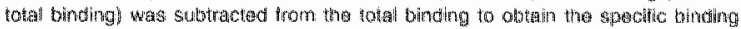

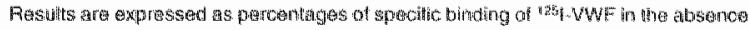

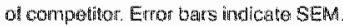

reduced platelet adhesion when compared with flbrin incubated with VWF. The eftect of Spll can be explanded by asthing that Spll prevents tlae interaction between fibrin and platelet- or

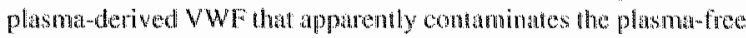
blood prepatation. Because Spll lacks the OP lb binding site, Spll cannat suppont platelet adhesion under conditions of thigh shestriness. Spll, however, does contain he GP Ib binding site but apporently hinds to fibrith with a lower affinity when compared with: VWF

As expected from the competition binding experinents $(\mathrm{ct}$

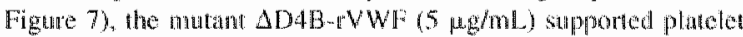
athesion, wherens the ratana $\Delta \mathrm{ClC}-\mathrm{r}^{\mathrm{V}} \mathrm{VWF}(\mathrm{s} \mu \mathrm{gmL})$ did not (Figute 8B). This finding strongly supports the nofion of at functional fobrin-binding site on the C-domains of VWE. To

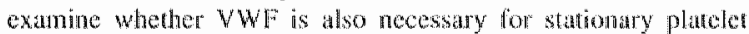

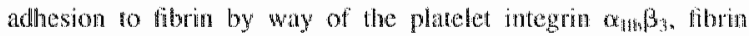
surtace was incubated with the mutan DI746G-VWF. This VWP

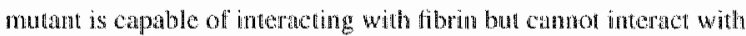
integritn $\alpha_{n b} \beta_{3}$ because it lacks the RGD sequance. Platele adhesion to fibrin incubated with D1746G-VWF (Figure 8B), did not differ from that observed with WT-rVWF $(P=.63)$.
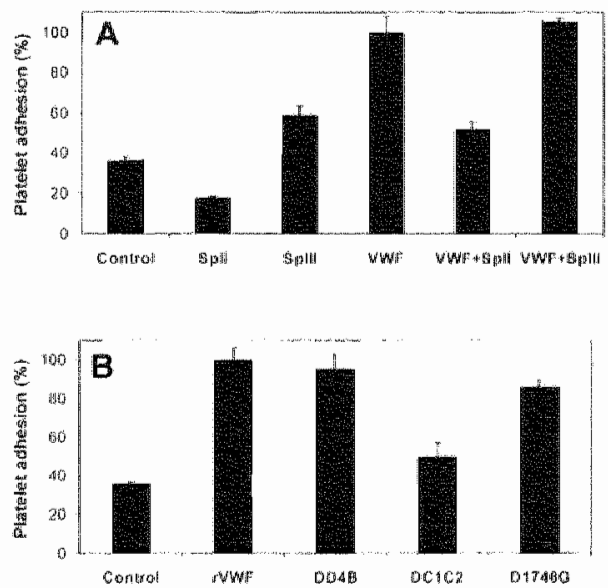

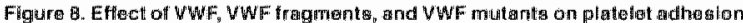

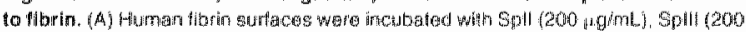

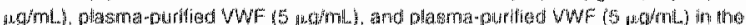

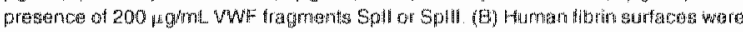

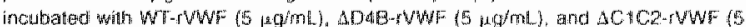

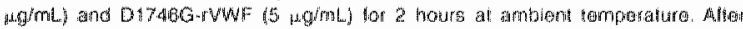

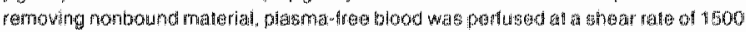

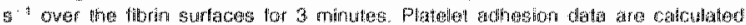

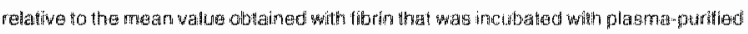

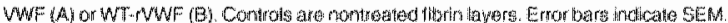




\section{Contribution of plasma-derive WW lo platelet adhestion on fibrin}

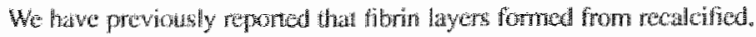

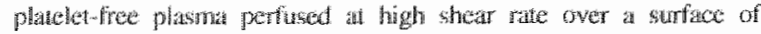

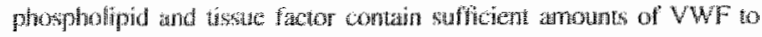
suppont platelat adhesion. To find stepport for the noton that VWF

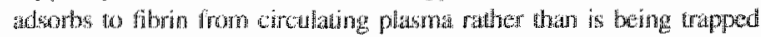
during clot fommation, perfusion speriments were perfomed with blood and fllorin layers from wildwpe and VWh-deficient mice at a

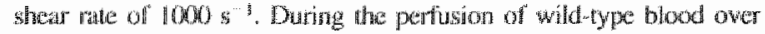
wrildine fibrin, the number of plateles that made contact with the fibrin

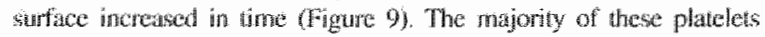
showed stop-and-go movenents with an average trunstocation velocity of $21=9 \mathrm{~mm} / \mathrm{s}$. few atherent platelets (about $5 \%$ w $10 \%$ of total)

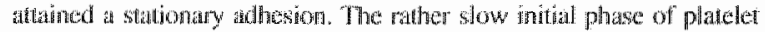
adhesion suggests bat optimal platalet ahesion requires the uptake of VWF from fowng blond. Tro contirm this notion, wild-lype fibrin was pertusced with VWradeficicat blond. Under these conditions, platelets did not contact the sutitace, suggesting that no functiond VWF remained atuched to the thibrin during its prepantion. To further confirm this notion, the complementary experiments was performed in which VWFdelicich fibrin was pertused with heally blood. Like platelet adhesion

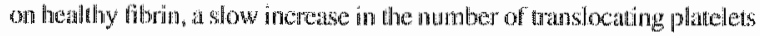
(mean waslocation velocity of $24 \pm 13 \mu \mathrm{m} / \mathrm{s}$ ) was observed durng the initial phise of the expetimerat, followed by a more rapd and linear

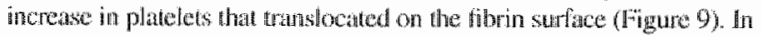
addition, a fow firmly adbertent platelets were observed the ond af the pertusion.

\section{Discussion}

The main findungs of this study are the following: (1) $\mathrm{VWF}$ binds specifically and in a saturable manner to fiorin, (2) the fibria highaffinity binding ste on VWF is located on the C-domain, and (3) plasma VWF binding to fibrin by way of its C-doman is essental for platelendinesion ander high shear tate conditions.

Wo found that WWe binds to polynerized, noncross-linked ftyoin

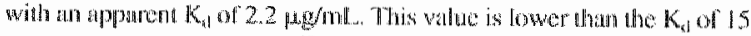

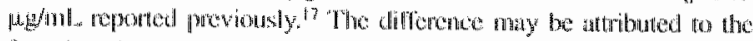

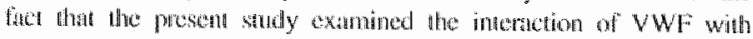

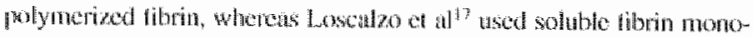

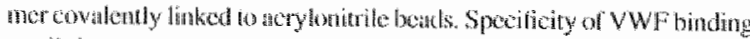

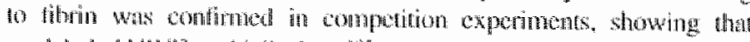

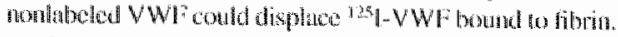

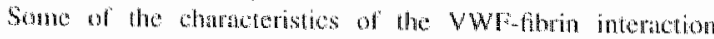

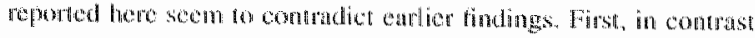

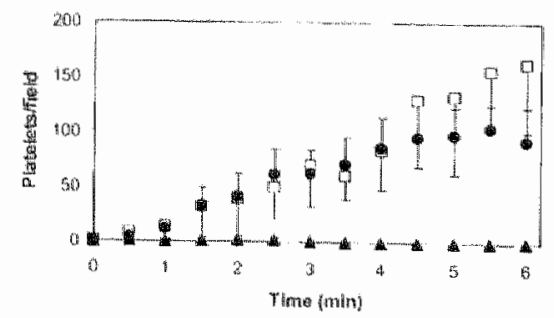

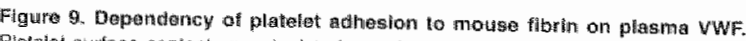

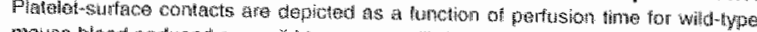
mouse blocd perlusedi cher wild type mouse fibrin (e). WW-deficient mouse blood

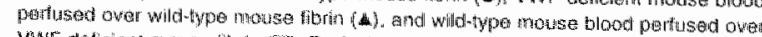

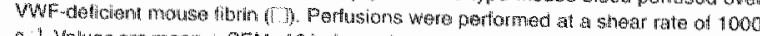

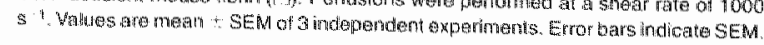

to a prewous report we did not hot any indication that fibrin bi

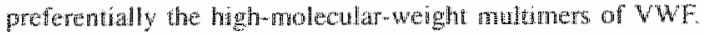
explanation of this difference is probably retated to difference the source of $\mathrm{VWF}$ released from endohelial cells versus plat derivedy and binding conditions (plama clot verses prefor fibrin. Second, wherets we found teat binding of radiowab WWF in a plasma enwonment was not different from that $i$ buffers system, others seported that no binding of $\mathrm{WWF}$ coulc derected moen plasma was perfused ower fibrin surace or w inmobilized ffbrinogen was incubated with control plasma in anyme-linked immunosorbent assay. We note howewer, that conthions of our binding assay differed markedly from that used others ${ }^{\text {Bs }}$ which oould explain our apparent conflicting obserwation.

To establish the localization of the fibrin binding site on the $W^{\prime}$ shbunit (1-2050), competition experiments of 125 . WWF binding performed in the presence of unfatheled complementary Splll atnd s fragments, with mutated rVWF contaning deletions or single resil salbstrtution, as well as inhibition studies in the presence of polycto artibodics prepared aganst each of thene fragments. Our resuls poin the C donain of WWE as the major binding site for fibrin, because Spll (recidues 1366-2050) was a beter competitor of WWF billding fibrin watn Splll (residues 1-1365), becaldse binding was reduced $50 \%$ in the presence of approximately $6 \mu \mathrm{g} / \mathrm{mL}$. Spll, whereas Splli this concentration hardly prevented the binding of WWF. (2) preincel tion of WWF with a polyclonal annitodly against Spll inhibited

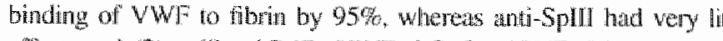
effect; and (3) unlike $\triangle D 4 B-V W F, \triangle C L C 2-r W W F$ ald not comp with - WWF for binding to fibrin. Becanse the RGD sequence is pres in the $C$ domain, we werified using the D 1746 CrVWF that binding not involve RGD, a fuding confirmed by the abscree of indtabition WWF buding to fibrin by an RODS peptide or the disintegrin kistrin.

We have further substantiated the role of WWF binding to fib by way of its C-domain by showing its importance in plate whession at a high shear rate. A 2- 10 3-fold increase in plate adhesion was measured when fibrin was preincubated with fu hength rVWF or $\triangle D 4 B-r W W F$, whereas a prexincubation wi $\triangle C 1 C 2-r V W F$ did not result in a significan increase $(\rho=21)$. separate experiments, we verined that $\triangle C 1 C 2-1 V W F$ contaned functional $G P$ to binding site, becase bonth WT-YVWF

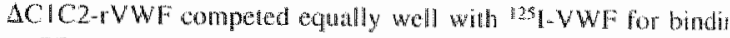
to GP Ib rdata not shown). The fact that after a 3-ininute perfusic wath platsma-free blood cells a substantiall number of adhere platelets were observad on the control hbrin sutfice suggests th the phasma-free blood preparation contains eithe plasma WWF, platelet WW that is released during the washing proced tre.

It has been repotted that WWF compotes with fibrin fi occupancy of activated integrin $\alpha_{t b} \beta_{3}{ }^{3}$. To re-investigate the ro of VWF interaction with the integrin $\alpha_{\mathrm{fl}} \beta_{3}$ in platellet adhesion Abrili at high shear rate, the VWF mutant D 7469 -VWF was usa D1746G-VWF was as offective als $r$ WF in platelet adhesion flbrin under onditions of high shear. This finding is conpantb with the notion that the forin binding site on VWF does not overh with its incgrin $\alpha_{i b}, \beta_{3}$ binding site and, therefore allows thin-boun VWF lo compete with fibrin tor binding o platele integrin $\alpha_{1 n}, \beta_{n}$.

To establish the role of platsma VWF in platelet adhesion tobrin at high shear rates, experments were performed witl boo and fibrin from wild-type and WWF-teficient mice. Inded, whe VWFudefient blood was perfused at high shear rate over a hori layer prepared from WWF-deficient plasma, no transslocating $c$ fumly andhenent platerets were deteated on fibrin. In contras mumerous trablocating platelets were observed when widetyp blood was pertused over wild-type fibrin. Surprisingly, whe numbe 
of surface-contacting platelets increaked relatwely slowly during the first minutes of the perfusion. It appeared that fibrin prepared from wild-type mouse plasmat does nof contain functional VWF. because no platelets adhered to this thin when pertused with blood from WWF doficient mouse. As expected, similar delay in plaiele adhesion was observed when fibrin preparad from VWFdeficien mouse plasma was pertused with wid-1ype nouse blood. If apparent that ander high shear rate conditions optimal plated athesion is achieved when sufficient amounts of plasma VWF ane adsorbed on thrin.

The perfusion experiments with mouse blood and nouse forin also disclose that, besides increastig numbers of translocating platulets in time, the number of stationary plateles increasad, as well. The finding that the majority of platelets show translocation, augesis that under the conditions of this expentreme integriv $\alpha_{3} \beta_{3}$ is not activated and, thus, refers to an earlier observation that

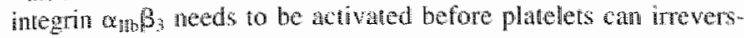
ibly bind to fibrin. ${ }^{3}$

In conclusion, this sudy demonstrates that the major binding site on WWF for dibrin resides in the C-domains between amino acids 1637 and 1899 at a site that does not overlas the RGD secuence. The retevance of the VWF-fibrin interaction in platelet adhesion at a high shear rate was demonstrated in perfusion?

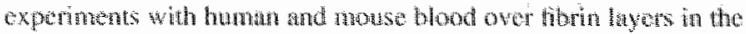

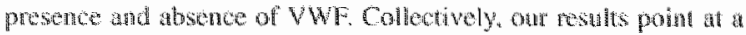

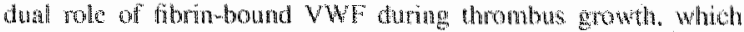

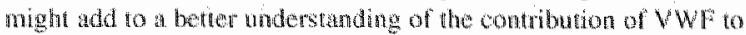

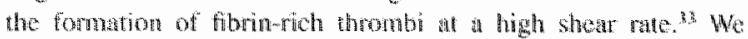
suggest alut horin-bound WWr present at an inghed wessel wall ar discuped atherosclerotic plaque mat critically contributa to thrombus growh by tethering (nomativat) phateds from fus fowing blood. Subsequenty. WWF bound to fibrin woud stalihe the fibrin-rich thrombas by bridging more platelets through ativited

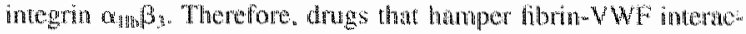
ron could be effective antithomboto atgents, not atusing hemorthagic tendency becase platelct intertions with extancellnular matrix proteins would be preserwed.

\section{Acknowledgments}

We thank. Drs P. G. dile Groot and I. W. M. Heenwkerk tor helphul discussions.

\section{References}

1. Jackson SP, Misloy P. Yuan YP. PHatelets and the injured vessel wall -" "nofling into action": focus on givcoprotein tor/fx and alhos platelet critosketeton. Trends Cardiovase Fied. 2000:10;192-197.

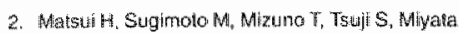

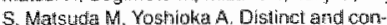
certed functions of won Willebrand factor arud ftbringgen iry mual thrombus growth under high: shear llow. Blood. 2002:"100:3604m3610.

3. Sawage B. Sixma w, Fuggeri ZM. Functional self. association of won willebrand factor during platelet adtesion under llow. Proc Nall Acad Sci USA. 2002;99:425-43\%

4. Bernd MC, Ward Ch, Boom WJ, Castaldi PA. Mazurov AV, Andrews RK. Identificetion of aspar

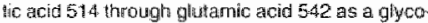
protein lb-x complex receptor recogribution sequence in won Willabiand hactor: mechanism of matulation of von whatiebrand factor by ristocetin

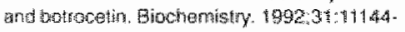
11:51.

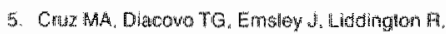

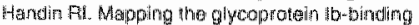

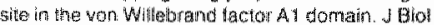
Chent 2000;275:19008-19105.

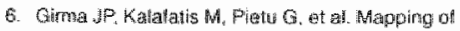
dingtinct won Willebrand factor domalins meracting

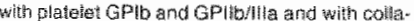
gen using monoclonal antubodies. brood. 1986 $67: 1356-1366$

7. Larkhor H. Wu Ye. Vink $T$, et al Aole of the glycoprotein to-binding A repoat and the Frote sequence in faldelet achesion to fhuman acombi

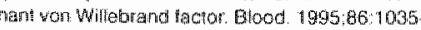
1062

8. Beacham DA, Wiš HA, Tutci SM, Handin Fi, Se lective inachivation of the Arg $\times$ G hy A A Sp-Ses (RODS) binding site ha won Willaberand factor by

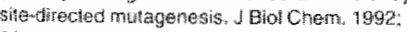
$267: 3: 409-34 \div 5$.

9. Pruggen $2 M$. Plateleis ir a therothombosis. Nat Mes $2002 ; 8: 1227-1234$

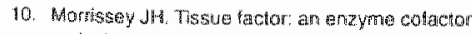
and a thive receptor. Thromb Haemose 2001:86: 667.76 .

11. Heemskerk WWh, Bewers EM, Lindhout T. Plate let actwation and biood corgulation, Thomb

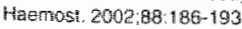

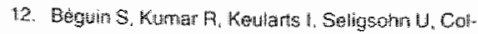

ler BS. Hemker HC. Hibrin-dependent platelet procoggutan activity requires Geptib receptors an won Willebrand factlon: Blood. 1999,93.564-5\%0.

13. Briende Whelders SuH, Hoemsken JWH, Ba ruch D. Hemker HC, Lindhout T, war Willebiand factor stimulates thrombininduced exposure of procoagulant phosphoilpids om the surface of thbrir -adherent piatelets. I Thromb temost. $2003 ; 1: 559-506$

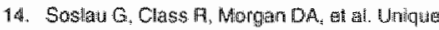

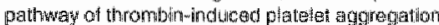
medlated by glycoprotein lb. $\mathrm{d}$ Biol Chem, 200 276:21173-21183.

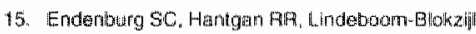
$L_{\text {. el all }}$ On the role of won Willebendad fiactor in promoting platelet adhesion to tib irn ir flowing biood Blood, 1995, $26,4158-4155$.

16. Hada M, Kaminsikï H. Bockenstedt P. HcDonagh

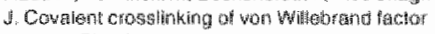

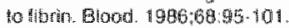

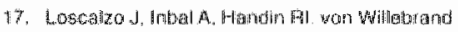

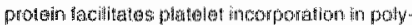

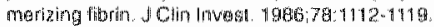

19. Fibes JA France CW. Mtitimer sire dependener of won Willewarand Hactor bindung to crosstinked of

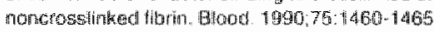

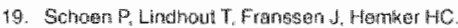

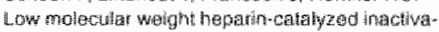
lion of lacter $x a$ and thrombin by antitrombin II:--itfect of phatelet farion 4. Thromils Haemost 1991:66:435 441 .

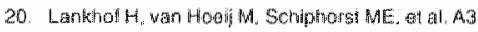
domain is essential for intersation of won Wiltebrand tactor arith collagen type lli. "Thromb thas fort. 1996,75,950-958:

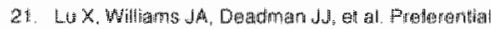
antagonism ol the moteractions of and integrio att-

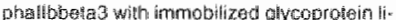
gands by snake veram AGO (A.roly - Asp proteirs: evidence supporting a hunctoral role for the arruino aciod residuse flarkitreg the tripeptide FuC itu determining the intibitory properties of

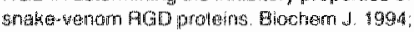
$304: 29-936$

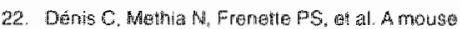
model al sewere ton whoband disease: defects on hemostasis and thombosis. Proc ivatl Acad SoU S A, $1998,95.952+9529$

23. Fine JM, Steinbuch A A simple 1achnique ior qua isolation or monoclonal lgo ano IgA. Few Eur

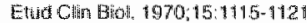

24. Arugtlon N, Gima JP, theyer D, Lavergne JNa, Shoa' I, Lanthou MS Wartants of von Wiltebrand"s

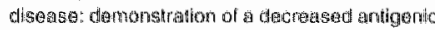

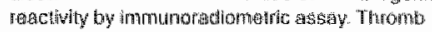
Aes. $1979 \div 12: 817 \times 890$

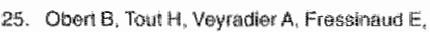
Meyer D. Girma JP. Estimation of the won with bramd lactor-cleaving protegse in plasma taithy mongelonal antibodias to WhF, Thomb Hatmos 1999,82:1382-1385.

20. Franker P., Speck JC Jr. Frotein and cell myembane bodnations with a sparingly solubie chloro amide: 1,3,4,6-totrachoro-3a,6a-dipher

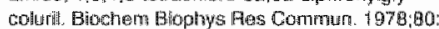
$949-9957$

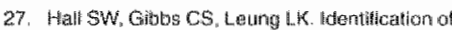

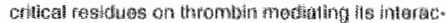

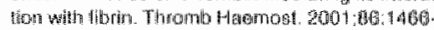
147 혀:

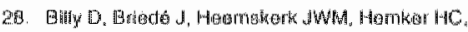

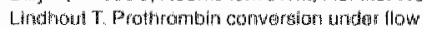

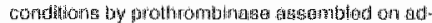

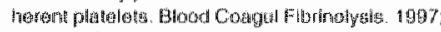
8: $168-174$

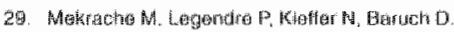
Activition of lintegrin aphatibbetas 3 expressed in

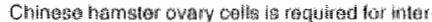

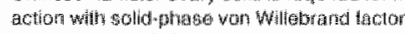
Br d Amemontol 2002;19:1024-1632.

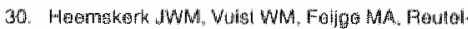

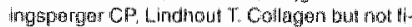
brinogen surfaces indiuco blab fomation, oxpo.

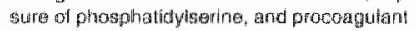

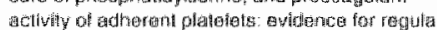

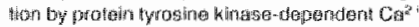

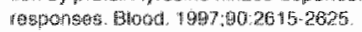

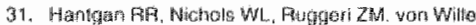
brand factor competes with hismin for occupsericy of GP

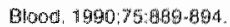

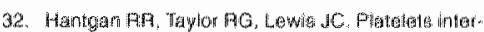

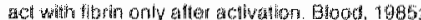
$65: 1209-911$

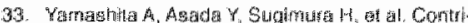

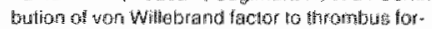

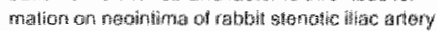
urder high blood-flow velocily. Anteriogr

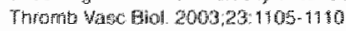


Synergistic effect of thrombin on collagen-induced platelet procoagulant activity is mediated through PAR-1 


\section{Synergistic effect of thrombin on collagen-induced platelet procoagulant activity is mediated through PAR-1}

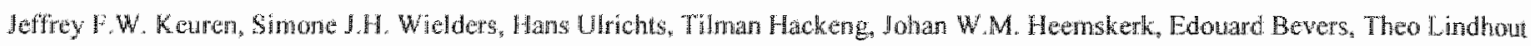

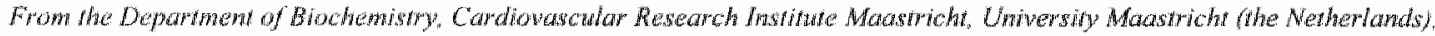

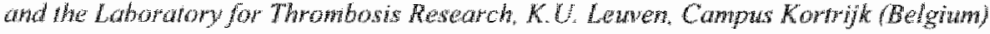

It the blood coagulation process, the rate of thrombin formation is critically dependent on the presence of phosphatidylserine (PtdSer) ar the surface of activated platelets. Whereas thrombin alone is only a weak agonist to Induce platelet procoagulant activity, it synergilstically enhances the collagen-induced platelet procoagulant response. The objective of this study is fo elucidate the mechanism of this synergistic action af thrombin with a focus on the intracelluhir $\mathrm{Ca}^{2 *}$ concentration $\left(\left[\mathrm{Ca} \mathrm{a}^{2+} \mathrm{d}\right)\right.$ and the various platelet receptors for thrombin. We demonstrate that procoagulant activity is related to a sustained increased [Ca ${ }^{24}$ rather than peak levels of

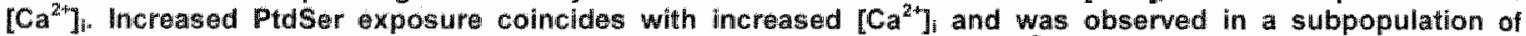
the platelets for each of the various agonists used. Sustained increased [Ca ${ }^{2}$ ] lievels appeared to depend on the influx of extracellular $\mathrm{Ca}^{2+}$. Fab-fragments of the monoclonal antibody $2 \mathrm{D} 2$ against the thrombin binding site on GPIbd made clear that this receptor did not signal for platelet procoagulant activity. Intibition of protease. activated receptor 1 (PAR-1) and PAR-4 by selective intracellular inhibitors and selective desensitization of these receptors revealed that $P A R-1$ activation is a prerequisite for both sustained elevations in [Ca ${ }^{2+}$ i and procoagulant activity induced by collagen plus thrombin. It remains to be elucidated why activation of PAR-1 by thrombin, but not by the PAR-1 activation peptide SFLLRN, amplifies collagen-induced procoagulant activity.

\section{Introduction}

Patelet mermbranes have an asymmetric distribution of phospholipids over the two membrane leaflets with arninophosphotipids almost exclusively present in the cytoplasmic leallet. This asymmetric distribution can be disupated by the action of a phospholipid scramblase activity, resulting in surface exposure of phosphatidylserine (Pidser). Presence of PtdSer in the exoleatlet of platelet plasma membme is of physological mortance because it unthes thrombin formation. which is essental to the formation of atable hathostatic phug or which contribates to the formation of stable thrombithat ma ouclude blood vessits.

Scveral decades ago, il became clara that a combination of collagen and flrombin lis a fat more potent agonist in generating procoaguan platelet surfaces than wach of the individual agonsts alone." "the mechanism behind this synergistic action of thrombin and collagen, however, remaling to be elucidatod. A key element in the process is the level of the cytosolit for $\mathrm{Ca}^{2}\left(\left[\mathrm{Ca}^{2}\right]\right.$. For instance, thromin alone is poor platelet agonist in tems of inducing a procoagulant response, but when lsed logether With an inlibior of sarodendoplasmic reticulum $\mathrm{Ca}^{2}$ ATPase (SERCA) a strong procoagulant response was otserwed that is associated wilh a high and sustaned

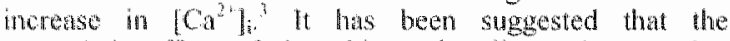

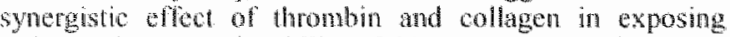
Pidser is based on the ability of this combination of agonists to indues a high calcim inmux that porsists during a sultictenty long pertod to stimulate soramblase that mansters Pidser from inner leallet to outer-leaflet and to intribit aminophospholipid iranslocase that transports Buber from the onter lathet to the inner leaflet We hypothesize that thrombin and ollagen must act togethat dhrough distinct platelet receptors and signalling pathways that reinfores their indivdual capacities in elevating the platelet intracthulat calcium level.
Gilycoprotwin (GP)VI is the major collagen-signalling receptor that induces platelet procoagulant activity (reviewed in ). However, in spite of the increasing knowledge of receptor related platelet activation, the contribution of the different thombin-dependent signal pathways leading to a net transport of Ptiser to the exoleaflet is still a matter of debate. The platelet thrombin receptors, PAR-1, PAR-4 and GPIb-IX-V are all dentified as potential contributors to the thrombin induced procoagulant response. Whereas, it was claimed that PAR-1 is the primary mediator of thrombin-induced procoagulart activity, thereby excluding a role lor $\mathrm{PAR}-4{ }^{7}$, other reports stressed the importance of the thrombin binding wite on the GPlbo chain of the GPIb- $\mathrm{X}-\mathrm{V}$ complex. The mpontance of PAR-1 was further emphasized in work that showed a shorter clotting time of whole blood in the presence of the PAR-1 agonist SFLLRN." An explanation for these different findings could be the neglected role of Giba as a cofactor in the thrombin-catalyzed activation of PAR-1."

Interaction of thombin with GPlbo may enhance the efleiency of thrombin to activate PAR-1, hence lowering its concentration required to evoke platelet procoagulan activity. It has been demonstrated that GPlbox is not in cofnetor in the thrombin-catalyzed activation of PAR-4. Athough at ligh thombin concentrations an increased and sustaned $\left[\mathrm{Ca}^{2}\right]_{i}$ is induced via $\mathrm{PAR}-4,{ }^{4,15}$, this thronbin receptor appears insignificant in the generation of procoagulant platelat surfaces. In one study it was show: that PAR-4 activation pephide acts synergistically with PAR-I activation peptide in the generation of collagenmediated procoagulant acrivity.

The objective of this study is to delineate the relative contributions of PAR-1, PAR 4 and $G P$ P Ib- $X-V$ in thrombin and thrombin plus collagen-induced platelet procoagulan activity and to further explore the relationship between increases in intracellular calcium and the generation of procoagulant surface. We have found that the interaction of thrombin with its receptors GPIbo, PAR-1 and PAR-4 
resulted in very rapid elevations of $\left[\mathrm{Ca}^{2}\right]_{\text {is }}$ but none of the interactions resulted in a significant increase in platelet procoagulart activity. Only in combination with collager, thrombin, but rot SFLLRN or AYPGKF, caused a high and sustained $\left[\mathrm{Ca}^{2}\right]$, as well as a high procoagulant activity. We also established that intracellular PAR-1 and PAR-4 antagonists, but not a MoAb against the thrombin binding site on GPIba, inhibited the smergisic effect of thrombin on the collagen-induced platelet procoagulant response.

\section{Experimental Procedures}

\section{General reagents and Antibodies}

Bovine serum albumin (BSA) and apyrase were from Sigma. Chromogenic stustrate for thrombin (S2238) was from Chromogenix. Fibrillar HORM-type collagen was from Nycomed. Alexa Fluor 647-conjugated Annexin As, Fura Red-AM and Fura-2 AM were from Molecular Probes. Lactadherin was a kind gift of Prol. Jan Trige Rasmussen (University of Aarhus, Denmark) and was conjugated with FITC using a standard procedure. Human factor Xa, haman prothrombin, human thrombin and bovine factor $\mathrm{Va}$ were purifted as described before. against the N-terminal globular domain of GPlba and completely blocks thrombin interaction with glycocalicin (data not shown). The palmitoylated peptides palRCLSSSAVANRS (PAR.I antagonist; PIpal-12 $12^{1020}$ ) and pal-SGRRYGHALR (PAR-4 antagonist: P4pal-10 $10^{13}$, 3 , and the PAR-1 activating peptide SFLLRN-NHI and the PAR-4 activaling peptide AYPGKF.NHz were prepared in our laboratory by solid-platse peptide synthesis using the in sith metralization/HBTU activation procedure for $t B o c$ chemistry as previously described. ${ }^{2}$

\section{Platellet preparation}

Blood ( 1 volume) was collected into $1 / 6$ volume of acid/ citrate/dextrose $(80 \mathrm{mmnol} / \mathrm{L}$ trisodium citrate, $52 \mathrm{mmol} / \mathrm{L}$ citric acid and $180 \mathrm{mmol} / \mathrm{L}$ ghcose). Platetet-rich plasma (PRP) was obtained by centrifugation at $190 \mathrm{~kg}$ for 15 minutes. For catchum measurements platelets were loaded whin Fura-2 (3 unolL) or Fura-ked (20 unolL) during 45 minules at $37^{\circ} \mathrm{C}$. Platelets were then washed and finally resuspended in Hepes buffer $136 \mathrm{mmol} / \mathrm{L} \mathrm{NaCl}, 2.7 \mathrm{mmol}$ L. $\mathrm{KCl}, 5 \mathrm{mmol} / \mathrm{L}$ Hepes, $2 \mathrm{mmol} / \mathrm{MgCl}, 10 \mathrm{mmol} / \mathrm{L}$ ghocose, 0.1\% BSA, pH 7.45), as described before. ${ }^{27}$

\section{Measurement of $\left[\mathrm{Ca}^{25} \mathrm{li}\right.$ in platelet suspension}

Changes in $\left[\mathrm{Ca}^{2}\right.$ ] of Furd-2 loaded platelets were measured at $37^{\circ} \mathrm{C}$ under conimuous stiring by dual excitation fluorometry in an SLM-Aminco 8100 spectrofluoroneter (SLM Instruments). Ratio values of fluorescence at 340 and $380 \mathrm{~nm}$ were converted to levels of $\left[\mathrm{Ca}^{2}\right]$; as deseribed Experiments were performed in triplicate. Peak amplindes of the calcium signal were defined as $\mathrm{A}\left[\mathrm{Ca}^{3}\right]_{\text {twas }}$, representing the maximal increase in $\left[\mathrm{Ca}^{23}\right]$; with respect to $\left[\mathrm{Ca}^{2 *}\right]_{i}$ of non-stimulated cells. The increase in $\left.\mid \mathrm{Ca}^{2}\right]_{\text {i }}$ with respect to $\mathrm{Ca}^{2}{ }^{2}$ jiof non-stimulated cells after 5 minutes of

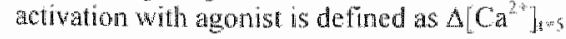

\section{Combined assay of $\left[\mathrm{Ca}^{2} \mathrm{I}_{\mathrm{i}}\right.$ and Ptelsere exposure in single plafelets}

Analyses were performed with a FACScan flow cylometer (Beckton Dickenson). Fura-Red was used to determine changes in $\left[\mathrm{Ca}^{23}\right]$. Upon calcium binding fuorescence intensity of Fura-Red decreases. Alexa Fluor 647 conjugated Amexin A5 (1:250 dilution) was used to measure PtdSer exposure. Fura-Red is excited with the argon laser tuned at $488 \mathrm{~nm}$. Alexa Fluor 647 -annexin $A 5$ is exoited with the HeNe laser at 633 nm. The instrument was set to measure forward angle scattered light (Fs), side angle

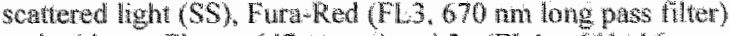
and Alexa fluor 647-annexin A5 (FLA, 661 46 mm bandpass filter). Planelets $(1.3 \times 10 / \mathrm{mL})$ were activated with agonists in the prosence of 3 mmol/L cralcium for 5 min at $37^{\circ} \mathrm{C}$ under continuous stiring (200 rpm) and then incubated for two minutes at 37 C with FrTClactadherin or Alexa Fluor 647-annexin As to reach soturation of the lactadherin and annexin As binding sites on the platelet surface. Platelets were identified by using andytical gates based on FS and SS log sigrals. To quantify pidser exposure of platelets in the absence of extracethular calcium, FTTC-lactadherin (1:50 dilution) was used. Fluorescence was collected in FLI through $530 \pm 30$ mn bandpass lihter. Fluorescence intensities of 10,000 individual piatelets in FLI, FL2 and FL 3 was detemined. Data were analysed using WinMDl soltware (totpd/facs soripps edu/softwate. htonli).

\section{Prothrombinase assay}

Platelets $\left(1.3 \times 10^{7} / \mathrm{mL}\right)$ in a wolume of $50 \mu \mathrm{L}$ were stimulated with agonists for 5 mirutes at $37^{\circ} \mathrm{C}$ under continuous stirring with a small stirring bar (200 rpm). A solution (45 $4 \mathrm{~L}$ ) of factor Xa and factor Va in Hepes buffer contaning $3 \mathrm{mmol} / \mathrm{L}$. $\mathrm{Ca}^{2 *}$ was added and affer $30 \mathrm{~s}$ thrombin generation was started by the addition of $5 \mu \mathrm{L}$ prothrombin. The final concentrations were: 40 pmollt Xa. 100 pmol/L $\mathrm{Va}, 3 \mathrm{mmol} / \mathrm{L} \mathrm{CaCl}, 100 \mathrm{nmol} / \mathrm{L}$ prothrombin and $6.5 \times 10^{6}$ platelets/nt L. Thrombin generation was stopped after $1 \mathrm{~min}$ by addition of Hepes buffer containing $20 \mathrm{~mm}$ ol/ L-EDTA and assayed as described. ${ }^{24}$ When thrombin was used as an agonist, changes in OD at 405 nm were corrected for substrate conversion by this exogenous thrombin. The assay conditions were chosen such that the rate of thrombin formation was linear in time (up to 5 min) and linestr with both the factor Xa and platelet conceniration (up io $7 \times 10^{6}$ sonicated platelets $/ \mathrm{mL}$ ). Exogenous factor $\mathrm{Va}$ was added, 10 make the rate of thrombin formation independent on release and activation of platelet factor $\mathrm{V}$. A reference curve was constructed using washed platelets that were sonicated for three minutes on ice. Data are expressed as percentage of the rate of thrombin gencration obvaned for $6.5 \times 10^{\text {6 }}$ sonicated platelets/mi.

\section{Statistick}

To determine the statistical significance of differences, $P$. values were oblained with a non-paranetric test for two independent variables (Mann-Whitney Test). Dimerences were defined significant when $P<0.05$. Data are expressed as mean values $\pm \mathrm{SD}$ of at least 3 independent experinents.

\section{Results}

\section{Thrombin-induced intracellular calcium response and} platelet prothrombinase activity.

Low amounts of thrombin $(0-2$ mol/L) cause a rapid and transient rise in platelet $\left[\mathrm{Ca}^{2}\right]$, whereas higher thrombin concentrations o $2 \mathrm{nmol} / \mathrm{L}$ ) induce a rapid but fnore sustaned rise in $\left[\mathrm{Ca}^{2}{ }^{2}\right.$ (Fig. IA) The dose-dependent differences in calcum mobilisation probably arise from differences in the kinetics of activation and desensitization of the thrombin receptors PAR-1 and PAR-4. Al low thrombin concentrations. PAR- 1 is more readily activated than PAR-4 However, the half-life of aclivated PAR-1 was reporied to be shorter than that of PAR-4. ${ }^{1523}$ Consequenty, the more sustaned $\mathrm{Ca}^{3}$ ' fux seen at higher thrombin concentrations likely reflects the slower kinetics of 
activation ard inactivation of PAR-4. Indeed, when used at

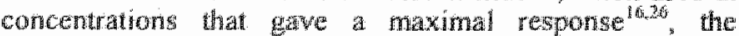
specific PAR-1 activating peptide SFLLRN (10 umolL) induced a sharp increase in $\left[\mathrm{Ca}^{22}\right]$, hat was followed by an inmediate and rapid decrease of $\left[\mathrm{Ca}^{2}\right]$. Platelets treated with the specific PAR-4 activating peptide AYPGKF 10.5 mol/L), showed a similar steep rise in $\left[\mathrm{Ca}^{2}\right]$ but with a significant slower decline (Fig. IA). Table I depicts the parameiers $\triangle\left[\mathrm{Ca}^{2}\right]_{\text {man }}$ and $\triangle\left[\mathrm{Ca}^{2}\right]_{\mathrm{i}}$ (defined under Experimental Procedures). $\triangle\left[\mathrm{Ca}^{2}\right]_{\text {max }}$ values of about I Hmollc were obtained with thrombin concentrations $\geq 5$ nmol/L. The $\Delta\left[\mathrm{Ca}^{2} \mathrm{~h}^{\mathrm{s}} \mathrm{s}\right.$ wallue increased proportionally wh the thrombin concentration, reflecting the role of $P A R-4$ in sustaining $\Delta\left[\mathrm{Ca}^{2}\right]$ levels. Our data also reveal that thrombin induces a higher $\Delta\left[\mathrm{C}^{2}{ }^{2}\right]=5$ than each of the specific PAR-1 and $P A R-4$ activation peptides. This difference might be artributed to the presence of a third thombin receptor, namelly GPIb-IX-V. To study the participation of GPIbo, we made wse of Fab-fragments of $2 \mathrm{D} 2 \mathrm{MoAb}$ (2D2-Fab). $2 \mathrm{D} 2$ MoAb and 2D2-frab completely inhilbited low dose $(0.2-0.6$ nmol/L) $\alpha$-thrombin-induced platelet aggregation and had no inhibitory effect on platelet aggregation induced by hrigher $\alpha$-thrombir concentrations (2 nmol/L). Aggregation by ADP, collagen, ristocetin, botrocetin or the PAR-1 agonist SFLLRN was unaffected by MoAb $2 \mathrm{D} 2$ (data not shown). 2D2-Fab $(10 \mu \mathrm{g} / \mathrm{mL})$ in hributed the thrombin $(2$ nmol/L - ninduced $\Delta\left[\mathrm{Ca}^{2}\right]_{\text {max }}$ with $40 \%$, but not $\Delta\left[\mathrm{Ca}^{2+}\right]_{t=5}$. Because higher concentrations of 2 D2-Fab did not resulf in a more reduced calcium flux, it is unlikely that the affinity of $2 \mathrm{D} 2$ - Fab for GPJbo is too low to compete with thrombin (2 nmol/L) for the binding site on GPIbo (data not shown). When platelets were stimulated with 0.5 ninol/ $L$ thrombin in the presence of $2 \mathrm{D} 2-\mathrm{Fab}(10 \mathrm{mg} / \mathrm{mL})$, we found $70 \%$ reduced $\triangle\left[\mathrm{Ca}^{2+}\right]_{\text {min }}$ and a $40 \%$ reduced $\Delta\left[\mathrm{Ca}^{2+}\right]_{\mathrm{r}}$ value it is apparent that the relative contribution of GPlbo in the calcium response increases with decreasing thrombin concentrations. The capacity of thrombin-treated pllatelet suspensions to support prothrombin activation by the factor Xa-factor $\mathrm{Va}$ complex is plotted in Fig. $1 \mathrm{~B}$ and $\mathrm{C}$ as a function of $\Delta\left[\mathrm{Ca}^{2}\right]_{\text {max }}$ and $\Delta\left[\mathrm{Ca}^{2+1}\right]_{\mathrm{t}-5,}$ respectively. $t \mathrm{t}$ is clearly shown that while $\triangle\left[\mathrm{Ca}^{2+}\right]_{\text {max }}$ and $\triangle\left[\mathrm{Ca}^{2}\right]_{\text {los }}$ values increase with thrombin concentrations above $0.5 \mathrm{nmol} / \mathrm{L}$. prothrombinase activity (closed circles) does not increase more than 2-fold $(P<0.05)$ compared to resting platelets (chosed square). PAR-1 and PAR-4 activation peptides SFL LARN (open square) and $\triangle$ YPGKF (open triangle) were unable to generate procoagulant platelet surfaces. Both SFLLRN and AYPOKF generate $\triangle\left[\mathrm{Ca}^{2}\right]_{\text {max }}$ walues that are higher than the threshold thombun concentration of 0.5 mol/L. Futhermore, AYPGKF", but not SFLLRN, produces

Table 1. Changes in intracellular calcium peak values $\left[\mathrm{Ca}^{2+}\right]_{\text {nugi }}$ and intraceflular calcium concentralion after 5 min incubation $\left[\mathrm{Ca}^{2}{ }^{2}\right]$ with thrombin. SFLLRN and AYPGKF

\begin{tabular}{|c|c|c|c|}
\hline Agonis: & Comkentration & 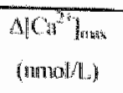 & 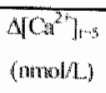 \\
\hline \multirow[t]{5}{*}{ Thrombin } & $02 \mathrm{nmol} / \mathrm{L}$ & $1.59 \pm 22$ & $344: 4$ \\
\hline & 0.5 manol/ & 2864121 & $65=18$ \\
\hline & $2 \mathrm{~mol} / \mathrm{L}$ & 544130 & $229+70$ \\
\hline & $5 \mathrm{nmol} / \mathrm{h}$ & $917+111$ & 20464 \\
\hline & 10 nmol/ 1 & 988426 & 360421 \\
\hline SFLLRN & 10 puntols. & 1002136 & 3601 \\
\hline$A Y{ }^{P C K F}$ & 500 นกา & $450 \times 75$ & $71 \pm \| 1$ \\
\hline
\end{tabular}

4

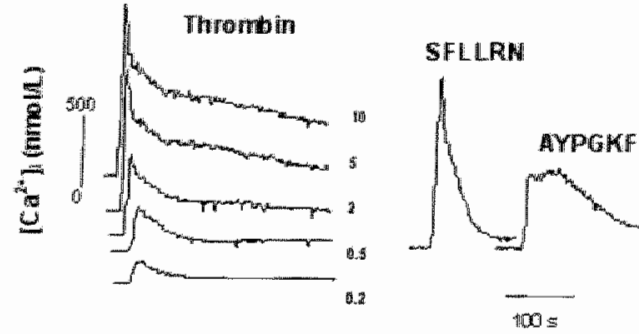

8:

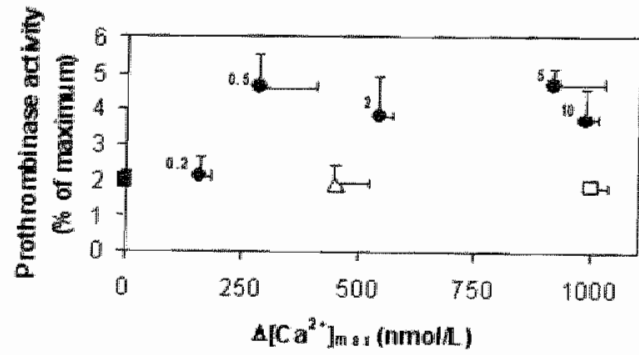

c

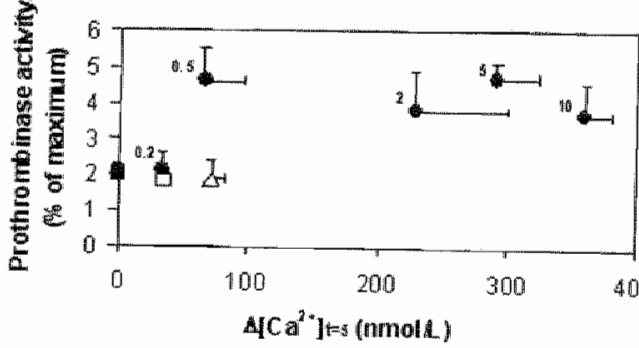

Figure 1: Effect of thrombin. SFLLRN and AYPGKF on plat $\left[\mathrm{Ca}^{2+}\right]$ responses and platelet supported prothrombinase act (PPA). Fura-2 loaded washed platelets were incubated thrombin (0.2-10 nmol/L), SFLLLRN (10 mmollL) and AYPGKF mmol/ $L$ ) Changes in $\left[\mathrm{Ca}^{2+}\right]$, during stimulation under stir conditions at $37^{\circ} \mathrm{C}$ are depicted in panel $A$. The calo responses represented by $\left[\mathrm{Ca}^{2 *}\right]_{\max }$ (panel $\mathrm{B}$ ) am $\left[\mathrm{Ca}{ }^{24}\right]_{\text {ros }}$ (pa c) were plotted versus corresponding prothrombinase activiti expressed as percentage with respect to sonicated platelets details see Experimental Procedures;. The symbols indic unstimulated platelets (w) platelets activated with SFLLRN

$\Delta\left[\mathrm{Ca}^{2+}\right]^{2}=$ values comparable with 0.5 nmol/d thrombin. These data indicate that neither SFLLRN nor AYPG minics thrombin with respect to generation of procoagula plateler membranes, in spite of relatively high calcin responses. Because of the demonstrated participation GPlbo in the thrombin ( $\leq 0.5$ nmol/L)-induced calciu response, platelet procoagulant activity was also measur under the same conditions but in the presence of $2 \mathrm{D} 2-\mathrm{F}$ $(10 \mathrm{\mu g} / \mathrm{mL})$. GPlbo seems not involved in platel procoagulant activity induced by low thromb concentrations, since the blocking $2 \mathrm{D} 2$-Fab does not inhit (data not shown).

Thrombin receptor-mediated calcium flo synergistically enhances collagen-receptor mediate generation of platelet procoagulant activity. Collagen induces a rise in $\left[\mathrm{Ca}^{2+}\right]_{\text {, }}$ a a GPVI-mediate pathway ${ }^{2}$, which appears to be associated with an increas in platelet procoagulant activity. Whereas thrombin alon 
Table If. Changes in intracellular calcium peak values $\left.1 \mathrm{Ca}^{2+7}\right]_{\text {max }}$ and intracelluar calcium concentration after 5 min ncubation $\left[\mathrm{Ca}^{2 *}\right]_{=5}$ with collagen plus either thrombin, SFLLRN or AYPGKF

\begin{tabular}{|c|c|c|c|}
\hline Agonist & Concentumion & 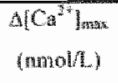 & 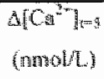 \\
\hline Collagen & $10 \mathrm{jg} / \mathrm{ml}$ & $441+4$ & 198833 \\
\hline \multirow[t]{5}{*}{ plass thromibing } & $0.2 \mathrm{nM}$ & $441 \pm 123$ & $265 \pm 44$ \\
\hline & $0.5 \mathrm{raM}$ & $484+251$ & 374441 \\
\hline & $2 \mathrm{mM}$ & $589 \pm 94$ & $450 \pm 21$ \\
\hline & $\sin$ & 718120 & 54927 \\
\hline & 10 $\mathrm{nM}$ & 74856 & $626 \pm 71$ \\
\hline plas SFLLERN & $10 \mathrm{FMM}$ & $829: 136$ & $227+48$ \\
\hline plas AYPGKF & 500 HMM & $598+142$ & 205458 \\
\hline
\end{tabular}

hardly induces procoagulant activity, it acts synergistically in combination with collagen, but the precise mechanism of this synergism remains to be elucidated. We therefore investigated the effect of increasing thrombin concentrations on collagen-mediated $\left[\mathrm{Ca}^{2-}\right]_{\text {i }}$ changes and generation of platelet procoagulant activity. In the absence of thrombin, collagen $(10 \mu \mathrm{g} / \mathrm{ml})$ causes a modest, but mather sustained $\left[\mathrm{Ca}^{2}\right]$, level (Fig $2 \mathrm{~A}$, bottom trace). Low concentrations of thrombin greatly increase the collagen-mediated initial rate of the calcium flux. In addition, thrombin dose dependently increases the sustained $\left[\mathrm{Ca}^{2+}\right]_{\mathrm{i}}$ levels (Table II). Because of the relatively short half-life of both activated PAR-I and $P A R-4$, this synergistic action of thrombin as demonstrated by sustained and elevated calcium levels, is remarkable. Neither SFLLRN nor AYPGKF in combination with collagen could induce a similar sustained calcium influx (Fig. 2A). Fig. 2B and 2C depict the capacity of thrombin plus collagen activated platelets to support prothrombin activation as a function of $\Delta\left[\mathrm{Ca}^{2+}\right]_{\max }$ and $\Delta\left[\mathrm{Ca}^{2+}\right]_{\mathrm{r}}{ }^{2}, \mathrm{~s}$, respectively. In the absence of thrombin and compared with non-treated platelets, collagen generates a five times higher prothrombinase activity, while in the presence of thrombin concentrations $\geq 0.5$ nmol/ $\mathrm{L}$ a 15 -fold increase was found (Fig. 2B). While this increase is associated with a significant increase in $\Delta\left[\mathrm{Ca}^{2+}\right]_{\mathrm{i} w \xi}$, the $\Delta\left[\mathrm{Ca}^{2+}\right]_{\max }$ is not affected when the thrombin concentration is increased from 0 to $0.5 \mathrm{mmol}$, L. This strongly suggesis that $\Delta\left[\mathrm{Ca}^{2 ;}\right]_{1-5}$ but not $\Delta\left[\mathrm{Ca}^{2 i}\right]_{\text {nuas, }}$ is closely related to the platelet procoagulant response. Increasing the thrombin concentration above $0.5 \mathrm{nmol} / \mathrm{L}$ significantly increased $\Delta\left[\mathrm{Ca}^{2+}\right]_{1-5}$ and $\Delta\left[\mathrm{Ca}^{2}\right]_{\text {max* }}$ but did not further increase procoagulant activity.

SFLLRN increased the $\triangle\left[\mathrm{Ca}^{24}\right]_{\max }$ of collagen-induced calcium response $(\mathbb{P}<0.05)$ and increased prothrombinase activity 1.5 -fold $(\mathrm{P}=0.05)$ (Fig. $2 \mathrm{~B}$, open square). The PAR4 activation peptide AYPGKF had less effect on $\triangle\left[\mathrm{Ca}^{2+}\right]_{\text {metr }}$ and prothrombinase activity (Fig. 2B, open triangle). Interestingly, even at saturating concentrations of SPLLRN and $A Y P G K F$, the $\triangle\left[\mathrm{Ca}^{2+}\right.$ lers values remained below the value found with thrombin $(0.5 \mathrm{mmol} / \mathrm{L})$ plus collagen.

Calcium influx and gemeration of procoagulant platellet surfaces in individual cells

Our interpretations, thus far, did not take into account the possibility that treatment of platelets in suspension with collagen plus thrombin results in the appearance of subpopulations with different calcium fluxes and variable extent of PtdSer exposure. ${ }^{5.20 .30}$ Flow cytometry analysis (Fig. 3) showed that treatment of platelets with the calcium ionophore, ionomycin, yielded a single population of annexin A5 positive platelets which all showed an increased

$\left[\mathrm{Ca}^{2+}\right]_{\mathrm{i}}$ lewel. Stimulation of platelets with collagen $10 \mathrm{~kg} /$ mL) plus thrombin $(0.5 \mathrm{mmol} / \mathrm{L})$ resulted in two populations: one large population of annexin A5 negative platalets, low in $\left[\mathrm{Ca}^{2}\right]$ and at snall poptation with increased $\left[\mathrm{Ca}^{2}\right]$ that did bind annexin AS. In addition, Fig. 3 shows that in platelets activated with thrombin or collagen stone, the subpopulation of platelets that bind annexin As and have increased $\left[\mathrm{Ca}^{23}\right]$ is substantially smaller when conipared to collagen plus thrombin activated platelets. Table III shows the distribution of high and low $\left[\mathrm{Ca}^{2}\right]$ in anexin $\mathrm{A} 5$ positive platelets for the different agonists. These data indicate that the generation of procoagulant platelet surfaces, probed by annexin $A 5$ binding, is closely associated with a sustained high $\left[\mathrm{Ca}^{2}\right]$. It should be emphasized that the $\left[\mathrm{Ca}^{2+}\right]$, levels and annexim $\mathrm{As}$ binding

A
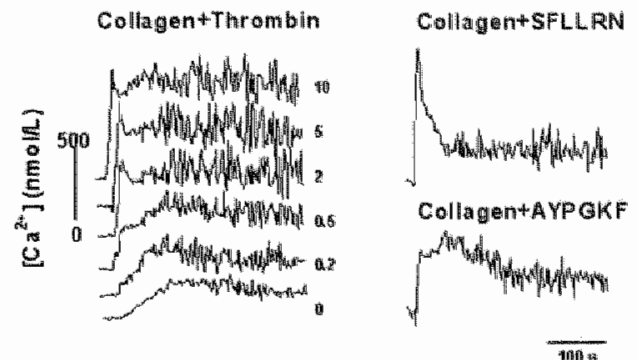

B
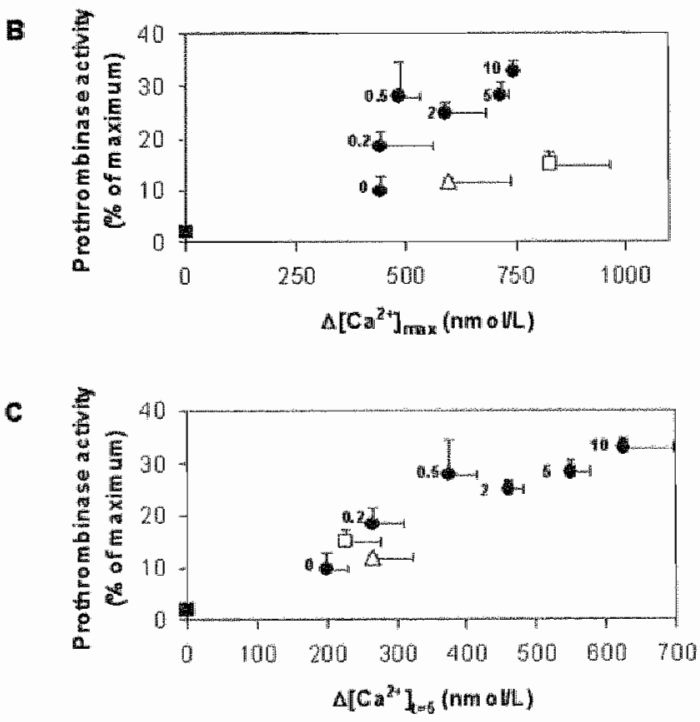

Figure 2: Effect of collagen plus thrombin. SFLLRN and AYPGKF

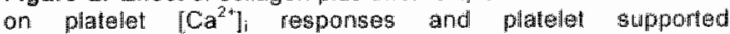
prothrombinase activity. Fura-2 loaded wasthed platelets were incubated with collagen $(10 \mu \mathrm{g} / \mathrm{mL})$ in the presence of thrombin (0.2-10 mol/L), SFLLRN (10 mmol/h) and AYPGKF $(0.5 \mathrm{mmol} / \mathrm{L})$. Changes in $\left[\mathrm{Ca}^{2+}\right]$ during stimulation under stiring conditions at $37{ }^{\circ} \mathrm{C}$ are depicted in panel $\mathrm{A}$. The calcium responses represented by $\left[\mathrm{Ca}^{2+}\right]_{\text {gnas }}$ (panel $\mathrm{B}$ ) and $\left[\mathrm{Ca}^{2 *}\right]_{\text {iws }}$ (panel $\mathrm{C}$ ) were plotted wersus comesponding prothrombinase activities, expressed as percentage whith respect to sonicated platelets for detalls see Experimental Procedures). The symbols indicate unstimulated platelets (w). platelests activated with collagen plus SFLLRN (n), collagen phis AYPGKF (A) and collagen plus thrombin at the indicated concentrations (*). Values are meanis and SD of three independent experiments. 

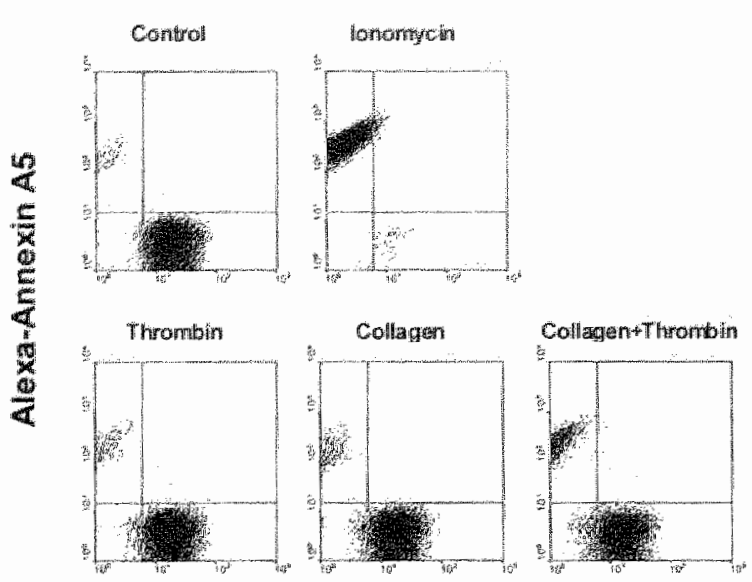

Fura red

Figure 3: Felation betwoen $1 \mathrm{Ca}^{2} \mathrm{j}_{\text {; }}$ and Ptoser exposure in single phatches. Washed. Furarifed loaded plathets were activated during 5 min at $37^{\circ} \mathrm{C}$ under comtimuous stirring with ionomycin 15 mmobL), thrombin (0.5 mmoll.), collagen (10 mgiml and collagen

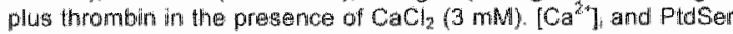
exposivire were aratyzed by flow cyllometry as described under Experimental procedures. Shown is one representative experiment out of four performed. Quadrants were chosen so that $>97 \%$ of control phatelets was present in the lower-right quadrant.

Tablo III. Distribution of annexin A5 positive platelets vilh high and low $\left.\mathrm{CP}^{\mathrm{2}+}\right]$

\begin{tabular}{|c|c|c|}
\hline & \multicolumn{2}{|c|}{ Annexin As binding (\% of total) } \\
\hline Agonist & High $\left[\mathrm{Ca}^{2}\right]^{* * *}$ & 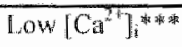 \\
\hline Thrombin & $1.2+0.3$ & $0.2 \pm 0.1$ \\
\hline Collagen & $2.7 \pm 0.1$ & $0.3 \pm 0.2$ \\
\hline Collagen plas ihrombin & $12.2+1.3$ & $0.7 \pm 0.2$ \\
\hline Iononycin & $87.9 \pm 1.4$ & $2.4 \pm 0.4$ \\
\hline
\end{tabular}

- Corfected for controt putatets. Walues were taken from corresponding

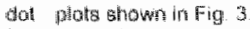

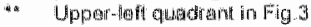

a** upperight quatration in Fig

were measured 5 min after the addition of the agonist. Thus, the apporent wetatonship between thigh calcium levels and annexin As binding is only true for thase platelets that are not transient in their calcium response.

The rellative contributions of thrombin receptors to the collagen plus thrombin-stimulated generation of procoagulant pldatelet surfaces.

The relative contribution of thrombin-activated PAR-I and PAR-4 to the thrombin plus collagen stimulation of platelet procoaguan anctivity was investigated by using the intracellutar PAR-1 and PAR-4 antagonists, PIPall-12 and P4pal-10, at a concentration $(5 \mu$ mol/L) that was sufficient to completely inhibit the calciun response induced with 0.5 mol/L. thrombin. Plpal-12 and P4pal-10 decreased the thrombin plus collagen induced $\triangle\left[C \mathrm{Ca}^{3}\right]_{\operatorname{mix}}$ (Fig. $4 \mathrm{~A}$ ) and

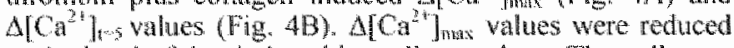
to the level of that induced by collagen alone. The collageninduced calcium response was not inhibited by $\mathrm{P} 1$ pal-12 and P4pal-10 (data not shown).
Fig. $4 \mathrm{C}$ shows that the inhibition of the thromb induced calcium thux is associated with a decreased abil of the stimulated platelets to support prothrombin activati Both Plpal-12 and Pal-10 reduce the prothrombim activity to the level of that induced by collagem alone should be emphasized that PI pal-12 and P4pal-10 have inhibiting effect on prothrombinase as such, as measu with vesicles of 20 mol\% Ptdser and 80 mol\% PedCho (d not shown. These data suggest that both the PAR-1 a PAR-4 receptor are involved in the synergistic stimulati of platelets by collagen and thrombin. However, P4palhas been reported to inhibit platelet functions also signal through activated PAR - I.

In an attempt to further delineate the role of PAR-I at PAR-4, experiments were performed with PAR-1 and PA] 4 desensitized platelets. Desensitization of the receptors w achieved by incubation of platelets with SFLLRN (10 Hm L) or AYPGKF $(500 \mathrm{fmol} / \mathrm{L})$ and was confirmed by al inability of these platelets to increase $\left[\mathrm{Ca}^{27}\right]$ whe challenged again with SFLLRN or AYPGKF (data n shown). When PAR-1 desensidized platelets wel challenged with collagen $(10 \mu \mathrm{g} / \mathrm{mL})$ plus thrombin $(0)$ nmol/L), prothrombinase activity was not higher than that collagen stimulated platelets (Fig. 4C). In contrast, PAR desensitization had no significant effect on the thrombi
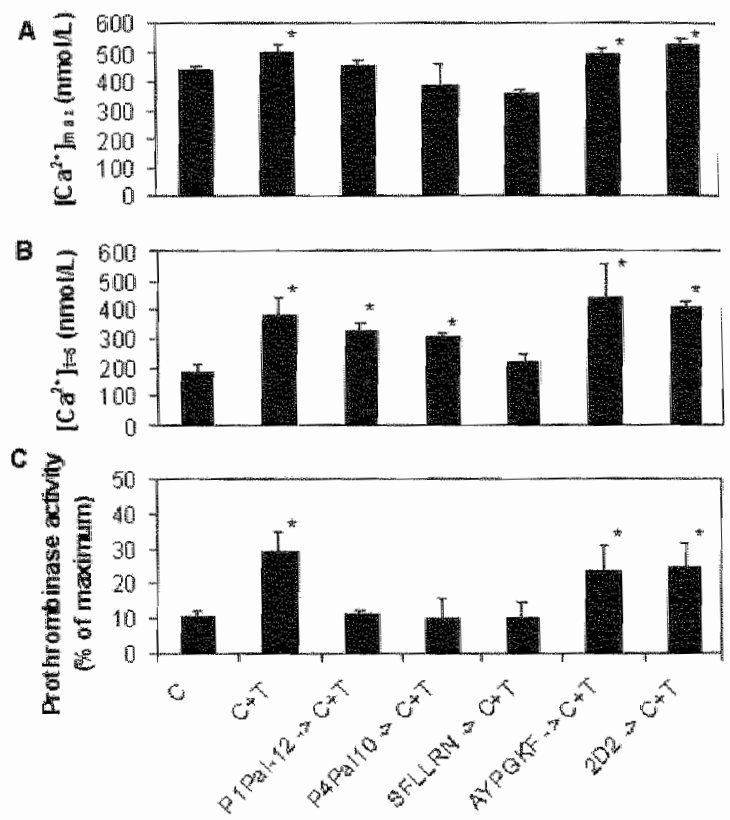

Figure 4: Inwolvement of thrombin receptors GPlba, PAR-11 anc PAR-4 in calcium and procoaguhlant responses induced bi collagen plus thrombin. Washed platelets were pre-incubalad cluring $10 \mathrm{~min}$ under continuous stiring with P1pail 12 (5 $\mathrm{mM}$ ) P4pal-10 (5 mM), SFLLRN (10 mM). AYPCIKF (0.5 mM) or 202 Fab (10 mo/m) before addition of $\mathrm{CaCl}_{2}(3 \mathrm{mM})$ and collagen (C)

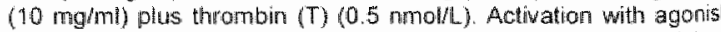
was dono during 5 min al $37^{\circ} \mathrm{C}$ under continuous stimirg. Calciuth signals were analysed for $\left[\mathrm{Ca}^{2+}\right]_{\text {max }}$ (panel $\mathrm{A}$ ) and $\left[\mathrm{Ca}^{2+}\right]_{\mathrm{r}=5}$ (panel B). Prothombinase activity (panel C) was measured after 5 mont and expressed as percentage with respect to the activity measured with sonicated platelets. Values are means and SD of three independent experiments. "Significantly increased with respect to collagen $\{$ p $<0.05\}$. 
plus collagen-induced generation of platelet procoagulant activity.

As reported in a previous section, blocking the interaction of 0.5 nmolL (on lless) thrombin with GPlba with the 2D2-Fab significanty reduced the thombin induced sacium fux. The calcium response of platelets that were stinulated with collagen plus drombin was not inhibited by 2D2 Fab (Fig. $4 \mathrm{~A}$ and B). Also, the generation of platelet procoagulant surfaces was not inhibited by 202 Fab. These findings suggest that thrombin CrPlbo interaction is not required for the synergistic effect of thrombin on the collagen-induced procoagulant response

It is beconing increasingly apparent that collagenmediated platelet actiwation is enforced by secreted $A D P^{3.32}$ From the impaired prothrombinase activity in collagen plus thrombin stimulated platelets from patients with storage pool deficiency, it was concluded that secreted ADP may play an important role in the generation of prothronbinase activity by contributing to the maintenance of a critical [ $\mathrm{Ca}^{2+}$. We confirm that also under the controlled conditions of our calcium flux and prothrombinase assays, secreted ADP reinforces the platelet calcium response and prothrombinase activity induced by thrombia, collagen and the combination of thrombin and collagen (data not shown). To establish whether this secondary effect of $\mathrm{ADP}$ masks the contribution of GPIbo to the procoagulant response, platelets were activated with collagen plus thrombin in the presence of $2 \mathrm{D} 2-\mathrm{Fab}$ and apyrase. In spite of the presence of apyrase, the generation of procoagulant activity by collagen phus thrombin was not affected by $2 \mathrm{D} 2-\mathrm{Fab}^{\circ}(\mathrm{P}=0.85)$, further empliasizing that GPlbo-thrombin interaction does not contribute to the thrombin plus collagen induced procoagulant platelet response.

Thrombin-mediated infux of extracellular calcium enhances collagen-induced procoagullant response

To establish the role of extracellular calcium influx in the collagen plus thrombin induced generation of procoagulant platelet surfaces, $\left[\mathrm{Ca}^{2+1}\right]$ changes and platelet prothrombinase activity were determined in the presence of

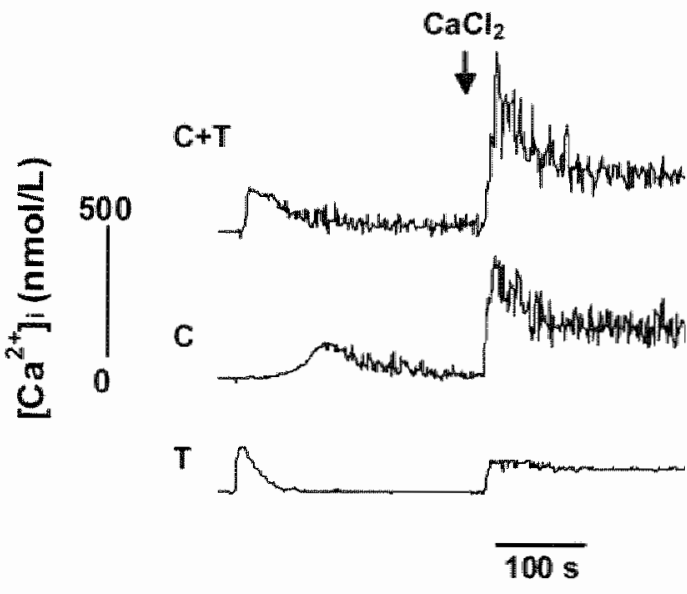

Figure 5: Calcium signals of platelets activated with collagien, thrombin and collagen plus thrombin in the absence of extracelular calcium and after recalcification. Fura-2 loaded platelets were activated in the absence of extracellular calcium with $0.5 \mathrm{nM}$ thrombin $(\mathrm{T}), 10 \mathrm{mg} / \mathrm{ml}$ collagen $(\mathrm{C}$ ) ar a combination of both agonists $(C+T)$. Five minutes after activation $1 \mathrm{~mm} \mathrm{CaCl}$ was added. Shown is one representative experiment out of three performed.

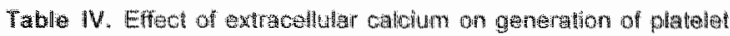
prothombinase achivity (PPA) and changes in intracellular colchum

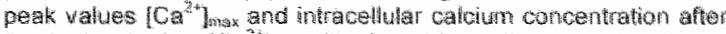

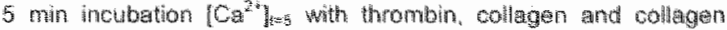
pilus thrombin

\begin{tabular}{|c|c|c|c|c|c|c|}
\hline \multirow[t]{2}{*}{ A Sutist } & \multicolumn{2}{|c|}{ 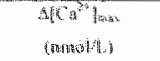 } & \multicolumn{2}{|c|}{ 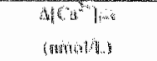 } & \multicolumn{2}{|c|}{ 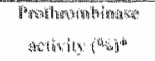 } \\
\hline & 4 & Ext & (5) & MYMA & $\mathrm{t}^{\mathrm{i}^{3}}$ & Wint \\
\hline Ththengh & 37423 & 14635 & 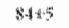 & pan & a.benteg & $2.5+9.8$ \\
\hline Contentents & 973 ig.4 & $122 \times 18$ & 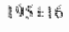 & औU & $97+20$ & 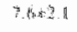 \\
\hline 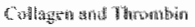 & 4ात) 1 एकी & $989+15$ & $4 n+x=3$ & $10 \div 1$ & $2 x+156$ & (a) 1. \\
\hline
\end{tabular}

Prothrombinase actwity is expressed as of mothal, which was oblained with sonthated platedetis

EGTA. The calcium flux in the presence of EGTA was greatly reduced $\Delta\left[\mathrm{Ca}^{2}\right]_{\text {rmin }}$ and $\Delta\left[\mathrm{Ca}^{2+}\right]_{1}$ values wate $491 \pm 69$ and $383 \pm 83$ in the presence of 1 mrnolf. $\mathrm{Ca}^{2+}$ and 183.15 and $19 \pm 11$ in the presence of 1 mmol/L BGTA. These reductions were also observed when platelets were activated with thrombin or collagen alone (Table IV). Interestingly, there was no significant reduction irt collagen induced procoagulant activity ith the absence of extra-

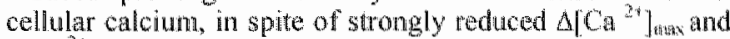
$\triangle \mathrm{Ca}^{2+}=$. The ability of thrombin plas collagen-activated platelets to support prothrombin activation was greatly reduced when platelet stimulation was performed in the presence of EGTA. In the absence of extracellular calcium the synergistic elfect of thrombin seems to disappear (Table V). In this respect it is of interest to note that thi procoagulant activity assay is performed in the presence of extracelluar calcium ( 3 mmol/L) and, as shown in Fig. 5 , addition of calcium to platelets, stimulated in the presence of EGTA, caused a rapid and strong increase in $\left[\mathrm{Ca}^{2+}\right]$ which could have resulted in an additional exposure of PtdSer and thus in an overestimation of the platelet procoagulant activity.

To investigate the effect of recalcification on expression of PidSer, we conducted the following experiment. Platelets $\left(1.3 \times 10^{7} / \mathrm{ml}\right)$ were stimulated for 5 min with thrombin plus collagen in the presence of EGTA. At 5 min, a sample was taken from the activation mixture, diluted 1:10 and supplied with FITC-lactadherin, a calcium-independent andonic phospholipid binding protein. "Five minutes after the stant of the reaction, extracellatar calcium was added (3 mmol/L) and PtdSer exposure was deternined again wilh FIClactadherin. The percentage of lactadherin positive atls before $(16.3+4.5 \%, n=3)$ and 1.5 min after the atdition of extracellular calcium $(19.744 .2 \%$, nom did not differ significantly, inducating that in wasc of thrombin plus collagen stimulated platelets influx of extracellular calcium did not further increase PidSer exposure in the outer leallet of the platelet membrane.

\section{Discussion}

The importance of procoagulant plateldat surfaces for normal hemostasis is evident from the relatwely sewere bleeding tendency of patients that have impared platelet prothrombinase acturity. ${ }^{33-35}$ it is generally assumed that platelets contribute to the generation of thrombin by prowiding a procoagulant surface through the rearangement of their membrane phospholipids resulting in the exposure of megatively charged Pldser in the exo-leaflet of the platelet plasma membrane and that such a rearrangements initiated by an increase in the intracellular calcium concentration. ${ }^{3,3}$ In spite of several studies on the relationship between 
intracellutar calciun concentration and generation of platelet procoagulant activity and the platelet thrombin receptors that are involved, a number of questions are still unanswerel. For example, in the presence of collagen, thrombin becomes a much more potent inducer of platelet procoagulant activity. Whether this symergistic effect is related to changes in intracellular calcium and to what extent the thrombin receptors GPYb-V-IX, PAR-1 and PAR-4 are involved remains to be elucidated.

\section{A Iransient increased $\left[\mathrm{Ca}^{2+}\right]$ is not associated with the generation of a procoagulant surface}

We found that a transient increase of $\left[\mathrm{Ca}^{2}\right]$ induced by thrombin resulted in a relatively small increase in platelet prothrombinase activity of about 2-fold. In addition, saturating amounts of the thrombin receptor agonists SFLLRN and AYPGKF also transiently increased $\left[\mathrm{Ca}^{2+} \|_{1}\right.$ but did not affect prothrombinase actiwity. Thus, at this point, the generation of platelet procoagulant activity could not be relatted to the changes in $\left[\mathrm{Ca}^{2+}\right]$, according lo peak values $\left(\Delta\left[\mathrm{Ca}^{21}\right]_{\text {nux }}\right)$ and persistence $\left(\Delta\left[\mathrm{Ca}^{2+}\right]_{\mathrm{w}}\right)$. While collagen alone increased prothrombinase activity 5-fold, saturating levels of thrombin caused an additional 3-fold increase. Again, compared with thrombin, saturating levels of SFLLRN and AYPGKF were unable to enhance the collagen-induced generation in platelet procoagulant activity. Thrombin, SFLLRN and AYPGKF, had a strong additional effect on collatgen-induced $\Delta\left[\mathrm{Ca}^{23}\right]_{\text {atak }}$. Increasing concentrations of thrombin, but not SFLLRN and AYPGKE, greatly increased $\Delta\left[\mathrm{Ca}^{2-}\right]_{1=5}$. These findings suggest that the generation of platelet procoagulant activity requires sustained high $\left[\mathrm{Ca}^{2+}\right]_{i}$ values and that a rapid, but transient increase during $1-2$ minutes is not sufficient. This notion is in agreement with the observations of Dachery- Prigent et $a^{3 i}$ using flow cytometry to establish a relationship between $\mathrm{Ca}^{2}$ fluxes and PtdSer exposure. However, our data are in disagreement with those reported by Andersen et al? ${ }^{7}$. These investigators speculated in their studies with PAR activation peptides that transient $\left[\mathrm{Ca}^{23}\right]_{i}$ peak values of $0.8 \mu \mathrm{mol} / \mathrm{L}$ and higher are required to maximally generate platelet procoagulant activity. It should however be noted that their conclusion was based only on calcium peak values of single concentrations thrombin, SFLLRN and AYPGKF, while we

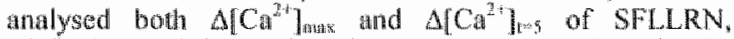
AYPGKF and increasing thrombin concentrations in the presence and absence of collagen. We found that even in the presence of collagen, in spite of thigh $\Delta\left[\mathrm{Ca}^{3}{ }^{3}\right.$ ]ens values, SFLLRN and AYPGKF did not generate platelet procoagulant activity. The synergistic effect of thrombin was alleady maximal at 0.5 amol/L giving rise to a $\Delta\left[\mathrm{Ca}^{27}\right]$ r.s. between 0.3 and 0.4 kmol/L. Thus, in spite of increasing $\Delta\left[\mathrm{Ca}^{2}\right]_{\text {max }}$ and $\Delta\left[\mathrm{Ca}^{2}\right]_{1,5}$ values with increasing thrombin concentrations above $0.5 \mathrm{nmol} / \mathrm{L}$, the procoagulant activity did not further increase.

\section{Thrombin receptors and their role in the generation of platelet procongulant activity.}

The marked difference in both calcium and prothrombinase responses induced by the different thrombin receptor agonists suggests a differential involvement of thrombin on the one hand and PAR activation peptides on the other hand. The apparent key element appears to be the ability of the agonist to mantain sufficient elevated $\left[\mathrm{Ca}^{2+}\right]$, for at least 5 min. We clearly demonstrated that when PAR-I signalling is inhibited, coliagen plus thrombin-induced calcium signal and generation of platelet procoagulant activity are reduced to the level of that obtained with collagen alone. This probably also explains why a relatively low thrombin concentration of $0.5 \mathrm{nmol} / \mathrm{L}$ was already sufficient to obtain maximal prothrombinase activity, since PAR-1, but wht th lower affinity receptor PAR-4, is readily activated by thi thrombin concentration. We note that this concept is in contrast with recently published work ${ }^{16}$ suggesting that : combination of PAR-1 and PAR-4 activation peptides is active as thrombin to enhance collagen-induced generation of platelet procoagulant activity. Yet, in that sturdy, the differences between collagen induced procoagulant activitg in the absence and presence of SFLLRN and AYPGKF wert only marginall and therefore its significance can $b$ * questioned. We also measured the platelet prothrombinase activity induced by SFLLRN plus AYPGKF in the presence and absence of collagen. It was found that this combination of PAR -1 and PAR-4 agonists did not significantly enhance the platelet procoagulant response when compared with that of thrombin (data not shown).

Untike thrombin, SFLLRN and AYPGKF do not interac with the high affinity thrombin receptor GPIbo. Differences in the response of these agonists are therefore likely to reflect the interaction of thrombin with GPIbo. ${ }^{8.16,37-39}$ In a recent study by Liu et all, 4 , no evidence was found for a role of GPIbo in thrombin mediated platelet activation. Using 2D2-Fab directed against the thrombin exosite II binding site on GPIbo, we confirmed that this receptor is involved in calciurn signaling and platelet aggregation induced by low thrombin concentrations $(\leq 0.5 \mathrm{mmol} / \mathrm{L})$. However, saturating amounts of the 2D2-Fab did not affect thrombin of thrombin plus collagen-induced generation of procoagulant activity, excluding a significant role of thrombin-GPlba interaction in this particular platelet function.

Weiss and Lages ${ }^{33}$ established that platelets from patients with storage pool deficiency showed a diminished calcium and procoagulant response upon activation with collagen plus turombin. These "nvestigators disclosed that the decrease in calcium mobilisation and the impaired prothrombinase activity could be corrected by the addition of $A D P$ after stimulation. It is further revealed that the $\mathrm{P}_{2} \mathrm{Y}_{12}$ receptor is likely involved in the ADP.induced exposure of PidSer. ${ }^{16,11}$ We confirmed that when platelets were activated with collagen and/or thrombin in the presence of apyrase, calcium influx and prothrombinase activity decreased about $25 \%$. This indicates that in addition to $\mathrm{PAR}-1, \mathrm{ADP}$ release is required to obtain maximal PPA in response to collagen plus thrombin. Notably, other platelet activation processes like calcium responses and aggregation, induced via the collagen receptor GPVI or the thrombin receptor PAR-1, but not PAR -4 , are known to be dependent on ADP release 13 . tal In view of a recent finding that the role of GPlbo in the activation of the GTPatse Rap IB is masked by ADP receptar signaling, we examined whether this is also true for the function of GPIbo in generating platelet procoagulant activity. The finding that platelets in the presence of the ADP scavenger apyrase responded equally in the thrombin plus collagen-unduced generation of platelet procoagulan activity, either in the presence or absence of $202-\mathrm{Fab}$, however excludes the possibility that under the conditions of our experiments signaling via GPlbo remains unnoticed because of $A D P$ receptor signaling.

\section{Platelets are heterogeneous with respect to calcium and procoagulant response.}

Earlier published work demonstrated a heterogeneity among individual platelets in responding to agonist-induced increases in $\left[\mathrm{Ca}^{2+}\right]$ and PtdSer exposure. ${ }^{3.36 .36}$ Thus far, our observations were made with platelet suspensions and could therefore be subjected to erroneous interpretations when 
only a small fraction of the whole platelet population responds. Dachary-Prigent et al specifically demonstrated that after ten minute activation under non-stiring conditions with collagen $(20 \mu \mathrm{g} / \mathrm{ml})$ and thrombin $(10 \mathrm{mmo} / \mathrm{L})$ only a small subpopulation of the platelets exposed PtdSer and that all these platelets had an elevated $\left[\mathrm{Ca}^{2}\right]$. We have performed the same experiments but at much bower thrombin concentrations. In addition, our measurements were performed under stirring conditions, which appears to be necessary for optimal collagen induced calcinim signalling and prothrombinase activy We found that atter 5 min stimulation with collagen $(10 \mu \mathrm{g} / \mathrm{ml})$ or thrombin $(0.5 \mathrm{rmol} / \mathrm{L})$ the percentage of annexin $A 5$ binding platelets with elevated calcium levels is about $1-3 \%$. When platelets are activated with collagen plus thrombin the percentage of these platelets increased to about $12 \%$ of the total population. Because these increases correlated nicely with the increase in procoagulan activity measured in platelet suspension, we conclude that only a small fraction of thrombin plus collagen treated platelets is responsible for coagulation amplification. We also note an excellent relationship between the percentage of single platelets with elewated $\left[\mathrm{Ca}^{2+}\right.$, after 5 min activation with collagen and thrombin as measured by flow cytometry and the $\left[\mathrm{Ca}^{2+}\right]_{4=5}$ values measured in platelet suspensions under the same conditions. This again confirms that sustained elevations in $\left[\mathrm{Ca}^{2}\right]$ are required for platelets to loose their phospholipid membrane asymmetry. Further studies are necessary to determine why only a specific subpopulation of platelets is able to maintain high $\left[\mathrm{Ca}^{2+}\right]_{i}$ and expose PudSer after activation with collagen plus thrombin. A likely explanation could be that older platelets become less responsive due to reduced receptor functioning.

\section{Infux of extracellular calcium is essential to generate platelet procostanilant activity.}

A number of studies have indicated that influx of extracellular calcium is necessary for PtdSer exposure. $33,47,4: 4$ The mechanism by which this infux is regulated remains to be elucidated. In view of the rapid desensitization of PAR-1 and the need of a sustained high $\left[\mathrm{Ca}^{27}\right]$ we examined the temporal relationship between extracellular calcium concentration and generation of platelet procowaguant activity. When platelets were challenged with collagen, Hrombin or a combination of both in the absence of extracelluar calcium, [Ca $\left.{ }^{2+}\right]$ ishohty increased and callum levels rapidly retuined to those of resting platelets (Fig. 5), indicating that extracellular calcium influx is required to obtain sustained $\left[\mathrm{Ca}^{2}\right]$. When the procoagulant activities of platelets that were treated with collagen, thrombir and collagen plus thrombin in the presence or absence of extracellular Care compared, it becones clear that the absence of extracellular calcium does not affect significantly the collagen-induced procoagulant response $(\rho=0.25)$ but reduced the collagen plus thrombin-induced response significantly to that of collagen alone $(P<0.01)$. The combined findings suggest a stronger extracellular $\mathrm{Ca}^{2+}$. dependency for the collagen plus trombin-induced procoagulant response than for the collagen-induced response. The notion that collagen might stimulate platelet procoagulant actiwicy in a calcium independent manner is supported by a recent study demonstrating that the GPVIf FCRgamma/SLP-76 signal pathway, essential for calcium signalling, is not essential for platelet procoagulant activity induced by collagen. ${ }^{49}$ These investigators showed that librillar collagen, but not the GPVI specific agonist convulxin, stimulates procoagulant activity in murine SLP. 76 null platelets. From these findings it is tempting to speculate that there is redundaney of cpvealciundependent ${ }^{53}$ and catcium-indeprendew pathway contributing to collagen induced platelat procongulant activity. Wo conclude that inthut of extracellutar calcimis is necessary to obain a sufteiently high sustained $1 \mathrm{Ca}^{2}$ ] for a maxinal procoeguant response and that of the two agonists collagen phus thrombin, thrombin is the essentud determinant.

The validity of the interpretations of oul findings could be questionable when the extracellutar catoin that was added to perform the prothombinemse mexurements induces the generation of platelet procosgulant activity. If hrue, platelets stimulated in the presence of EGTA are expected to have intially lower procongulant activity values. However, determination of PtdSer exposure using the calciumindependent $\mathbb{P}$ dSer binding protein lactadherin loy flow cytometry, prior to and after recalcification of platelet suspensions treated with thrombin plus collagen, revealed no differences in the amount of bound lactadherin. suggesting that the influx of extracellular calcium thiner the conditions of the prothrombinase assay did not increase platelet procoagulant activity. We can think of severnl reasons why the rapid increase of [Ca $\left.{ }^{23}\right]$ caused by the inllux of extracellidar calciun does not result in an additional procoagulant suface generation. firstly, althongh the temporal relationship between changes in $\left[\mathrm{Cat}^{2+}\right]_{i}$ and exposure of PtdSen cannot be easily made because of the relatively slow binding kinetics of PtdSer-binding protents like annexin $A 5^{5}$, it is evident that the generation of platelet procoagulant activity is a delayed response to a sudden increase of $\left[\mathrm{Ca}^{2}\right]$. It is feasible that more prolonged incubation period than used in the prothrombinase assay is required to memstre a significant increase in platelet procoagulant activity. However, anallysis of FTC-labeled lactadherin-binding by flow cytometrite rime drive during 5 min after recalcification of the platelet suspension failed to demonstrate an increase in lactadleren binding. Secondly, it is an interesting thought that during the incubation of platelets with collagen plus thrombin, PAR-1 became desensitized, which in turn prevents somehow the preservation of a high thrombin-mediated sustained $\left[\mathrm{Ca}^{2}\right]$ lewell.

In conclusion, treatment of platelets with collagen plus thrombin causes as sustaned increase in $\left[\mathrm{Ca}^{23}\right]$ in $12 \%$ of the whole platelet population. Only these platadeta had axposed Pider at their aell surlaces and supported prothrombin activation. The sustaned elevation in $\left[\mathrm{Ca}^{2} \|_{\text {i }}\right.$ is the result of an increased influx of extracellular calcum, which in turn is the result of a thrombin-dependent signeling pathway mediated through PAR-I actiwation. The proposed function of PAR-1 is apparenty incompatibis wh bith rather short half-ife." We speculdet that the interaction of collagen with GPVI alters in some way the kinetics of intetivation of PAR-1. It is also possible that thrombin, via PAR-1, stimulaties collater receplot signaling. Since it has been suggested that lipid rafts orchestrate signaling by platelet collagen receptor GPVI, thrombin could stimulate recruitment of GPVI to lipid fafts. It remans to be elucidated why PAR-1 activation by thrombin, but not by PAR I activation peptide SFLLRN, mediales collagen and thrombin induced platelet procoagulant activily. In contrast to the PAR-1 activating peptide SPLLRN, thrombin is a tather a-specific protease of multiple substrates. Besides cleaving the $N$-teminal region of $P A R-I$ rasulting in the relate of a 41 -amino acid peptide, in also cleaves $\mathrm{GPV}$ at the platelet surface. Although the exact roles of the 41 . amino acid pepticle and cleaved $\mathrm{GPV}$ in memostasis are largely unknown, both cleavage products were shown to positively mediate platelet adhesion and activation 


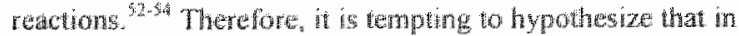

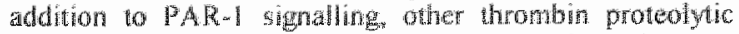

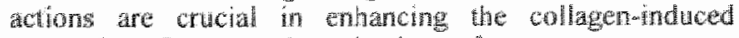

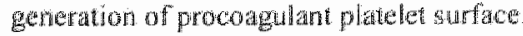

\section{Acknowledgement}

Thas work was supported by a grant from the Dutch Thrombosis Foundation (TSW). The authors thank Wencke Adriaen for symesizing the intracellular PAR anagonists.

\section{References}

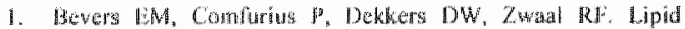

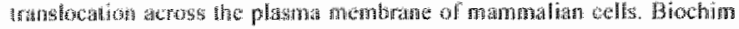

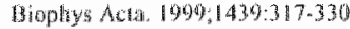

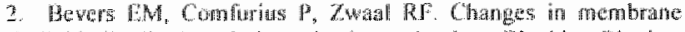

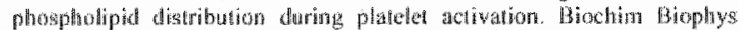

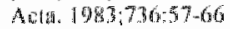

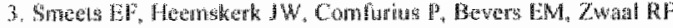

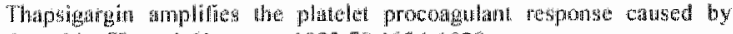
thrombin. Thromb themost. 1993:70:1024-1029

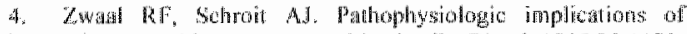

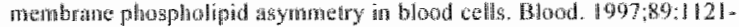
1122

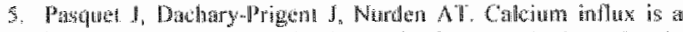

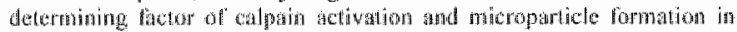
platelers. Fur f Biodhem. 1996,239:647-654

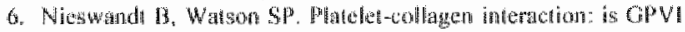

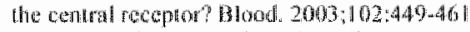

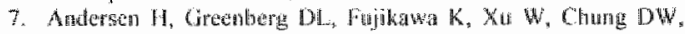

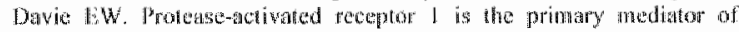

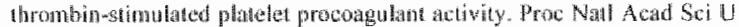
S A. $1909,96: 11189411193$

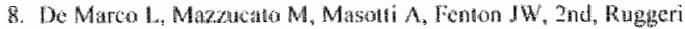

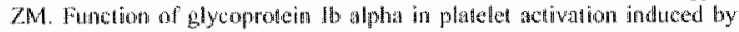

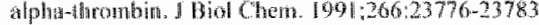

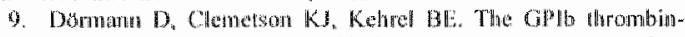

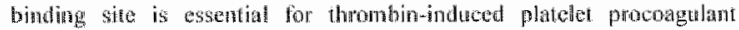

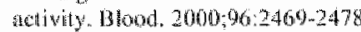

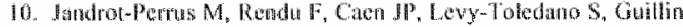

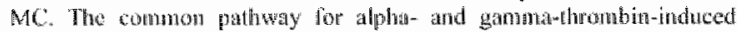

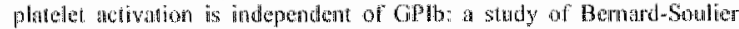

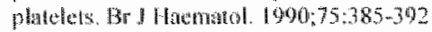

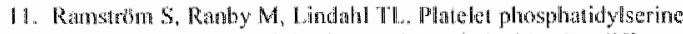
aposure and procongulant activily in chothe whote blood - ditfarent

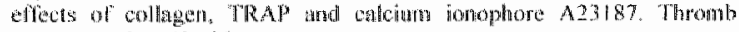

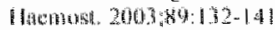

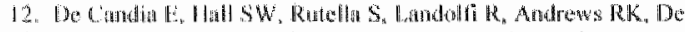

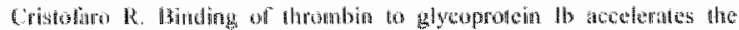

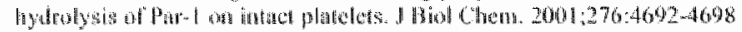

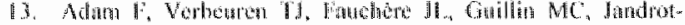

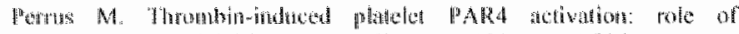

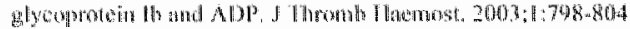

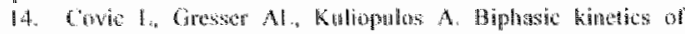

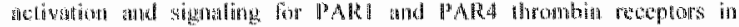

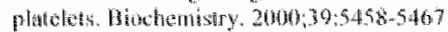

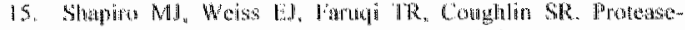

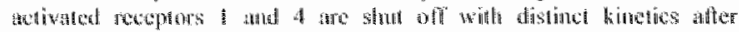

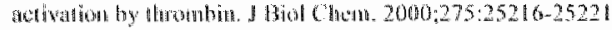

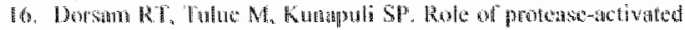

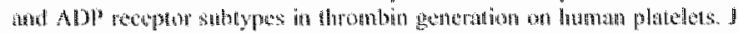

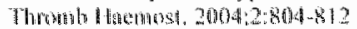

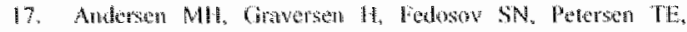

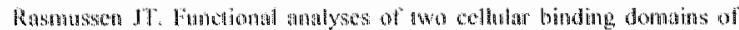

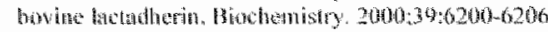

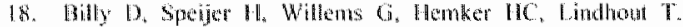

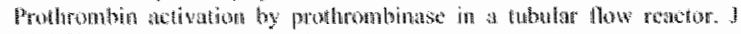

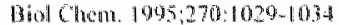

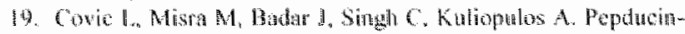

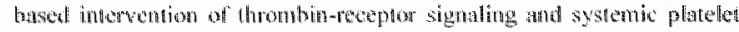
antivition. Nature Met. $20028: 1161-1165$

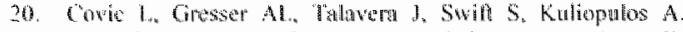

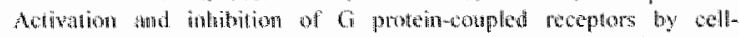

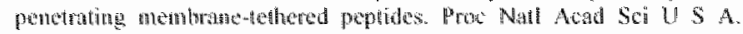

\section{$2002.90 \cdot 643.648$}

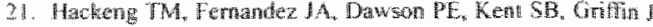

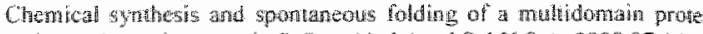

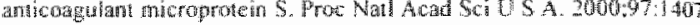
$407 \%$

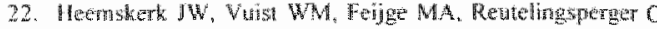

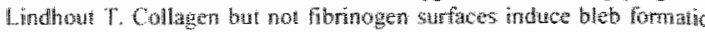

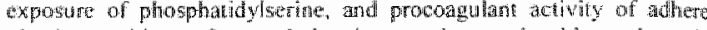

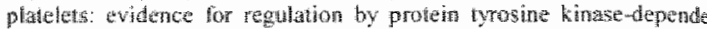

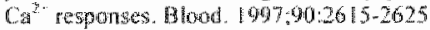

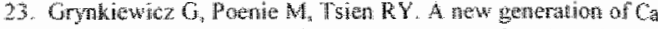

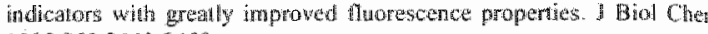
$1985,260: 3440-340$

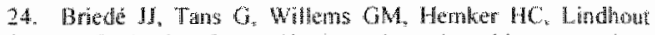

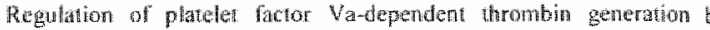

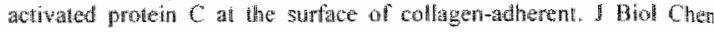
$2001 \cdot 276: 71647160$

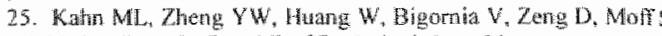

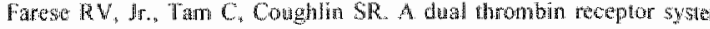
for platele activation. Nature, 1998; 394:600-694

26. Kin 5 Foster C. Leceni A Ouluton TW, Prosser DM. Jin

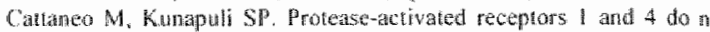

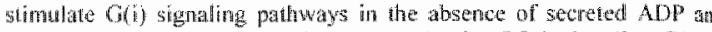

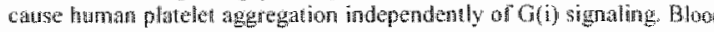
$2002999: 3629-3636$

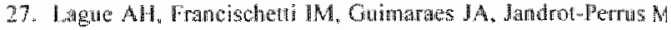

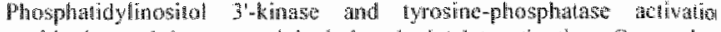

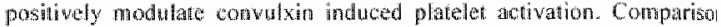
with collagen. FeBS lett. $1909 \% ; 48 \div 95-100$

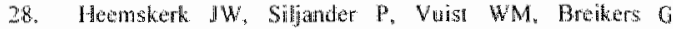

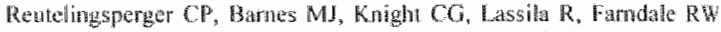

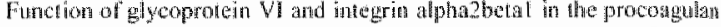
neponse of single, collagen-adheren platedes. Thromb Honnos $1909,81: 782.792$

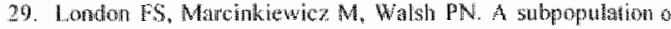

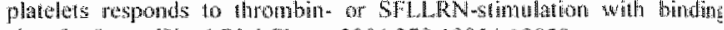
siles for factor XXa. \& B tol Chem. 2004:279:19854-19899

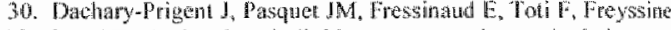

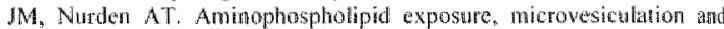

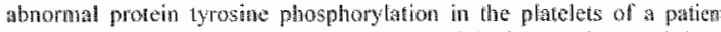

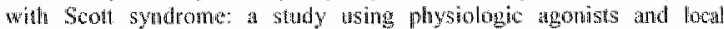

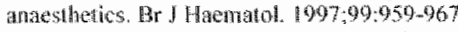

31. Roner 8 , Prwlonski M, Hathib A, Jandrot Pemes M, Rasa MP Bryckact M. Costimulation of the Giteotpled ADP receptor and the Gig-

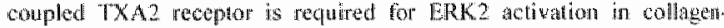

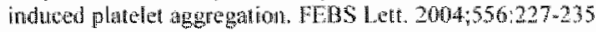

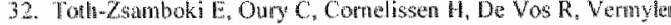

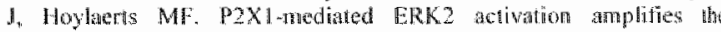

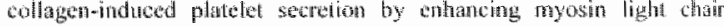

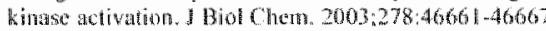

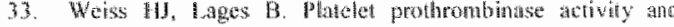

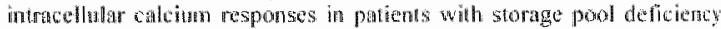

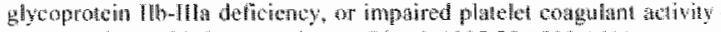

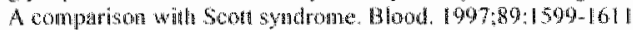

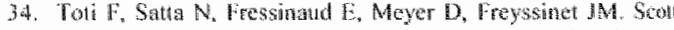

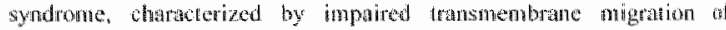

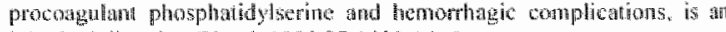
intherited disorder. Blopd $19096,87: 1409-1415$

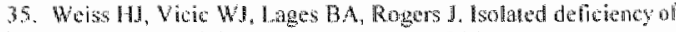

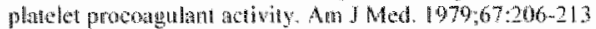

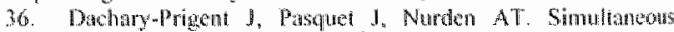

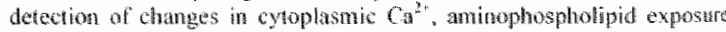

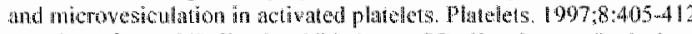

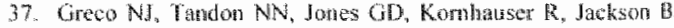

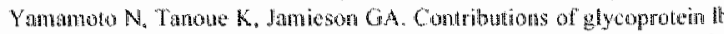

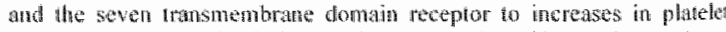
atophsmic $[$ Cast. $1996,35906-914$

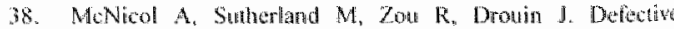

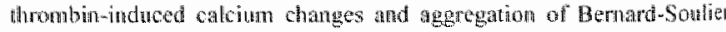

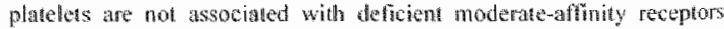

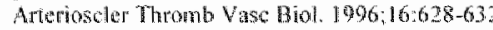

39. Gindwin CA, Whe lor-Jones CP, kalkar WV, Deadman I] Alth" KS. Scully MI". Thrombin receptor activaling peptide does not

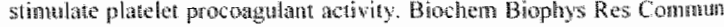
$1994,202: 321.323$

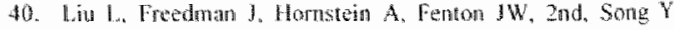




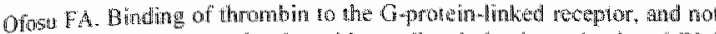

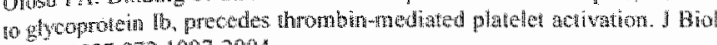
Chem. 1097:272:1997-2004

4. Leon $C$, Ravanat $C$. Frend M, Caranye JP, Gachet $C$

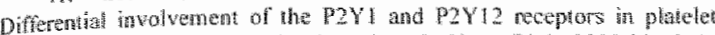

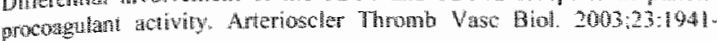
1947

42. Resendiz JO, Lawsita R, Kroll W. Distinct mechanisms of profaseactivated receptor (PAR) I and PAR 4 indwed

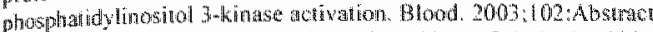

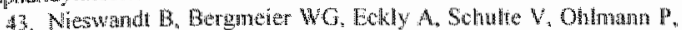
Carenave JP, Zimgibl H, oremanns $S$, Gache C. Exidence for cross

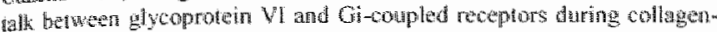
induced platelel aggregation. Blood, $2001 ; 97: 3829-3835$

44. Larson MK. Chen $M$, Kation ML. Taylor AM, labre JE Montensem RM, Conley PA, Parise $1 \mathrm{~V}$. Identification ol $\mathrm{P} 2 \mathrm{~V} 12$ dependent and independent mecharasms of glycoprotein VI-mediated Rapl activatom in platelets. Blood. $2003,10 \mathrm{H}: 1.409-1415$

45. Lova P. Campus F. Lombardi R. Cattaneo M, Singagla $\mathrm{F}$ Baldumi C. Torti M. Contribution of protease-acrwated receptors 1 and 4 and glyoprotein $1 \mathrm{~b}-\mathrm{K}-\mathrm{Y}$ in the G(i)-independent activation of platelet

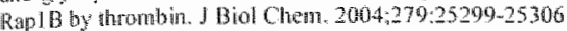

46. do Cea Monteiro M. Sansonety F, Goncalwas My, OConnor

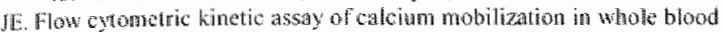
platelets asing Fluo-3 and CD 41 . Cytomety. 1999-35,302-310

d7. Kunzelmanls $\mathrm{C}$. Theyssinet JM, Martinez $\mathrm{MC}$. Rho A participates in the regulation of phosphatigylserine-dependent proconghant activity athe surface of thegakaryocytic cells. I Thromb
Hemost: $2004-2.64464$

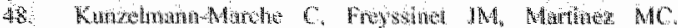

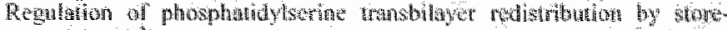

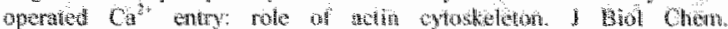
$2001: 276: 5194-5139$

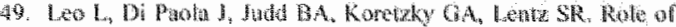

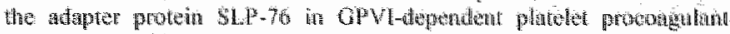

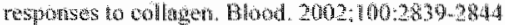

50. Siljarder P" Fandale RW, Fibe MA, Com furiug P, Kos S.

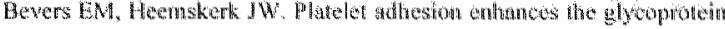

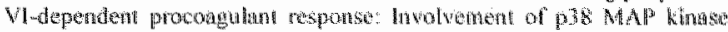

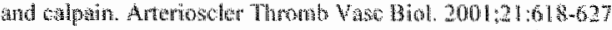

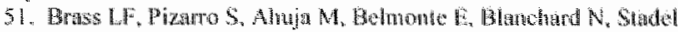

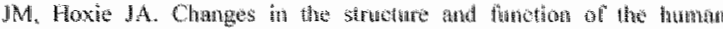

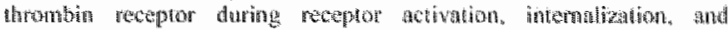
roeyoling. J Brol Chem, 1994;269>2943,2952

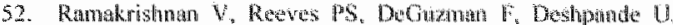

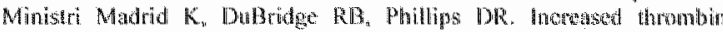

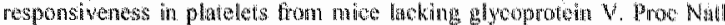

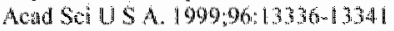

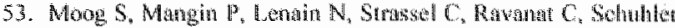

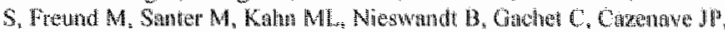
Lanza $\mathbb{F}$. Plateled glycoprotern $V$ binds to collager and partietipates in

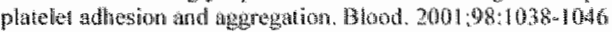

54. Clayor RB, Michelson AD, Li JM, Frelinger AL, Rohrer MD, Gamete CS, Banatrd MR, Krieger LA, Fuman MA. The cleaved peptide

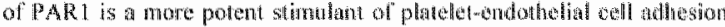
than is thrombin. I Verse Sting. $2009,37: 4404445$ 
Fibrinogen adsorption, platelet adhesion and thrombin generation at heparinized surfaces exposed to flowing blood.

Thromb Haemost. 2002;87:742-7 


\title{
Fibrinogen Adsorption, Platelet Adhesion and Thrombin Generation at Heparinized Surfaces Exposed to Flowing Bloo
}

\author{
Jeffrey F. W. Keuren', 2, Simone $₫$. H. Welders ', George M. Willems², Marco Morra3. \\ Theo Lindhout 1.2
}

Department of Blochemistry and 2 Cordiovascular Research institute. Moastricht University, Madastrih The Netherlands: "Nobil Bio Ricerche, Villafranco d'Asti,

\section{Keywords}

Heparin coating, artificid surface, fibrinogen, plateles, thrombin

\section{Summary}

Thrombes formation at an artilicial surface in conlact with blood is a complex process that encompasses accration of platelets from flowing blood and fibrin deposition. Platelet adhesion and fibrin formation are intimately intertwined reactions that are triggered by different sets of surface adsorbed plasma proteins. "To dissect the contribution of protein adsorption and platelet adhesion to thrombin formation, a coherent study was pertormed with non-conted $(\mathrm{NC})$ and heparin-coated $(\mathrm{HC})$ surfaces. Thrombin production in whole blood, plateler adhesion and protein adsorpprion were studied using an anidolytic thrombin alsisy, a dynamic platelet adhesion assay and ellipsometry, respectively. Thrombing generntion in llowing whole blood exposed to HC surfaces was greatly diminished when compared with NC surfaces. However, separate platelet adhesion atrd protein adsorption studies with antio congulated whole blood revealled that platelets do not adhere because fibringen is not awaillable in the protein layer that was deposited durng the perfusion. These findings indicate that the in vitro thrombogenicity of a material cannot be predicted from platel athesion and protein adsorphion data when these measuements are pertormed with

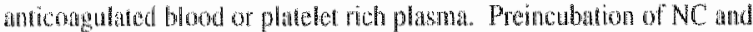
HC surfaces with fibrinogen or 2000 -fold difutcal plasma resulted in similar umotunts of stuface-bound fobringen and mediated massive platelet ablesion from thowing whole blood. These results indicate that a) platelet athesion correlates with the avalability of surfacebound fibrinogen and by $N C$ and $H C$ surfwees are indistinguishable with respect to protein (thomogen) adsorption and platelet adhesion. It is apparent that the lyeparinized surface used in our studies exens its anti-Hrombagenic propesties by newtralizing locally formed thrombin and wot by reducing fibrinogen-dependent platelet adhesion.

\section{introduction}

The imitat response of bloot exposed to an artificial surface is adsorption of blood proteins. This ovent triggers anumber of biological reachions like inlanmotion and blood cosigulation (1). It is widely

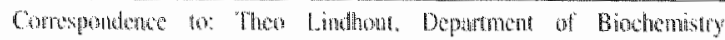

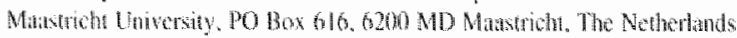

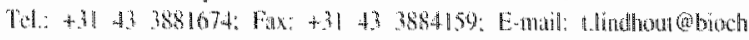

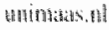

accepted that the nature of the adsorbed proten layer detemines w biological systems and blood cells respond and to what ex Thrombus tormation at an artificial surface in contact with bloo thought 10 occur when platelets adhere va (activated) integrins on platelet plasma membrane to a selective group of adsorbed pla proteins (e.g. fibrinogen) tleposited at an artificial surface 12 However, because of the intimately intertwined nature of platelet blood coagulation reactions, thrombin formation is also essentia surface thrombogenicity $(5,6)$. Thrombin generation in this case is $n$ likely initiated by the contad system that in wirn is triggered by adsorption of specific plasma proteins (factor XII. HMWK prekallikrein) (7). Theretore, activation of platelets and coagula might be initiated by the adsorption of two different classes of pla proteins.

In spite of numerous studies on the rellationship between surt chemistry and protein adsorption on the one hand (8-10) and betw protein adsorption and platelet adhesion on the other hand (1!it sill remains to be clarified what precise molecular and cell interactions contribute, and to what extent, lo surface thrombogenix under conditions that are physiologically relevant. Moreover. prediction of the in vivo thrombogenic properties of artificial surfa from isolated protein adsorption studies per se might be questioned several reasons (15). To is well known that the adsorption and desorpt kinetics of the plasma proteins that are involved in the thromboge processes at artificial surfaces are strongly influenced by concentration and surface affinity of oher plasma proteins, In additu the conformation of adsorbed proleins and thus its biologi functiontrog might also change in a time dependent manner (16.20).

In this study we compared the thrombin generating potential of no coated and heparin-eoated surfaces in relation to proten adsorption a platelet adhecion properties of these surfaces under flow conditio Thrombin generation and platelet adbesion experinents were $p$ formed with lowing whole blowd, while guarntiative protein adsorpur in particular that of fibrinogen, was sidied from baffer systems a from a plasma envirenment also under flow conditions. The findings. this sudy contirmed the reduced thrombogenicity of heparin-coat surtices. However, the potental of this particular heparincoat surface with respect to protein adsorption and platelet adhesion was $n$ differen from that of a non-couted surface.

\section{Materials and Methods}

\section{Matering}

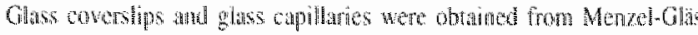

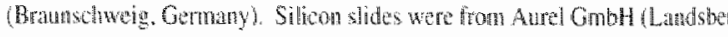

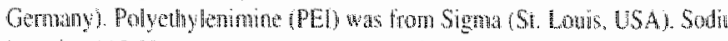

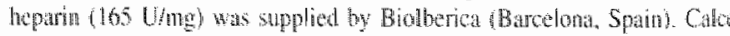


wotoumenthy cater was obained fron Molecular Probes (Leiden. The Nether-

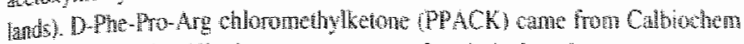
(San Ding, USA, All other reagents were of analytical gnte.

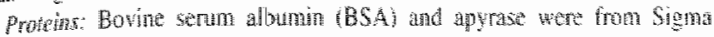

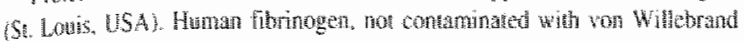

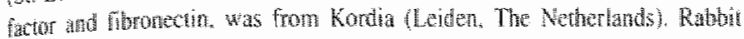
ani-human thitogen and rabil IgC were purdased from DAKO CGosmp. Dentiatiak

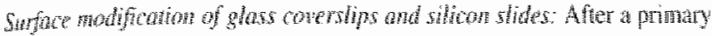
rinse by sonication in isopropanol, glas coverstips and silicon sileses went subjected to glow discharge air plasma cleaning. Brienly, neatment was

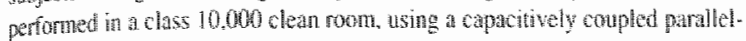

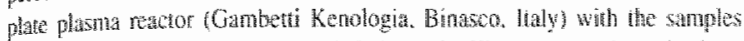

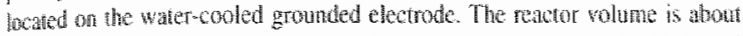
3 . and ha distance be weer the electrodes $10 \mathrm{~cm}$. Fow rate was $20 \mathrm{~m} / \mathrm{min}$ and

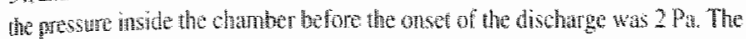
power discharge was 50 W and the treathent ime 180 s. These surfaces will be

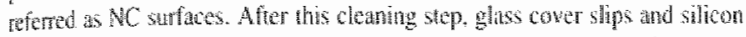

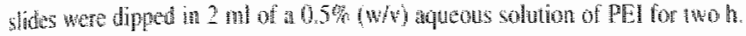

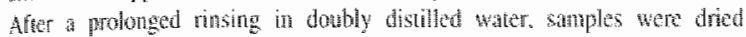
in a lamiras how hood. The PEl treated sanples were then immered in 5 mal a) periodate tratced heparin in $0.4 \mathrm{M}$ acelate solution, pH 4.7. Periodate haparin was pepared by discolving $20 \mathrm{mg}$ soding periodate into $100 \mathrm{~mol}$ of a 0.5\% sotium heparm solution in $0.05 \mathrm{M}$ phosphate bufter (pH 6.9. Perouate oxidation was performed for $12 \mathrm{~h}$ in the dark $\mathrm{NaCNBH}$, wis added to the

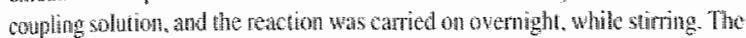
theparth-coted surfaces were atenswely rinsed, stored overight in doubly distled water and dred in a laminar flow hood. The coupling of beparill was confined by roludine bue stanings.

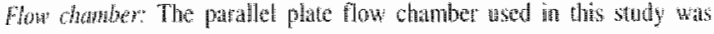

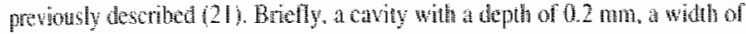

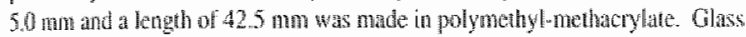

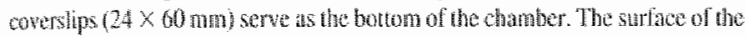
coverslip in contact with parfusion solution is $2 \mathrm{~cm}^{2}$.

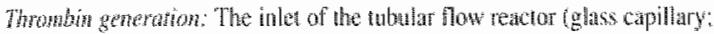
length $65 \mathrm{~mm}$ and inner diameter of $0.5 \mathrm{~mm}$ was connected 10 two 5 yringes: one containg cilrated whole blow and the oher contwinging $0.2 \mathrm{M} \mathrm{CaCl}$ in HEPE bufer. The pump driven syringes were set at low rates of 54 and

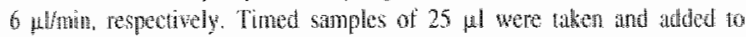

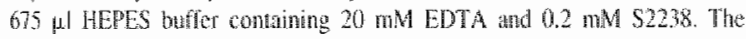

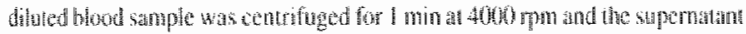

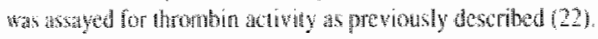

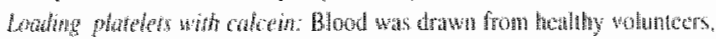

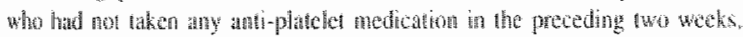

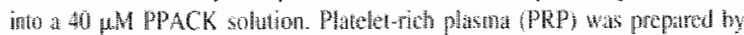

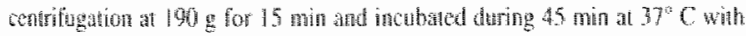

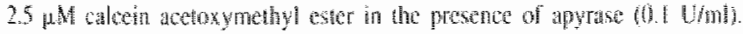

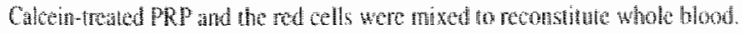

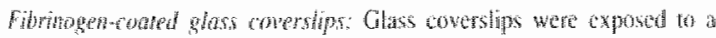

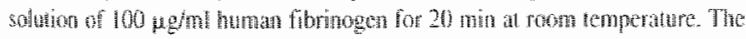

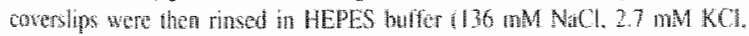

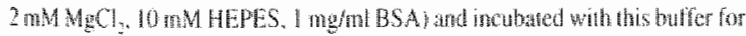
15 mint

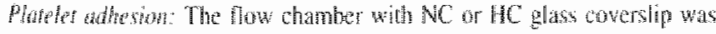

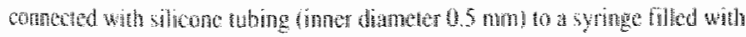

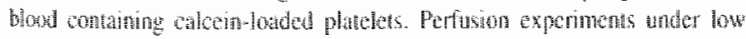

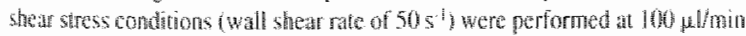

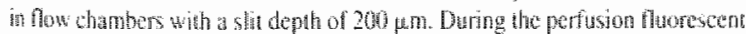

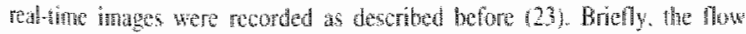
chamber was pliced on the stuge of an inverted mieroscope 4 Diaplobl 200.

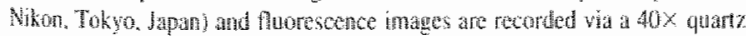

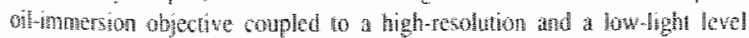

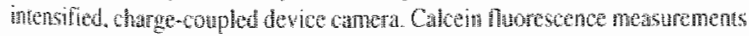

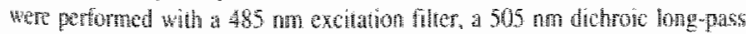

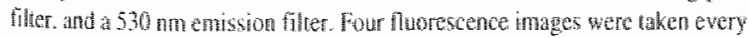

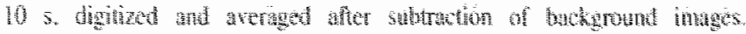

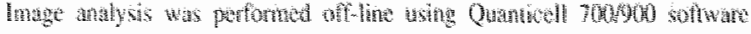

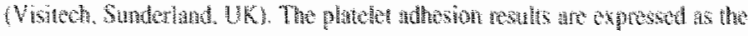

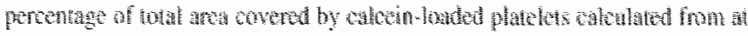

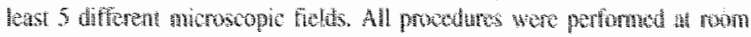
lemperturter.

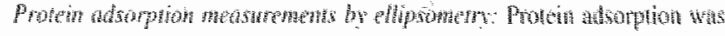

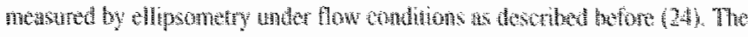

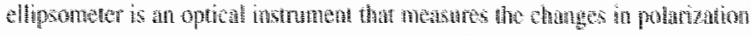

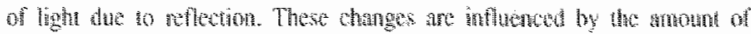

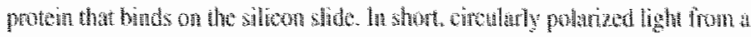

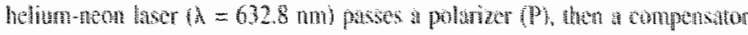

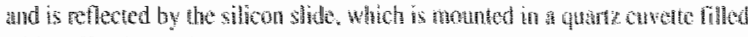

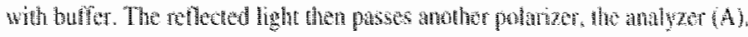

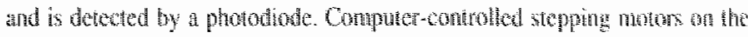

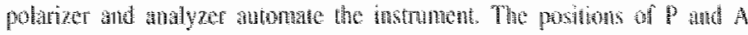

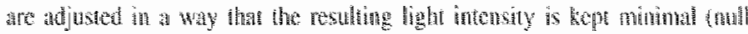

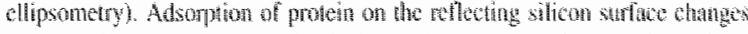

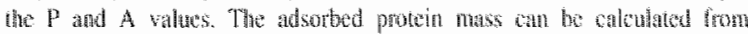

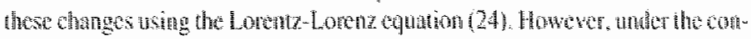

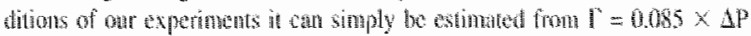

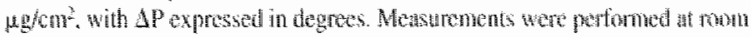
temperingure.

\section{Results}

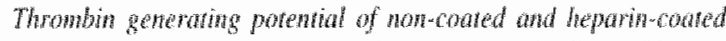
surfaces: Thrombing generation an the mer surface of NC and $\mathrm{HC}$ glass capillaries exposed to thowing recalcified whole blond was monitored in timed samples, fatken the onted of the capillary, with an amidolytic assay for thombin activy. Anatked difference in the thrombin generating potential of NC and HC surfaces was ohsersed (Fig. 1): whereas NC surfaces showed a rapid onse of unombin generation 5 min after the stant of the perfision, only small amounts of thrombin were detected in the efluen of HC capillanes at the end of the perfusion experiment. It is apparent that on the NC surfaces shonly after the initiation of the blood coaguatation system the thrombindependent positive feedback reactions are responsible for the studen onset of a sleady state thrombin production. The grealy diminished thrombin production at $\mathrm{HC}$ surtaces is likely atributed by the hepanti-

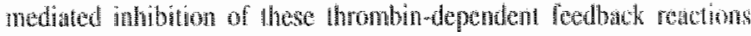

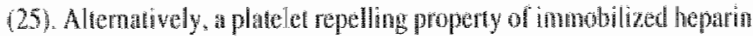
could aso be responsible for the diminishod thrombin genentidon becatuse adhenent plateles have been shown to be critical to the

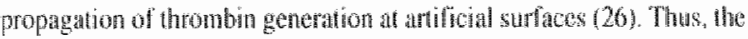

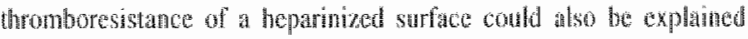
by a reduced platelet adhesion because of a diminisued fubrinogen adsorption. We, therefore, next eximined adsomplion of librinogen on NC and HC suraces.

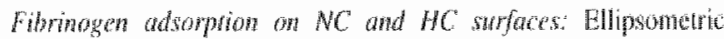
measurements were perfomed to obtain quantititl ive data on fibrinogen adsoption for No and $H C$ silicon surfaces oxpesed to purited librinogen and platelet free plastrat. We found that an incubation of $\mathrm{NC}$ and HC sufaces why $10 \%$ dituted plated free plasma resulfed in rapid adsorption of $0.47 \mathrm{and} 0.48 \mathrm{mg} / \mathrm{cm}^{2}$ protein. respecively (Fig. 2 ). To exame whether the addortbed proten layer also contaned fibrinogen, rabbit ant-human fibnogen $\lg G$ was added atter the plasma was replaced by HEPES buffer (rig. 25. The plasma depletion step resulfed in a slighly decreased mass of adsortbet protoin. indicating that some protein desorbed from the surlaces. Addinom of anti-human fibrinogen $1 \mathrm{gG}^{\mathrm{G}}$ however, did not resull in a significantly increased protein andsorption. The two possible explanations lon this 


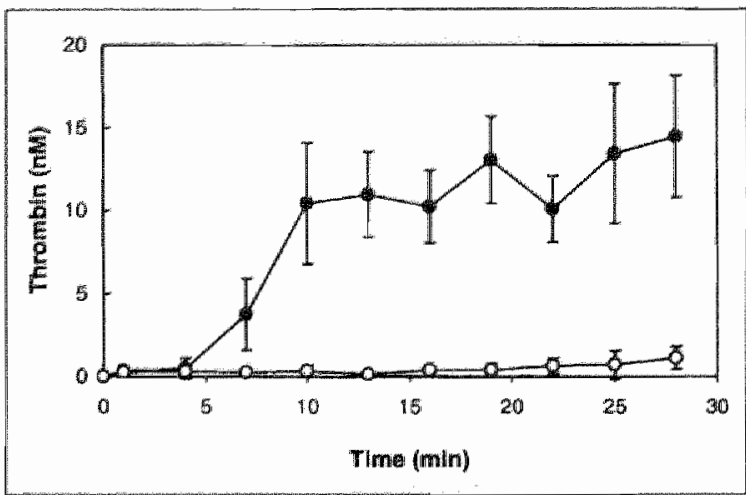

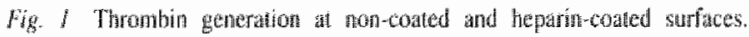
flowing cilrated whole blood (wall shour rate $50 \mathrm{~s}^{-1}$ ) was recallified just

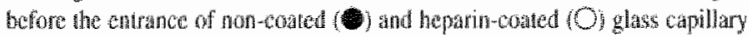
(length $6.5 \mathrm{~mm}$, inner diancter $0.5 \mathrm{~mm}$ ) as ow wrothed the text. Samples were

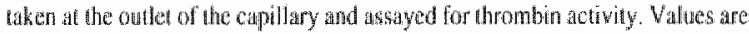
mean $\pm S D(n-3)$

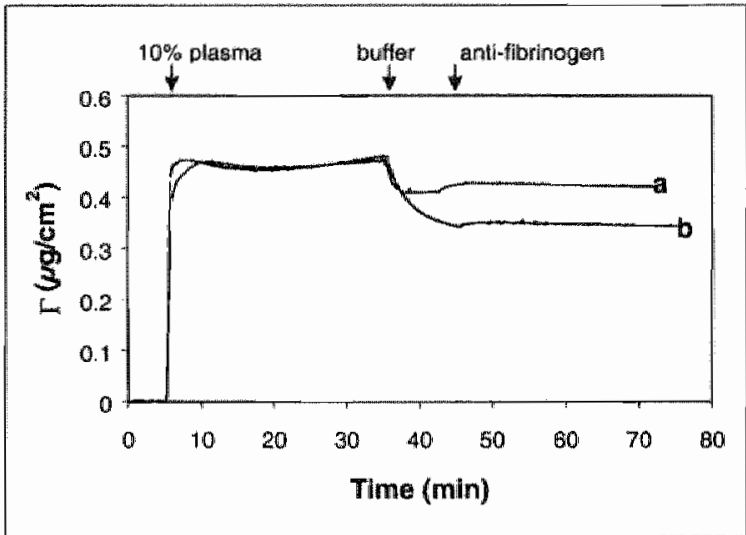

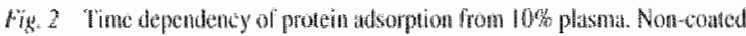

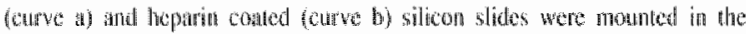

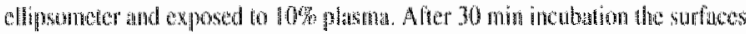

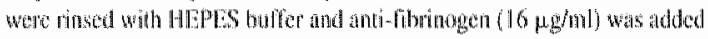

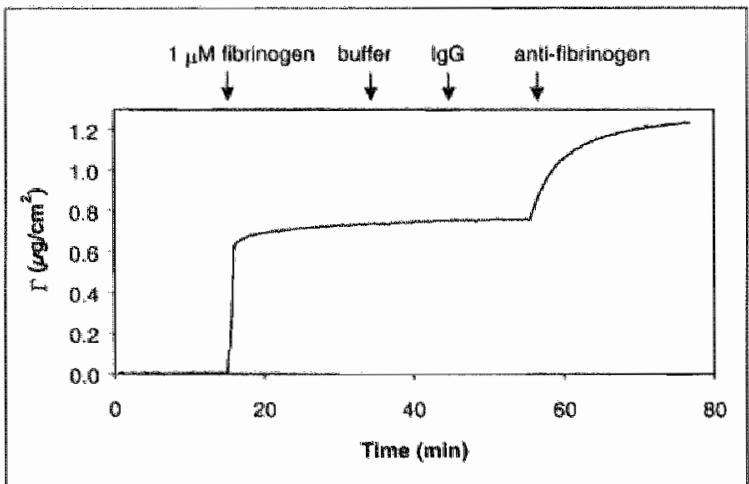

Fig. 3 Detection of alsolved Tbringen by anli-fibringen. Non-coated silicon slide was mounted in the ellipsometer and exposed to $1 \mu \mathrm{M}$ human fibringgen. After 20 min incubation the surtige was rinsed with HEPES buffer.

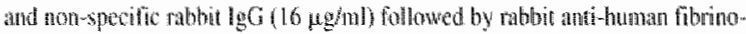
ger $16 \mu \mathrm{g} m \mathrm{~m})$ were added

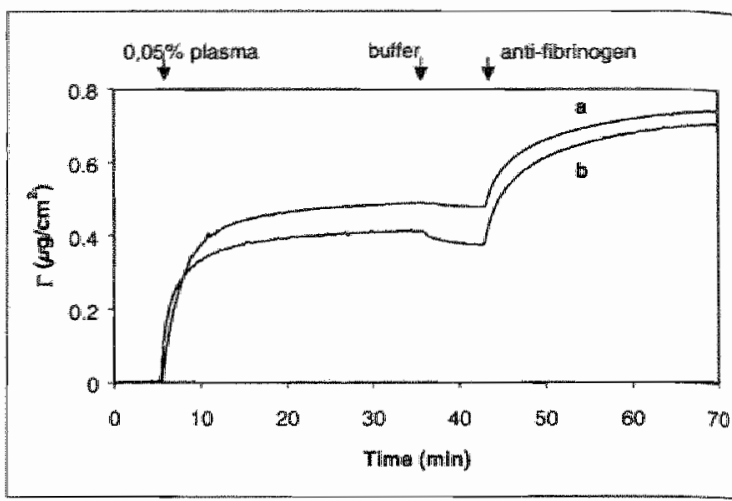

Fig. 4 Time dependency of protein adsorption fiom $0.05 \%$ plasma. Now coated (curve a) and hejarin coated (curve b) silicon slides were mounted it the chipsorneter and exposed to $005 \%$ plasma. After 30 matn incubation th surfaces were rinsed with HEPES buffer and anti-fibrinogen $(16 \mu \mathrm{g} / \mathrm{ml})$ wat added

findirg are: 1) the anti-human fibrinogen antibody does not recogniz fibrivogen in the protein layer or 2 ) fibrinogen is nof present or exposed in the protein layer. To explore these possibilities, the following contro. experiments were performed. Firstly. NC surface was exposed to $1 \mu \mathrm{M}$ purfited human fibrimogen. A rapid adsorption of fibringgen was ob. served, yielding a naximum mass of adsorbed fibrinogen of $0.76 \mu \mathrm{g} / \mathrm{cm}$ (Fig. 3). The same experiment with $\mathrm{HC}$ surface gave a slighty lowe

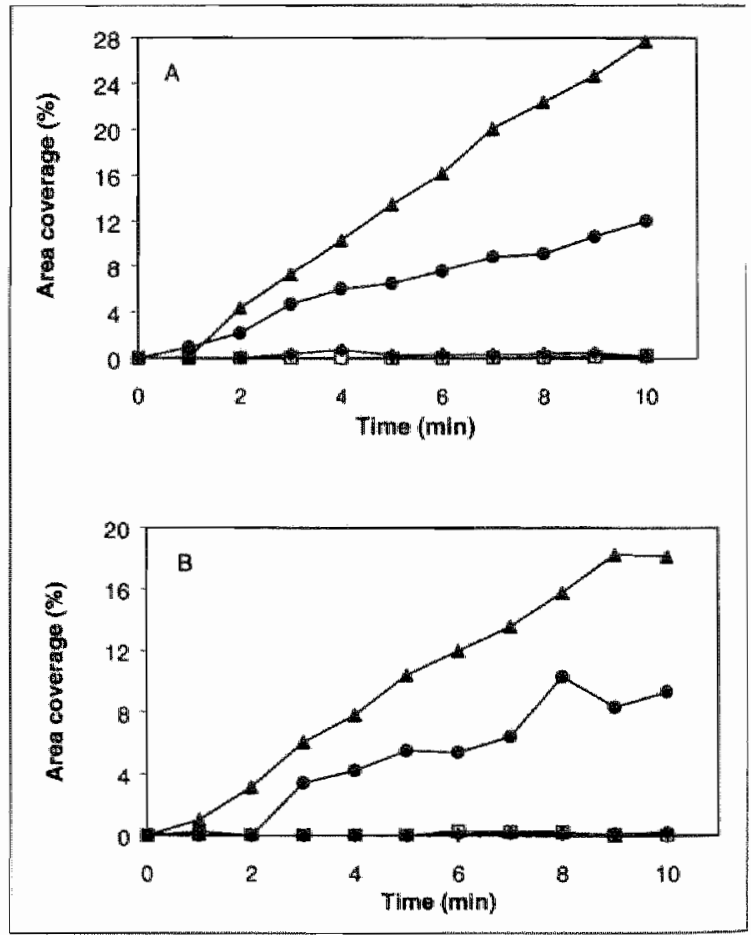

Fig. 5 Time depadency of platelet adhestor from whole blood. Non-coated (A) and heparin-coated (B) glass coverslips were pretreated with $0.3 \mu \mathrm{M}$ human fibrinogen ( 4 , 10\% plasma (\$). 0.05\% plasma (O) or non-reated (D). and subsequenty exposed to PBACK anticoagulated whole blood in a flow chamber al a strear rate of $25 \mathrm{~s}^{\text {: }}$ 
Toble 1 Platwet athesion on nori-coated (NC) and thepantineated (HC) glass covershos

\begin{tabular}{|c|c|c|c|c|}
\hline \multirow[t]{2}{*}{ Pre-incubation } & \multicolumn{2}{|c|}{ Area coverage $(a)^{n}$} & \multicolumn{2}{|c|}{$\begin{array}{l}\text { Ratc of plateded adhesson } \\
\text { (\% area coveragesmin) }\end{array}$} \\
\hline & NC surface & HC surface & NC sufface & MC surface \\
\hline None & $0.1 \pm 0.1$ & $0.1+0.1$ & $0.0 \mathrm{l}$ & 0.01 \\
\hline Fibrimogen & $27.3 \pm 06$ & 18.1199 & 2.93 & 215 \\
\hline $0.05 \%$ plasma & 12.013 .1 & $9.3 \div 3.2$ & 1.18 & 1.01 \\
\hline $10 \%$ plasma & $0.2+0.2$ & $0.2 \pm 0.2$ & 003 & 0.02 \\
\hline \multicolumn{5}{|c|}{$\begin{array}{l}\text { Values are means i } \mathrm{SD}(\mathrm{n}-10) \text { after } 10 \text { minutes perfiston with whole blaod ani- } \\
\text { coaguated with PPACK. }\end{array}$} \\
\hline
\end{tabular}

Table 2 Protein adsorption on non-coated (NC) and haparin-coated ( $\mathrm{GC}$ C) silicon suffaces

\begin{tabular}{|c|c|c|c|c|}
\hline \multirow[t]{2}{*}{ Pre-incubation } & \multicolumn{2}{|c|}{$\left.\Gamma(\mu \mathrm{a} / \mathrm{cm})^{2}\right)^{\mathrm{H}}$} & \multicolumn{2}{|c|}{$\Delta \Gamma\left(1 \mathrm{dem}^{2}\right)^{\mathrm{b}}$} \\
\hline & $\mathrm{NC}$ & $\mathrm{HC}$ & $\mathrm{NC}$ & HC \\
\hline Pibrinogen & 0.76 & 0.60 & 0.46 & noc \\
\hline $0.05 \%$ plasma & 0.49 & 0.41 & $0.2 \%$ & 0.3 . \\
\hline $10 \%$ plasmat & 0.47 & 0.48 & 0 & 0 \\
\hline \multicolumn{5}{|c|}{ "Protein mass before rinsing. } \\
\hline \multicolumn{5}{|c|}{ bucrease in protein mass atter rinsing and addition of anti-human tibrinogen antibody. } \\
\hline CNot deternine & & & & \\
\hline
\end{tabular}

mass of adsorbed fibrinogen $\left(0.60 \mu \mathrm{g} / \mathrm{cm}^{2}\right.$ ) (data not shown). Fig. 3 further shows that relacement of the fibrinogen solution with HEPES buffer did not result in desorption of immobilized fibrinogen from the NC strtace. The addion of purited rabbit $\lg (\mathrm{C}(16 \mu \mathrm{g} / \mathrm{ml})$ resuled in no furher increase in protein atdsorption, indicating that the surface was areaty saturated with proten and that this non-spectic rabbit $\lg G$ did not recognize adsonbed human fobrinogen. In contrast, addition of rabbil anti-human ribrimagen $1 \mathrm{gCi}$ resulted in an additional increase of about $0.46 \mu \mathrm{g} / \mathrm{cm}^{2}$ of adsorbed protein. Evidently. this merease in protein adsorption can be attributed to the binding of anti-human fibringen IgG with: surface-bound hbrinogen. These resulls thus clealy thdicute that the rabit ant -human fibrinogen $\operatorname{lgG}$ is a sutable tool for the detection of adsorbed fibrinogen. We therefore conclude from the proten adsorption data for $\mathrm{NC}$ and $\mathrm{HC}$ surfaces preincubated with $10 \%$ diluted plasma (Fig. 2) that fibrinogen is not detectable in the protein layers thus oblained.

The absence of derectable librinogen in a protwin layer adsorbed trom whole blood could indicate a fast replacement of that protein by other plasma proteins $(16,27)$. This repiacement will not occur when protein adsorption is conducted from a highly dilufed plasma solution 28. 29\%. Exposume of NC and HC surfaces to 0.05\% plasma resulted in the adsorption of 0.49 and $0.41 \mathrm{\mu g}^{\mathrm{c} \mathrm{cm}^{2}}$ protein, respectively. Remarkably, these amounts are only little less than those found with $10 \%$ divted plasma, indicating that under these conditions again saturation of proten adsorption is obtaned. In contrast to the results seen for both NC and HC surfaces with $10 \%$ dinnted plasma (Fig. 2), the addition of rabbit anti-human fibrinogen $\lg$ G yielded a significant increase in protein adsoption (Ty. 4), indicating the presence of fibrinogen in that protein layar:

Platelet adhesion from flowing whole blowd no now-dowed and he-

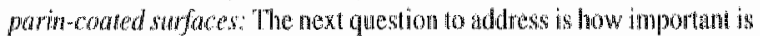
the avalability of fibrinogen for the platelet atheswe properties of surfaces in contact with flowing blood. PPACK anticoagulated whol blood of which the colls wete loaded with calcen was passed durting 10 min through flow chambers with monded NC and HC surfaces. The surface coveroge with lluorescent platedes dung the perfusion was momitoned in reatlime and of line analyzed. Nearly no platelet associated fluorescence could be deteded on boll surfaces during a 10 min perfusion (Fig. 5). If this finding is compatible with our

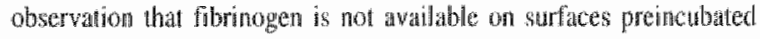

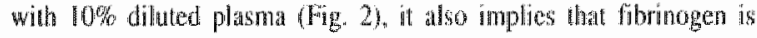
atready unavallable from the star of the pertision. This points a very rapid dislocation of fibrinogen during the process of protein adsorption.

To find support for this nohot, platelet adhesion studies wert performed on NC and HC surfaces that were prancubatod with puritied fibringen and highly difuted (2000 fold) platha. Previous experiments atready established that NC and HC surfaces treated in this way adsorbed fibrinogen that was recognized by a rabit anti-humath fubrinogen antibody (Figs. 3 and 4). A subsequerat perfusion of these surfaces with whole bood resulted in a linear increase in the number of 
atherent piatelets with perusion time (Fig. 5 ). A4ter a perision of 10 min the filbrinogen-pretreated $\mathrm{NC}$ and $\mathrm{HC}$ surfaces were covered for $273 \pm 0,6 \%($ meals $\pm S D, n=5)$ and $18.1 \pm 7.9 \%($ mean $\pm S D, n=5)$, respectively, with adherent plattels. The coverage of $\mathrm{NC}$ and $\mathrm{HC}$ surfaces pretreated with $0.05 \%$ diluted plasma was $12.0 \pm 3.1 \%$ and $9.3 \pm 3.3 \%$, respectively. It is apparent that the rate at which the surfaces were cowered with platelets increased proportionally with the anoun of a valiable fibringen (ct. Table I and Table 2).

\section{Discussion}

Il is generally believed that surface thrombogenicity is associated with the potential of is surface to adthere blood platelets. Platedet adhesion, in turn, is thought to depend on the ability of a surface to adsorb fibrinogen. Therefore, protein adsorption and platelet adhesion experiments are frequenly performed to evaluate the thrombogenicity of artificial surfaces. This study confirms the dependency of platelet adhesion on the avallabillify of forrinogen in the protein layer deposited at an artificial surface under conditions that mimic the physiological situation, i.e. flowing whole blood or plasma. However, a relationship between the level of thrombin generation and platelet adhesion could not be established. Our experimenal data indicate that platelet adhesion data do not predict the thrombogenic nature of artificial surfaces in contacl with blood, raising the questions: 1) what factors prevent platelets from adhering to these surfares and 2) should the mediating role of adherent platelets in thrombin generation be reconsidered? Answers to these questions would be helpful in understanding why heparinization of artificial surfaces reduces the intrinsic thrombogenicity of such surfaces.

Fithrinogen adsorpuion and plateler adhesion: Ellipsometric measurements showed that NC and HC surfaces exposed to 10 . Fold difuied plasma adsorbed similar amounts of plasma protein (around $\left.0.5 \mu \mathrm{\mu g} / \mathrm{cm}^{2}\right)$, suggesting that heparinized surfaces are not protein repelling. In spite of the presence of a protein layer, surface-bound fibringen could not be detected with rabbit anti-human fibrinogern (Table 2). Exposure of NC and HC surfaces to 2000-folld diluted plasma resulted in 0.49 and $0.41 \mu \mathrm{g} / \mathrm{con}^{3}$ adsorbed protein, respectivelly, which is sinuilat to the amounts found with 10-fold diluted plasma. This relatively small anounl of proiein in $0.05 \%$ plasmat (about $40 \mu \mathrm{kg} / \mathrm{ml}$ ) is apparently sulficient to saturate NC and HC surfaces. In the protein layef tulsoftred from 2000 -1old diluted plasma, we readily detected an abundan presence of tibringgen in contrast to our findings with 10-fold diluted plasma. It is of interest to note that the platelet area coverage of both NC and HC surfaces parallels the amount of fibrinogen that was detected in the prowan layer on the artilicial surface after exposure to 10-10ld diluted and 2000-fold dilued plasma (Table 1). This finding once moe indicales that with respect 10 fibrinogen adsoption and platelat adhesion, the heparinized surface used in this study is indistinguishable from a non-costed hydrophitic surface.

While tibringen absorbs from a buffer solution to $\mathrm{NC}$ and $\mathrm{HC}$ surtaces and such pretreated surfaces accrete readily platelets from Dowing whole blood. only a few platelets adhered during the perfusion of non-pretrated surfaces with tlowing whole blood. These data confirm that the deposition of a protein layer from flowing whole blood is followed by a reatrangement of that layer in which fibrinogen is very rapidy displaced. This rearrangemem, also called the Vroman effect $(16,30)$, is apparently slowed down or absent when the protein concentration in the thut phase is greatly decreased (29).

Platele adhesion and thrombin generation: We have previously denonstrated that, under flow conditions, the presence of surfacebound anionic phospholipids are mandatory to the propagation of thrombin generation at an artificial surface (25). Simlarly, significa thrombin generation at artificial surfaces was only seen when exposs to platelet rich plasma but not when exposed to platelet poor plasn (26). The apparent platelet-independent thrombin generation no reported seems io contrast with these earlier observations. Howeves, in must emphasize that the platelet adthesion study was performed i flowing PPACK-anticoagulated blood and that thrombin generatio was measured in flowing citrated blood that was recalcified just befos it entered the glass capillary. Thus it is feasible that a few free flowin platelets are tethered by fibrinogen that adsorbed to the surface befon it is displaced by other plasma proteins. The first traces of thrombil gemerated in recalcified citrated blood, at the surfaces of these adheret platelets probably induce additional platelet adhesion and so amplify su face-located thrombin generation, which in turn results in an explosit increase in the tate of thrombin generation. The thrombin generatio data with heparinized surfaces strongly support this notion. Becalis HC surfaces are indistingurishable from NC surfaces with respect i protein adsorption and platellet achesion a diminished thrombin genera tion on HC surfaces can only be explained by the rapid heparindepen dent inhibition of thrombin-medialed positive feedback reactions, e.g platelet activation and generation of the critical cofactors Va and VIlla

In conclusion, our work suggests that protein adsorption and platele adhesion data from anticoagulated whole blood are inappropriati parameters 10 assess the thrombogenic properties of biomaterial because anticoagulation prevents a key fearure of thrombin, i.e. it: positive feedhack function in platelet adhesion and activation and thit surface thrombus formation. Predictions for the adverse haemostatio reactions at the blood-material interface could therefore be better based on thrombin generation measurements in blood passing by an artificial surface. Our findings also imply that surface thrombogenicity is probably most effectively reduced by inmobilized agents, like heparin: that cause enhanced inhibition of surface-localized, thrombin-dependent positive feedback reactions.

\section{Acknanledgements}

We are grateful to Patrick and Linda Cahalan for helplul discussion. This work was supponted in pan by NWO grant $902-698-241$

\section{References}

1. Lamba NWK, Cooper SL. Antenaction of blond with artificial surfaces, th:

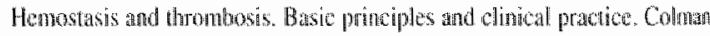
RW, Hirsh I, Marder VJ Clowes AW. George JN, eds. Philadelphia:

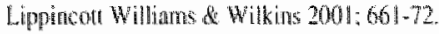

2. Hunson SR, Harker LA, Rander BD. Hoffman AS. In wo evaluation of artine J Lab Clin Med 1980:95:289-304.

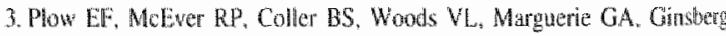
MH. Related binding mechanisms for florinogen, bbronectin, von Whllobrand factor, and thrmbospondin on thronimin-simuluted platelets. Blow 1985:66: $724-7$

4. Goodnats SL, Cooper SL, Albrech RM. Integrin receptors and plateles

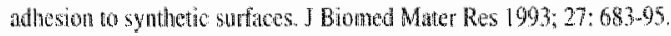

5. Wagner WR, Hublell JA. Lowl thrombin synthesis and robrin formation in an in vitro thombosis model results in phatelet recruitment and thrombus stabillatuon an collagen in hepariazed blood. J Lab Clin Med 190 : 116 6.50 .50

6. Grunkenerer M. Tsai WB. Hobet TA. Hennocompatibity of treake polysiyene subrates: confact activation, platelet athesion, and procongttant activily of atherent phatelets. J Biomed Mater Res 1998; 41:657-70. 


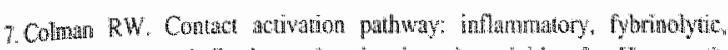

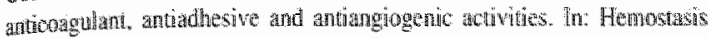

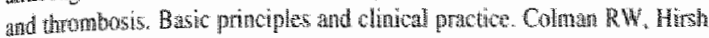
J. Marder VJ. Cowes AW, George JN, ads. Philadohia: Lippineot

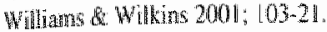

8. Andrate JD. Principles of pretern adsorpton. In Surface and Interfacial Aspects of Bhomedical Polymers. Andrade 1. ed. New Tork: Plenum Prbl. $1.985 ; 1.90$.

9. Horbet TA, Brash M. Proteins at intertaces: cument iscues and future asperts. In: Proteins at interaces Physiochenticat and birchemical studies.

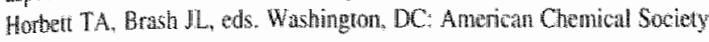
$1987:-33$

10. Green RH, Davies I. Daries MC, Robers CJ, Tendler $\$$ J. Surtace plasnon jesonance for real time in situ analysis of protein adsorption fo polymer surfaces. Biomaterials 1997; 18: 405-13.

II. Jen Cl. Lin IS. Direct observation of pateled athesion to fibringenth and Gibrincoatce surfaces. An J Pbysol 1991: 261:41457-63.

12. Endenburg SC, Lindaboom Blok zijl L. Zwaginga J], Sixma JI, de Groot PG. PJissma fibrinogen inhibuts platelets adhesion in flowing blood io

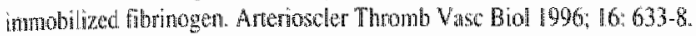

13. Fenersvain IA McClung WG. Hobet: TA. Platelet adtherence and detach-

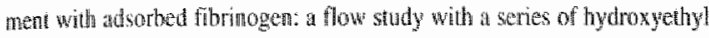
methacrjate-ethy metheryhate copolymers using video nowoscopy. I Binmed Mater Res 1992: 26:221-37.

[4. Lee JH, Ju YM. Kin DM. Platelet adhesion onto segniented polyurethane flim sufaces modified by addition and crosslinking of PEO-containing bock copolymers. Biomateriats $2000,21: 683,91$.

15. Gintinkeneier M.M. Tsai WB, MeFarkand CD. Horbet TA. The stefere of adkorbed fibringeren, Fibronctin, von Willebrand facor and vitronectin on the procoagulan state of atherent platelets. Bionaterials 2000; 21 : 2243.52

16. Vronary L, Adams AL. Fischer GC, Munod PC. Imeraction of high molecetar weight kiniriogen, actor Xll, and hbrinogen in plasmat intertaces, Bilood 1980; $55: 156-9$.

17. Cuypers PA, Wllems GM, Hemker HC, Hermens WT. Adsoption kineties of proten mixtures. A tentative explatat ion of the Vroman effect. Ann $\mathrm{N} Y$ Acad Sci $1987 ; 516: 244-52$.

18. Chin JA, Posso SE, Horbett TA, Raner BD. Postandsorptive transitions in fibrinogen addsorbed to polyurethanes: changes in antibody binding and sodum dodecyl sulfate elutability. J Biomed Mater Res 1992; 26: 757-78.

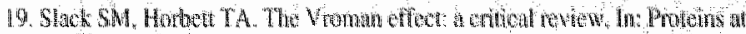

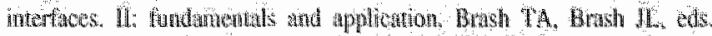

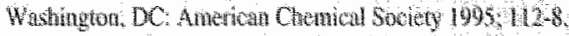

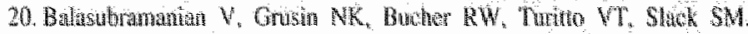

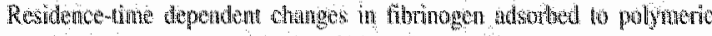

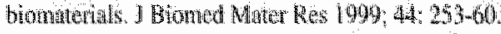

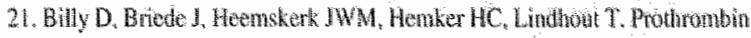

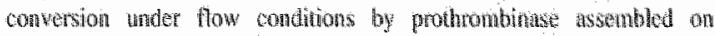

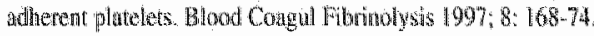

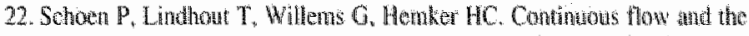

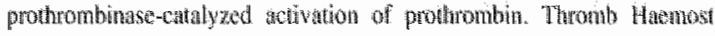
1990; 64:542-7.

23. Hoenskerk IW, Vust WM, Fenge MA, Reutelingsperger CP, Lindhour $\mathrm{T}$. Collagen bat not fibrinogen surfaces indto bich formiton, exposure of

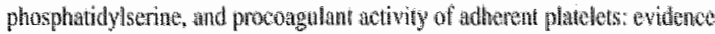

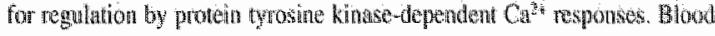
1997: $90 \mathrm{k} 2615-25$

24. Cupers PA, Corgel JW, hansed MP, Kop JM, Hernens WT, Henther HC.

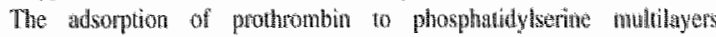
quantitated by ellipsometry. I Bul Cham $1983 ; 258,2426-31$.

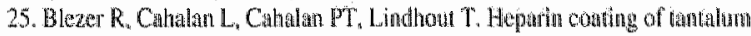
coronary stents reduces surface thrombin genteration bot not frotor IXa genaration. Blood Congul Fibrinolysis 1998,$9 ; 4,75-40$.

26. Blezer R, Willems GM, Cahalan PT, Lindhout T. J hithation and propagarion of blood coagulation at artificial surfaces studied in a capitary flow reachor. Thromb Haemosi 1998; 79: 296-301.

27. Hobet TA. Frinciples anderying the rote of adsorbed phasma proteins in

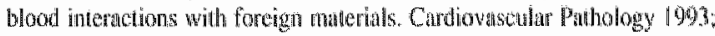
2: $1375-48 \mathrm{~s}$.

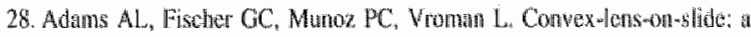
simpte system for the study of lluman plasma and blood in narrow spaces. I Bitoned Mater Res 1984; 18: 64:3454.

29. Burash JL, ten Howe P. Bffect of plasma dilution on adsoption of fibrinogen lo solid surfaces. Thromb Henost 1984:51: $26-30$.

30. Horbet TA. Mass action effects on connpetinge sudsonption of fibrimgen from hemoglobin solutions and from plasma. Thomb Hemost 1984; 51 : $174-81$.

Received July 9, 2001. Accepted after resubmission December 28, 2001 


\section{Thrombogenicity of polysaccharide-coated surfaces.}

Biomaterials. 2003;24:1917-24 


\title{
Biomateri
}

\section{Thrombogenicity of polysaccharide-coated surfaces}

\author{
Jeffey F.W. Keuren ${ }^{a, b}$, Simone J.H. Wielders ${ }^{b}$, George M. Willems, \\ Marco Morrac ${ }^{c}$ Linda Cahalan ${ }^{d}$, Patrick Cahalan ${ }^{d}$, Theo Lindhout ${ }^{\mathrm{a}, \mathrm{b}, *}$

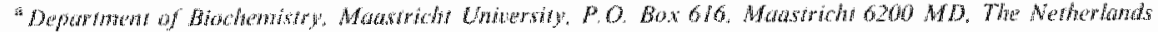

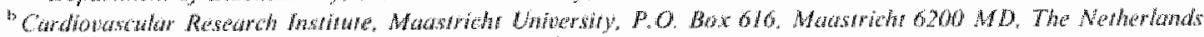

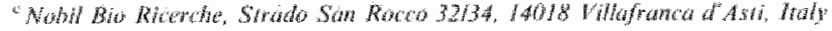

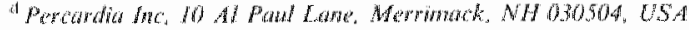 \\ Recoived 16 July 2002 accepted $\|$ Decenber 2002
}

\begin{abstract}
Albstract

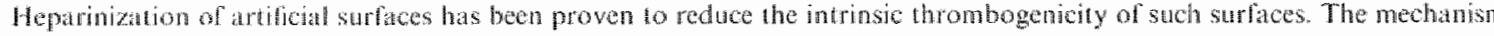
Wheh immobilized heparin reduces thrombogenicity is not completely understood. In the present study theparin-. alginic acid-

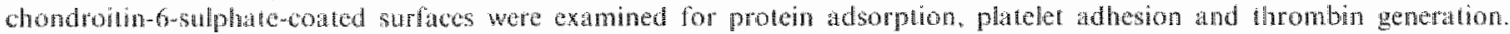

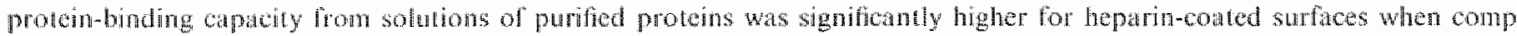

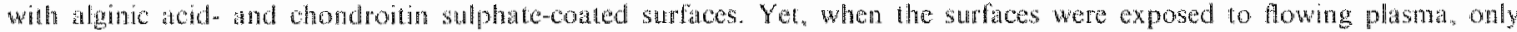

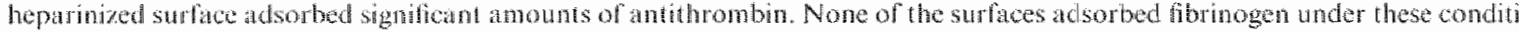

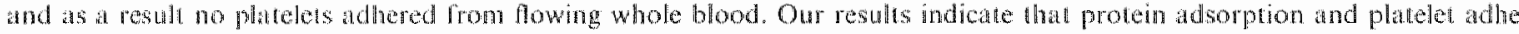

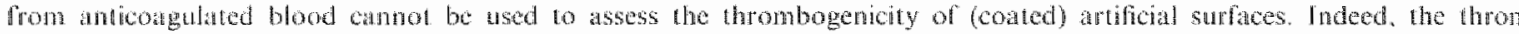

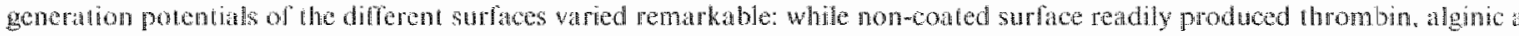

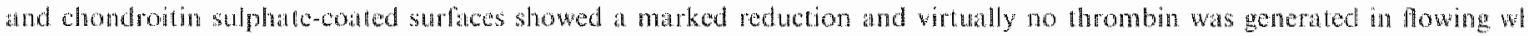
blood passing by hopringed surficos.
\end{abstract}

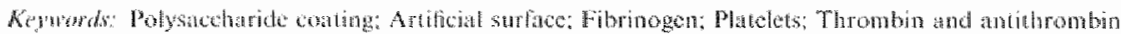

\section{Introduction}

Arithial surfaces in contact with blood trigger a number of biological systems through the adsorption of protens and cells. It is generally believed that the rature of the adsorbed protein layer determines all adverse events that impatir the use of artificial materials in medical devices; thrombes formation as a result of platelet adhesion, platelet activation and unitation of coagulation $[1-3]$ and activation of the complement system that in turn results in leukocyte adhesion and activation [4]. The most widely used method to prevent thrombus formation at artificial surfaces is the administration of hepatin (for a review see Ref. [5])

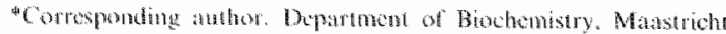

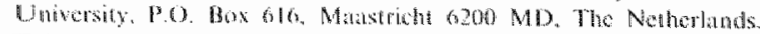

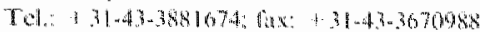

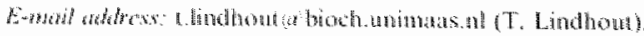

Heparin is a sulphated polysaccharide with a repe ing disaccharide of alpha-b-glucosamine and uro acid [6]. The repeating disaccharide units conti clusters of $O$ - and $N$-sulphated groups. The an thrombotic action of heparin is based on its stro stimulatory effect on the neutralization of throm and factor $X a$ by antithrombin [7,8], a member the serine protease inhibitor (serpin) super fam $[9,10]$. However, the anticoagulant response to hepat is unpredictable becatuse the heparin-antithrom complex is unable to inhibit fibrin-bound thromt [11. This finding explains why in experimen animals heparin is less effective than direct thromt inhibitors [12]. Yet, immobilization of heparin , the artificial surface is successfully used to redu surface thrombogenicity [13]. Moreover, hepat coated surfaces are thought to significantly impro in vitro haemoconpatibility because of reduc adsorption of procoagulant and proinfammato enzymes [14]. 
Immobilization of negatively charged sulphated polysaccharides could make surfaces more biocompatible because of the electrostatic repulsion of negatively charged blood components. Furthermore, an increased wettability as a result of the presence of negatively charged groups may lead to a diminished or more reversible protein adsorption [15]. Yet, highly sulphated polysaccharides like heparin, have been reported to stumulate the process of neo-intima formation. This sumulation is probably the result of an interacion between growth factors and these polysaccharides [16181. Interestingly, fucosylated chondroitin sulphate has a strong inhibitory effect on smooth muscle cell proliferat ton [19]. Thus, it should be questioned whether other sulphated polysaccharides could be an attractive alternative for heparin to decrease the thrombogenic activity of artificial surfaces.

In this sudy we have compared the antithrombogenic properties of immobilized heparin with that of immobilized chondroitin-6-sulphate and alginic acid. Chondroiin-6-sulphate is a sulphated polysaceharide in which $\mathrm{N}$ acetyl $\beta$-D-galactosamine and $\beta$-1 -glucuronic acid are the altemating saccharide units [6]. The sulphate group is at the 6-position of the galactosamine residne. Alginate contains manmuronic (M) and glucuronic (G) groups [20]. It was reported that the G-groups are prothrombotic and that the $\mathrm{M}$-groups have an anticoagulant effect 211. The alginic acid used in this study is a non-sulphated bydrophilic polyuronic acid composed primarily of anhydro- $\beta$-D-nannuronic acid residues. An additional adwantage using this polysaccharide in humans could be its non-mammalian source, which eliminates the risk of contamination with pathogenic agents [8]. The thrombogenic parameters that were evaluated in this study are: (1) adsorption of the purfied plasma proteins albumin, fibrinogen, high molecular weight kininogen (HMWK). IgG and antithrombin. (2) platelet adhesion from flowing whole blood, and (3) thrombin generation at the artificial surfaces in flowing whole blood.

\section{Materials and methods}

\subsection{Materials}

Glass cover slips $\left(24 \times 60 \mathrm{~mm}^{2}\right)$ and glass capillaries (length $60 \mathrm{~mm}$ and inner diameter $11.2 \mathrm{~mm}$ ) were oblained from Menzel-Gläser (Braunschweig, Germany). Silicon slides were tron Aurel GmbH (Landsberg. Germany). Polyethylene-imine (PE), Chondroitin-6ustulphate and alginic acid came from Sigma (St. Louis, USA). Sodium heparin (165 U/mg) was supplied by Bioiberica (Barcelona, Spain). D-PhePro-Arg chloromethylketone (PPACK) came rrom Calbiochem (San Diego, USA). All other reagents were of analytical grade.

\subsection{Proteins}

Human serum abumin was obtained from Sigma (St. Louis, USA). Human fibrinogen, not contaminated with yon Willebrand factor and fibronectin, and HMWK were from Kordia (Leiden, The Netherlands). Rabbit IgG was purchased from DAKO (Glostrup. Denmarky. Human IgG was purified by affinity chromatography on Protein A Sepharose. Antithrombin was purified according to the method of Thater and Schmer [22].

\subsection{Surface modification}

Glass coverslips, glass capillaries and silticon slides were rinsed and coated with the polysacharides as previously described [23]. Briefly, glass coverslips and silicon slides were dipped in $2 \mathrm{ml}$ of a $0.5 \%$ (w/v) aqueous solution of PEI for $2 \mathrm{~h}$. After a prolonged rinse in double distilled water, samples were dried in a laminar flow hood. The PEI treated samples were then immersed in $5 \mathrm{ml}$ of a periodate treated polysaccharide in $0.4 \mathrm{M}$ acetale solution, $\mathrm{pH} 4.7$. NaCNBH, was used to couple the polysachinarides to the PEI-coated surface.

\subsection{Protein adsorption measwements by ellipsowntry}

The ellipsometer is an optical instrument that measures the changes in the polarization of light due to reflection. These changes are strongly influenced by the amount of protein that adsorbs to the silicon slide. In short, circularly polarized light from a helium--neon laser $(\lambda=632.8 \mathrm{~mm})$ passes a polarizer $(P)$, then a compensator and is reflected by the silicon slide, which is mounted in a quartz cuvette filled with buffer. The refected light then passes another polarizer. the andlyzer (A), and is detected by a photodiode. Compulercontrolled stepping motors on the polatizer and anatyzer automate the instrument. The positions of $P$ and $A$ are adjusted in a way that the resulting light intensity is kept minimal (null ellipsometry). Adsorption of protein on the reffecting silicon surface changes the $P$ and $A$ values. The adsorbed protein mass $\Gamma$ can be calculated rrom these changes using the Lorentz Loreny equation [24]. However, under the conditions of our experiments it can simply be estimated from $\Gamma=0.085 \times \Delta P \mu g / \mathrm{cm}^{2}$, with $\Delta P$ expressed in degrees. Measurements were performed at ambient temperature $\left(20-22^{\circ} \mathrm{C}\right)$ under vigorously stirring conditions.

\subsection{Detection of plasmat antithrowbin in surface adsorbed protem layes"}

Heparin-coated and mon-coated silicon slides were incubated with dilluted plasma $\left(10^{\mathrm{k}} \%\right.$ ) for $10 \mathrm{~min}$. The 
plasmat was then removed and replaced by Hepes buffer Rabbit antihuman antithrombin antibody $(16 \mu \mathrm{g} / \mathrm{ml})$ was added and proten adsorption was monitored by ellipsometry. To confin that antithrombin adsorbed on non-coated and hepatimized surfaces is equally detectable by the rabbit antihuman antithrombin antibody, heparin-coated and non-coated silicon slides were incubated with Hepes buffer containing $0.5 \mu \mathrm{M}$ antithrombin, rinsed with Hepes buffer and then incubated with rabit antihuman antithrombin antibody $(\| 6 \mathrm{Lg} / \mathrm{mm})$.

\subsection{Thrombin geweration in fowing blood}

The inlet of a capillary was connected to two syringes: one containing citrated whole blood and the other containing $0.2 \mathrm{M} \mathrm{CaCl}_{2}$ in Hepes buffer $\mathrm{pH} 7.45$ (20 mm Hepes, $140 \mathrm{~mm}$ NaCl). Pump-driwen syringes were set at flow rates of 54 and $6 \mu / \mathrm{min}$, respectively. Timed samples of $25 \mu \mathrm{l}$ were taken at the outlet and added to $675 \mu$ Hepes buffer containing $20 \mathrm{~mm}$ EDTA and $0.2 \mathrm{~mm}$ \$2238. The erythrocytes were removed by centrifugation and the supernatant was assayed for thrombin activity as previously described [25].

\subsection{Preparation of fibrinogen coated coverslips}

Glass coverslips were exposed for 60 min at room temperature to a solution of $1 \mathrm{mg} / \mathrm{ml}$ fibrinogen. After that the surfaces were rinsed in Hepes buffer and incubated with this buffer for 15 min.

\subsection{Platelet adhesion sfudies:}

Blood (9 vol) was collected into $0.13 \mathrm{M}$ trisodium citrata (I vol) or into a small aliquot of $40 \mu \mathrm{M}$ PPACK. Plateletwich plasma (PRP) was separated from the red and white blood cells by centrifugation at $190 \mathrm{~g}$ for 15 min. PRP was 45 min incubated al $37^{\circ} \mathrm{C}$ with 2.5 pus calcein acetoxymethyl ester in the presence of apyrase $(0.1 \mathrm{U} / \mathrm{ml})$. Reconstituted whole blood (I volume PRP mixed with I volume red blood cell suspension from the first centrifugation step) was used for the platelet adhesion study using a parallel plate flow chamber [23]. Flow experiments are performed at a flow rate of $50 \mu / / \mathrm{min}$, (wall shear rate of $25 \mathrm{~s}^{-1}$ ). Platelet adhesion was monitored in realme using an inverted microscope (Nikon diaphot 200; Nikon, Tokyo, Japan). Surace coverage with calceinmloaded platelets was measured with a combined fuorescence imaging and mierophotometric system (FIMS) connected to the microscope and conmanded by a UNIX/Quanticell-driven computer system (Applied Imaging, Sunderland, UK) [26].

\section{Results}

\subsection{Protein adsorption}

Protein adsorption was measured by ellipsom from solutions contaning various concentrations purfied albumin, $\operatorname{lgG}$, fibrinogen, antithrombin : HMWK. The amount of protein adsorbed per uni area $\left(\mu \mathrm{gg} / \mathrm{cm}^{2}\right)$ of the non-coated, PEI-, chondroitir sulphate-, alginic acid-, and heparin-coated surfaces a function of their concentration in free solution depicted in Fig. $\mathbb{1}$. For all proteins examined, adsorpi on chondroitin-6-sulphate-coated surfaces was it $10-20 \%$ of the amounts found on non-treated surfac Slightly more protein was adsorbed by alginic ac coated surfaces. In comparison to chondroitin-6-s phate-coated surfaces, heparin-coated surfaces bou relaively high amounts of fibrinogen and antithromb The relative high adsorption of antithrombin expected for a heparinized surface; the high adsorpti of fibrinogen was however rather surprising. A protein adsorption from plasma was higher for 1 heparin-coated surface when compared with the algi acid-and chondroitin-6-sulphate-coated surfaces. The data indicate that chondroitin-6-sulphate and algi acid are more protein repelling polysaccharides th heparin.

\subsection{Specificity of the antithrombin binding to heparin. coated surfaces}

Fig. I also demonstrates that a non-coated a heparin-coated surface exposed to $1 \mu \mathrm{M}$ antithromb binds about similat amounts of antithrombin: 0.47 an $0.52 \mu \mathrm{g} / \mathrm{cm}^{2}$, respectively. To investigate the specifici of this binding, a heparin solution was addled aft maximal adsorption of antithrombin was achieved. Tl amount of adsorbed antithrombin prior to and after $t$ addition of heparin are summarized in Table 1. The data clearly show that in case of the heparinized surfac $35 \%$ of initially absorbed antithrombin desorbed fro the surface, suggesting that only part of antithrombin reversibly bound to immobilized heparin. Most of it: antithrombin (about $65 \%$ ) binds apparently irreversib and non-specifically to the heparin-coated surface. non-coated surface apparently adsorbs antithrombi irreversibly and thus not specifically.

\subsection{Analability of anithrombin on heparin-coated swrfaces}

We earlier demonstrated that fibrinogen, adsorbe from plasma on heparin-coated surfaces, is rapid! displaced by other plasma proteins [23]. Because th thromboresistance of heparin-coated surfaces relies a least in part on the ability of adsorbed antithrombin ti 

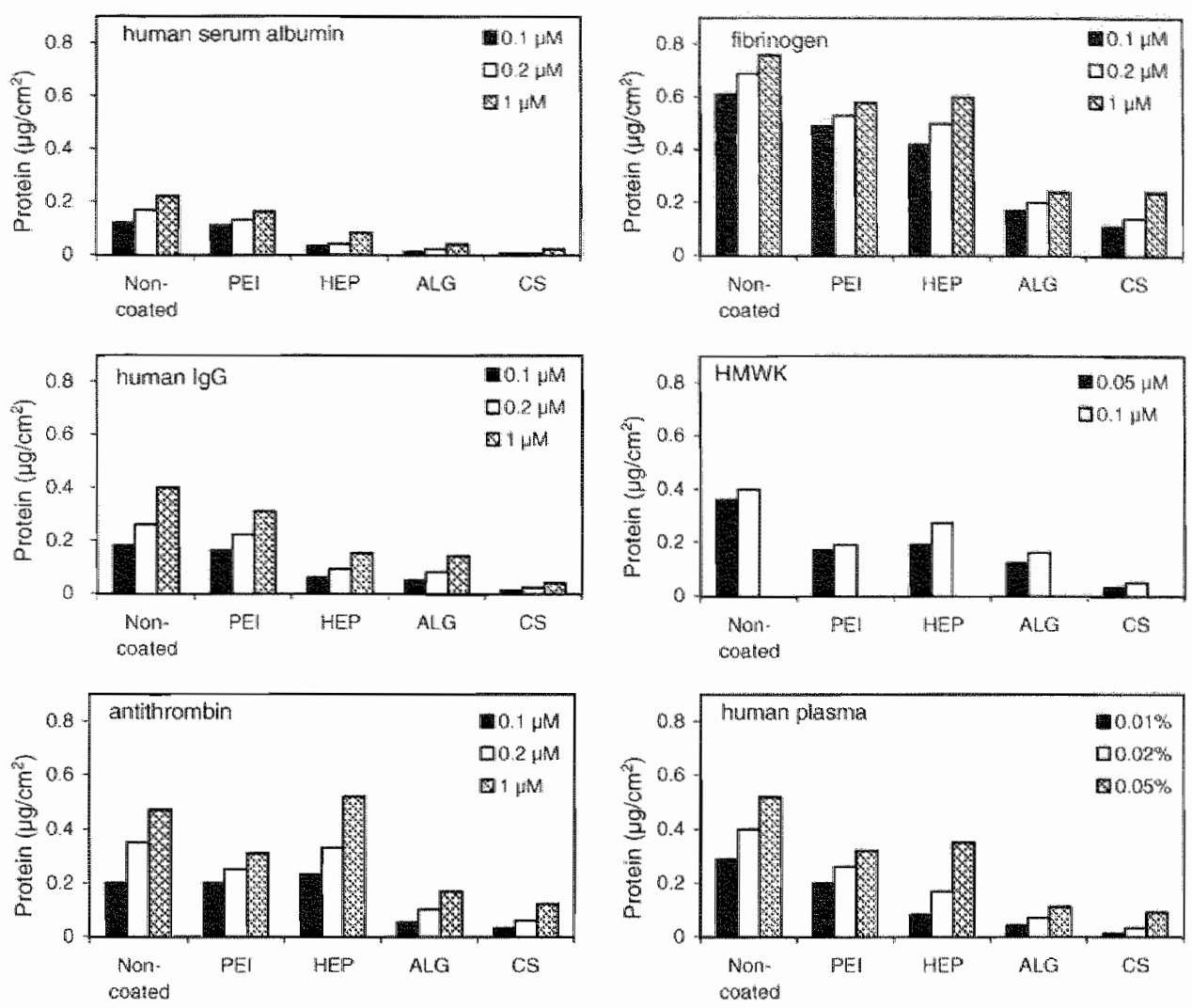

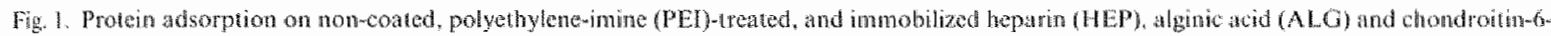
sulphare (CS) silicon surtaces

Tabic 1

Displatement of surface-bound artilhrombin by free heparin

\begin{tabular}{|c|c|c|c|}
\hline \multirow[t]{2}{*}{ Addition } & \multirow[t]{2}{*}{ Conc. } & \multicolumn{2}{|l|}{ Protein adsorption } \\
\hline & & $\begin{array}{l}\text { Non-coaled } \\
\left.\text { surface (1.g/ } \mathrm{cm}^{2}\right)\end{array}$ & $\begin{array}{l}\text { Hepariu-contcd } \\
\text { surface }\left(\mu \mathrm{cm} \mathrm{cm}^{2}\right)\end{array}$ \\
\hline Ancthrombira & 1. HM & 0.43 & 0.41 \\
\hline Fepartin & $10 \cup \mathrm{ml}$ & 0.43 & 0.28 \\
\hline theparien & $20 \mathrm{Um}$ & 0.43 & 0.26 \\
\hline
\end{tabular}

inactivate coagulation enzymes, it is important to know what fraction of antithrombin bound to immobilized heparin can be displaced by other plasma proteins. Fig. $2 A$ shows that a non-coated surface that was first exposed to plasma and then incubated with antianithrombin antibody apparently did not adsorb more protein (curve a). In contrast, a significant amount of IgG from the anti-antithrombin antibody solution adsorbed to a heparinized surface. These findings indicate that the protein layer deposited from plasma on a heparinized surface retains antithrombin, while the protein layer on non-coated surfaces does not. A control experiment as shown in Fig. $2 \mathrm{~B}$ reveals that a non- specific rabbit $\lg G$ did not adsorb to heparin-coated and non-coated surfaces that were pretreatled with $0.5 \mu \mathrm{m}$ antithrombin. However, when the antithrombin pretreated surfaces were incubated with rabbit antihuman antithrombin $\lg G$, the amount of adsorbed protein significantly increased in both cases, It is our conclusion that if antithrombin adsorbs from plasma on noncoated surfaces it is rapidly displaced by other plasma proteins. We found that antithrombin was also teadily displaced on alginic acid-en chondroitin-6-sulphatecoated surfaces when these surfaces were exposed to plasma (data not shown). Together, these findings inply that antithrombin is only available in plasma protein layers when the surface is coated with heparin. This notion is in agreement with an earlier report that demonstrated that histidine rich glycoprotein competes with antithrombin for immobilized dermatan sulphate and chondroitin sulphate but not on heparan sulphate with high affinity for antithrombin [27].

\subsection{Plarelet adhesion for forning whole blood}

We next examined platelet adhesion from flowing whole blood that was anticoagulated with the 

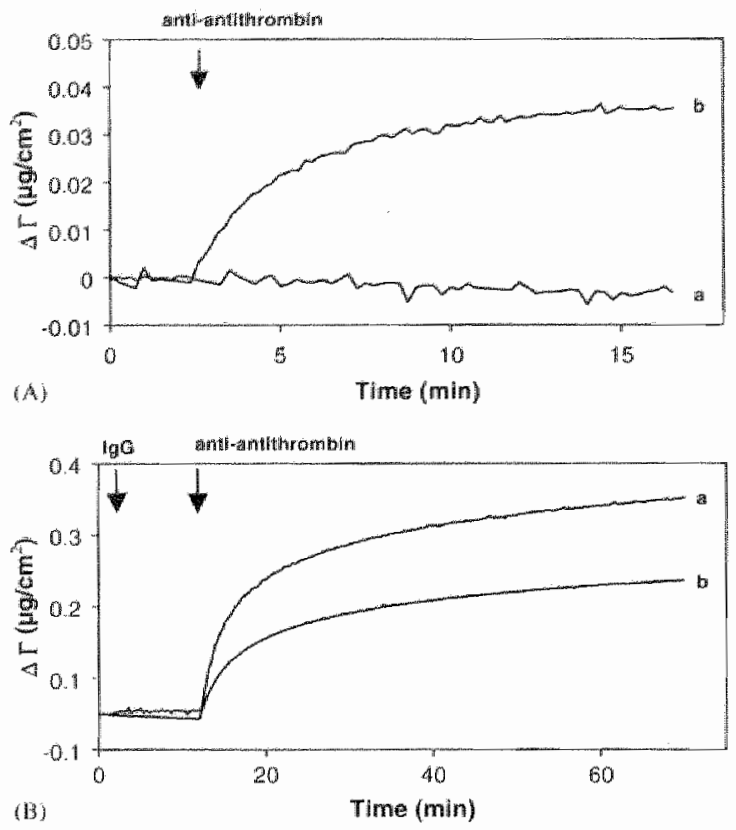

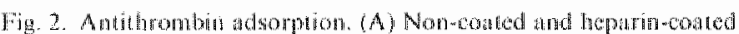

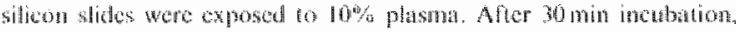

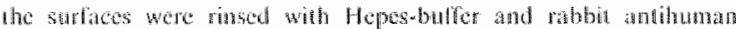

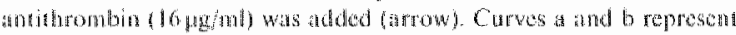

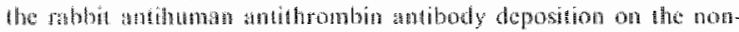

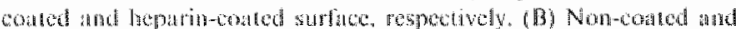

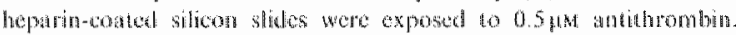

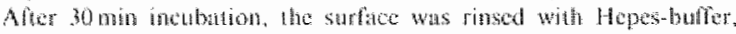

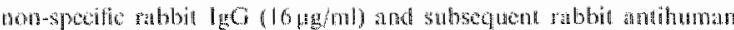
antithrombin (16ughot) were addeat. Curves a and b represend the antrody daposition on the non-comed and heparmaned surbace. respecively

thrombin inlibitor PPACK. Fig. $3 A$ shows that platele adthesion was almost negligible for all surfaces except for the posilively charged PEI-coated surface. We previously demonstrated that the protein layer adsorbed from undiluted plasma on hydrophilic surfaces does not contain fibrinogen $\llbracket 23]$. To confirm the notion that fibrinogen adsorbed from plasma is readily displaced by other plasma proteins, polysaccharide conted surfices were first exposed to purified tibrinogen and then to flowing PPACK-anticoagulated whole blood. The increase in surface coverage with adherent platelets as a function of the perfusion time is shown in Fig. 3B. Non-conted surfaces bind the most platelets, followed by heparin. PEI- and alginic acidroated surfaces. No platelet adhesion was observed on chondroitin-6-sulphate-coated surfaces. Preadsorption with fibrinogen did not affect the platelet adhesion capacity of PEI=coated surfaces, suggesting that platelet adhesion to this surface is fibrinogen independent.
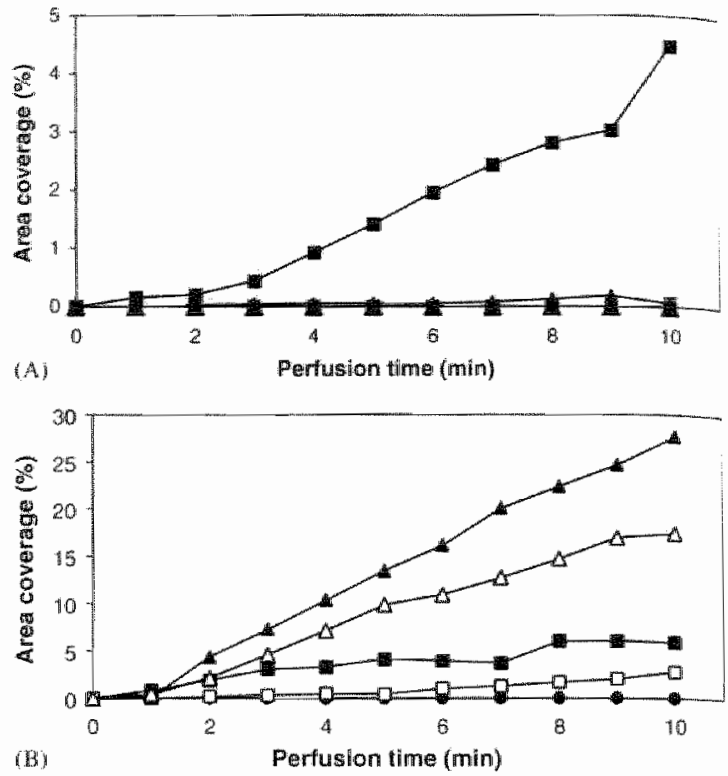

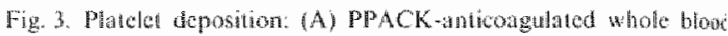

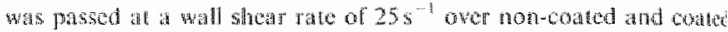
ghts coven conted cowersips were pretreted with hbrnogen $60.1 \mathrm{mg} / \mathrm{m}$ turm

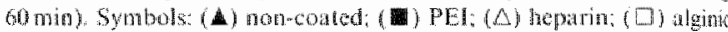
acd, and ( chondrotin-6-sulphate

\subsection{Thrombin generation in flowing whole blood}

Overall thrombogenicity was assessed in a global assay that measures thombin generation at the artificia surface in contact with flowing recalcified whole blood The highest thrombin production was observed for noicoated surfaces (Fig. 4). As a matter of fact, in this case clot formation at the outlet of the tube was seen $10 \mathrm{~min}$ after the stan of the perfusion. Significant thrombin generation was also measured for PEl-coated surfaces, albeit at a much slower rate. Polysacharide-coated surfaces showed the least thrombogenic activity. In case of the heparinized surface thrombin generation was virtually absent during a 1 .h perfusion with recalcified whole blood. Interestingly, both alginic acid and chondroitin-6-sulphate-coated surfaces also show very little thrombin generation. Because these polysaccharides do not catalyze thrombin inactivation, it is assumed that thromboresistance of these surfaces is associated with their protein and platelet repeling properties.

\section{Discussion}

This study demonstrates that polysaccharide coatings greatly reduce the thrombogenicity of artificial surfaces when measured as surface-associated thrombin 


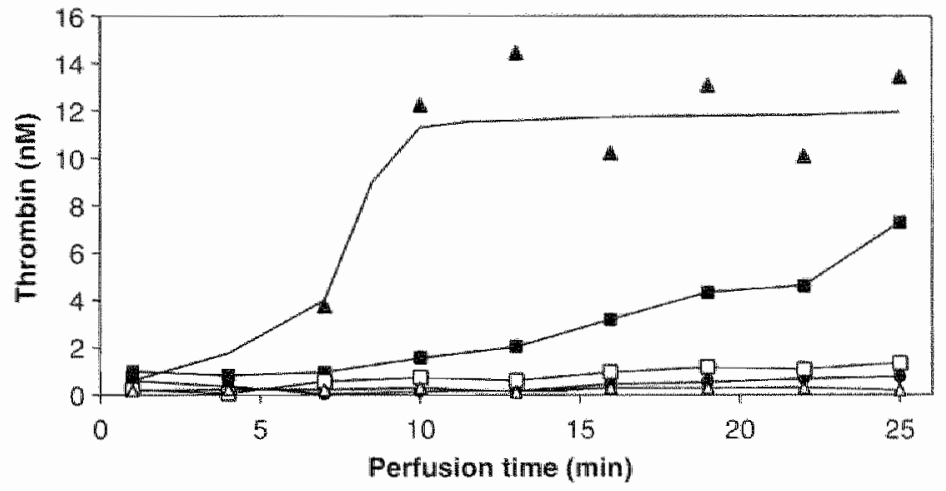

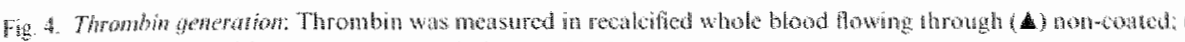

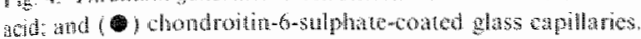

generation. Protein adsorption and platelet adhesion properties of these polysaccharides, however, markedly differ. Heparin-coated surfaces adsorbed the highest amount of (plasma) proteins, whereas chondroitin-6sulphate and the non-sulphated polysaccharide alginic acid adsorb rellatively small amounts of plasma proteins. Platelet adhesion was closely associated with the fibrinogen binding capacity of these surfaces but only when the surfaces were incubated with puriffed fibrinogen prior to exposure to flowing whole blood. Under these conditions non-coated, PEL-coaled and heparincoated surfaces accreted much more platelets than chondrotin-6-sulphate and alginic acid-coated surfaces. Surfaces that were directly exposed to flowing blood did, with the exception of the PEI-coated surface, not adhere platelets. Thus, the fibrinogen adsorption capacity of artificial surfaces apparently does not predict their platelet adhesion properly. The rapid displacement of fibrimogen in the protein layer at the surface-blood interlace apparently prevents the accretion of platelets $[23,28]$

In spite of the apparent absence of platelet adhesion. the thrombogenic activities of the examined surfaces differ grastly when assessed from their thrombin generating potential. Taking into account that platelets are indispensable for thrombin generation and thrombus formation (reviewed in [29]), the physiological sense of in vitro platelet adhesion sudies, even when flowing whole blood is nsed, should be questioned. It is apparent that evaluation of the inrombogenicity of artificial surfaces should be performed under conditions that allow thrombin generation. Presently, we can only speculate about how coatings of immobilized polysaccharides reduce the thrombogenic activity of artificial surfaces. We previously reported that a rapid inactivation of surface-localized thrombin by antithrombin bound to immobilized heparin is likely the most effective way to prevent further thrombin generation and thus thrombus fomation artificial surfaces [30]. The present work strongly supports this notion. Antilhombin adsorbs readily to all surfaces, but, with the exception of heparin-coated surlices. no antithrombin could be detected in the proten layer loal was deposited from flowing plasma. It is apparent that in these cases antithrombin is readily displaced or masked by other plasma proteins. Importanly, antithrombin bound 10 imnobilized heparin can apparently not be displaced and retans tits anticongubant activity. It appeared that a small fraction of total bound ant thrombin (about $35 \%$ ) could be displaced by adding free heparin, indicating that most of the antithrombin is not heparin bound. Yet, this fraction of heparn-bound anthrombin seems to be extremely efficient lo abrogate thrombin formation at artificial surfaces. The two important feilures that can explain this efficiency are: (1) thrombin plays a critcal role in its own generation (reviewed in [31]), and (2) Lowlizing antithrombin noar the site of thrombin generation greatly eliminates the transpor limitations in the thrombin-antithrombin reaction.

Immobilized atginic acid and chondroith-6 sulphate atre devoid of antithrombirs achivity and yet makes an artificial surface thromboresistant. We note, however. that blood coagulation is initated in a plateletindependent mamer. namely by tissue fatctor or by activation of the contact factors at negatively charged artificial surfaces. One of the proteins involved in the intiation phase of blood coagulation is $H M W K$. During the propagation phase thrombin converis fibringgen into fibrin, which in turn is essential for platelet adhesion and activation \$32]. Interestingly, when compared with non-lrealed surfaces alginic acid and chondroitin-6r-sulphate coated surfaces adsorb relatively small amounis of both HMWK and fibrinogen. It is therefore reasible that this low protein adsorption acts synergistically in reducing thrombus formation at these surfaces. 
From an interfacial physical-chemical point of view it is important to appreciate that the charged polysaccharides were immobilized by muli-point atuachment directly on the PEll layer. This way of linking is expected to yield a fat." "side-on"s configuration of the polysaccharides on the surface [33]. It is known that the nature of polysacchande-surface coupling affects the architecture of the aqueous interface and, as a consequence, the propertieg of the surface layer [34]. Thus, the data stemming from this work can be considered as a wseful first step towards the building up of a structure-properties database, aimed at the fine tuning of surfaceimmobilized polysaccharide layers. Our work further implies that if a high surface density of immobilized hepatin exerts an adverse effect like stimulation of neointima Cormation, mixtures of heparin and low sulphated (chondroitin-6r-sulphate) or non-sulphated polysaccharides (alginic acid) could be an interesting alternative to improve the haemocompatibility of artificial surfaces.

\section{Conclusions}

Numerous materials have been used to coat artificial surfaces in an attempt to reduce their inherent thronbogenicity. Coatings with naturally oceurring bioactive or bioinert substances like heparin and phosphorylcholine, respectively, improve biocompatibility by preventing the activation of blood conponents such as platelets and coagulation factors. In vitro thrombogenicity testing includes often protein adsorption and platelet adhesion. A major drawback of these testing algorithms is that they are performed in the absence of thrombin generation. Our present work demonstrates that the results from protein adsorption and platelet adhesion studies not necessarily predict the thrombogenicity of materials. In contrast to the lower sulphated polysaccharides, alginic acid and chondrotin sulphate, immobilized heparin as used in this study is not protein repelling and interacts with platelets when preincubated with purified fibrinogen. Yet, when recalcified whole blood is perfused through capillaries with a heparin coating. thrombin generation remains below the detection limit. In contrast, capillaries coated with the other supthated polysaccharides showed a partial thromboresistance. Although all surfaces adsorbed antithrombin from a purified protein solution, albeit to different extent, only heparinized surfaces adsorbed antithrombin from fllowing whole plasma. It is evident that the thromboressitant ptoperty of heparinized surfaces relies on neutralization of locally formed thrombin by surfacebound heparin-antithrombin bound complexes. The thromboresistance of alginic acid- and chondroitin sulphate-conted surfaces is most likely due to reduced protein adsorption, which in turn results in a reduced contact activation of the coagulation system.

\section{References}

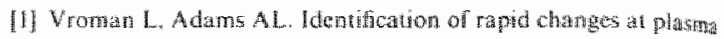

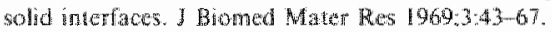

[2] Zhang M, Desesi $T$, Fertari M. Proteins and wells on Pro unmobilued silicen surfaces. Biomateriats 1998;19,957 69.

fl Tanaka M. Molonura $T$, Kanada M. Amza T. Kasan Shiraya T. Shmarat K. Onishi M, Mochizuki A. Bloga compatible aspects of polye-methoxyethylacryate) (PMEA) relationship between proterin sudsorption and platefet andhesiof Dn PMEA surface. Bionateriats 2000:21:1471-81.

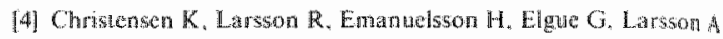
Heparin cotang of the stent graft-effects on plateds coagulation and complement actiration. Bomaterals 2004 .2 $349-55$

151 Crowthe MA, Ginsherg JS. Hirh 1. Practical aspects o anticoagulant therapy. In: Colman $\mathbb{R}$ W. Hirsh $\mathrm{J}$. Mardar W. Clowes AW. George JN, cditors. Henostasis and thrombosis Basto principles and ollinical practice. Philadelphia: Lippincot Willams and Wikins, 2001 p. $1497-516$.

$16 \rrbracket$ Mulloy B. Moura PA. Gray $\mathbb{E}$. Strucioreflindion shadies a arteoaggame sulphated polysachardes using NMR. I Biotch. nol $2000 ; 77: 12335$

[7] Biork 1, Lindath U. Mechaniste of the anticatgulant action of hopantur. Mol Coll Biochen 1982-48: $161-82$

[8] Mourao PA. Giumaraes B. Mulloy B. Thomas S, Gray E Antithrombonic activity of a fucosylated chondroitin sulphate from edithoderm: sulphrated freose brancines on the polysuchat. ide acoonnt for its antithrombotic acion. Br $\mathrm{J}$ Hacmatol $1903,10: 647 \ldots 52$.

[9] Huber R. Carrell RW. Inmalications of the Unree-dimensional structure of alphat 1-antilrypsin for serture and futction of serpins. Biochentsity $1989 ; 28: 8951-66$

[llo] Potcmpa f. Korzus E, Trawis J. The sempin supertamily of proteinase inhibitors structure, function, and reguataion. J Biol Chern 1994:269:15957-60.

[1]] Liaw PCW, Becker DL, Stafrorid AR, Fredenburgh JC, Weic d!. Molecular basis for the susceptibility of fibrin-bound thrombin to inactivation by heparin cofactor II in the presence of dermatan sulfate but not heparia. J Biol Chen 2001:276:20959-65.

[12] Hirsh J. Warkentin TE, Shaughessy SG, Anand SS, Haperin JL. Rascloke $\mathbb{R}$, Granger C. Olman EM. Dalen JE. Heparin and tow.

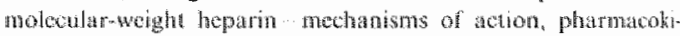

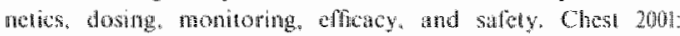
$119: 64: 54.45$

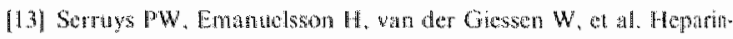
coated Patrax-Schats stents in human comonary arteries. Early outconne of the Benestone-1f pilon study. Circulation 1996,93 41222

[14] Wentel HP. Weber M. Ziender G. Adsorption of plasma proteita

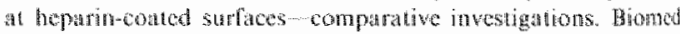
Technol 2000,45:282-7

[15] Lens JP. Tertingen JG, Enghers GH, llejen J Prepatration ont heparin-like surtaces by indroducing sulfate and cabboxylate groups on poly(ethylene) tangh an argon plasmat treatment. 1) Biomatch Sci Polym Ed 1998;9\%357-72.

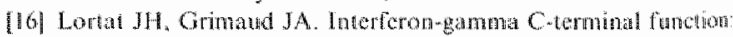
new wokking hypothesis. Heparan sulfar and heparin, new targets for IFN-gamma, protoc. relax the cytokine and regulat its activy. Cell Mol Biol $1991 ; 37: 25360$

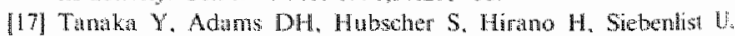
Shaw S. Thedl adhesion induced by proteoglyean-immobilized cytokine MUP-I biata Nature 1993;36479-82.

[18. Nelson SR, doSouza NM, Allison Dy. Endowasculatr stents and stent-grals: is heparin coating desirable? Catdiovasc Interent Ratiol $2000 ; 23: 252-5$. 
(19) Tapon Bretaudien 1, Drowet B. Matou S, Mourio PA. Bros A. Letoumear D. Fischer AM. Modulation of wascular human endoknelial and rat smooth muscle cell growth by a fucosylated chondroun sulfate from echinoderm. Thromb Haenost $2000,84332-7$.

[30) Rehm BH, Valla $\mathrm{S}$. Hacterial alginates: biosynthesis and applicam tons. Appl Microbiol Biotethnol 1997:48:281-8.

121) Segal HC. Hont BI, Oilding $K$. The effects of alginate and nonalginate wound dressings on blood coagulation and platelet actiration. J Biomater Appl 1998;12:249-57.

(22) Thater E. Schmer G. A simple two-step isolation procedure for thuman and bovine antithrombio filll (heparin dofactor) a comparison of wo methods. Br I Haemato 1975,3123344 .

133) Keuren JFW, Wielders SHH. Whllems OM. Morra M. Lindhout $T$. Pibrinogen adsorption, platele adhesion and thrombin genera. ton an heparinized surfaces exposed to fowing whole blood. Thront Hamost 2002:87:742-7.

124n Cuypers PA. Corsel JW, Janssen MP. Kop JM. Hemens WT. Hemker HC. The adsorption of prothrombin to phosphatidylserine multefayes quantiated by ellipsometry, I Biol Chem $198325852426-31$.

25l Schoen P. Lindhout T, Willems G. Hemket HC. Cominums flow and the prothombinase-catalyzed activation of prothrombin. Thromb Hacmost 1990;64:542-7.

29. Heenakerk JWM, Vuist WMU, Feijge MAH, Rentelingerperger CPM, Lindhou T. Collagen but not fibringgen surfaces induce bicb formation, expostre of phosphatidylserine, and procoagu-

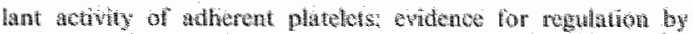

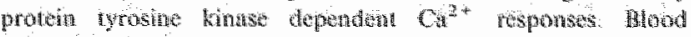
$1997,902615-25$

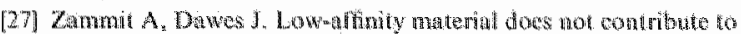
the antithombotic actury of Orgaran (Org 10172 in human ptama. Thromb Haenost 199,4,71:759-67.

[28] Horben TA. Mass action whets on compelitive adsarphoh of

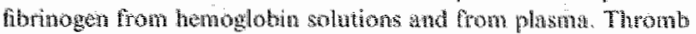
Haemost 1984;51:174-81.

[29] Heenskerk IWM. Bevers EM Lindhou T. Platelot aetionion

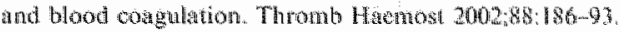

[30] Blezer R. Fouthe B, Willems OM. Lindhot T. Aetivation of

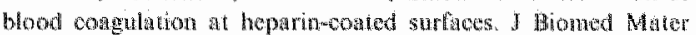
Res $199 \% 37: 108,13$

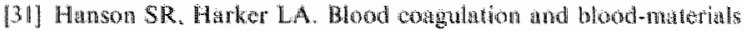
intertetions. In: Ratner BD, Hoftman AS, Schoen Fil, Lemons JE, editors. Blomaterials Scienes: an introducton to mante bils and medicine. San Diego: Acadente Press. 1906. p. 19,3.200.

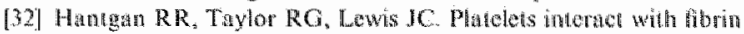
only after activation. Blood 1985;65:1299-311.

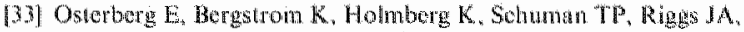

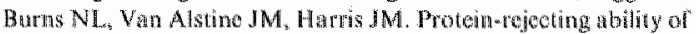
surface-botand dextran in endon and side-on confagmations:

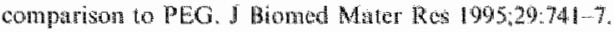

[34] Morta M, Cassinall $C$. Hydrophitic polysachande ocatings In:

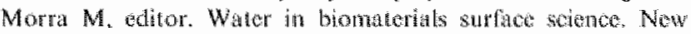
York: Wiley, 2001. p, 353-87. 


\section{Covalently-bound heparin makes collagen thromboresistant.}

Arterioscler Thromb Vasc Biol. 2004;24:613-7 


\title{
Covalently-Bound Heparin Makes Collagen Thromboresistant
}

\author{
Jeffrey F.W. Keuren, Simone J.H. Wielders, Anita Driessen, Michel Verhoeven, \\ Marc Hendriks, Theo Lindhout
}

Objective-Blood compatibility of artificial surfaces depends on their immunogenic and thrombogenic properties Collagen's weak antigenicity ritakes it an attractive candidate for stent coatings or fabrication of vascular grafts However, the thrombogenic nature of collagen limits its application. We examined whether heparinization can mak collagen more thromboresistant.

Methods and Results-Collagen was heparinized by crosslinking collagen with extenisively periodate oxidized hepari and/or by covalently bonding of mildly periodate oxidized heparin. Both ways of heparinization have no effect of platelet adhesion and could not abolish induction of platelet procoagulant activity. However, thrombin generation wa completely prevented under static and flow conditions. The functionality of immobilized heparin was confirmed by specific uptake of antithrombin, $13.5 \pm 4.7 \mathrm{pmol} / \mathrm{cm}^{2}$ and $1.95 \pm 0.21 \mathrm{pmol} / \mathrm{cm}^{2}$ for millly and heavily periodate heparin, respectively.

Conclusions - These results indicate that immobilization of heparin on collagen, even as a crosslinker, is a very effectiv way to prevent surface thrombus formation. These data encourage the application of heparinized collagen as stent-graf material in animal and eventually human studies. (Arterioscler Thromb Vasc Biol. 2004;24:613-617.)

Key Words: collagen heparin thrombogenicity thrombosis blood flow

\begin{abstract}
$\mathrm{C}$ ardiovascular disease, including vascular stenosis, is still the leading cause of death in Western society. Obstructive atherosclerolic disease, casusing angina pectoris or even myocardial infarction, is currently treated by the implantation of a stent or through bypass surgery. Unfortunately, attempts to implant vascular grafts with a small diameter are not successful because of thrombotic and inflammatory reactions. 6 Thus, to enhance blood compatibility, a surface has to be designed that is both anti-immunogenic and thromboresistant. Collagen has been widely used in medical applicalions, including skin replacenent, bone substitutes, and artificial walvess ${ }^{2.3}$ Recently, a number of investigators attempted to use modified collagen as a vascular graft material. ${ }^{3-12}$ Potentiat itdvantages of the natural biological polymer collagen are ils weak antigenicity and high tensile strength, which can resist high arterial blood pressures. Furthemore, collagen is a suitable substrate for endothelial cell growth in vitrog ${ }^{11}$ which makes is application as an artificial vessel even more attrative. Nevertheless, the prothrombotic properties of collagent" ane a major drawback in its applicability in blood contacting deviees.

To make collagen more thromboresistant, Wissink et al ${ }^{\text {th }}$ coupled the sultated polysuccharide, heparin, to collagen. An in vitro assaly slowed that the immobilized heparin was
\end{abstract}

functionally active as it accelerated the thrombin antithrombin (AT) reaction. In addition, this group demon strated that crosslinking of collagen thad an adverse effect on the antigenicity and degradation rate of collagen, but stims lated endothelial cell adhesion and proliferation. ${ }^{1.12} \mathrm{Th}$ suitability of collagen as a vascular graft material was alst emphasized in a rabbit study, which established that collagen grafts were completely endothelialized after one month ol implantation. ${ }^{10}$

This study was undertaken to get a better understanding of the precise antithrombotic functions of immobilized heparin Three types of heparirized collagen (heparin-crosslinkes collagen, heparinized hepatin-crosslinked collagen, and hep arinized EDC/NHS crosslinked collagen) were evaluated for their thrombogenicity by measuring platelet adhesion, platele activation, and thrombin generation.

\section{Methods}

\section{Preparation of Collagen and Heparinized Collagen Sheets}

Four differem types of type I collagen (Syntacoll) sheets were prepared; namely, noncrosslinked collagen (NC). heparim crosslinked collagen (HC), heparinized EDCN NHS-crosslinked col

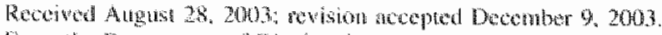

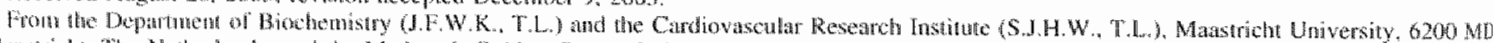

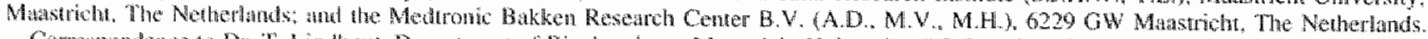

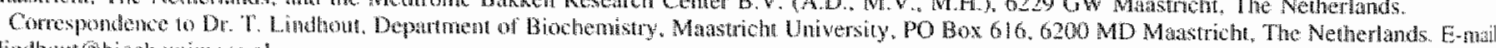

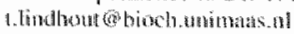




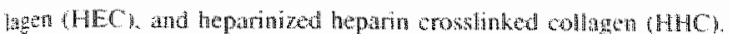

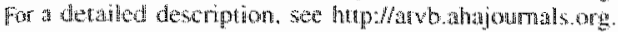

\section{Heparin Assay}

In all (staric) experimems collagen and heparinized collagen shots.

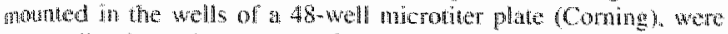

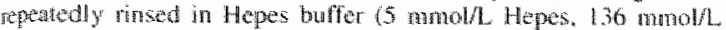

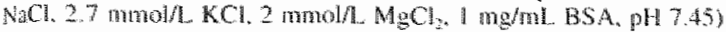
fo remove unbound heparis. The anoun of heparin in the rimsewher whs massured by adding a $30 \mu \mathrm{L}$ aliquor into $112.5 \mathrm{HL}$ AT

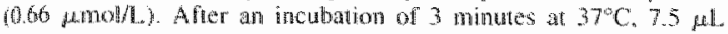

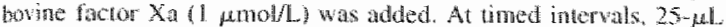
samples were lransferred bro it cuvette contanimg $425 \mu \mathrm{L}$ Hepes buter confianing 20 mmol/L EDTA and $50 \mathrm{\mu L}$ chromogeric sublithe $\$ 2765$ (2 mmoll. Chromogenix). The amount of heparin was calculated from the ate al disappenance of the fretor $\mathrm{X}$ at

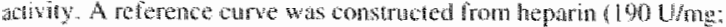

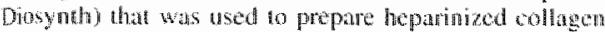

\section{Platelet Adhesion and Procoagulant Activity}

Venot: blow was obianded from wolunters who denied taking any medication in the 2 week before sumpling. Washod platelets were

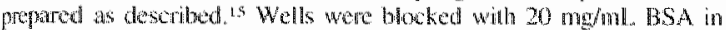
Hepes butfer. A 1.-mL suspension of washed platelets $\left(3 \times 10^{\circ}\right.$ plateles was then added 10 oolagen and heparinized colagen filmos in a 48 -well macoliter plate, and nonbond phateles were remowed atich an incubatisn of 45 minutes at roon tempersture under statonay bonditions. For scanting eloctron maroscopy (SEM) anatysis, olligen sheets were

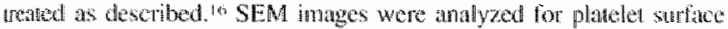

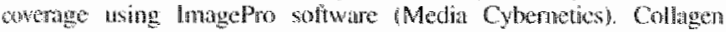

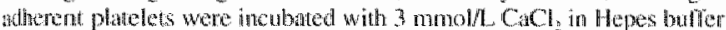
for 15 minutes. This was followed by incubetion with $1 \mu \mathrm{g} / \mathrm{wL}$. Oregon Geen-labeled annexin $V$ (NeXins) and 3 moroll. $\mathrm{CaCl}_{2}$ in Hepes bufter. Nonbound and $\mathrm{V}$. was remowed wh thepes buffer containjug 3 mmol/t $\mathrm{CaCl}_{2}$, and patelet bownd antexin $\mathrm{V}$ was eluted in Hepes

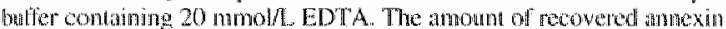
$\checkmark$ was meastred in a spectrofloroneter (SLM) wath exciation wab-

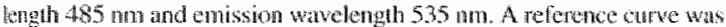
axistructed witt known anouns of Oregon Grentaheled annexin $V$.

\section{Determination of Specific Antithrombin Binding to Heparinized Collagen}

Specific binding of $\mathrm{A}^{\prime \prime}$ to heparinized collagen was determined ats

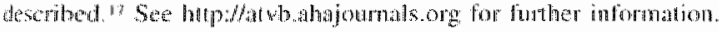

\section{Thrombin Generation}

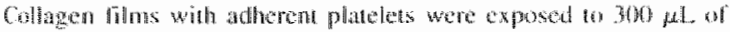

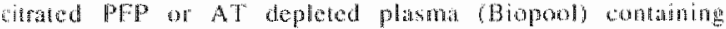

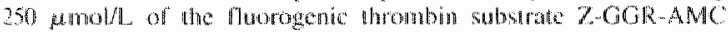

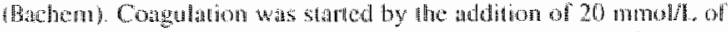
CiCl. Fluoresence tareings as a resull of thronbingeneration were

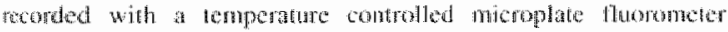

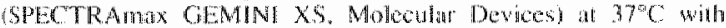

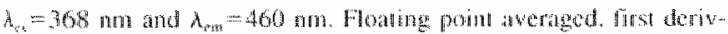

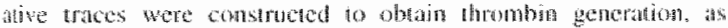
dexclithed by Howker at al th

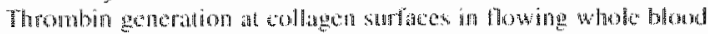

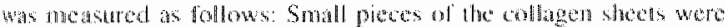

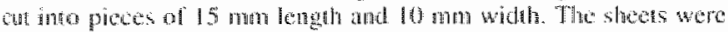

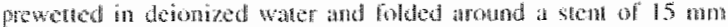

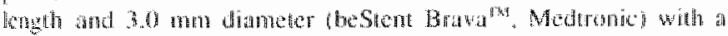

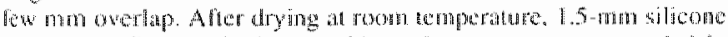
finges were lixed at both ends. Next, the sents were expanded is

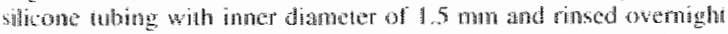
will Hepes butrer an allow rate or $500 \mu \mathrm{l} / \mathrm{m}$ in to remove nombout

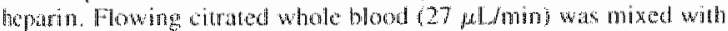

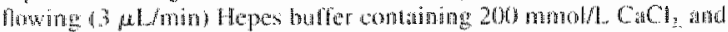

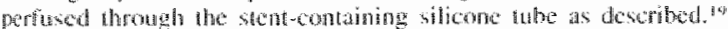

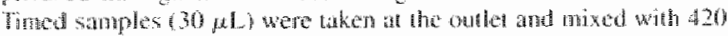
$\mu \mathrm{L}$. Hepes butfer containimg $20 \mathrm{mbol} / \mathrm{L}$ CDTA and $200 \mu \mathrm{moh} / \mathrm{L}$.
A

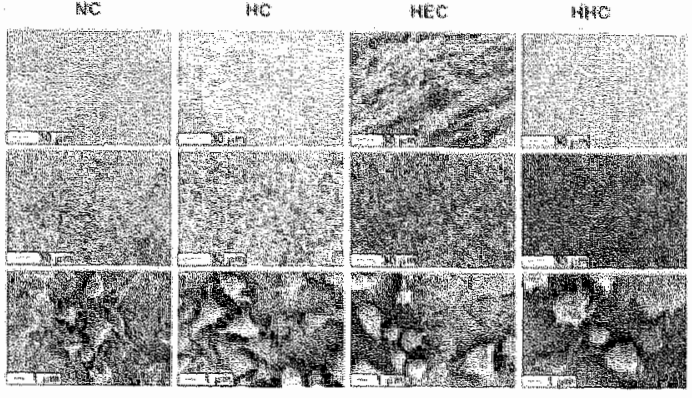

B

35

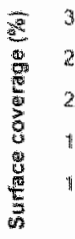

30

25

20

15

过

5

H
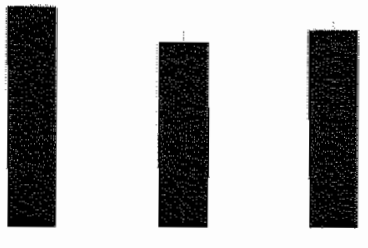

HEC

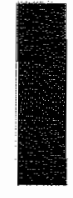

HHC

Figure 1. Adhesion of platelets to heparinized coliagen fillnts. A, SEM images of nomcrosslintked collagen MC), collagen crosslinked with heparin (HC) "collagen crosslinked with carbodimide and additional heparin treatmen (HEC), and colkgen crossinked with heparin and additional heparin treatment (HHO) before (top) and after platelet adhesion (midd and bottom). B. platelet surface coverage as a percentage of total area. Shown are mean $\mathrm{SDD}$ of at least 10 different fields

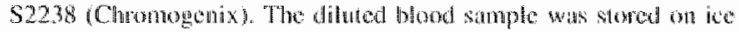
for the duration of the flow experiment and subsectumilly centriluged at 10,000 mon for 20 seconds. The supernatiant was assotyed for thrombin: ateivity as described."20

\section{Statistical Analysis}

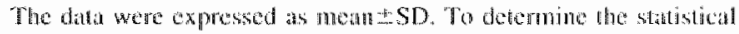

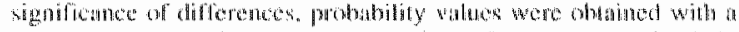

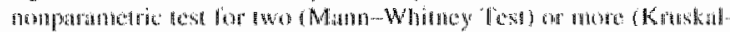
Wallia Fesh iphelependen variables.

\section{Results}

\section{Effect of Heparinization on Platelet Adhesion}

Prior to experimentation, collagen filmu were cxtensively rinsed to remove any nonbound heparin. Heparin in the effluen was assatyed as described. The colllagen films were then incubated with washed platelets. Platelet adhesion was assessed from SEM micrographs (Figure $1 A$. middle), It is clearly seen that all adherent platelets formed pseudopods (Figure $1 \mathrm{~A}$, bottom). No significant differences in platelet adhesion to $\mathrm{NC}, \mathrm{HC}, \mathrm{HEC}$, and $\mathrm{HHC}$ were observed, indicating that heparinization of collagen does not affect platelet adhesion (Figure $1 \mathrm{~B}$ ).

\section{Effect of Heparinization on Collagen-Induced Platelet Procoagulant Activity}

Collaten-adherent platelets were examined for their lows of plasma membrane phospholipid asymmetry, unitiong the property of annexin $V$ to bind only to cell membranes 
Anmexin V Binting to Collagen-Adnerent Platelets

\begin{tabular}{|c|c|c|}
\hline \multirow[b]{2}{*}{ Suface } & \multicolumn{2}{|c|}{ Annexili v sanding } \\
\hline & $\begin{array}{c}\text { Ahrence of Piatelets } \\
\text { nog/surface }\end{array}$ & $\begin{array}{l}\text { Pressence of Pllatedefts } \\
\text { (rofsurface) }\end{array}$ \\
\hline $\mathrm{ME}$ & 0 & $44.4+20$ \\
\hline $\mathrm{HC}$ & 0 & $47.5 \pm 10.3$ \\
\hline HEC & 0 & $26.9+7.4$ \\
\hline HHC & $4.4 \pm 4.7$ & 28.2 .2 .5 \\
\hline
\end{tabular}

Data are mean $\pm \mathrm{SO}$ of three indegendent experimemts $(n=5$.

containing anionic phospholipids such as phosphatidylserine. 21 The collagen surfaces, except $\mathrm{HHC}$, did not bind annexin $V$. No significant difference could be observed in the amount of annesin $V$ bound to platelets on $\mathrm{NC}$ and $\mathrm{HC}$ $(P=0.42$, Mam-Whiney test), indicating that multi-point coupled heparin, when used as a crosslimker of collagen, does not prevent the collagen-induced activation of adherent platelets (Table 1). However, annexin V binding was significantly reduced for HEC and HHC surfaces with adherent platelets $(P \leq 0.01$, Kruskal-Wallis test). It is apparent that immobilization of heparin, using mildly periodate oxidized heparin. partially inhibits collagen-induced exposure of anionic phospholipids in the outer leaflet of the platelet plasma membrane.

\section{Antithrombin Binding}

The AT binding capactices of the different collagen surfaces are shown in Figure 2. The NC surface bound hardly any AT $\left(0.09 \pm 0.08 \mathrm{pmol} / \mathrm{cm}^{2} \mathrm{n}^{3}\right)$. When the collagen surfaces contained heparin, either as crosslinker (HC) or immobilized on crosslinked collagen (HHC or HEC), sigmificant amounts of AT bound to these surfaces. HC bound $1.95 \pm 0.21 \mathrm{pmol} / \mathrm{cm}^{2}$ AT, which is about 25-fold more than NC. Interestingly, heparinization of HC greatly increased the AT binding capacity $\left(23.8 \pm 4.1 \mathrm{pmol} / \mathrm{cm}^{2}\right)$. It is very likely that the mild periodate oxidation procedure used to immobilize heparin to the HC preserves the binding sites for AT to a latger extent than the modification of the crosslinker heparin. This notion is stapported by the finding that HEC also binds relatively high amounts of $\mathrm{AT}\left(1.3 .5 \pm 4.7 \mathrm{pmol} / \mathrm{wm}^{2}\right)$.

\section{Thrombin Generation at Collagen Surfaces under Static Conditions}

Colligen surthes with atherent platelets were exposed to resatcilved citrated platelet-free plasmis, and thrombin gener-

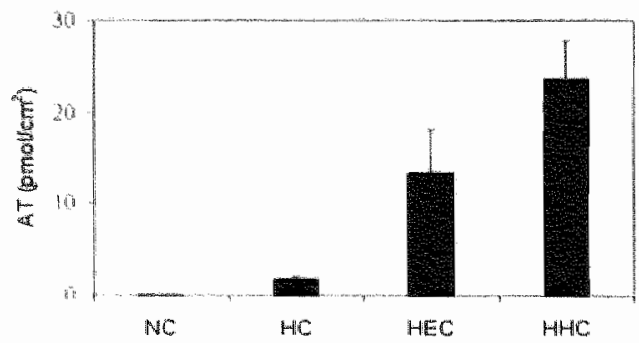

Figure 2. Binding of antithrombin to immobizzed heparin. NC. HC. MEC, and HHC were incubated wh AT (5 umol/L) for one hour, Unbound AT was removed and bound AT was eluted with heparin and ouantified isee http:/atwb.ahajoumals org for more details, bata are mean $\mathrm{SO}$ of three independent experiments.

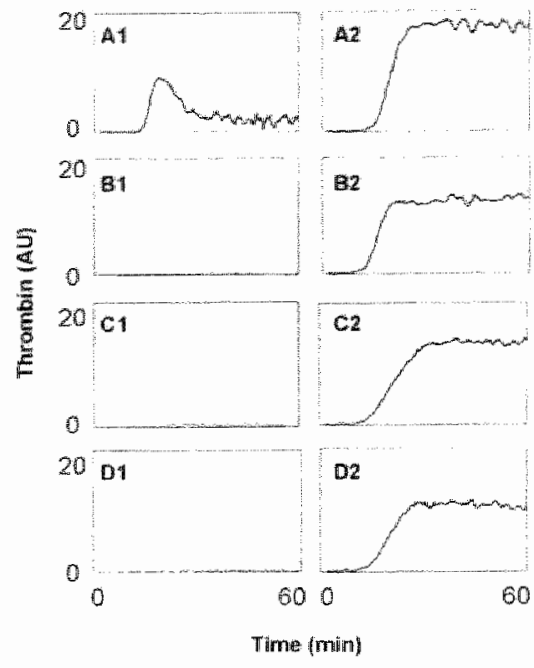

Figure 3. Thrombin generation under static conditions. Collagen and heparinized collagen films with adherent platelets were exposed to recalcified platelet-free plasma $(A)-D 1)$ or AT deficient plasma (A2-D2) containing the fluorogenic thrombin subsitrate Z-GGR-AMC. Thrombin formation on NC (A), HC (B), HEO $(C)$, and $\mathrm{HHC}(\mathrm{D})$ are shown as a function of tirne:

ation was continuously monitored as described. It was firs established that under the conditions of the assay, collagen does not generate thrombin in the absence of adheren platelets. Thus, under the conditions of the experiment thrombin generation requires the presence of (activated) platelets (data not shown). When NC surfaces with adtheren platelets were exposed to PFP, thrombin activity becante detectable after a lag phase of about 12 minutes, and a preak level of thrombin was reacthed after about 20 minutes (Figure 3, left). In contrast, when the same experiment was performed with $\mathrm{HC}, \mathrm{HEC}$, or $\mathrm{HHC}$, thrombin generation was nol detected. To examine the contribution of heparin cofactor ll heparinizod collagen surfaces with adherent platelets were exposed to AT-depleted plasma. In contrast with nomat PFP significant amounts of thrombin were generated on heparinized collagen films. Maximal levels of thrombin were reached after approximately 20 mimures for $\mathrm{HC}$ and 25 minutes for HEC and HHC surfaces (Figure 3, right). The sustained levels of thrombin activity in the ase of AT-depleted plasma indicate that heparin cofactor If hardly contributes to the inactivation of thrombin in plasma. Consequently. heparinized-collagen surfaces do not inhibit thrombin generation in AT-depleted plasma.

\section{Thrombin Generation at Collagen Surfaces under Flow Conditions}

Stents were wrapped in a collagen sheet, inserted in silicone tubes (inner dianeter $1.5 \mathrm{~mm}$ ), expanded, and perlused with recalcified whole blood. Figure 4 shows the thrombin concentration measured at the outlet of the flow system as a function of the perfusion time. In the control, an empty silicone sleeve with (Figure 4, $\Delta$ ) and without (Figure 4, $\Delta$ ) atu inserted stent, traces of thrombin appeared 16 and 18 minutes after the start of the pertusion, respectively. Non- 


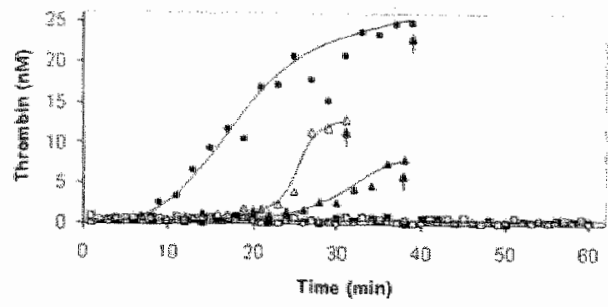

Figure 4. Thrombin generation in flowing blood in contact with collagen coated stents. Empty silicone sleeve (A), bare stent (c). and stent wrapped in a sheet of $\mathrm{NC}(\mathrm{HC}, \mathrm{HC}, \mathrm{HEC}(\mathrm{B})$. or HHC (O) were perísed with recalcified whole blood at a flow rate of $30 \mu \mathrm{L} / \mathrm{min}$. Depicted is the thrombir concentration al the outlet of the flow reactor as a function of pierfusion time. Arrows. indicate time of extensive clot formation and occlusion of the tow reactor tubing.

crosslinked collagen dramatically shortened the lag phase in thrombin generation and increased the maximal thrombin concentration (Figure 4, ). The blood pertusion had to be stopped after 40 minutes because of massive clot formation in the silicone tube, resulling in an irregular flow. Neither thrombin generation, nor blond clot formation, were detectable in silicon tubes with stents that were wrapped in collagen that had been cross-linked with heparin or heparinized after cross-linking with heparim or EDC/NHS. These findings suggest that also with flowing whole blood, multi-point attached heparin as a cross-linker by virtue of its AT binding capacity can prevent the initiation and propagation of collagen-induced thrombin generation at the surface of adherent platelets. These findings suggest that multi-point attached heparin, as a cross-linker by virtue of its AT binding capacity, can also prevent the initiation and propagation of collagen-induced thrombin generation at the surface of adherent platelets with flowing whole blood.

\section{Discussion}

Different heparinized collagen preparations, namely collagen crosstinked with extensively periodated heparin $\mathrm{HC}, \mathrm{HC}$ with inmobilized mildy periodated heparith (HHC), and collagen crosslinked with EDCINHS and treated with mildly periodated heparim-crosslink (HEC), were evaluated for theil thrombogenic properties. We wished to reveal to what extent heparin as a collagen crosslinker or cowalently bound to the collagen surface is able to reduce collagen's thrombogenicity. Our results demonstrats that numerous platelets adhered to collagen films, and that these platelets supported the process of thrombin generation at the collagen surface. Heparinization of collagen could not abolish the binding and collageninduced activation af platelets. However, in comtrast to nontreated collagen surfaces, no thrombin generation could be detected on heparinized surfaces.

Platelet adhesion, determined as the percentage of surtace cowerage, was the same for NC, HC, HEC, and HHC. This result elearly indicates that heparinization of collagen (either as a crossinker or immobilized on crosslinked collagen does not prevent, or even reduce, platelet adhesion. Moreover, platelets that adhere to heparinized collagen becone activated, resulting in pseudopod formation and the appearance of phosphatidylserine in the outer leane of the plasma membrane. This result appears to contrast with findings of other investigators, who demonstrated that heparin costings significanily decreased platelet adhesion. ${ }^{2.23}$ However, our observaton that plateler adhesion on collagen is not inhibited by the presence of immobilized heparin is in line with a previously reported study that demonstrated that heparin immobilization on cabbodimide crosslinked coltagen even slightly increased the number of adherent platelets. ${ }^{4}$ Conm dictory findings in the effects of immobilized heparin on platelet adhesion might be related to the lype of surface to which heparin is bound.

Collagen-induced platelet procoagulant activity is mediated by the interaction of collagen with its plitelet receplor. GPVL. ${ }^{24}$ It is apparent that crosslinking collagen with heparin did not inhibit the loss in phospholipid membrane asymnetry. as monitored by amexin- $V$ binding. In contrat, collageninduced platelet procongulant activity was significantly rem duced when collagen films were treated with mildy perodate oxidized heparin, implying that under these circumstances, when the polysaccharide chain of heparin is almost lully intact, immobilized heparin interferes with platelet activation by collagen. Whether immobilized heparin affects the interaction of collagen with its primary platelen receptor GPVI or with a secondary one (P2Y2 andfor P2Y12) awaits further experimentation. Because these experiments were pertormed with adherent platelets that were extensively washed, heparin-accelerated inactivation of traces of thrombin in highly unlikely. Interference of heparin with platelet activation by collagen was previously demonstrated under both static and flow conditions. ${ }^{23-27}$ One study showed that unden static conditions or at low shear rate, inmobillized heparin did not affect platelet deposition to collagen, but strongly inhib. ited the platelet release reaction. ${ }^{23}$ A nother study in rats revealed that under flow conditions (low and high shear rate). heparin released by stimulated mast cells did not block $\alpha_{2} \beta_{1}$-dependent platelet adhesion, but attenuated subsequent platelet activation as well as fibrinogen binding to platelets. ${ }^{27}$ Together, these resules support the notion that mildy periodate oxidired heparin may interlere with collagen-induced platelet activation fice, releatse reaction and exposure of negatively charged phospluolipids in outer leaflet of the plasma membrane).

Exposure of heparinized collagen fitms with adherent (activated) platelets to recalcitied platelet.free plasma demonstruted that, iradependem of the method of heparinization. thrombin formation is abolished completely during the time of the experiment ( 60 minutes). We surmise that the amoum of $A T+2 \mathrm{pmol} / \mathrm{cm}$ ' that binds to colligen film crosslinked with highly periodated heparin is already sufficient to prevent. thrombin generation at these surfaces. These results extend earlier findings from our group illustrating that AT bound o immotilized heparin is probably the most effective way to

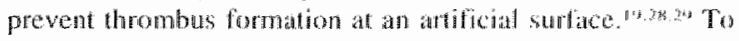
confin that the thromboresistance of the heparnixed collagen surfaces was indeed AT-dependem, thrombin generation was measured with AT-depleted phasma. While thronbin generation on heparinized collagen with adhering plattelats was strongly inbibited when exposed to normal plasma, 


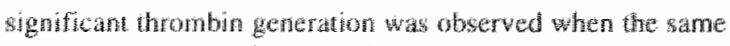
experiment was pertomed with AT-depleted plasma, ster gesting that the thromboresistane of heparinged collagen sturtaces is fully dependen on the presence of AT. The: phystological relevance of our finding was establighed in a perfusion setup where stents coated with heparinized collagen film: were exposed to flowing whole blood. While an explosive thrombin fomation was observed in blood that passes the nonheparinized collagen-coated stents. stents cotted with heparinized collagen appeared to be fully thromborestatan. We postulate that inmobilization of heparin effectively adxilyzes the thrombin antathrombin reaction. whreby levels of surface located thrombin remain below the threshold walues that are needed to exen uts positive fedback reactions, such as activation of the cofactors factor $V$ and VIII and generation of procoagulant cell memberanes, that regulate thrombiry formation. The in vitro findiga that heparinized collagen films are highly thromboresistant encourages further resestrch on the application of collagen in medicat devices in contact with blowd.

\section{References}

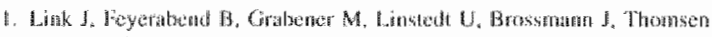

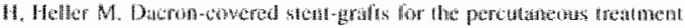

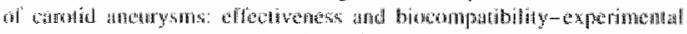

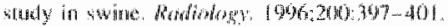

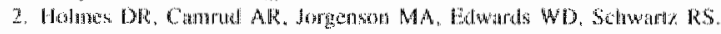

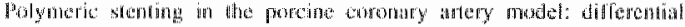

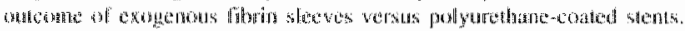

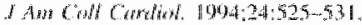

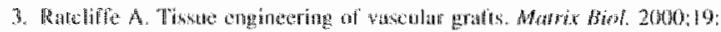
$353-357$

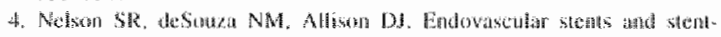

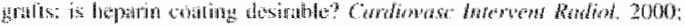
$23 \cdot 252 \ldots 255$

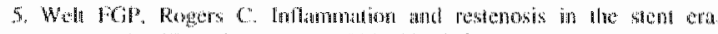

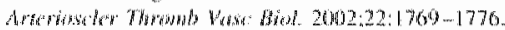

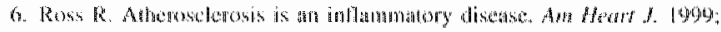
$138.9110-3+20$

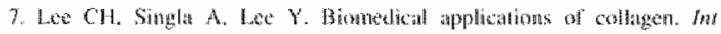

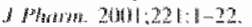

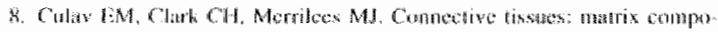

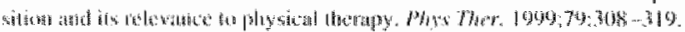

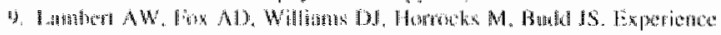

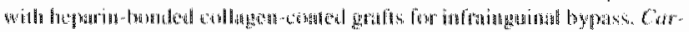

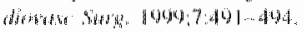

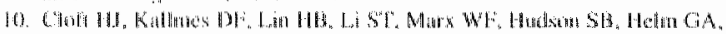

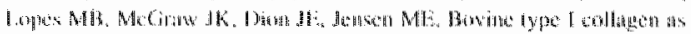

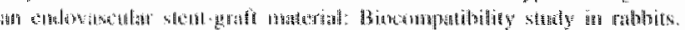

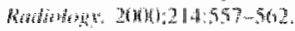

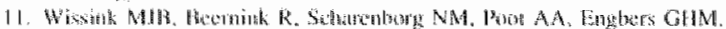

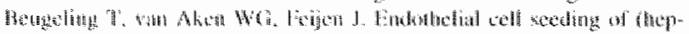

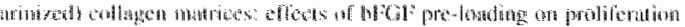

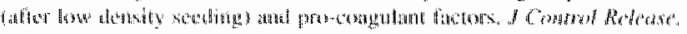
$2006 \%: 141-25,5$

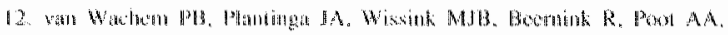

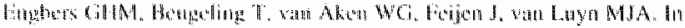

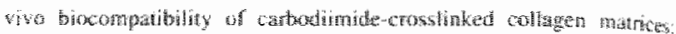

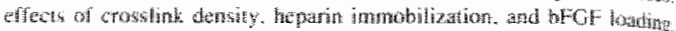

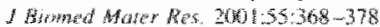

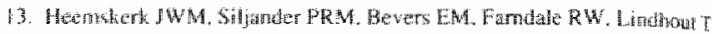

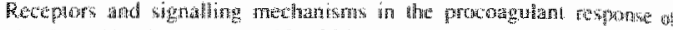

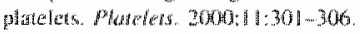

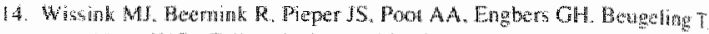

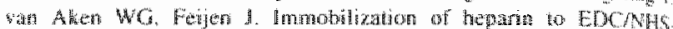

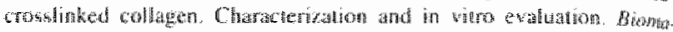

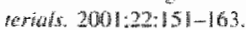

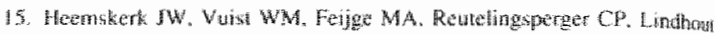

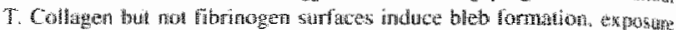

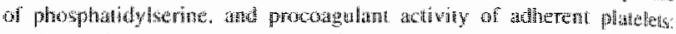

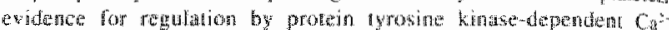

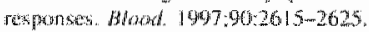

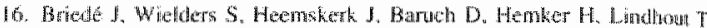

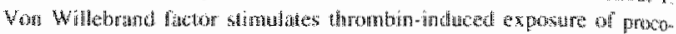

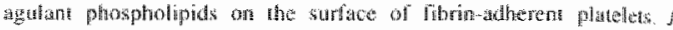

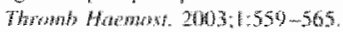

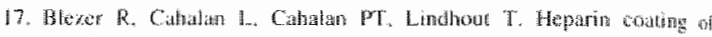

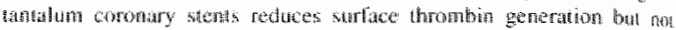

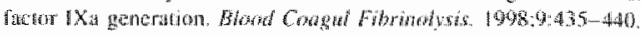

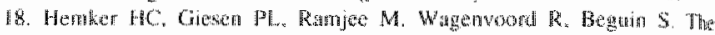

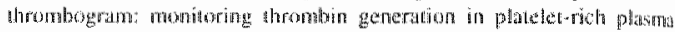

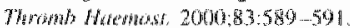

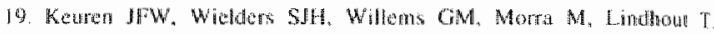

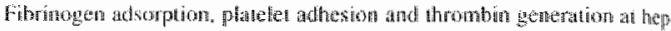

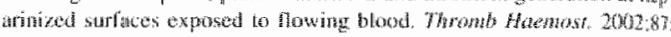
$742-747$

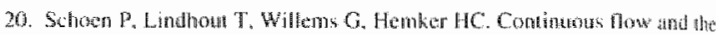

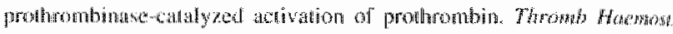
$1900,64: 542-547$

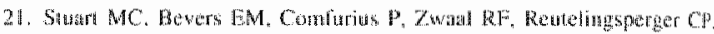

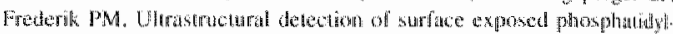

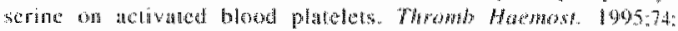
$|1-5-\|\mid 15\|$.

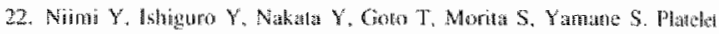

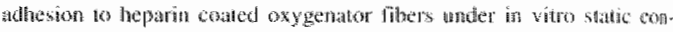

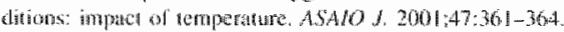

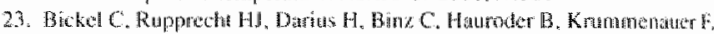

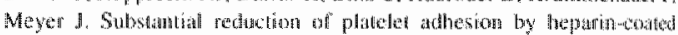

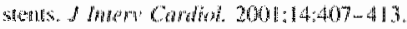

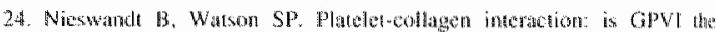

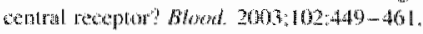

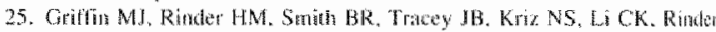

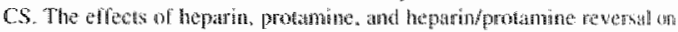

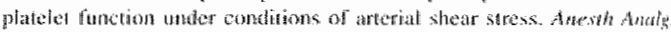
$294: 197: 20-27$

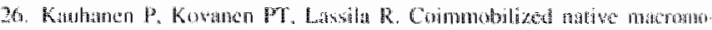

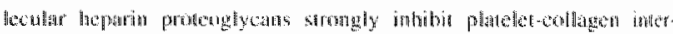

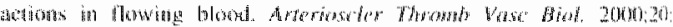
B:i: $3-1: 019$

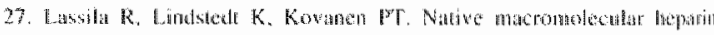

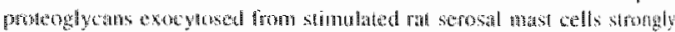

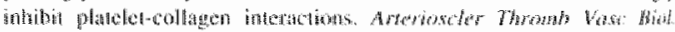
$1007: 17: 3572-3587$.

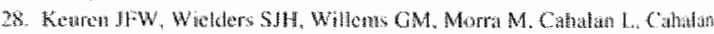

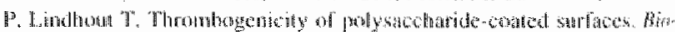

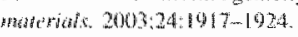

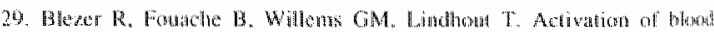

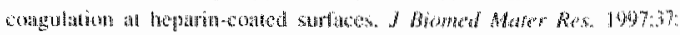
$108-113$ 
Chapter VIII

GENERAL DISCUSSION 


\section{Introduction}

"Te physological signicance of thombin generaton in man is apparent from the observations that even incomplete defichency of prothrombin or deficiency of factors VIIJ and IX is associated with severe bleeding disorders. "In addition, mice defucient in protrombin dic shorty after birth from thatemorthage, indicating that thrombin deficiency is incompatible with hatemostasis and post nata survival. Actrvated platelets play a critical role in thrombin generation. The surfaces of these platelets serve as binding sules for enzymatic complexes that catalyze prothrombin and factor $X$ activation. The studies presented in the first part of this thesis (chapters $2,3,4$ ) were ained to obtain better insight in the mechanisms of thrombus formation, in particular with respect to exposure of procoagulant platelet surfaces and thrombin generation at these surfaces. Progress in understanding the process of thrombus formation can improve current anthrombotic therapies. To date, treatment of unombotic vessels includes implantation of stents or vascular grafts io recuperate blood flow. There is, however, a high perentage of restenosis or thrombo-embolic complicaltions accurring within months or even weeks after surgery (rewewed in "). Moreover, the anticoagulant therapy that is newded to prevent acute thrombus formation is frequently associated with a severe bleeding risk. The second part of this thesis (chapters $5,6,7$ ) is therefore concened with artificinl surtaces in contact with blood. Because of its pivolal role in thrombus formation, we considered that surface modification with thrombin inhibitors, like heparin, coud improve haemocompatibility. Although various heparin coatings have currently been developed, reports on the improvement of climical manifestation have been mixed. "The studies described in this thesis were undertaken to gain more insight in the working mechanism of surface immobilized heparin.

\section{Adhesive receptors GP $\mathrm{Ib} \alpha$ and integrin $\alpha_{1 b} \beta_{3}$ stimullate thrombin generation in platelet-rich plasma}

Thrombin (and thrombus) formation is highlly dependent on: 1) initation of coandation, via the extrinsic tissue factor pathway or through contac activation on artificial blood contating surface and 2) procoagulant cell membrancs, which caliase temase and prothrombirase reactions.

Alter endothelat damage or rupture of an atherosclerotic plaque, congulation is initated by TF exposed on vascular cells (i.e. fibroblasts, smooth muscle and endolhelial cells). Thombin generation is then antalysed on the membrane of procoagulant platelets allucting to manix proteins like collagen, since Mbroblasts or smootl muscle cells do not provide suitable surfaces to wallyse this process." Anter the cells in the vessel wall are covered with platelets and fibritu, an initiator different from vessel wall derived $\mathrm{TF}$ is essential for thrombus propagation. Recently, it was proposed that leukocytederived micropaticles, bearing both Th and PSGL-1, circulate an blood and accumulate in the developing platele rich thrombus (rewiewed in ${ }^{14}$, Platelats interac with these particles wia their membrane proten P-Selectin. The significance of this blood borne tissue factor for thrombus formation is however still a matter of debate. An allemative for "Th dependent propagation of thrombus formation is activation of FXI by thrombin. $1 \%$. In this process, thrombin that is intially produced via the "TF pathway, activates FXI on the surface of activated platels.
Several inwestigators described that platelets in a thrombus, adherent to fibrin, required activation via the GP lba-VWH: axis and thrombin to become procoagulant ${ }^{2}$ In contrast, Doman al reporied that VWF binding to GP Ibot is not essential for the procotgulant response of thrombin stimulated platelets? In chapter 2, we demonstrate that the stimulating affect of the GP Ibo-VWF interaction on thrombin induced platelet procoagulam activity is only observed when platelets are subjected to high shear rates. This likely explains the deviating results of Domann at at ${ }^{22}$, since their work was conducted in the absence of high shear stress.

Besides GP Ibo, another platelet adhesive receptor, namely the integrin $\alpha_{16} \beta_{3}$. Was shown to contribute to procoagulant activity. Antagonists of this integrin, such as the c7e3 Fab fragment abcimab, effectively decrease thrombing generation in coagulating plasma (chapter 2). . $^{23.24}$ Our resulus indicate for the first time that the inhibitory effect of abciximab on thrombin generation increases with shear rate. This suggests that GP lba-VWF and integrin $\alpha_{11} \beta, 3$ signals act symergistically in platelet procoagulant activation. Experiments with blood from Glanzmann patients further confim a role of integrin $a_{14} \beta_{15}$ in thrombin generation, since thrombin formation is strongly reduced (chapter 2). ${ }^{20}$ To our surprise, abciximab stimulated coagulation in Glandmann patients. Because abciximab had no effect in platelet free plasma, the effect must be platele dependent. Thus far, we have no explanation for this strikng eflect of abciximab. Overall we conclude that at arterlal shear rate platelet interaction with fibrin through $\mathrm{GP}$ Iba-WWF and by way of integrin $\alpha_{11 b} \beta_{3}$ plays an important role in the procoagulant response of platelets.

\section{VWF C-domain mediates platelet adhesion to fibrin}

The traditional view of flaemostasis in which fibrin only functions in stabilizing the platelet plug has to be changed. First of all, fibrin was shown to be actively involved in platelet adhesion and ageregation. ${ }^{25.25}$ Its active role in haemostasis was further emphasized in patients with platelet disorders, in which fibrin formed through addition of recombinant factor Wlia, compensated for a lack of platele adhesion. ${ }^{26}$ Furthermore, fibrin stimulates thrombin induced platelet procoagulant activation, which might stimulate thrombus growth. Bit.

It is well acepted that under conditions of high shear stress VWF plays a critical role in the recruitment of circulating platelets to the fibrin nework. ${ }^{26}{ }^{3 z}$ In addition, we tevealled that thrombin induced procoagulant activity of fibrin adherent platelets is dependent on Gip Ibo-VWF interaction when shear stress is high (chapter 2). Preventing the interaction of platelers with fibrin could thenefore be $a$ novel anitillombotic approach for several reasons: 1) only excessive thrombus growth is inhibited, implying that there is no hemorrhagic tendency as platelet interactions with extracelluk matrix proteins remain unaffected, 2 ) fibrin is a major adhesive protein in diseased vessels, since pathologic studies revealed that there is constant formation and breakdown of tibrin whin an atherosclerotic vessel wall." To specifically inhibit platelet athesion to fibrin, it was important to investigate how fibrin and VWF interact. In chapter 3. we therefore attempted to localize VWF domains that bind to fibrin. As depicted in Fig. 1, the high aftinity binding site on VWF for fibrin was found in the C-domain (amino acids $1637-1899)$. Perfusion experinents with $\Delta C$. rVWF further established that this C-domain was critical for platelet adhesion to fibrin under conditions of high shear 


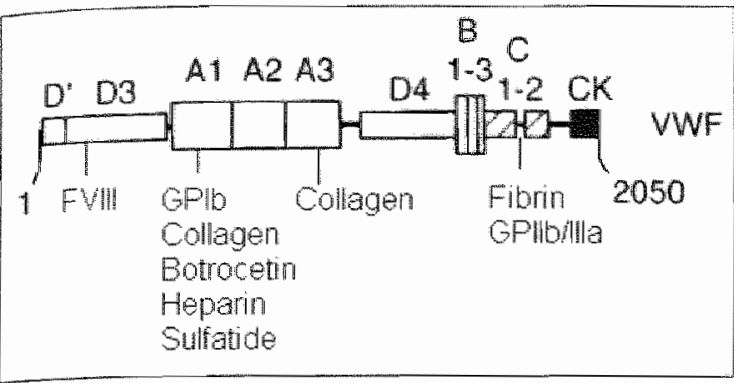

Figure 1: Structure of won Witlebrand factor. The locations of tre xinds of conserved structurall domains $(A, B, C, D, C B S)$ are indicated Amino acid residues of the malure MHF subunil are numbered $1-2050$. Binding sites within the subunit have been lacilized for several macromolecules as indicated. The location of the fibrin binding site in the C1C2-domain was determined in chapter 3 of this thesis.

stress (chapter 3). Further research is required to reveal which specitic amino-acid sequence in the C-tomain is responsible for fibrin binding.

Recently, the adhesive protein thrombospondin-1 was slyown to be an alternative substrate for VWF under high shear stress conditions, which was able to interact directly with GP lbo. In addition, thrombospondin-1 was identified as an adhesive substrate for red blood cells to fibrin. We noted a $26 \%$ identity in 33 amino acids between thrombospondin-1 amino acids 317.409 and the VWF-C domain (amino acids 1667-1789). This suggests that thrombospondin-1 might interact with fibrin through the same amino-acid sequence as VWF and through this interaction could mediate the adhesion of red blood cells at venous shear rate. It is not feasible that thrombospondin-1 bound to fibrin acts as an adhesive protein for platelets under high shear conditions since we observed no platelet adlesion when VWF deficient monse blood was perfused over fibrin layers made fron VWF deticient plasma (chapter 4).

\section{Role of thrombin receptors in platelet procoagulant activity}

Current literature points to thrombin as a key mediator of the platelet procoagulant response. While thrombin alone appeared to be a weak stimulator of procoagulant activity,

it strongly stimulates this process in platelets residing in a thrombus and thus in contact with adhesive substrates like collagen, VWF or fibrin(ogen). ${ }^{25.21 .37}$ To date, results are rather inconsistent with respect to which thrombin receptor is implicated in platelet procoagulant actiwation. ${ }^{2236,38.34}$ To study the role of thrombin receptors GP Iba, PAR $I$ and PAR-4 in the generation of a procoagulant membrane surface, we activated platelets with collagen and thrombin in the presence of various antagonists of these receptors. When PAR-I signalling was ceased, due to treatment of platelets with the intracellular antagonist PIpal. $12^{46}$ or receptor desensitisation, procoagulant activity was severely reduced to that of collagen activated platelets. On the other hand, blocking the interaction of thrombin with GP lba or abolition of PAR-4 signalling did not interrupt with collagen plus thrombin induced platelet procoagulant activity (Chapter 4).

We established by flow cytometry that all platelets exposing PtdSer in their exoleaflet, had sustained elevations in $\left[\mathrm{CA}^{2}\right]$. In addition, intertring with PAR-I signalling revealed that activation of PAR-1 by thrombin was cructal for the sustained elevations in [Ca $\left.\right|_{\text {i }}$ induced by collagenthrombin (chaptet 4). These results suggest that PAR-1 activation evoles a sustained elevation in $\left[\mathrm{Ca}^{2}{ }^{2}\right.$ is which strongly enhances a phospholipid scramblase that shutes negatively charged phospholipids fron the inner lestlet tot the outer leaflet of the plasma membrame in collagen adherent platelets. Stil. it is rather puzzling by which mechanism this thrombin receptor is able to maintain a high sustained intracellular level because of its short thatf-life. It is tempting to speculate that collagen receptor signalling alters the kinetics of inactivation of PAR-1.

\section{The validity of current in vitro thrombogenicity tests shoulds be questioned}

To improve biocompatibility of medical devices in contact with blood, surfaces have to be destgned that are both antiimmunogenic and antithrombotic. th th developing stich surfaces it is important to use assays with a high prognostic value Currently, there is a tendency to focus on individual aspects thrombus formation rather than considering the whole process. For example, biocompatibility of antificial surfaces in contact with blood is often assessed as adsorption of purified proteins or platelet adhesion sidudes from anticoagulated blood, and thus in the absence of thrombin generation. ${ }^{4} 34$ In chapters 5 and 6 of this thesis we questioned whether such assays can predict the in viwo thrombogenic properties.

We demonstrated that the results of adsorption studies with isolated proteins are not predictive for in vivo functioning. (chapter 5). Non-coated and heparin-coated surfaces adsorbed high amounts of fibrinogen fron buffer solution. However, no fibrinogen could be detected in protein layers adsorbed from plasma. On the other hand, when plasma was strongly dituted, fobrinogen bound to both surfaces. These data confirmed the findings of Vroman et al. ${ }^{45}$, showing that the deposition of a protein layer from nlowing whole blood is followed by a rearangement, in which fibrinogen is rapidly displaced. If fibrinogen adsorption is important for platelet adhesion, the fict that adsorption and desorption kinedics of plasma proteins are strongly influenced by the concentration and surface affinity of other plasma proteins ${ }^{\text {th }}$, makes protein adsorption studies from buffer solutions waretiable in predicting platelet adhesion to such surfaces. Purified antithrombin (AT) adsorbed readily to both non treated and heparinized surfaces. However, when these surfaces were exposed 10 flowing plasma. AT could be detected only in the protein layer deposited on the heparinized surlace. Apparently, it is readily displaced or masked by other protens on non-coated surfaces, but on heparinized surfaces AT cannot be dislodged due to a specific interaction with heparin. This again indicates that adsorption assays with purified plasma proteins have a low prognostic walue with respect to the in vivo situation.

With respect to platelet adhesion from flowing anticoagulated whole blood, surfaces with immobilized heparin were indistingusshable from uncoated hydrophilio surfaces, suggesting that heparin coatings do not affect thrombus formation (chapter 4, 5). Nevertheless, thrombin production and the formation of occluding thrombi was greatly diminished in recalcified whole blood passing by heparinized strfaces when compared with noill-coated surfaces. Overall, our findings indicate that platelet adhesion 
studies from anticoagulated blood not necessarily predict thronbogenichty of materials, since anticoagulation preverts thronbin formation and its positive feedback reactions necessary for thrombus formation. In vitro predictions of blood compatibility could therefore better be based on thrombin generation measurements in blood passing by the arrificial surface.

\section{Working mechanism of immobilized heparin}

Heparin is widely used to prewent thrombosis at blood contacting devices (reviewed in ${ }^{4}$ ). The antithrombotic action of heparin is based on the stimulatory effect on the meutratization of thrombin and factor $X a$ by antithrombin. ${ }^{*}$ A disadvantage of systemic heparin is its rather narrow therapeutic window. In addition, heparin treatment is associated with an increased bleeding risk. Immobilization of heparin on the artificial surface overcomes this problem while reducing surface thrombogenicity. We found that no significant amounts of thrombin could be generated on heparinized surfaces exposed to flowing blood (chapters 5 7) and while some investigators proposed that heparinized surfaces are protein and platelet repelling ${ }^{36-53}$, we (chapters 5 and 6) and others ${ }^{5}$ demonstrated that there is no difference in protein adsorption and platelet adhesion on non-coated and heparinized surfaces. Yet, imnobilized heparin specifically interacted with AT and in this way thrombin generated near the blood contacting surface could be neutralized. Evidence for this was provided in chapter 5 , showing that AT could only be detected in protein layers deposited on heparinized surfaces. Chapter 6 further confined that binding of AT to immobilized heparin was fully responsible for the antithrombotic actions of heparinized surfaces, since surface heparinization abolished thrombin generation in normal, but not AT deficient blood. Surface heparinization even prevented coagulation in blood exposed to collagen surfaces with adherent procoagulant

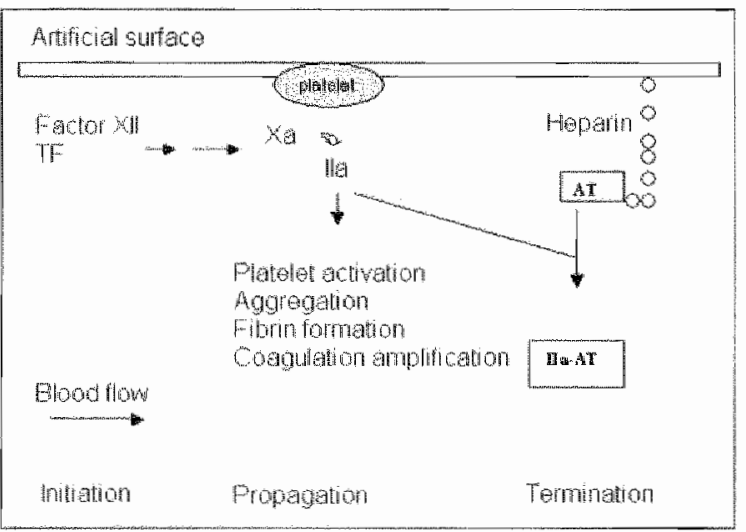

Figure 2: When an artificial surface comes in contact with blood. coagulation is triggered via activation of factor XII or via inflammatory monocytes that ralease tissue factor (initiation). Thrombin fomation is then catalysed on the membranes of adherent platelats, potentiating thrombus formation wia fibrin deposition and by positive feedback reactions, o.g. platelet activation and generation of the critical cofactors $\mathrm{Va}$ and Villa (propagation). When heparin is inmobilized on the blood contacting surface, heparin-bound AT readily neutralizes the first traces of thrombim, and thus all further positive feedback reaction necessary for thrombus formation (Temination) platelets (chapter 7). Figure 2 schematically depicts our idea how immobilized heparin prevents thrombus formation on blood contacting materials.

\section{Are heparin coatings desirable?}

Several heparin coatings have reached the commercial stage in cardiopulmonary bypass and in coronary stents. Yet reports on the improvement of in vivo biocompatibility are

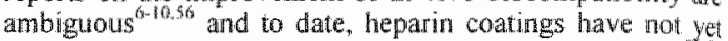
been shown to significantly improve patient outcone ${ }^{56-59}$ This could be due to the fact that heparin is a powerfiul anticoagulant, but it only partially reduces the inflanmatory response associated with artificial surfaces in contaci with blood. ${ }^{54}$ dat To improve biocompatibility a surface has to be designed that affects both coagulation and inflammatory processes. Because of its weak antigenicity and its proven biocompatibility in other medical applications $s^{\text {st }}$ (skin replacement, bone substitutes, artificial valves), we proposed to use collagen as stent coating or vascular graf material (chapter 7). In addition, collagen was shown to be a suitable substrate for endothelial cell growth, which make its application as an artificial vessel even more attractive ${ }^{6 ?}$ A drawback of using collagen in contact with blood is its active role in thrombus formation via platelet adhesion and activation. Yet, the data presented in chapter 7 of this thesis revealed that inmobilized heparin, used as a crosslinker of type If collaggen, was able to fully prewent occlusive thrombus formation in flowing whole blood passing through stents coated with heparinized-collagen.

On the other hand, highly sulphated polysaccharides. like heparin, could stimulate the process of neo-inima formation by forming complexes with growth factors. ${ }^{11.63: \text { an }}$ Interestingly, less sulphated polysaccharides were shown to inhibit snooh muscle cell proliferation. ${ }^{\circ}$. We therefore compared the antithrombogenic properties of immobilized heparin with those of the less sulphated polysaccharides: chondroitin-6-sulphate and alginic acid (chapter 6). We revealed that the thrombin generation potential of the low sulphated polysaccharide coatings was greatly diminished with respect to non treated surfaces. This antithromboric potential is probably explained by the protein repelling. property of these surfaces, which in turn results in a reduced contact activation of the coagulation system. Still, in comparison with the heparinized surface, where thrombin generation remains below the detection limit, surtaces. coated with chondroitin-6-sulphate and alginic acid showed only partial thromboresistance. It thus appears that heparin bound AT most efficiently abrogates thrombin formation. These findings imply that if a high surface density of immobilized heparin exerts adverse effects, like neo-intima stimulation, mixtures of heparin and lowly sulphated polysaccharides could be an interesting alternative to improve hatemocompatibility of artificial surfaces. Other alternatives might be mixtures of immobilized heparin and local drug delivery systems to prevent platelet activation. For instance, platelet thrombin receptor antagonist PI Pal-12. which was shown to fully prewent platele procoagulant activation induced by thrombin (chapter 4)

\section{References}

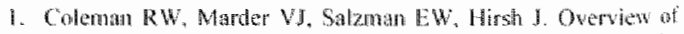

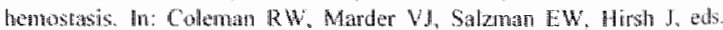

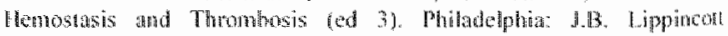
Compryty; 1994:184-190

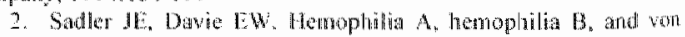

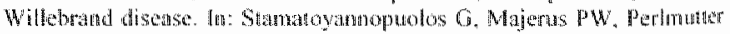




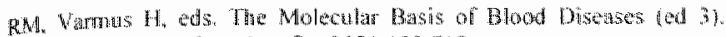

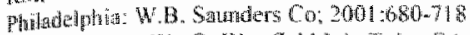

3. Xued, Wh Q, Westheld LA, Tuley EA, La D, Zhang O Shin K.

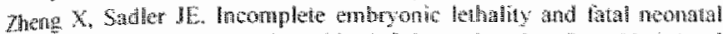
hemorylage causwd by prothrombin defiency un mice. Pron Nasil Acad 56 U 5 A $1908: 95: 7603-7603$

4. Sun Wr. What DP, Degen Jt. Colbert MC, Burkan MC.

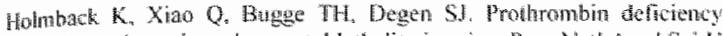
nesulis irs embryonic and neomatal lethaliy in mice. Proc Nat Acad Sci it S.A. $1008: 95 \% 7597-7602$

5. Gorthet MB. Seffor MV. Biomaterialogsocisted thrombosis:

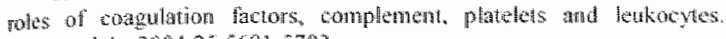
Biomalenials. 2004,25:5681-5703

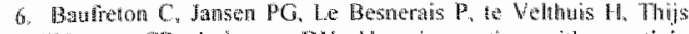

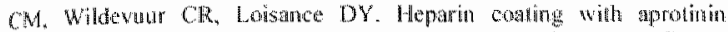
seduces blood activation daring coronaty artery operations. Ano Thortc Surg. $1997,63950-56$

7. Defaigne 10, Pincemal J. Larbuisson R, Bughart F. Lumet R. Crtokine actedse and metaphlit activation are not prevented by heparityconed circuits and aprotinir administration. Ana Thoras Surg. $3000 \cdot 69: 1084-1091$

8. Gorman RC, 2Gats W, Ram AK, Gikakis N, Su L. Khar MM.

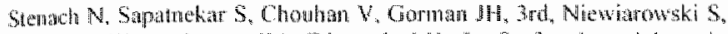

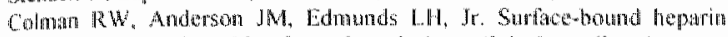

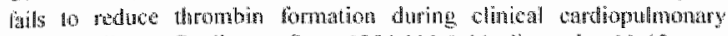
bypass. Thorac Candiovase Sure 1996:1 1 1:1.11: discusion 11-12

9. Mown O, Hogesen K, Hosse E, Dregelid E. Brotkme id $\mathrm{V}$, Venge

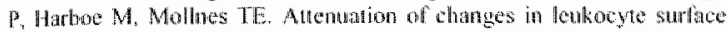
markers and complement activanon with heparin-coated cardiopulnonary bysass. An Thene Surg 1997,63:105-118

10. Muatyrcke DD, MeCarly PM, Kotke-Marchant K. Marasati li. Pierre-Yared J, Borsh JA, Ogetla D, Cosgrove DM. Biocompatibility al heparinwcoated extacompoteal bypass circuis: a randonized, masked clinical trial. IThow Cardiovase Sure. 1996;/12,472-483

11. Nelson SR, deSouza MM, Allson DJ. Endowasedar stents and stentownth: is heparin coating desirable? Candiowase Inlerven Ratiol. $2000 \cdot 23,252-255$

12. Holliman M, Manme DM, 3rd. A cell-based node of

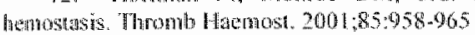

13. Cambien $B$, Watener DD. A new rote in hemastusts for the adhesion receptor P-selectin. Trends Mol Med, 2004-10:179-186

14. Furie B, Furie BC. Role of platele1 P-setectin and microparticle PSGL -1 in thrombus formation. Trends Mol Med. $2004 ; 10: 171-178$

15. Chou J, Mackman N, Menill-Skotoff G. Pedersen B, Furie BC, Furit B. Hematopoictic Cell-Derived Micoparticle Tissue Factor Contributes to Fibrin Formation During Thrombus Propagation. Blood. 2004

16. Day SM, Regve JL, Pedersen B. Farris BM, Myers DII, fm M.

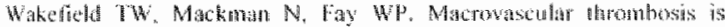

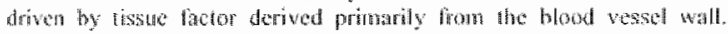
Bhockl. 2004

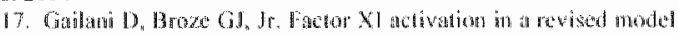

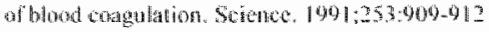

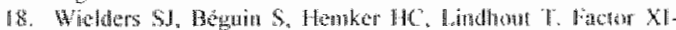

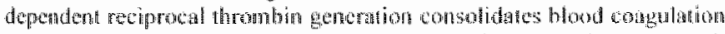

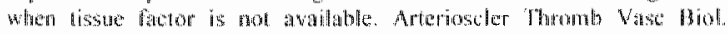
$2000424 ; 1138-1142$

10. Bagha CA wash PN. Thrombin-mediated feedback activation of tacer $\mathrm{Xl}$ on the actuat plated surtace is prefered over contact

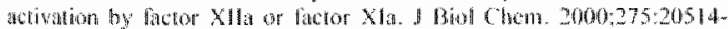
201519

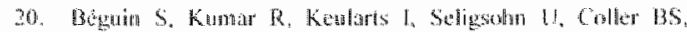

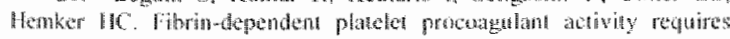

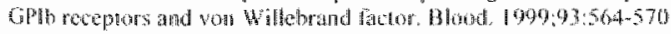

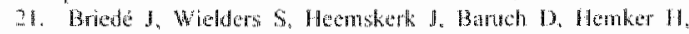
L.indhou $T$. Won Willebrand factor stamulates ahrombin-induced

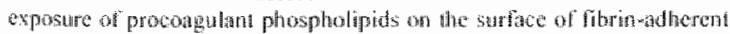
platelets. J Themb Haemost. $2003,1.55 \% .565$

22. Dormann D. CHemeson KJ, Kohrel BI. The GPlb thombinbinding sine is essential for thrombin-induced platelet proconguling

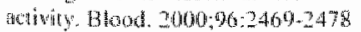

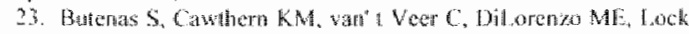

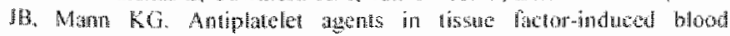
coagulation, Blyod. $2001: 97: 2314-2322$

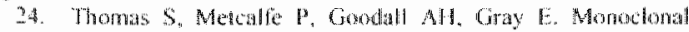

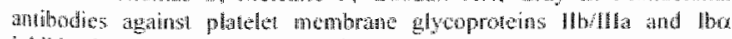

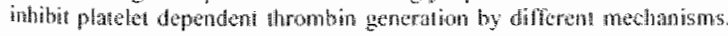

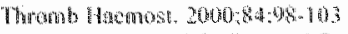

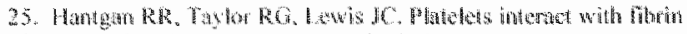

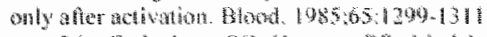

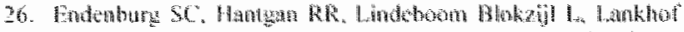

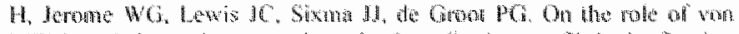

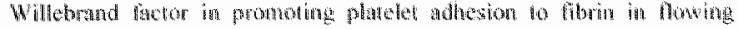

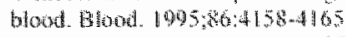

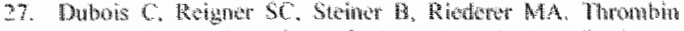

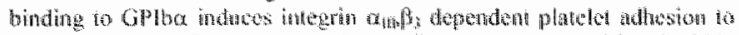

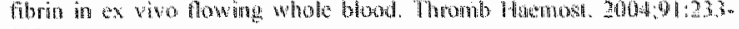
237

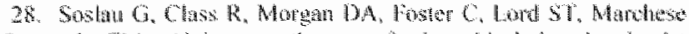

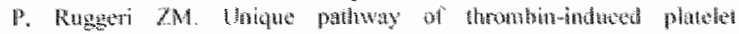

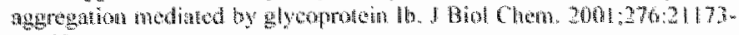
21183

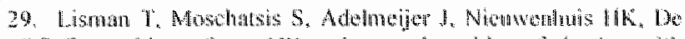

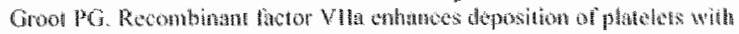

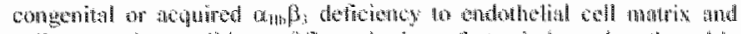

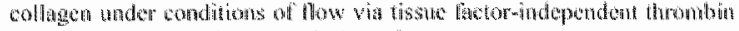
generation. Blond. $2603 ; 101: 1864-1870$

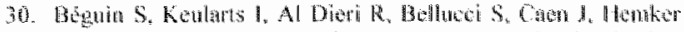

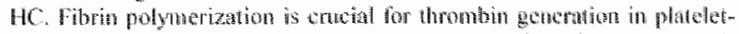

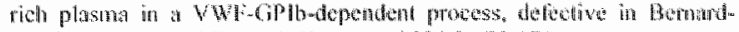

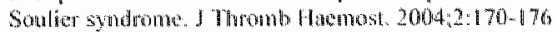

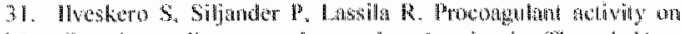

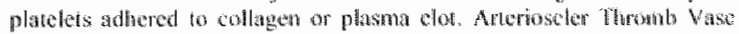
Biol. $2001 ; 21628-635$

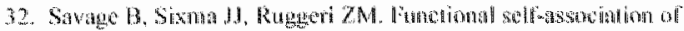

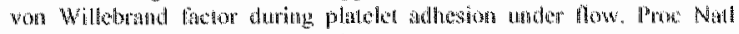
Acad Sci USA $2002 \cdot 99 \times 425430$

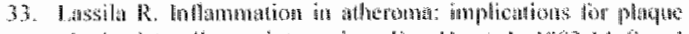

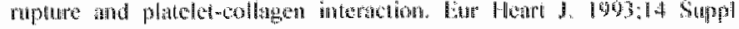
$k, 94.97$

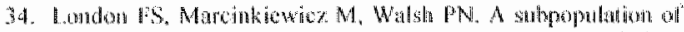

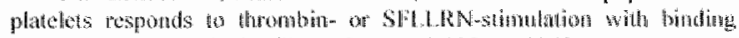

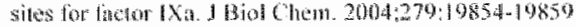

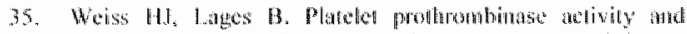

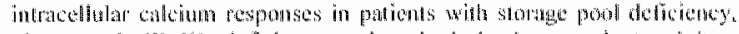

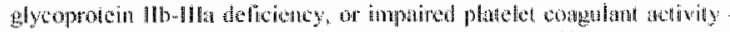

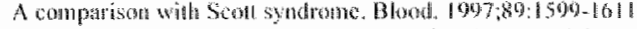

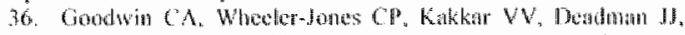

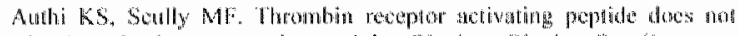

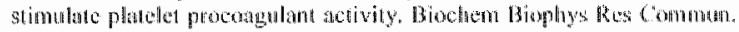
$1994: 202321-327$

37. Bewars EM, Comburius $\mathrm{B}$, Zwath Re. Changes in membram

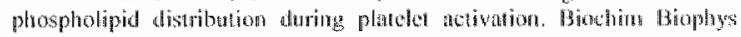
Acta. $1983.73657-60$

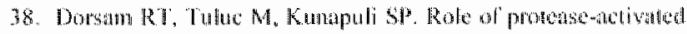

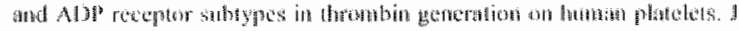

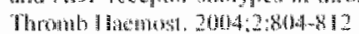

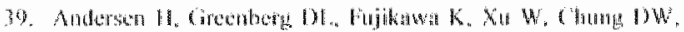

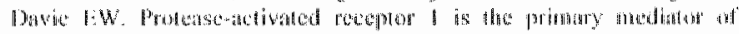

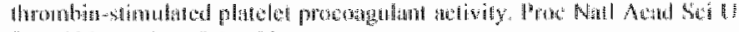
SA. $1909 \% 96: 11189.11193$

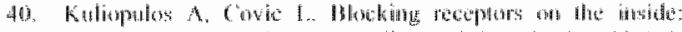

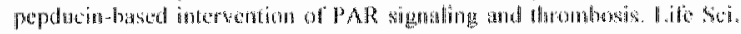
$2607 ; 4,255-262$

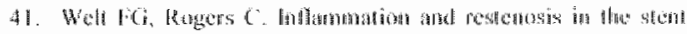

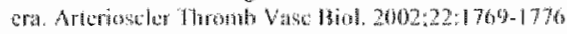

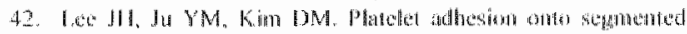

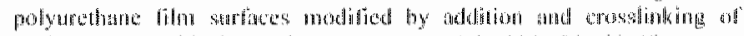

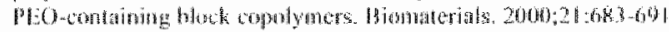

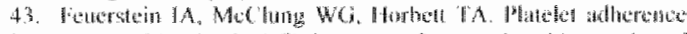

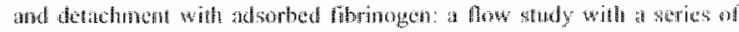

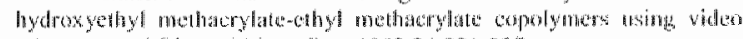

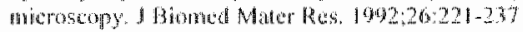

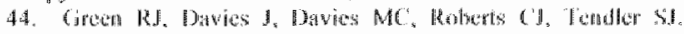

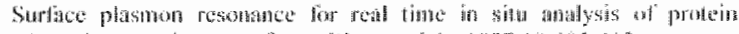

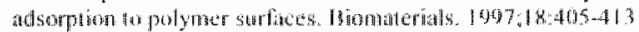

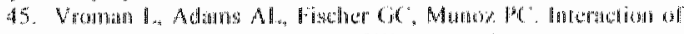

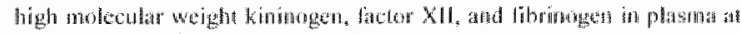

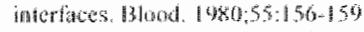

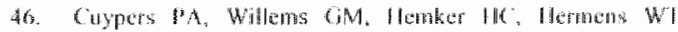

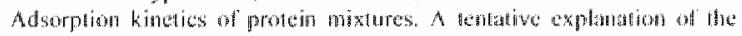

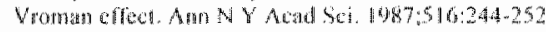

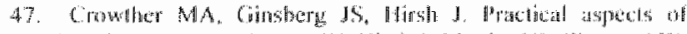

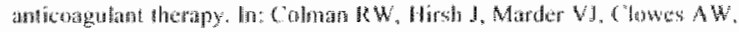




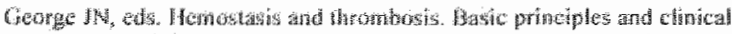

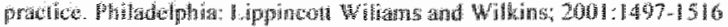

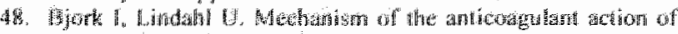

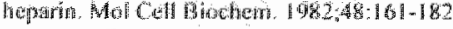

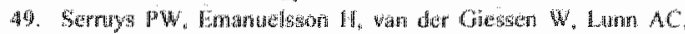

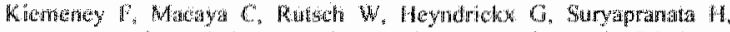

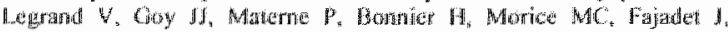

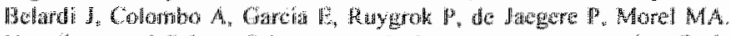

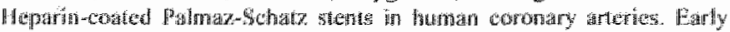

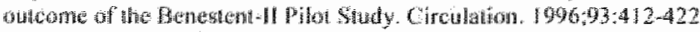

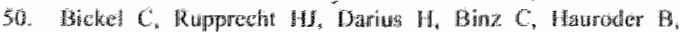

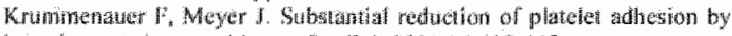
heparin-ebated stents. I intery Cardiol. 2001;14:407-4 13

51. Latio 0 , Larsen $R_{y}$ Oleson $P$. A new non-thrombogenic surface prepared by adedive eowalent binding of heparin via a modiffed reducing terminal residue. Bighater Med Devices Artip organs. 1983,1 1:161-173

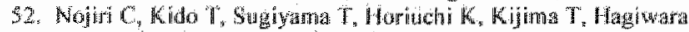

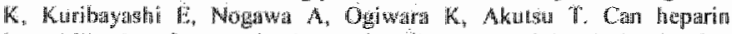

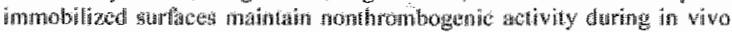
long-tem implantallion? Asato J. 1996; 2 - M469-475

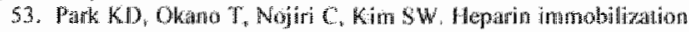

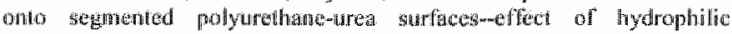

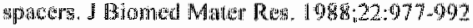

54. Wissink MI, Beernink P, Pieper 1S, Pool AA, donglors OH,

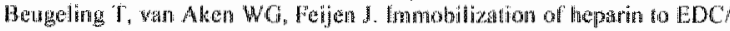
NHS-crosslinked collagen. Chastaterization and in witro evatuation. Bionattertats. $2001 ; 22: 151-163$

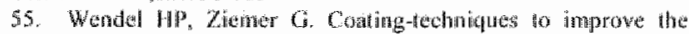
hemowompatibility of arlificial devices used for extracorporeal circulation. Eur J Candionhorac Surg. 1909:16:342-350

56. Lewy Mo Harthan AR. Heparindented bypass circuits in cardicpulmonary bypass: improved biocompatitility or not In 8 Cardiol.

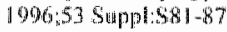

57. Viden $V$, Wollnes TE, fosse E, Mohr B, Bergh K. llagva TA.

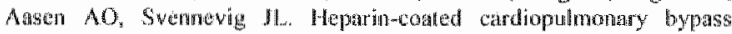

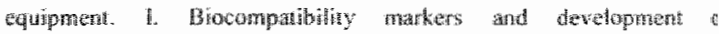

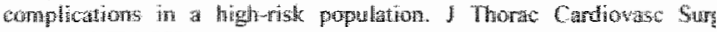
19697117799,4802

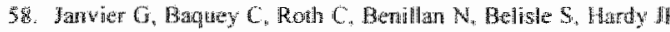
Extracorporal circhaton, hemocong patbility, and biomaterals. An Thorke Sarg. 1966:62:1926-1934

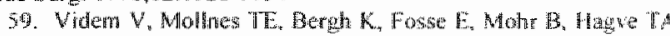

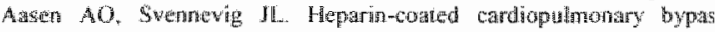
equipmen. II. Mechanisms for reduced complenten activation in wivo. Thond Cardiowase Surg. 1999:17803-909

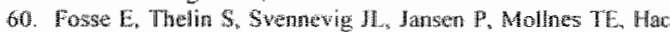

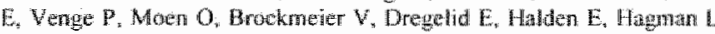
Videm $V_{n}$ pedersen T, Mohr D. Duriflo II coating of cardiopulunonar bypass cincusth reduces complement actiwation, but does not affect th retease of grartulocye enzymes: a Furopeun multacentre study. Fur Cardiounorac Surg. 1997:11:320-327

61. Tee CH, Singla A, Lee Y. Bionedical applications of collagor Int If Pharm. $2001,221: 1,22$

62. Wissint MuB, Beenink R, Selatanborg NM, Poot AA, Engber GHM, Bengeting T, van Aken WG, Feijen J. Endothetial cell seeding o (hepprinized) collagen matrices: afects of bfoF pretouding of profitaraion (afler low density seeding) and proworgulant fichors. Control Release, 2000;67:141-155

63. Lortat Jacob H, Grimaud JA. Interferongamma C-Lemina function: new working hypothesis. Heparan sulfate and heparmin. nfew largets for IfN-gammi, proted, relax ithe cyoking and regulate activisy. Cell Mol Bol. 1991;37:253-260

64. Tanaka Y, Adams DH, Hubseher S. Hirano H, Siebenlist U Shaw $\mathrm{S}$. Twell adhesion inded by proteglycan-inumobinzed cyokin MTP-1 beta. Nature 1993;361:79-82

65. Tappon-B3ratandiere I, Chabul D, Zierer M. Matur S, Hethey D

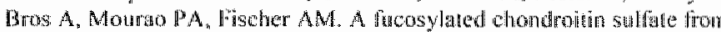
echinodem modtates in vitro fibroblast growth factor 2 atependen angiogencsis. Mol Cancer Res. 2002;1:96-102 
NEDERLANDSE SAMENVATTING 
Mlowdplatjes verwallan wen belangrijke rol h de blocdstoling (hemostase). De bintenbekteding wan an intad bloedvat bestat ut endotheelcellen die antionbotsche eigengchappen hebben. Als het endotheet beschadigd rakt gan bloedplatjes zich hechten aan subendothelate matro cwiten zoals collageen (adhesie) Bij gazonde personen is er een evenwich dat ervoor zorgt dat boedingen shel gestelpt kunen worden en er niet onnodig stolsels gevormd worden. Wanner er spontaan een unmbus onlstat die cen bloedvat afsluit noemen we dit trombose. Bij wen arieriele trombose kom er hn het weefsel acther do trombose gen bloed meer wardoor dit weefsel kan afstemen na werloop van tijd. Anteriele trombose is een acute complicatie die zich kan onwikkelen in atheroselerotische (verkalkte) blowdwaten. Gebeurt dit in het hart, den spreken we van een hantinfaret en als dit in de hersenen plaatsvindi, noemen we dit en herseninfarct.

Fundanentele kennis omtrent het ontstan en groes van een trombus vormat de basis voor de ontwikkeling van effectieve antithrombotische middelen. Dit is dan ook de achterligende gedaclite van het onderzok dat beschrewen is in dit proefschrif. De studies in het earste gedeelte wan dit proefschrifh (hoofdsukken 2-4) zinn uitgewoerd om een beter begrijy te kriggen wan de eiwitten, receptoren en signaaltorasductie processen die verantwoordelijk zijin woor de vorming van platies met stollingsbevorderende (procongulante) activiteit

Bij behandeling wan vernawhde of door een trombus verstople bloedvaten wordt vaak lichaamsvremd materiaal gebrukt word, wat veelvuldig leidt tot klinusche complicaties. Een woorbeeld is het plaatsen van een stent na percutane transhminele angioplastie (dotteren). Beikende problemen zijn plotselinge occlusie van stants door trombi, ook well restenose genoend, of bloedingspoblemen als gevolg van antiplatjes of antistollingstherapie. Ondat trombine onontbeerlijk is in het proces van trombusvorming verondarstellen wij dat het coaten met trombine remners, zoals heparine, de biocompatibiliteit van lichamswreende opperwakken in contact met bloed zal verbeteren. De resthlaten van klinische studies met heparne coatings zujn echter niet consistent positief. Het tweede deel van dit proefschrift (hoofostukken 5-7) bestudeert contact van bloed met thotomsureemde oppervlakken. Het doel van deze studies is het verthrigen wan meer inzoth in he werkingsmechanisnat wan heparine coatings

\section{GP $I b \alpha$ en integrine $\alpha_{4 b} \beta_{3}$ stimuleren trombine generatie in plaatjes-rijk plasma}

Onder arteriste stromingsconditiss is platiesadhesie athankelijk van do binding an won Willebrand racton (VWI) via glycoproteine (GP) Ibo en integrine $\alpha_{81}, 3$. Belde receptoren zouden ook een rol kumen spelen in de vorming van plianges met prowogathlante activiteit. In hoofdstuk 2 hetbon wij gekeken nar het effect van a fschubselheden, veorzath door een roterende cilinder. op GP Ibx en intogrine $\alpha_{1 m} \beta_{3}$ athankelijke trombine gentratio in stollend plaatjes-rijk plasma (PRP). Trombineworming werd contmu gemeten met behulp van een Hurascerend trombinestbstrat. Antilichamen tegen VWE bindingsepitopen op $\mathrm{GP}$ lba reduceenden trombinevorning in $\mathrm{P}^{\mathrm{R} P}$ met $25-30 \%$ bij een hoge $\left(420 \mathrm{~s}^{-1}\right)$, matar niet bij een lage $\left(120 \mathrm{~s}^{4}\right)$, atschuilsnelheid. De integrine $\alpha_{1 / \mathrm{B}} \beta$, antagonist abciximab reduceerde de plaatjesathankelije trombuevorming 100 . $43 \%$. Verder nam het remmende effect van abciximab at bij hogere atschuifsmelheden. Do nol van integrine on $\beta_{3}$ werd werder bevestigd in experimenten met PRP van Glanzman prituten, die gen functionee integrine onbs tot expressie brengen. Trombinevorming in het PRP van dezw partënten was sterlt gereduceerd. Verassend genoeg stumuleerde de remmer wan de plaaties agoregatie (abcleirab) rombinevoming in PRP van Glanzmann patientem. Ondat abciximab geen effect had op de trombinevorming in platjes-vni plasma, moet dit effect platjesathankelik zijn. Tot nu toe hebben we nog geen verklaring gewonden voor dit fenomeen. We concluderen dat bij arteriële afschuirsmelheden de vorming van een procoagulant bloedplaate en trombinewoming afhankelijk zinn wan plaatjesadhesie (aan fbrine) via GP Ibo en integrine $\alpha_{13} \rho$.

\section{WWF-C domein is verantwoordelijk voor plaatjesadhesie aan fibrine}

Fibrine stimuleert de procoagulante activiteit van platjes door trombine en is op deze manier belangrik woor de groei wan een trombus. Onder arteriele stromingscondities is VWF nodig voor plaatjes interactic met fibrinedraden. Het doel wan de studie in hoofdstuk 3 was het lokaliseren van de domeinen op VWF die werantwoordelijk zijn voor de binding atan fibrine. Wij hebben gevonden dat VWF specifiek bindt aan fibrine. Met behulp van VWF mutanten, die bepalde domemen missen, hebben we aangetoond dat de bindingsplatas voor fibrine zich bevind in het C-domein. In een perfusiemodel waarin bloed onder hoge afschuifsnetheden $\left(1500 \mathrm{~s}^{\circ}\right)$ over fibrine oppervlakten stroomt hebben we verder laten zien dat het C-domein op VWF essentied is voor platjesadhesie op fibrine. Het specifiek blokkeren van de interactie wan plaatjes met fibrine zou eer doorbrak kumen zijn woor het ontwikkelen van een nieuw soort antitromboticum. Het voordeel is dat alleen excessieve trombusgroe: geremd wordt. Dit betekent waarschijnlijk dat het risico op bloedingen beperkt blift ondat plaafjes interactie met extracellulare matrix eiwitten niel verstoord is. Verder onderzoek is echter nodig om uit te zoeken welke specifieke aminozutir sequentie in het VW"-C domein verantwoordelijk is woor de binding an fibr ine.

\section{PAR-1 is verantwoordelijk voor het synergistisch effect van trombine op de collageen geïnduceerde procoagulante respons van plaatjes}

In het blowdstollingsproces is de snelheid wan rombinevorming athankelijk wan de anwezigheid wat megatef geladen fosfatidylserine an het oppervik var geactiveerde bloedplaatjes. Een bloedplantje dat fosfotidylserine tot expressie brengt noemen we daarom een procoagulant blowplaate. Over het algemen vord aangenomen dat de vorming van een procoagulant bloedplatije geinitieend wondt door een verhoging van de intracellulaire calciumconcentratie. Eerder onderzock heeft anangetoond dat trombine een zwakke agonist is met betrekking tot de voming van plaatjes met deze procoagulante activitent. Trombine bleek echter synergistisch te werken met collageen bij het induceren van procoagulante activiteit. In hoofdstuk 4 van dit proefschrif werd onderzoch of dit synergistisch effect gerelateerd is an veranderingen in intrace llulair calcium en wat de bijdrage is van de trombine receptoren GP Ibo, PAR-1 en PAR-4.

We toonden aan dat trombine slechts een tijdelijke werhoging geeft in intracellulair ealcium en nawwelifks effect heeft op de procoagulante respons van bloedplaatjes Echter, in anwezigheid van collageen bleef het calciumsignaal na activering met trombine langdurig op een 
hood nivad, wat resulteerde in eer. procoagulante activiteht die $15 \mathrm{keer} z 0$ hoog was als die bij controle platyes. Heruit concluderen we dat de procoagulante activiteit van en platje veroorzakt wordt door een langdurige verhoging in intracelluair calcium. Dit werd bevestigd met beluulp van how cytometrix, warrin angeloond werd dat da atnwezigheid van fosfatidylserine aan de butenkant wan het plaatjesinembraan altid samengat met en verhoogd intracellulair calcium niveau. Deze verhoging bleek afhankelijk te zin van de influx van extracellulair calcium. Verder werd slechts en subpopulatie van de platifes $(15 \%)$ procoagulant nat activering met collageen en mombine. Deze heterogene respons zou te maken kumen hebben mei een verminderde receptor functie bij oudere bloedplaaties, man dit moet verder uitgezocht worden.

Met behulp van een antilichaam (MoAb 2D2) tegen de trombine-bindingsplaats op GP Ibo werd duidelijk dat deze receptor nit betrokken was bij de worming van platjes net procoagulante activiteit. Remming van de trombinereceptoren PAR-I en PAR-4 nel selectieve intacellulaire remmers en selectieve receptor desensitisatie toonde an dat PAR-ll, maar niat $P A R-4$, activering noodzakelijk is voor zowel de tangdurig verhoogde intracellulare calciun niveaus, als de procoagulante respons geinduceerd door trombine en collageen. De bevinding dat PAR-A activering verantwoordelijk is voor de langdurig verhoogde intracellulaire calcium niveaus, is niet in vereenstemming met de korte levensdurir van de receptor na activering mei trombine. Wil speculeren dan ook dat de interactie van collageen met het bloedplatije de inactiveringskinetiek van de PAR-1 receptor veranderd.

Deze studie inapliceent dat antagonisme van PAR-I een drastisch remmend effect heef op de procoagulante activiteit wan collageen geadhereerde bloedplatiles. Dit suggereet dat specifieke remming van de $\mathrm{B} A \mathrm{R}-1$ receptor een effectieve strategie is on trombinevorming aran het oppervlak van een vormende trombus, en dus trombusgroel. te beperken. Verder onderzok in trombose modellen is nodig on dit te bevestigen.

\section{Fibrinogeen adsorptie, plaatjesadhesie en trombine vorming aan gehepariniseerde oppervlakken}

Thombus vorming aan een artificieel opperwak in contace met bloed is een complex proces dat begint met eiwi adsorptic wanuit plasma en eindigt met plarjesadhesic en fithinevoming. Om te kijken wat de bijdrage is van. eiwitadsomptie en platiesadhesie an trombineworming hebben we een studie uigevoed met niel-gecoate (NC) en gebpariniserde (HC) opperwlakken (hoofdstuk 5). Eiwit adsorptie, platjesadhesia en trombineworming in volbloed werden bestudert met respectievelijk ellipsomethe een dymamische plaatjesadhesie assay en een amidolytische trombine assay. De trombinevorming in bloed dat stroont (afschuifsnelheid $50 \mathrm{~s}^{-1}$ over HC oppervlakken. was sterk gereducerd in wergelijking met NC oppervlakken. Aan de andiere kant lieten platjesadhesic en eiwitadsorptic metingen vanuit ontstold bloed zien dat plaatjes niet hechten atan NC en HC oppervlakken omdal geen fibrinogeen anwezig was in de eiwitlag die gevornd is aan het oppervlak vanuit plasma. Deze bevindingen indiceren dat, in vitro, de trombogeniciteit van een materiaal net kan worden voorspeld met pladjesadhesie en eiwitadsorptie data vanuit ontstold bloed. Pre-incubatie van NC en HC oppervalkken met fibrinogeen of $2000 x$ werdund plasmat resulterde in vergelikbare hoevelheden geadsorbeerd fibrinogeen, wat resulteerde in platilesadiesie wanult stromend bloed. Deze resulaten geven an du planjesadhesta correleet met de beschikbarhed wan fibrinogen am her opperwak en dat or geen werschl is nussen $\mathrm{NC}$ an $\mathrm{MC}$ oppervlaken me

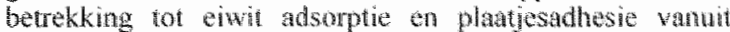
ontstold bloed. Het HC oppervlak is antimtrombogen vanwege de binding wan antitrombine, dall lokad gevormde trombine direkt neutratisect. Bew wordt geleverd in hooldsik 6. watain we whtoonden dat

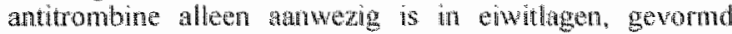
vanuit plasma, aan HC oppervakinen. Hoofdstuk 7 bewestigd verder dat anticronbine gebonden an $\mathrm{HC}$ oppervlakken volledig verantwoordelik is voor de antitrombotische eigensothappen, ondas heparinisatie do trombine voming platlegde in nomaal. mast niet in antitrombine deficient bloed.

Klinische studies laten zien dat hoparine coatings op stents of symthetische ombeidinger vasenlat grath de biocompatibiliteit van deze lichamsveenda oppervlakkon niet sigmificant verbeteren. Een reden dat heparine coatings tot nog toe geen verbetering oplevenden in pationtenstidios kan zijn dat gesulfateerde polysaccharites, zouls heparine, interacties aangaan met groefactoren en op deze manier neo-intime worning kuntwen stimulemen. Aangetoond is echer dat minder gestlateende polysaccharides gladde spiercel proliferatio remmen. In hoofdstuk 6 hebben we daarom de trombogene eigenschappen van geimobiliseerd heparine vergeleken met minder gesulfaterde polysaccharides chondroithe sulfat en algineat. Wo hebben laten zien dat trombine worming in bloed dat stroomt over de opperwakken gecoar met chondroitine sulfat an alginat sterk gereduceerd is in vergelijking met het NC oppervlak. Deze reductie kan verklard worden uit de verninderde eiwitadsorptie aan deze oppervlakken. Exhter, in vergeliking net HC oppervlakken waren de opperwaken gecoat met de minder gesulfateerde polysaccharide stechts gedeltelijk tromboresistent. Deze bevindingen geven aan dat als een hoge oppervlakte dichtheid van geinmobiliseerd heparine negatieve effecten heef, eon mongeling van heparine en alginat of chond oitin sulfat ean interessant alternatiof kan zijin.

\section{Geïmmobiliseerd heparine maakt collageen tromboresistent}

Bloedcompatibithent wh lichamsuremde oppervakken hangt af van immunologrsche son trombogene cigensehappen wan hel material. Het is bekend dat hoparine wanig affect heef op te ontstekinghreacthe die gepant gat net do bloed-material interactie. Wij stollen voon om collageen to gabruken als stent of vascular graft coatimg vanwoge zigli zwakke antigeniciteit, de bewezen biocompatibilitit bij verschillende nedische toepasingen (artificielo hartkleppen, huidvervanger) an het geven wan een goede ondergrond voor endotheeded groel. Hel nadeal vala collageen is wherard de achieve rol in platyesadluesic en actiweting. In hooldstuk 7 hobben wij onderzoch af het immobiliseren van heparine op collageen de trombogeniciteit omlaag kan brengen. Hei bleck dat. zowel onder slatische, als onder stromingscondities. trombinevorming an thet gehepariniseerde collagen oppervlak werd voorkomen. Dit indicent dat hel inmobiliseren wan heparine op collageen an eflectieve matregel is on trombusvorming an het oppervlak te verhinderen. Deze bevindinger zijn aen atanoediging om gehepariniseerd collageen te testen ats stent coating it? diermodellen en uiteindelikk in bumane studies 
NAWOORD 
Terugkijkend op rum vier jaar promotieonderzock valt mij op dat de lijd voorbij gevlogen is. I lik heb het alls een waardevolle periode wil mijn leven ervaren, watar ik veel gelferd, gelezen, geschreven, gepipetteerd, gebrainstormd en gereisd heb. Dit proefschrift betekent de afronding, wan deze periode en biji de totstandkoming erwan zijn weel menser betrokken geweest. Al deze mensen wil ik hartelijk bedanken. Een aantal mensen wil ik daarnaast in het bijzonder bedanken.

Mijn compromotor Theo Lindhout. Theo, zonder jouw was dit proefschrift nooit geworden wat het nu is. Door je kritische manier van vragen stellen wisi je mij na clk experiment weer aan het denken te zetten. Het vertrouwer en de vrijheid die je mij hebt gegeven tijdens dit onderzoek wasdeer ik enorm en de het commentaar "je gaat weer erg kort door de bocht "wall mij warschijuljik altijd bijblijven. Dat je neer was den alleen 'begeleider' blijkt wel tuit de gerellige barbecuts, zeiltochten en niet te vergeten de irip naar Zeeland. Ik ben dan ook blij dat onze samenwerking nog niat len einde is.

Mijn promotor, Jan Rosing, voor de mogelijkheid om bij de vakgroep Biochemie te werken en te promoveren.

Simone Wielders. Simone, vanaf dag I ben jij als directe collega betrokken geweest bij het overgrote deel van het uitgevoerde onderzoek. I $k$ heb jouw bijdrage erg gewaardeerd en heb altijd graag met je samengewerki.

Dominique Baruch. Dominique, je voudrais te remercier de la collaboration agréable et de la contribution immensurable au chapitre troisieme. J'espère qu'en avenir nous pouvions commener quelque-chose encore une fois. Ta hospitalité pendaun les sejours frequents á ton labo à Paris était magnifique. Encore, je voudrais naturellement remercier Paultete Legendre pour l'assistance techmique, JeanPierre Girma pour l'assistance theoricue, Cecile Démis pour mettre des souris VWF-déficient à ma disposition et Peter Lenting pour mettre des mutants VWF à mä disposition.

Johan Heemskerk. Johan, onze samenwerking begon vijf jaar geteden toen ik als student koos voor een afstudeerstage binnen jouw groep. De vruchtbaarheid van deze samenwerking blijkt uit de twee publicaties die voortgekomen zijn uit dit project. Ik wil je bedanken voor je enthousisusme en interesse in mijn onderzock.

Cdotard Bevers. Edouard. bedank voor de lange en zinnige discussies met betrekking tot het vierde hooidstuk. Jouw theoretische en praktische ondersteuning waren van groot belang bij de totstandkoming van dit ded van mim procefschrift.

George Willoms, George, bedankt voor de bijdrage an het wijtes en zesde hoofdstuk van dit proefschrift

Mijn kamergenoofjes Marion Feijge en Marijke Kuijpers.
Jullie opmerkingen "verloren met voetballen?" en "Goed weekend gehad?" maakten mijn maandagochtendkater draagzaam. Bedankt voor de gezelligheid!

Kristof Vanschoonbeek. Beste Kristof, vier jaar geleden begonnen we alan ons promotie-onderzoek, jij een maand eerder dan ik. In die vier jaar hebben we veel congres en cursuswermaak gedeeld en uiteraard ook over mooie auto's geprat. Bedankt dat jij en Marijke de rol als paranime willen verwullen.

Verder will ik Imke Munnix, Paola van der Meijden, Judith Cosemans, Mieke Janssen en Sandra Canwenberghs bedanken voor de plezierige rijd samen. Imke en Paola jullie behoren tot het beperkte aantal vrouwen dat mij aan het dansen heeft gekregen. Mieke, je staat er versteld wan wat zo'n BGKertje kan bereiken. Je vaak ondoordachte, maar (h)eerlujke uitspraken, zijn een genot on maar te luisteren. Sandra, ik vindt het prettig dat we ook in mijn nieuwe functie collega's zijn en hoop dat we het transfusie-onderzoek in Matastricht op een hoog niveau kunnen brengen

Wencke Adriaens, bedankt voor het synthetiseren van de PAR-antagonistem.

Marc Hendriks, Michel Verlhoeven en Anita Driessen Op de eerste plaats will ik Medtronic Bakken Research Center bedanken voor de financiele steun aan een groot dee van het onderzoek in dit proetschrift. Verder will ik Marc, Michel en Arita danken voor praktische en theoretische ondersteuring bij het zevende hooldstuk. Anita, dat de SEM foto's goed gelukt zijn bewijst de woorkant van dit boekje.

Hans. Ulrichts en Hans Deckmyn. Hans en Hans, bedankt voor het leveren van de antilichamen en de bijdrage aan het tweede en vierde hoofdsituk van dit proefschrift.

Joyce Curvers, Judith Hecremans, Eva Rombout, Ellen Francken, Costa Rachas. Mijn nieuwe collega's bij Sanquin Bloedbank in Mastricht wil ik bedanken voor do gelegenheid en steun die ze mij gegeven hebben on dit proefschift op een wardige manier af te ronden.

Trees Camphuisen, bedanki voor de secretaruêtle ondersteuning en de leuke gesprekken.

Verder wil it alle andere leden van de vakgroep biochemie bedanken voor de prettige tijd!

Uiteraard moog het toesfront neet ontbreke in dit dankword. Mien leef vrouw, Ellen, al meer dan 10 joar deile veer leef en leid. Dankzij diene stjeun, op illk dinkbaar gebied, hub ich dit promotie-ongerzeuk tot en good eind kinne bringe Bedank! Pap en Mam, uche onwoorwardelijke sjteun veut alle keuzes die ich in mien lève gemaak hub is wan onsjatbare weart geweas. Bedank! Verder wil ich uiteraard Leon, Wendy, Yon, Mino; mien sjooneljers en Roel en Janine bedanke, det ze mich "op aafstand i hubbe biegesjtange. 


\section{Curriculum vitae}

Jeffrey Keuren werd geboren op 28 maart 1978 te Roermond en kreeg de doopnamen Jozef Franciscus Wilhelmus. Hij volgde zijn middelbare schoolopleiding aan het Stedelijk Lyceum te Roermond, waar in 1996 het VWO diploma behaald werd. In datzelfde jaar werd aangevangen met de studie Gezondheidswetenschappen aan de Universiteit Maastricht (UM). In 1997 behaalde hij het certificaat Scheikunde aan het James Boswell Instituut, Universiteit Utrecht. Tijdens de studie Gezondheidswetenschappen werd de status van artikel 9-deskundige volgens de Wet op de Dierproeven behaald en slaagde hij voor het examen Stralingshygiëne, deskundigheidsniveau $5^{b}$. Na zijn afstudeerstage bij de vakgroep Biochemie (UM), werd in 2000 het doctoraal diploma Gezondheidswetenschappen met als afstudeerrichting Biologische Gezondheidkunde behaald. Van september 2000 tot april 2004 was hij werkzaam als assistent in opleiding bij de vakgroep Biochemie (UM) onder begeleiding van Dr. T. Lindhout. De resultaten van dit vierjarig promotieonderzoek zijn beschreven in dit proefschrift en gepresenteerd op congressen in onder andere Parijs, Aachen en Birmingham. Tijdens deze periode werd onder andere onderzoek verricht bij het Institute National de la Santé et de la Recherche Médicale (INSERM) in Parijs, Frankrijk. Na het succesvol volgen van een driejarig cursusprogramma aan de Cardiovasculaire Research School Maastricht-Amsterdam (CARMA), werd hem in 2003 het CARMA-PhD-Training Certificate uitgereikt. Sinds april 2004 is de schrijver van dit proefschrift werkzaam als onderzoeker bij de Unit Onderzoek en Onderwijs van Sanquin Bloedbank Regio Zuidoost. 


\section{Publications}

Keuren JFW, Wielders SJH, Willems GM, Morra M, Lindhout T. Fibrinogen adsorption, platelet adhesion and thrombin generation at heparinized surfaces exposed to flowing blood. Thromb Haemost 2002;87:742-7

Vanschoonbeek K, Feijge MAH, Keuren JFW, Hemker HC, Lodder JJ, Hamulyak K, van Pampus ECM, Heemskerk JWM. Thrombin-induced hyperactivity of platelets of young stroke patients. Thromb Haemost 2002;88:931-7

Keuren JFW, Ulrichts $H$, Feijge MAH, Hamulyàk K, Deckmyn H, Lindhout $T$, Heemskerk JWM. Integrin $\alpha_{1 \mathrm{lt}} \beta_{3}$ and shear-dependent action of glycoprotein Ib $\alpha$ stimulate platelet-dependent thrombin formation in stirred plasma. $J$ Lab Clin Med $2003 ; 141: 350-8$

Keuren JFW, Wielders SJH, Willems GM, Morra M, Cahalan L, Cahalan P, Lindhout T. Thrombogenicity of polysaccharide-coated surfaces. Biomaterials 2003;24:1917-24

Keuren JFW, Baruch D, Legendre P, Girma J-P, Lindhout T. Von Willebrand factor $\mathrm{C} 1 \mathrm{C} 2$ domain is involved in platelet adhesion to polymerized fibrin at high shear rate. Blood 2004; 103:1741-6

Keuren JFW, Wielders SJH, Driessen A, Verhoeven M, Hendriks M, Lindhout T. Covalently-bound heparin makes collagen thromboresistant. Arterioscler Thromb Vasc Biol 2004:24:613-7

Keuren JFW, Wielders SJH, Ulrichts H, Hackeng T, Heemskerk JWM, Bevers E, Lindhout T. Synergistic effect of thrombin on collagen-induced platelet procoagulant activity is mediated through PAR-1. Submitted 